\title{
Monographie der Gattung Canthon
}

von

E. v. Harold in München.

\section{Canthon}

Hoffmannsegg. Wiedem. Zool. Mag. 1817. I. p. 38.

Scarabaeus Drury, Oliv., Fabr. - Ateuchus Fabr., Latr., Say, Germ. - Coprobius Latr., Dej. - Coeloscelis Reiche. -

Tetraechma Blanch.

Corpus alatum, convexum, ovale. Antennae 9-articulatae. Oculorum pars superior minuta, angustato-ovalis. Caput clypeo bi-vel pluridentato, vertice mutico. Scutellum nullum. Pygidium liberum. Mesosternum brevissimum, a metasterno sutura rectilinea divisum. Pedes sat elongati; tibiae anticae versus apicem sensim dilatatae, extus tridentatae, posticae simplices, interdum arcuatae; tarsi postici compressi, articulis latis, longitudine fere aequalibus, primo non elongato.

Der Körper ist mehr oder weniger, meist aber ziemlich regelmäfsig von kurz eiförmiger Gestalt, dabei ziemlich gewölbt und auf dem Rücken, besonders den Flügeldecken, öfters etwas flachgedrückt. Der Scheitel ist stets flach und unbewaffnet, also weder mit Höckern noch mit Querleisten versehen; der obere Abschnitt der Augen ist klein, von verschmälert ovaler Form. Das Kopfschild ist in der Mitte mit zwei oder auch vier Zähnen versehen; in ersterem Falle sind diese Zähne immer stumpf und von dreieckiger Gestalt; bei vier Zähnen, und zwar je deutlicher dieselben entwickelt sind, erscheinen die mittleren in der Regel schmäler und länger, während die daneben befindlichen Ecken - die Nebenzähne - immer eine breitere, mehr dreieckige Form zeigen. Da auch die Wangen an der Stelle, wo sie vom Kopfschilde durch einen mehr oder minder deutlichen Einschnitt abgesetzt sind, ein kleines Eck bilden, so zeigt sich der vordere Kopfrand manchmal deutlich Berl. Entomol. Zeitschr. xur. 
6 zahnig. Dieses Wangeneck, welches ich in der Folge als vorderes $\mathrm{W}$ a n ge nende bezeichne, ist besonders deutlich bei einigen nordamerikanischen Arten, z. B. C. probus, ebeneus; hier ist der Einschnitt nämlich eben so tief wie jener, welcher die Mittel- und die Nebenzähne trennt, so dafs sechs grofse Zähne vorhanden sind. Ausnahmsweise ist das Kopfschild bei C. muticus und edentulus einfach ausgebuchtet, mit daneben abgerundeten Ecken.

Das Halsschild ist meist ziemlich slark kissenartig gewölbt; der Seitenrand bildet in der Mitte (nur bei $\boldsymbol{C}$. balteatus weiter hinter derselben) ein meist recht deutliches, manchmal (z. B. C. affinis) sehr scharfes Eck; bei einigen wenigen Arten (C. speculifer) ist derselbe jedoch ziemlich gleichmäfsig im Bogen gerundet. Der vordere Abschnitt dieses Seitenrandes, die Strecke also von diesem mittleren Ecke bis zu den Vorderecken, zeigt sich, von der Seite betrachtet, meist deutlich in einem Bogen gewölbt, dann wieder nach vorn zu verflacht; die Gränze dieses Bogens ist in der Regel nach vorn durch ein kleines Zähuchen - das Randzähnchen markirt.

Eine charakteristische Eigenthümlichkeit ist die Vertiefung der Schildchengegend - der Scutellareindruck -; ein Merkmal, welches mehr oder weniger allen Canthon-Arten zukommt und dieselben meist schon beim ersten Anblicke kenntlich macht. Dieser Scutellareindruck, welcher in der Regel auch die Mitte der Halsschildbasis angreift, ist sehr deutlich ausgeprägt bei $\boldsymbol{C}$. speculifer, virens, muticus, cinctellus, er fehlt hingegen fast ganz bei C. laevis, aequinoctialis $\mathrm{u}$. s. w.

Die Flügeldecken sind hinten verkürzt und lassen das Pygidium immer unbedeckt; sie haben regelmäfsig acht Streifen, die aber meist höchst fein und wohl auch ganz undeutlich sind; so ist C. virens vielleicht am deutlichsten, C. speculifer, gagatinus am undeutlichsten gestreift. Eine besondere, und für die Arten-Unterscheidung höchst wichtige Eigenthümlichkeit zeigt der achte Längsstreif, in. dem derselbe in seinem oberen Theile, zuweilen bis über die Mitte hinaus, deutlich sehr fein leistenartig erhaben ist, z. B. C. melancholicus, monilifer, virens; sehr subtil, aber doch immer mit Bestimmtheit zu erkennen ist er bei $\boldsymbol{C}$. triangularis, während er dem nahverwandten C. 7 maculatus fehlt. Die Epipleuren, nämlich der umgeschlagene Seitenrand der Flügeldecken, sind nur bei einigen Arten (C. affinis, tristis) scharf kantig abgesetzt, mit der Bauchfläche horizontal gelagert und daher bei Seitenansicht dem Blicke entzogen; bei der weitaus gröfsten Mehrzahl der Arten bildet ihre Fläche mit jener der Unterseite einen stumpfen Winkel. 
Das von den Flügeldecken immer unbedeckt gelassene Pygidium ist höchstens senkrecht gestellt, also nicht gegen die Bauchfläche gezogen; von Gestalt ist es mehr oder weniger dreieckig und meist mäfsig gewölbt, bei einigen Arten aber (C. speculifer, Chevrolati) stark und fast kegelförmig gewölbt, bei anderen wieder (C. smaragdulus, prasinus, tristis) fast ganz flach. In sehr vielen Fällen ist dasselbe fein punktirt und trägt jedes Pünktchen ein äusserst kurzes, zuweilen nur bei stärkerer Vergröfserung sichtbares Borstenhaar.

Im Allgemeinen ist die Oberseite bei der Mehrzahl der Arten sehr blank und von polirtem Aussehen; viele sind jedoch zum Theile, und zwar meist nur auf den Flügeldecken, äufserst fein netzartig gerunzelt, wodurch sie einen trüben, etwas seidenartigen Glanz erhalten. Eine allgemeine deutliche Punktirung zeigen nur sehr wenige Arten, z. B. C. perplexus und juvencus, letzterer sogar eine ziemlich derbe. Dagegen sind mehrere sehr deutlich gekörnelt $(\boldsymbol{C}$. laevis, vigilans, ebeneus, nigricornis), eine Sculptur, die jedoch auf die nordamerikanischen Arten beschränkt bleibt. Eine böchst feine Behaarung hat $\boldsymbol{C}$. perplexus, eine sehr deutliche dagegen findet sich bei $\boldsymbol{C}$. asper, villosus und sordidus. Nur ein paar Arten zeigen Unebenheiten auf den Flügeldecken, und zwar sind dieselben entweder ganz mit würfelartigen, flachen Erhöhungen bedeckt (C. Lacordairei, rugosus) oder es zeigen sich nur an den Rändern buckelige Erhabenheiten (C. signifer, callosus, violaceus).

Bei der Unterseite kommt zunächst das Prostern nm in Betracht, auf welchem sich zuweilen, wie bei den Choerididen, von den Hüften aus gegen den Seitenrand laufende Querleisten zeigen, wodurch das Prosternum in eine hintere und in eine vordere, manchmal leicht muldenartig vertiefte Hälfte getheilt wird. Wo solche Leisten vorhanden sind, fehlt auch das schon erwähnte Randzähnchen des Seitenrandes nicht und es lagern sich dann in dem Ausschnitte, welcher durch das Ende der Prosternalleiste und dem Randzähnchen begränzt wird, im Zustande der Ruhe die Kniee der Vorderbeine. Ueber den systematischen Werth dieser Querleisten habe ich mich schon bei Besprechung der Gattung Canthidium geäufsert (Col. Heft. I. p. 2 sq.); eine nähere Betrachtung derselben bei der gegenwärtigen Gattung hat mich in meiner Ansicht über ihre Werthlosigkeit als systematisches Unterscheidungsmerkmal nur bestärkt, indem diese Leisten bei den Canthon-Arten bald sehr deutlich, bald nur theilweise vorhanden sind oder wohl auch vollkommen fehlen. Ihr Vorhandensein oder ihre Abwesenheit bedingt auch 
durchaus keine habituellen Unterschiede, denn während z. B. C. gagatinus dieselben deutlich ausgebildet hat, fehlen sie dem nahverwandten, in einigen Varietäten sogar täuschend ähnlichen C. laevis. Immerhin bleiben dieselben für die Artunterscheidung in gewissen Gruppen von Wichtigkeit und habe ich sie daher bei keiner Art unerwähnt gelassen.

Das Mesosternum sowie das Melasternum sind durchweg von constant gleicher Beschaffenheit. Ersteres ist sehr kurz, auf einen schmalen Querstreifen reduzirt, letzteres um so gröfser, nimmt den ganzen Raum zwischen den Mittelhüften ein, ist in der Mitte gleichmäfsig gewölbt, ohne Eindrücke. Die Gränze zwischen diesen beiden Stücken ist immer eine fast ganz gerade Linie, welche sich von einem Vorderende der Mittelhüften zum andern hinzieht.

Die Beine sind ebenfalls gleichartig gebildet, doch zeigen sich in ihnen, die Geschlechtsdifferenzen abgerechnet, einige kleinere Formenunterschiede. Die in der Regel einfachen Vorderschenkel sind bei einigen Arten (C. dives, tetraodon) am Vorderrande mit einem Zahne versehen oder vor den Knieen doch merklich ausgebuchtet (C. rutilans); wäbrend die mittleren immer unbewaflnet bleiben, treten auch am hinterslen Paare bei ein paar Arten (C. curvipes) Zähnchen auf, oder nur eine kleine Ausrandung neben der Trochanterenspitze (C. 5-maculalus). Für die Artenunterscheidung ist eine bald vorhandene bald fehlende, dem Vorderrande der Hinterschenkel parallel laufende Randlinie von Wichtigkeit.

Mehr Verschiedenheiten zeigen die Schienen. Die vorderen sind gegen das Ende immer allmählig erweitert und mit den gewöhnlichen drei Randzähnen versehen, diese sind aber bald etwas mehr nach vorwärts, bald mehr nach aufsen gerichlet; in letzterem Falle ist dann meist das Schienenende meifselförmig abgestutzt $(\boldsymbol{C}$ latipes, affinis). Der Innenrand, meist geradlinig, zeigt bei $\boldsymbol{C}$. rutilans und einigen verwandten Arten stumpfe Zähne, bei $\boldsymbol{C}$. viridis und Genossen, eine stumpfwinkelige, aber starke Erweiterung vor der Mitte. Die mittleren Schienen sind in der Regel nach demselben Plane wie die hinteren gebaut; ihr äufserer Rand wird durch zwei Kanten gebildet, von denen die eine die Oberseite, die andere die untere Fläche der Schienen nach aufsen begränzt: diese beiden Kanten sind durch den schmalen Schienenkörper getrennt und laufen mit einander parallel. Nur der einzige $\boldsymbol{C}$. lituratus macht hiervon eine Ausnahme, indem bei ihm die äufsere Kante schon von der Mitte an sich winklig nach unten biegt, wodurch eine Art Querleiste auf der äufseren Fläche der Schiene entsteht. Während die 
untere Kante, welche die Seitenfläche oder eigentlich Unterseite der Schiene begränzt, immer gerade oder nur ganz allmählig gebogen ist, senkt sich die obere sehr oft schon von der Mitte an gegen den Endrand; hierdurch wird der Aufsenrand der Schiene mehr oder weniger deutlich vor der Spitze ausgebuchtet. Sehr stark ist diese Ansbuchtung der mittleren Schienen bei $\boldsymbol{C}$. fractipes, Lacordairei, gemellalus u. s. w., minder stark bei C. tristis, melancholicus, nur mehr schwach ausgeprägt bei $C$. violaceus, smaragdulus etc.; eine Andeutung derselben, nänlich eine leichte Verschmälerung oder Einschnürung des Schienenendes haben überhaupt die meisten Arten und ganz regelmärsig, gegen die Spitze allmählig breitere Schienen, deren Seitenkante nicht etwas winkelig gekrümmt wäre, haben vielleicht nur $\boldsymbol{C}$. aequinoctialis, virens und die mit $\boldsymbol{C}$. femoralis verwandten Arten, als C. semiopacus, angustalus, Lafargei u. s. w. Das hinterste Schienenpaar zeigt die nämliche Neigung zur Verschmälerung durch Ausschnitt vor der Spitze, nur ist hier die Ausrandung breiter, daher minder tief und fehlt wohl auch ganz bei solchen Arten, an denen die mittlern noch sehr deutlich ausgebuchtet sind, z. B. C.tristis. Sie sind bei der weitaus gröfsten Mehrzahl der Arten gerade oder nur höchst schwach gekrümmt, letzteres auch meist nur scheinbar, da ihr äufserer Rand, wegen der erwähnten Ausbuchtung gegen das Ende hin, meist eine Bogenlinie beschreibt, während der innere gerade bleibt. Bei einer ganzen Gruppe von Arten sind dieselben aber entschicden gekrümmt und zwar entweder gleichmäfsig im Bogen, wie bei $\boldsymbol{C}$. curvipes, oder durch Erweiterung des Innenrandes von der Mitte ab, C. 5maculatus, podagricus, cupricollis.

Als eine höchst auffallende, bisher indefs ganz isolirt dastehende Ausnahme mufs es betrachtet werden, dafs der nordamerikanische C. nigricornis $\mathrm{S}$ ay am Ende des hintersten Schienenpaares mit z we i Enddornen versehen ist, während bekanntlich der ganzen Hauptgruppe der Copriden nur ein solcher zukommt.

Die Füfse sind wieder sehr gleichmälsig gebaut und die breiten, flacbgedrückten, an Gröfse unter sich kaum verschiedenen Tarsenglieder der Hinterbeine sind charakteristisch für Canthon und die damit zunächst verwandten Gattungen. Wo diese Glieder von abnehmender Länge sind, wo also das erste auch zugleich das längste ist, was nur bei $\boldsymbol{C}$. sanguineomaculatus und allenfalls auch bei $\boldsymbol{C}$. edentulus und balteatus der Fall ist, treten damit zugleich andere fremdartige Erscheinungen auf, die sich bei keinem typischen Canthon mit normaler Fufsbildung wiederfinden. 
Die Unterseite zeigt eine nur spärliche Behaarung und beschränkt sich dieselbe meist auf die punktirten Stellen des Prosternums; die hinteren Schienen dagegen sind an ihren Kanten mit Borstenhaaren verschen', ebenso die Tarsen, letztere auf der unteren Kante dicbter, auf der oberen nur mit einzelnen Endborsten. Eigenthümlich ist ein Wimpernbesatz an der innern Kante der Hinterschenkel bei dem mexikanischen C. gagatinus, sowie die einzelne längere Borste, die ganz gerade von den Schenkelstützen der Hinterbeine absteht und die sich bei allen Arten vorfindet.

Die Geschlechtsunterschiede fallen, wie bei den Ateuchiden überhaupt, sehr wenig in die Augen und üben namentlich keinen Einflufs auf die Körpergestalt im Allgemeinen aus. Nur das Pygidium und insbesondere die Vorderschienen zeigen je nach den Geschlechtern einige Verschiedenheiten, die sich jedoch auch bei ersterem auf eine in der Regel elwas längere und gewölbtere Gestalt beim Männchen beschränken. Es bleiben sohin als die Träger absoluter Geschlechtsunterschiede nur die Vorderschienen übrig, an welchen fast wieder nur der Enddorn in Betracht kommt, da der abweichende Bau der Randzähne bei $\boldsymbol{C}$. sordidus und der Mangel eines dritten beim Männchen des $\boldsymbol{C}$. angustatus ganz vereinzelt dastehen. Was nun diesen Enddorn betrifft, so ist er, wie dies bei den Coprophagen überhaupt die Regel ist, in der Art je nach den Geschlechtern verschieden, dafs er immer beim Männchen derber gestaltet ist und die Neigung verräth, eine schaufelartige Ausbreitung anzunehmen, deren Endrand gewöhnlich durch einen Einschnitt in zwei Lappen oder Zähne gethei't wird; beim Weibchen ist derselbe schmäler und allmählig zugespitzt. Bei mehreren Arten indefs (C. speculifer, smaragdulus) nimmt der weibliche Enddorn ebenfalls die breitere Gestalt des männlichen an, unterscheidet sich aber doch noch bei näherer Betrachtung dadurch, dafs der innere der beiden Zähne oder Lappen, in welche er sich an der Spitze theilt, beim Männchen immer viel breiter und minder spitz geformt ist, als der entsprechende Zahn beim Weibchen, der überhaupt nur wenig stärker als der äufsere sich zeigt. Umgekehrt finden sich auch Arten (z. B. C. triangularis), bei welchen der männliche Enddorn sich der Gestalt des weiblichen so sehr nähert, dafs er höchstens noch durch etwas stumpferes Ende sich davon unterscheiden läfst.

In der Färbung zeigt sich bei den Canthon-Arten eine sehr grofse Mannigfaltigkeit, indem neben dunkelgefärbten und mattglänzenden Arten auch höchst prachtvoll metallisch scheinende vorkomnıen. Farbe und Zeichnung sind aber meist von äufserst veränder- 
licher Beschaffenheit und bei der Artenunterscheidung nur mit grosser Vorsicht zu benutzen; C. speculifer, curvipes, viridis sind bald ganz grün oder blau, bald kupferroth oder wohl auch schwarz, C. triangularis aber, 7 maculatus, 5maculatus, mutabilis, lituratus und andere zeigen ein höchst variables Farbenkleid.

Die Gattung Canthon ist eine ganz specifisch amerikanische und verbreiten sich ihre Arten über den ganzen dortigen Continent, mit Ausnahme der nördlichsten und südlichsten Theile. Am weitesten nach Norden geht wohl $C$. laevis, der aber kaum den $41^{\circ}$ nördl. Br. überschreitet; genau dieselbe Entfernung vom Aequator hält die am südlichsten sich aușdehneude Art, C. janthinus Blanch.; doch dürften aller Wahrscheinlichkeit nach in den wenig durchforschten Flächen Patagoniens uns noch unbekannte Arten noch weiter gegen Süden wohnen. Brasilien, das Gebiet des Amazonenstromes, und Columbien sind ganz besonders reich an Arten, Mexiko ist verhältnifsmäfsig arm, in den Vereinigten Staaten dürften kaum mehr als 10 Arten einheimisch sein. Auffallend ist der bisherige Mangel an Canthons in Chili, während doch auf der Ostseite einige Arten hart an die Cordilleras herantreten. Noch eigenthümlicher ist das Auftreten einiger liöchst ausgezeichneter Formen, wie $C$. violaceus, signifer, callosus auf St. Domingo, während doch das benachbarte, von Gundlach fleifsig durchforschte Cuba meines Wissens keinen einzigen ächten Canthon beherbergt. Ueber die geographische Verbreitung der einzelnen Arten kann ich deshalb nur geringe Auskunft geben, weil das Bedürfnifs nach genauerer Bezeichnung der Fundorte sich erst seit verhältnifsmäfsig kurzer Zeit geltend gemacht hat; die Bezeichnung: „Brasilien" der älteren Sammlungen und Kataloge ist als eine ganz ungenügende für die Folge zu beseitigen.

Immerhin läfst sich aus den vorhandenen Angaben der Schlufs ziehen, dafs einzelne Arten über sehr weite Gebiete sich erstrecken; so ist z. B. C. lituratus von Columbien aus durch ganz Brasilien bis nach Buenos-Aires und dem Pampaslande der argentinischen Republik verbreitet, $C$. rugosus reicht vom nördlichen Patagonien bis nach Peru.

Ueber die Lebensweise ist wenig bekannt, doch haben Perty (Delect. anim. 1830), Lacordaire (Annal. d. Sc. nat. XX. p. 260), Blanchard (Voy. d'Orb. Ent. p. 164) nnd Leconte (Col. of Kansas p. 11) die Bemerkung gemacht, dafs sich die Arten nicht nur in Exkrementen aufhalten, sondern auch auf Blättern und Gebïschen oder an wunden Baumstellen getroffen werden. Letzterer Fall bietet nichts Aufsergewöhuliches dar und ist vielleicht für viele süd- 
amerikanische Coprophilen vor Einführung der grölseren Säugethiere durch die Europäer die normale Existenzmethode gewesen; den Aufenthalt auf Blättern kann ich jedoch immer nur als einen ganz zufälligen betrachten, da das Thier mit seinen ganz schwachen Klauen und seiner gewölbten Unterseite durchaus kein Klettervermögen besitzen kann. Das Pillenwälzen hat wenigstens d'Orbigny bei einer Art (C. rugosus Blanch.) mit Bestimmtheit nachgewiesen: wahrscheinlich gilt dasselbe, dem mit Gymnopleurus nahverwandten Fufsbaue zu Folge, auch von den übrigen Arten.

Mit ganz geringen Ausnahmen umfafst die gegenwärtige Gattung sehr homogene Elemente. Reiche hat (Rev. zool. 1841. p. 213) auf einige Arten, bei welchen die hinteren Schienen vor dem Ende ausgebuchtet sind, eine Gattung Coeloscelis errichtet, deren Unhaltbarkeit jedoch durch den ganz allmähligen Uebergang dieser ausgebuchteten Schienen in einfache, nicht ausgebuchtete, einleuchtend ist. Lacordaire hat die Gattung beibehalten und sie auch noch durch die eigenthümliche Sculptur der Flügeldecken zu stützen gesucht. Dies geht wohl für $\boldsymbol{C}$. Lacordairei und rugosus an, C. fractipes aber, der dem Fufsbau nach ein besonders typischer Coelescelis wäre, hat die gewöhnlichen glatten Flügeldecken der ächten Canthons. Auch Blanchard hat (Voy. d'Orb. Ent. p. 67) auf C. sanguineomaculatus eine Gattung Tetraechma errichtet; bei dieser Art sind die vier Zähne des Clypeus in fast gleicher Entfernung von einander, die Wangen gehen unmittelbar ohne Eck in das Kopfschild über und der Kopf ist zugleich nach vorn etwas verschmälert. Lacordaire hat jedoch mit Recht (Geo. Col. III. p. 78) diese Gattung wieder eingezogen; C. lituratus vermittelt in der Kopfbildung diese Art vollkommen mit den typischen, vierzabnigen Formen, und dafs ein Unterschied zwischen diesen und den nur zweizahnigen in Wirklichkeit nicht besteht, ergiebt sich auf den ersten Blick.

Von den übrigen, mit Canthon überhaupt verwandten Ateuchiden-Gattungen tritt Deltochilum sehr nahe heran, so nahe, dafs für die Unterscheidung fast nur unbedeutende Charaktere übrig bleiben. Obwohl nämlich die grofsen Deltochilen, wie D. dentipes, gibbosum u. s. w. sehr abweichend geformt erscheinen, so lassen sich doch einige kleinere, meist unbeschriebene Arten, wie $D$. infirmum, zunächst aber das hier unten ${ }^{1}$ ) diagnosticirte $\boldsymbol{D}$. aberrans von den

$\left.{ }^{1}\right)$ D. aberrans: Elongato-ovale, sat convexum, subnitidum, nigroviride, elytris luteo-rufescentibus, interdum omnino nigrum. Clypeus me- 
ächten Canthon-Arten kaum mehr unterscheiden. Der Hauptunterschied, welcher die Gattung Deltochilum charakterisiren sollte, der Mangel der Vorderfüfse nämlich, erweist sich nicht als stichhaltig, denn mehrere, ganz unzweifelhaft ächte Deltochilen, wie D. Burmeisteri, speciosum, arrogans haben zwar kleine, aber doch recht deutliche Vordertarsen; die Gestalt der Epî̉pleuren bietet ebenfalls keinen Anhaltspunkt, dieselben sind nur bei den gröfseren Arten scharfkantig abgesetzt und horizontal umgeschlagen; bei der Mehrzahl der kleineren Arten, wie D. morbillosúm, irroratum u. s. w. weicht ihre Form in Nichts von der bei Canthon gewöhnlichen ab, unter welchen sogar mehrere Arten, wie C. affinis, breitere und flacher liegende Epipleuren haben, als die genannten Deltochilen. Auch die Höckerreihe am Endbuckel der Flügeldecken, scheinbar charakteristisch für Deltochilum, schwächt sich bei den kleineren Arten ganz ab und die Zahnung des Kopfschildes, bei den gröfseren Arlen eigenthümlich durch die weitere Entfernung der beiden Mittelzähne, ist bei $\boldsymbol{D}$. furcalum, rubripenne etc. durchaus wie bei Canthon geformt. Der einzige durchgreifende Unterschied, den ich aufzufinden vermochte, liegt in den Verschiedenheiten des Fufsbaues. Bei Deltochilum sind nämlich die Vorderschienen, bei einigen Arten jedoch nur die des Männchens, gegen das Ende nicht erweitert, sondern fast gleich schmal, böchstens vom obersten Randzahne ab etwas breiter, dabei im männlichen Geschlechte immer verlängert; bei Canthon dagegen sind diese Schienen in beiden Geschlechtern gleich, dabei regelmäfsig von den Knieen gegen die Spitze erweitert. $\mathrm{Zu}$ diesem sehr beständigen und leicht in die Augen fallenden Merkmale, durch welches sich auch das sehr trügerische $\boldsymbol{D}$. aberrans sofort als Deltochilum zu erkennen giebt, kommen noch bei zuletzt genannter Gattung ein durchwegs mehr länglicher Körper und meist sehr deutlich gekrümmte Hinterbeine.

Die Gattungen Anachalcos Hope (Chalconotus Reiche) und Megathopa Eschsch. haben beide, insbesondere aber letztere, den Körperbau und die kurzen, flachgedrückten hinteren Tarsenglieder mit Canthon gemein; Megathopa unterscheidet sich aber sehr be-

dio profunde rotundato-emarginatus, utrinque sat acute dentatus. Thorax lateribus medio angulatis, antice dente submarginali. Elytra obsoletissime subrugose plicatula, leviter striata, stria suturali distincte punctata. Palpi cum antennis picei. Corpus subtus cum pedibus obscure viridi-aeneum, prosterni carinis abbreviatis. Mas: tibiis anticis elongatis, thorace elytris latiore. - Long. $4 \frac{1}{3}-5$ lin. Columbia. 
stimmt durch die Anwesenheit eines Schildchens, Anachalcos durch die ganz verschiedenen Dimensionen von Meso- und Metasternum. Während nämlich bei Canthon das Mesosternum auf einen ganz kurzen Quertheil reducirt ist, welcher immer vor den Mittelhüften liegt und vom Metasternum, welches den ganzen Raum zwischen diesen Hüften einnimmt, durch eine gerade Linie abgegränzt wird, gewinnt bei Anachalcos ersteres schon erheblich an Ausdehnung, reicht beiderseits nach hinten bis zur Mitte der Mittellüften und bildet dessen Gränzlinie gegen das Mielasternum einen starken Bogen. Eben diese eigenthümliche Differenz in den Verbältnissen der beiden hinteren Sternaltheile sondert auch von Canthon die Gattung Epilissus ab, welche mit einigen kleineren Arten auch in Südamerika vertreten erscheint: hier sind aber schon die hinteren Füfse nicht mehr flachgedrückt, die einzelnen Glieder länger als breit, von leicht drehrunder Form, namentlich das Klauenglied. Die Versehiedenheit im Fufsbau entfernt auch die sonst mit Canthon sehr nahverwandten afrikanischen Epirhinen. Zwischen diesen und Canthon dürfte aber eine noch unbeschriebene, im Berliner Museum von Klug als Colonychus verzeichnete brasilianische Gattung sich einreihen, die durch fehlende Vordertarsen, den Hinterleib überragende Flügeldecken, seitlich nur sehr wenig flachgedrückte Hinterfüfse und am Ende nach innen hackig erweiterte Schienen ausgezeichnet ist.

Was schliefslich das Material anlangt, welches mir zur gegenwärtigen Bearbeitung vorlag, so kann ich dasselbe immerhin als ein sehr reichhaltiges bezeichnen, und ist mir namentlich die Einsichtnahme des Berliner Museums und der dorligen Erichson'schen Typen von grofsem Vortheile gewesen. Ich kann bei dieser Gelegenheit nicht umhin, Herrn Dr. Gerstäcker für die äufserst zuvorkommende Weise, in welcher mir die Benutzung der genannten Sammlung gestattet war, meinen verbindlichsten Dank auszudrücken. Ebenso fühle icb mich verpflichtet gegenüber den Herren Deyrolle, Bouvouloir, Haag, v. Heyden, Kirsch und mehreren anderen, die mir sämmtliche Canthon-Arten ihrer reichen Sammlungen in liberalster Weise zur Unterstützung meiner Arbeit mittheilten. Durch die Erwerbung der Germar'schen Typen aus der ehemaligen Schaumschen Sammlung, sowie durch den Vergleich der Perty'schen in der hiesigen Staatssammlung war ich ferner in der Lage manche Irrthümer in der Synonymie zu vermeiden. Leider konnte ich einige der von den Herren Blanchard und Lucas beschriebenen Arten, aus den Reisen d'Orbigny's und Castelnau's, niclıt in natura vergleichen und auch aus den Beschreibungen nicht mit Bestimmtheit enträth- 
seln; ein Verzeichnifs derselben, sowie der übrigen bisher beschriebenen, mir aber nicht näher bekannt gewordenen Arten folgt am Schlusse.

Von den 97 Arten, die ich untersuchen konnte, sind hier nahezu die Hälfte, nämlich 46, noch unbeschrieben gewesen; zur leichteren Bestimmung derselben dürfte die nachfolgende Tabelle dienen:

1. Elytra inaequalia, callosa vel elevato-tessellata

Elytra aequalia, laevia vel subtiliter tanlum granulata, vel ex parte tantum obsolete plicatula

2. Pygidium nigrum . . . . . . . . . . .

Pygidium flavum . . . . . . . . . . 5

3. Prosternum carinis transversis. . . . . sericinus.

Prosternum non carinatum . . . . . . . 4

4. Elytra 4 seriebus tuberculorum . . . . Lacordairei.

Elytra 9 seriebus tuberculorum minorum, planorum . . . . . . . . . . . rugosus.

5. Thorax postice medio non foveolatus . . . violaceus. Thorax postice longitudinaliter foveolatus . 6

6. Thorax lateribus foveolatus, clypeus 4 dentatus callosus. Thorax absque foveola laterali, clypeus bidentatus . . . . . . . . . . signifer.

7. Tibiae posticae apice bispinosae . . . . nigricornis. Tibiae posticae apice unispinosae. . . . . 8

8. Femora postica punctata, punctis setigeris, plerumque brunnea; clypeus bidentatus. .

Femora postica nuda, clypeus bi- vel pluridentatus . . . . . . . . . . . 12

9. Prosternum carinis transversis . . . . . 10

Prosternum absque carinis . . . . . sordidus.

10. Thorax laevis . . . . . . . . affinis.

Thorax villosus. . . . . . . . . . . 11

11. Thorax lateribus medio angulatus . . villosus.

Thorax lateribus ante medium angulatus. . asper.

12. Clypeus non dentatus, medio tantum emarginatus . . . . . . . . . . . . 13

Clypeus bi- vel pluridentatus . . . . . . . 14

13. Tibiae poslicae arcuatae, angustae . . . mulicus.

Tibiae posticae rectae, sensim dilatatae . edentulus.

14. Tibiae posticae arcuatae vel a medio incur-

vatae et intus ampliatae; clypeus 4 dentatus 
Tibiae posticae rectae vel vix distincte arcuatae; clypeus bi- vel pluridentatus . . .

15. Tibiae posticae arcuatae, versus apicem margine interno non amplialae . . . . . curvipes.

Tibiae posticae subangulatim incurvatae, versus apicem ampliatae . . . . . . . .

16. Elytra stria humerali parte basali subtiliter carinulata . . . . . . . . . .

Stria humeralis basi non carinulata, plerumque deficiens.

17. Femora postica basi subtus emarginata . .5maculatus. Femora postica integra . . . . . . . . 18

18. Femora postica rufa, basi apiceque infuscala . dentiger. Femora postica picea, vel medio tantum obscure rufa.

19. Tibiae posticae apice valde ampliatae . . podagricus.

Tibiae posticae sensim et minus fortiter ampliatae

20. Pygidium absque punctis distinctis . . . Sallei.

Omnino nitidus, pygidium distincte punctatum speciosus.

21. Corpus supra nitidum, totum viridi-aeneum. . spinosus.

Elytra opaca vel subopaca . . . . . . .

22. Antennarum clava rufa . . . . . . . compaclus.

Antennarum clava nigrocinerea . . . . cupricollis.

23. Femora postica medio vel omnino rufo aut testacea . . . . . . . . . . . . 24

Femora postica nigro-aenea vel ex immaturitate tantum rufescentia . . . . . . . 37

24. Prosternum non carinatum . . . . . . . 25

Prosternum carinis transversis . . . . . 31

25. Elytra stria humerali subtiliter carinata . . $\quad 26$

Elytra stria humerali non carinata vel nulla 28

26. Femora postica margine antico marginata, tho-

rax lateribus medio rotundato - augulatis monilifer.

Femora non marginata, thorax lateribus angulatis . $\cdot \cdot \cdot \cdot \cdot \cdot \cdot \cdot \cdot \cdot \cdot \cdot \cdot \cdot$

27. Tibiae intermediae margine superiore obtuse angulatae.

triangularis.

Tibiae intermediae graciles, sensim leviter arcuatae nigriceps. 
28. Femora postica marginata . . . . . . 7maculatus.

Femora absque linea marginali . . . . . . $\quad 29$

29. Supra omnino nitidus . . . . . . . cyanocephalus.

Subnitidus, elytris opacis . . . . . . 30

30. Thorax lateribus nonnihil pone medium angulatus . . . . . . . . . rufulus.

Thorax lateribus medio rotundatus . . . imitans.

31. Thorax nitidus, elytra opaca . . . . . . $\quad 32$

Omnino supra nitidus. . . . . . . . . 34

32. Thorax niger . . . . . . . . . semiopacus.

Thorax rufo-aeneus vel rufo-testaceus . . . 33

33. Thorax lateribus acute angulatis . . . nitidicollis.

Thorax lateribus rotundato-angulatis . . luteicollis.

34. Clypeus bidentatus . . . . . . . . . 35

Clypeus 4dentatus. . . . . . . . . . . . $\quad 36$

35. Elytra concoloria, femora rufa . . . politus.

Elytra rufofasciata, pedes flavi . . . Lafargei.

36. Obscure aeneus. . . . . . . . femoralis.

Castaneus vel rufescens . . . . . . angustalus.

37. Clypeus dentibus 6 aequalibus, genis a clypeo profunde divisae . . . . . . . . . . . $\quad 38$

Clypeus bi- vel 4 dentatus, genae vel rotundatis vel antice leviter tantum angulatis .

38. Corpus laeve . . . . . . . . . . probus.

Corpus asperato-granulatum ...... ebeneus.

39. Elytra punctis subtilissime squamuligeris; oculi majores; corpus minutum . . . . . perplexus.

Elytra laevia, absque punctis squamuligeris, simpliciter interdum punctata vel granulata

40. Elytra stria humerali parte basali distincte carinulata . . . . . . . . . . . .

Elytra stria humerali vel impressa vel omnino nulla . . . . . . . . . . . . . . . 63

41. Femora postica absque linea antica marginali 42

Femora postica antice marginata. . . . . 49

42. Thorax subtiliter granulatus, corpus nigrum . Lecontei.

Thorax laevis . . . . . . . . . . . . 43

43. Pygidium nitidum, gibbose convexum . . . 44

Pygidium minus nitidum, planum . . . . 45

44. Thoracis anguli antici acuti, oculi minuti . speculifer. 
Thoracis anguli antici obtusi, oculi majores . bicolor.

45. Antennae piceae, clava nigro-cinerea . . . 46 Antennae rufae. . . . . . . . . . . 47

46. Prosternum carinis transversis. . . . circulalus. Prosternum absque carinis . . . . . melancholicus.

47. Fusçus, opacus . .. . . . . . . . . . fuscipes. Nitidus, metallicus. . . . . . . . . . . 48

48. Prosternum transversim carinatum . . . smaragdulus. Prosternum absque carinis . . . . . . prasinus.

49. Thorax laevis vel lateribus tantum punctulatus $\quad \mathbf{5 0}$ Thorax et disco distincte punctatus . . . $\quad 60$

50. Prosterni carinae transversae integrae . . . 51 Prosterni carinae abbreviatae . . . . . . $\quad 53$

51. Convexus, impressio scutellaris nulla . . aequinoctialis. Impressio sculellaris distincta, elytra dorso deplanata . . . . . . . . . . . . . . . $\quad 52$

52. Clypei dentes laterales acuti, thorax nitidus . deplanatus. Dentes laterales obtusi, omnino subnitidus forcipatus.

53. Thorax lateribus fortiter punetatus, elytra distinctius striala . . . . . . . . . . virens.

Thorax lateribus laevis vel subtiliter tantum

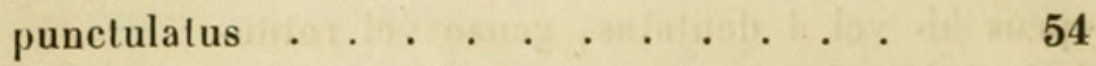

54. Tibiae intermediae sensim et aequaliter versus apicem dilatatae . . . . . . . . .

Tibiae intermediae extus ante apicem emarginatae, margine externo subangulatae. . .

55. Antennae rufae . . . . . . . . . . substriatus. Antennae piceae . . . . . . . . . . . 56

56. Thorax lateribus rotundatus, corpus minutum seminulum. Thorax lateribus medio angulatis. . . .

57. Thorax lateribus non punctatus, elytra obsoletissime inaequalia . . . . . . . seminitens. Thorax lateribus leviter punctatus, elytra aequalia . . . . . . . . conformis.

58. Genae acuminatae, elytra distinctius striata . fastuosus.

Genae anticae leviter tantum angulatae, ely-

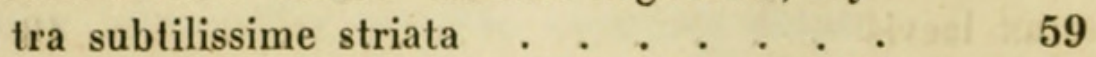

59. Thorax rofo-testaceus, antennae obscure rufae thoracicus. Thorax atro-cyanescens, antennae nigrae . . janthinus.

60. Impressio scutellaris distincta . . . . . 61 Impressio scutellaris nulla vel obsoleta . . $\quad 62$ 
61. Thorax ater, tibiae intermediae apice leviter emarginatae . . . . . . . bispinus.

Thorax aeneus, tibiae intermediae integrae, minor . . . . . . . . . . cinctellus.

62. Tibiae intermediae oblique transversim carinatae . . . . . . . . . . lituratus.

Tibiae intermediae non transversim carinatae

sanguineomaculalus.

63. Clypeus bidentatus et utrinque rotundatus, absque dentibus lateralibus . . . . . . $\quad 64$

Clypeus distincte 4 dentatus . . . . . . $\quad 85$

64. Supra granulatus . . . . . . . . . . 65

Supra laevis vel punctatus . . . . . . . . $\quad 66$

65. Oculi angusti, antennae fuscae . . . laevis.

Oculi majores, antennae ferrugineae. . . vigilans.

66. Tibiae intermediae et posticae ad apicem valde emarginatae . . . . . . . fractipes.

Tibiae vel simplices vel leviter tantum emarginatae. . . . . . . . . . . 67

67. Tibiae posticae margine postico ciliatae - gagatinus.

Tibiae posticae non ciliatae . . . . . . $\quad 68$

68. Tibiae anticae apice recte truncatae . . . . $\quad 69$

Tibiae anticae apice oblique truncatae. . . 80

69. Femora postica antice marginata. . . . . 70

Femora postica absque linea marginali. . . $\quad 75$

70. Totus nitidissimus . . . . . . . angularis.

Ex parte vel totus opacus . . . . . . . 71

71. Thorax sericeo-maculatus . . . . . velutinus.

Thorax absque maculis sericeis . . . . . $\quad 72$

72. Tibiae anticae margine interno ante medium non dentatae. . . . . . . . . . . 73

Tibiae auticae ante medium dentatae vel an gulatae . . . . . . . . . . . . . 74

73. Thoracis anguli postici prominuli . . . corpulentus.

Thoracis anguli postici non prominuli . . coeruleicollis.

74. Femora antica versus apicem sinuata et in sinu dentata. . . . . . . . . rutilans.

Femora antica leviter sinuata, in sinu non denticulata . . . . . . . latipes.

75. Elytra fortiter punctata, piliger . . . . juvencus.

Elytra absque punctis, corpus glabrum . . 76 
76. Tibiae anticae margine interno angulatim dilatatae . . . . . . . . . . . . .

Tibiae anticae intus non dilatatae, leviter arcuatae . . . . . . . . . . . . 78

77. Subnitidus, elytris subopacis . . . . . viridis. Totus nitidus . . . . . . . . . fallax.

78. Caput cum thorace distincte punctulatum. . viduus. Caput et thorax laevia . . . . . . . . . $\quad 79$

79. Thorax nitidus, elytra subnitida . . . . acutus. Omnino subopacus. . . . . . . . . subcyaneus.

80. Prosternum absque carinis transversis. . . 81 Prosternum carinis transversis. . . . . . 84

81. Nitidus, pygidium convexum . . . . Chevrolati. Subnitidus vel opacus, pygidium planum . . 82

82. Elytra humeris longitudinaliter tuberculatis . gemellatus. Elytra humeris non tuberculatis . . . . . 83

83. Thorax lateribus antice absque dente submarginali . . . . . . . . . . tristis.

Thorax margine laterali antico subtus dentato luctuosus.

84. Pygidium sericeo-opacum . . . . . . quadriguttatus.

Pygidium leviter nitidum, non sericans . . subhyalinus.

85. Thorax longe pone medium versus angulos po-

sticos angulatus. . . . . . . . . balleatus.

Thorax lateribus medio vel angulatus vel rotundatus . . . . . . . . . . 86

86. Thorax distincte et disco punctatus, vel opacus aut granulatus. . . . . . . . . 87

Thorax laevis, nitidus vel subnitidus . . . $\quad 89$

87. Thorax aeneus, femora postica marginata. mutabilis. Thorax niger, opacus, femora non marginata

88. Tho:ax absque punctis impressis . . . . . simplex. Thorax punctis distincte impressis . . . . corvinus.

89. Femora antica dentata . . . . . . . . 90 Femora antica mutica . . . . . . . . 91

90. Atro-violaceus, elytris nitidis . . . . tetraodon. Viridis, elytris subnitidis . . . . . dives.

91. Corpus supra nitidum . . . . . . . . . 92

Corpus elytris opacis. . . . . . . . . . 94

92. Prosternum transversim carinatum . . Deyrollei.

Prosternum absque carinis transversis.. . . 93

93. Pygidium opacum . . . . . . . formosus. 
Pygidium nitidum . . . . . . . modestus.

94. Femora postica marginata . . . . . . carbonarius.

Femora postica absque linea marginali. . . 95

95. Ovalis . . . . . . . . . . . . confluens.

Elongato-ovalis . . . . . . . . . . laesus.

1. C. Lacordairei Cast.: Subrotundatus, convexus, subnitidus, niger, capite thoraceque subaeneis. Caput rugose punctatum, clypeo quadridentato, dentibus autem lateralibus obtuse rotundatis, genis antice leviter angulatis. Thorax parum dense punctatus, inaequalis, medio longitudinaliter postice subsulcalus, utrinque callositate obliqua, nitida. Elytra seriebus quatuor tuberculorum, tuberculis subquadratis, nitidis, serie quarta interdum obsoleta, pone humeros carinula brevi. Pygidium planum, opacum, subtilissime granulosum. Corpus subtus cum pedibus leviter nitidum, nigrum; metasterno apice obtuse tuberculato, prosterno absque carinis transversis; pedibus sat longe rufo-ciliatis, tibiis anticis dente quarto marginali superiore, minore; intermediis et posticis profunde ante apicem emarginatis. - Long. 5 lin.

Hyboma Lacordairei Cast Hist. nat. p. 74. (1840.)

Epirinus caesus Lacord. Dej. Cat. 3 ed. p. 152.

C. gemmatus Blanch. Voy. d'Orb. Col. p. 160.

Von gerundeter und gewölibter Gestalt, mälsig glänzend, schwarz, Kopf und Halsschild leicht erzfarben. Der Kopf ineinander fliefsend und runzlig punktirt, hinten glatter, das Kopfschid vierzahnig, die mittleren Zähne ziemlich scharf, die Nebenzähne jedoch sehr stumpf abgerundet, das vordere Wangenende deutlich eckig. Das Halsschild mit einer gleichmäfsig über die erhabenen oder tieferen Stellen ausgebreiteten, zerstreuten Punktirung; in der Mitte eine nach hinten breiter werdende Längsfurche, deren Ränder etwas wulstig und namentlich hinten eine schief nach vorn gerichtete Beule bildend; neben dieser, gegen den Aufsenrand hin, aufser dem sehr merklichen Seitenrandhöckerchen, noch drei bis vier undeutlich erhabene Stel. len; die erhöhten Beulen sind glänzend, die tiefer liegenden Stellen bingegen matt und äufserst fein körnig gerunzelt; der Seitenrand ziemlich flach, in der Mitte stark bogig hervortretend, nach vorn leicht geschweift. Die Flügeldecken etwas kürzer als zusammen breit, mattglänzend, jede mit vier Längsreihen länglich-viereckiger, glänzender Erhabenheiten, die durch Quereindrücke von einander getrennt sind; in der vierten oder äufsersten Reihe, welche mit dem Schulterbuckel beginnt, sind diese Beulen meist kleiner 
und häufiger durch Querlinien unterbrochen; unter dem Schulterbuckel läuft noch eine kurze, unregelmäfsig erhabene Querleiste. Das Pygidium flach, matt, höchst fein gekörnelt. Taster und Fühler schwarz. Die Unterseite sammt den Beinen schwarz, mäfsig glänzend; die Hinterbrust vorn in einer stumpfen Beule endend, das Prosternum mit nur angedeutetem Basaltheile von Querleisten; alle Schenkel an beiden Rändern rothbraun behaart; die Vorderschienen oberhalb des ersten der gewöhnlichen drei Randzähne mit einem kleineren aber deutlichen vierten; die hinteren und dic mittleren Schienen, besonders letztere, tief vor dem Ende ausgebuchtet, ihre Kanten mit längeren Wimperhaaren besetzt.

Vaterland: Tucuman, nördliches Patagonien.

Aus der Münchener Staatssammlung; von d'Orbigny während des Monats Januar gesammelt.

2. C. sericinus: Subdilatalo-ovalis, parum convexus, niger, omnino sericeo-maculatus, capite thoraceque nonnihil virescentibus. Caput obsoletissime punctatum, clypeo bidentato. Thorax disco parce et valde punclatus, leviler foveolatim impressus, lateribus ante medium rolundato-angulatis. Impressio scutellaris fere nulla. Elytra inaequalia et transversim leviter plicata, distincte striata, interstiliis internis ad apicem leviter callosis. Pygidium leviter convexum, opacum, longitudinaliter obsolete carinalum. Corpus sultus cum pe. dibus sat nitidum, nigrum, metasterno medio subchalybeo; prosterno transversim carinato et antice foveolato, femoribus posticis marginatis, tibiis anticis apice recte truncalis. - Long. 4 lin.

Von breit-eiförmiger, nur wenig gewölbter Gestalt, schwarz, wie bereift und mit seidig glänzenden Makeln, Kopf und Halsschild dabei mit schwachem erzgrünen Glanze. Der Kopf mit äufserst feinen, kaum wahrnehmbaren Pünktchen, das Kopfschild vorn mit zwei breiten $Z$ ähnen, daneben gerundet, das $\mathbf{W}$ angenende eine kleine Ecke bildend. Das Halsschild mit mehreren flachen Grübchen, auf der Scheibe und hinten mit zerstreuten, gröfseren Punkten besetzt, der Seitenrand vor der Mitte stumpfeckig gebogen, nach hinten fast gerade, nach vorn leicht bogig gewölbt; die Basis in der Mitte ziemlich geradlinig. Der Scutellareindruck ist nur schwach angedeutet. Die Flügeldecken mit sehr seichten Streifen, die aber deutliche, ganz

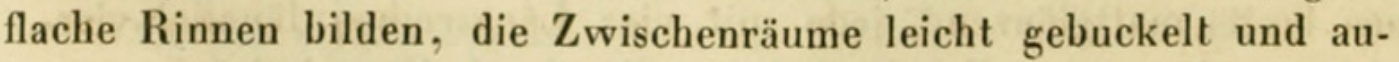
fserdem stellenweise mit schwachen Querfältchen versehen, die inneren am Ende leicht höckerig gewölbt. Das Pygidium mattscheinend, schwarz, glatt, der Länge nach leicht gekielt. Taster und 
Fühler dunkel rothbraun. Die Unterseite sammt den Beinen ziemlich glänzend, schwarz, die Hinterbrust in der Mitte bläulichschwarz, das Prosternum mit scharfen Querkanten und vor denselben etwas grubig vertieft; die hinteren Schenkel mit Randlinien; das Ende der Vorderschienen gerade abgestutzt, die hinteren ohne Ausbuch. tung vor der Spitze; die Tarsenglieder verhältnifsmäfsig schmal.

Vaterland: Brasilien.

Ein einzelnes Weibchen aus der Reich'schen Sammlung. Durch die unebene, leicht gebuckelte Oberfläche kommt diese Art in der synoptischen Tabelle neben $C$. rugosus zu stehen: habiluell hat sie jedoch mehr Aehnlichkeit mit C. opacus und C. luctuosus, welche beide, wenigstens auf dem Halsschilde, eine sehr analoge seidiggefleckte Zeichnung haben. Ersterer ist jedoch viel gewölbter, hat nur sehr feine Querleislen und ein Randzähnchen am Prosternum, aufserdem ganz glatte Flügeldecken; C. lucluosus ist ebenfalls glatt, hat gleichfalls ein Randzähnchen und weicht durch die schief abgestutzten Vorderschienen wesentlich ab. Die Arten nit seidiggeflecktem Halsschilde zusammenzustellen, schien mir deshalb nicht thunlich, weil bei $C$. lucluosus diese Zeichnung mitunter sehr abgeschwächt ist.

3. C. rugosus Blanch : Subdilatato-ovalus, parum convexus, niger, subnitidus. Caput rugose punctatum, vertice subconvexo, clypeo obtuse bidentalo. Thorax rugose-foveolatus, medio longitudinaliter subsulcalus, lateribus rotundatis. Elytra parum profunde striata, opaca, interstitiis tuberculis nitidis deplanat is et subquadrat is, interdum longitudinaliter confluentibus. Pygidium convexum, transverse-rugosum. Corpus sublus cum pedibus leviler nilidum, nigrum; metasterno antice obtuse tuberculato, prosterno absque carinis transversis; femoribus antice et postice ciliatis, tibiis anticis tridentatis, posticis et intermediis apice valde emarginat is. - Long. $5 \frac{3}{4}-6 \frac{1}{3}$ lin.

C. rugosus Blanch. Voy. d'Orbig. Col. p. 159. (1843.)

C. tessellatus Er. Wiegm. Arch. 1847. I. p. 105.

C, coriaceus Reiche i. litt.

Von etwas kurz-eiförmiger, nur wenig gewölbter Gestalt, schwarz, mäfsig glänzend. Der Kopf runzlig-punktirt, der Scheitel leicht gewölbt, das Kopfschild voru in der Mitte mit zwei dreieckigen, etwas stumpfen und wenig genäherten Zähnen. Das Halsschild narbig gerunzelt, längs der Mitte eine leichte Vertiefung, der Seitenrand bogig gerundet, die Hinterecken sehr stumpf abgerundet. 
Die Flügeldecken in der Mitte am breitesten, mattglänzend, seicht gestreift, die Zwischenräume mit glänzenden, leicht quadratischen Erhabenheiten, die zuweilen in der Längsrichtung theilweise zusammenfliefsen, eine Sculptur, welche der des Gymnopleurus flagellatus oder noch mehr der des Epirhinus scabratus nicht unähnlich ist, nur dafs bei jenem die glatten Stellen minder regelmäfsig viereckig sind. Das Pygidium leicht gewölbt, leicht quergerunzelt und schwach gekörnelt. Taster und Fühler schwarz. Die Unterseite sammt den Beineu ziemlich glänzend, sehwarz; das Metaslernum vorn einen stumpfen Höcker bildend, das Prosternum körnig punktirt, ohne Spur von Querleisten; sämmtliche Schenkel an beiden Rändern mit dunkel röthlichbraunen Borstenhaaren; die Vorderschienen mit drei, wenig genäherten Randzähnen, die mittleren und die hinteren aufsen vor dem Ende sehr merklich ausgebuchtet.

Vaterland: Patagonien, Bolivia und Peru.

Aus der Münchener Staatssammlung und von Herrn Dohrn mitgetheilt. Herr d'Orbigny hat diese Art im Monal October auf den Bergen zwischen Baca und Pecona in der Provinz Mizqué, dann im Monate Januar in der Provinz Chuquisaca, bei Yampares und auf den Hochebenen der Cordilleren von Palosi bis la Paz aufgefunden. Sie findet sich dort in grofser Anzahl auf Exkrementen und betreibt das Pillenwälzen wie die Gymnopleuren. C. tessellatus Er. ist nach dem typischen Exemplar im Berliner Museum ein kleines Exemplar dieser Art.

4. C. violaceus Oliv.: Nitidus, sat convexus, laevis, nigro. violaceus, pygidio teslaceo. Caput antice subtiliter subrugose punctulatum, clypeo 4 dentato, dentibus parum acutis, lateralibus obtusis. Thorax lateribus medio rotundatis, angulis posticis spinosulis, basi medio longitudinaliter impressus. Elytra lateribus leviter callosa, parum dislincle striala. Palpi cum antennis obscure rufo-picei, his albido-testaceo clavalis. Corpus subtus nigrum, subnitidum, pedibus leviter virescentibus, prosterno absque carinis transversis, tibiis intermediis et poslicis apice leviter subemarginatis. - Long. 5-6 lin.

Scarab. violaceus Oliv. Ent. I. 3. p. 171. t. 27. fig. 229.

Ateuch, violaceus $\mathrm{F}$ ab r. Syst. El. I. p. 65.

C. leucopygus Klug i. litt.

In der Gestalt dem C. Chevrolati ähnlich, ziemlich gewölbt, glänzend, glatt, dunkel violetlschwarz, das Pygidium weifslich-gelb. Der Kopf hinten glatt, vorn fein runzlig, das Kopfschild in der Mitte mit vier breiten, wenig spitzen Zähnen, das vordere Wangenende 
stumpf eckig. Das Halsschild mit in der Mitte nur gerundetem, nicht eckigem Seitenrande, die Basis neben den Hinterecken tief ausgebuchtet, diese daher zahnartig abstehend; gegen den Hinterrand in der Mitte eine leichte Längsvertiefung. Der Sculellareindruck unmerklich, nur die eigentliche Schildchenstelle leicht vertieft. Die Flügeldecken an den Seiten uneben; es machen sich nämlich aufser der Schulterbeule noch drei leichte Wölbungen bemerkbar; auch die Endbeule ist markirt und der unmittelbar neben der Schulterbeule nach innen liegende $Z_{\text {wischenraum }}$ ist ebenfalls in seinem Wurzeltheile deutlich gewölbt; Längsstreifen sind keine zu bemerken. Das Pygidium leicht gewölbt, glatt, etwas mattglänzend, strohgelb. Die Taster und Fühler dunkel rothbraun, letztere mit weifsgelber Keule. Die Unterseite sammt den Beinen ziemlich glänzend, schwarz, mit schwachem bläulichen Scheine; das Proslernum ohne Querleisten, die hinteren Sclıenkel ohne Randlinie; die mittleren und die hinteren Schienen vor der Spitze leicht ausgerandet, letztere eigentlich nur verschmälert.

Vaterland: St. Domingo.

In Mehrzahl von verschiedenen Seiten. Eine an der Färbung, den leicht an den Seiten gebuckelten Flügeldecken und namentlich dem gelben Pygidium leicht kenntliche Art, die durch letzteres Merkmal in nahe Beziehung mit den gleichfalls auf St. Domingo einheimischen C. signifer und C. callosus tritt. Diese drei Arten scheinen wirklich auf die genannte Insel beschränkt zu sein, es ist mir wenigstens von dem in den Sammlungen vielfach verbreiteten C. violaceus keine andere Herkunftsangabe vorgekommen.

5. C. callosus: Similis C. signifero, at minor, obscure cupreo-aeneus, thoracis macula utrinque postica elytrorumque apice rufo-testaceis, pygidio testaceo. Caput margine postico biimpresso, fronte intra oculos subbiluberculata, clypeo quadridentalo, genis antice sat acutis. Thorax basi medio foveolatus, lateribus medio angulato-rotundatis, utrinque foveolatus et leviter tuberculatus. Elytra basi, lateribus et apice callosa. Pygidium leviter convexum, laeve. Palpi cum antennis rufi, his rufo-testaceo-clavatis. Corpus subtus cum pedibus nigro-cupreum, metasterno medio abdominisque lateribus obscure rufis, prosterno non carinato nec denticulato, femoribus posticis antice non marginatis, tibiis intermediis et posticis apice subemarginatis. - Long. $3 \frac{1}{4}$ lin.

Dem C. signifer ähnlich, doch kleiner und etwas schmäler, glänzend, schwärzlich kupferfarben, das Halsschild hinten zu jeder 
Seite mit einem gelbrothen Fleck, auch die äufsere Spitze der Flügeldecken röthlich. Der Kopf uneben, der Hinterrand mit zwei grübchenartigen Eindrücken, die Stirn zwischen den Augen mit zwei schwach angedeuteten Höckerchen, das Kopfschild vierzahnig, die beiden mittleren Zähne stark, aber doch nicht schmal, die Nebenzähne einen stumpfen, an der äufsersten Spitze etwas abgerundeten Winkel bildend, das vordere Wangenende deutlich winkelig. Das Halsschild hinten wie bei $\boldsymbol{C}$. signifer in der Mitte mit einem tiefen Grübchen, das gewöhnliche Seitenrandgrübchen stark markirt und vor demselben ein Höckerchen, der Seitenrand in der Mitte winkelig gerundet, die Hinterecken etwas vertieft. Die Flügeldecken mit deutlich erlabenem Humeralstreif, an der Basis mit Einschlufs des Schulterbuckels drei starke Beulen, dann drei am Seitenrande und aufserdem eine Endbeule; Querfältchen machen sich übrigens nicht bemerkbar. Das Pygidium leicht gewölbt, glatt, gelb. Taster und Fühler rothbraun, letztere mit gelbrother Keule. Die Unterseite sammt den Beinen schwärzlich mit Kupferglanz, die Mitte der Hinterbrust und die Hinterleibsringe an der Seite roth gefleckt; das Prosternum ohne Querkanten und ohne Randzähnchen; die hinteren Schenkel ungerandet; die mittleren und hinteren Schienen leicht vor der Spitze ausgebuchtet.

Vaterland: St. Domingo.

Von Herrn Deyrolle mitgetheilt, ebenfalls als C. signifer bestimmt, von dem jedoch diese Art, trotz mancher Analogie, sehr wesentlich abweicht. Abgesehen von der geringeren Gröfse und der mehr kupfrigen Färbung ist das Kopfschild ganz anders gebildet, nämlich deutlich vierzahnig, am Seitenrande des Halsschildes findet sich bei jenem weder das tiefe Grübchen noch der Höcker davor, das Pygidium ist viel flacher gewölbt, auf den Flügeldecken fehlen die Querfältchen, die bei $\boldsymbol{C}$. signifer unter der Schullerbeule und in der Mitte neben der Naht erscheinen, endlich sind die hinteren Schienen bei der gegenwärtigen Art an der Spitze viel unmerklicher ausgebuchtet.

6. C. signifer: Ovalis, postice leviter subacuminalus, sat convexus, nitidus, nigro-piceus, thoracis lateribus pygidioque pallidotestaceis. Caput sat inaequale, clypeo oblique antice angustato et apice profunde inciso. Thorax lateribus medio leviter rotundatis, basi medio foveolatus. Elytra inaequalia, lateribus apiceque callosa, stria humerali usque ad medium fere distincla. Palpi cum antennis rufo-picei, his pallido-testaceo-clavatis. Corpus subtus cum pedibus 
nigro-aeneum, metasterno medio et abdomine lateribus flavo-maculatis; prosterno non carinato nec denticulato; femoribus posticis non marginatis, tibiis intermediis et posticis apice distincte emarginatis. - Long. $3 \frac{4}{5}$ lin.

C. signifer Uannerh. i. litt.

Von etwas länglich-eiförmiger, mäfsig gewölbter Gestalt, glänzend, schwarz, das Halsschild zu beiden Seiten und das Pygidium blafsgelb. Der Kopf elwas uneben, namentlich zwischen den Augen mit zwei ziemlich deutlichen Höckerchen und einem dritten in der Mitte, etwas weiter vorgerücktem; nach vorn verschmälert und am Ende ziemlich tief eingeschnitten, so dafs zwei zipfelartige Zähne entstehen; das vordere Wangenende einen sehr stumpfen Winkel bildend. Das Halsschild hinten in der Mitte grübchenartig vertieft, der Seitenrand in der Mitte gerundet, die Basis neben den Hinterecken ausgebuchtet. Die Flügeldecken mit deutlich erhabenem Humeralstreifen, sonst aber nur undeutlich gestreift, dagegen an der Basis, dem Seitenrande und der Spitze mit mehreren höckerartigen Buckeln, von denen aufser der Schulterbeule, zwei an der Basis und drei am Seitenrande besonders auffallend sind, von den letzteren wieder ist besonders der mittlere entwickelt, der ober ihm befindliche kleiner und mehr länglich. Das Pygidium glatt, gegen die Spitze stark gewölbt, an der Basis und an den Seiten hier und da etwas erzfarben. Die Taster und Fühler rothbraun, letztere mit weifslich-gelber Keule. Die Unterseite sammt den Beinen schwarz, mit etwas kupfrigem Glanze; die Mitte der Hinterbrust und die Hinterleibsringe an den Seiten rothgelb gefleckt; das Prosternum ohne Querkanten und auch ohne Randzähnchen; die hinteren Schenkel vorn ohne Randlinie, die mittleren sowie die hinteren Schienen vor der Spitze sehr deutlich ausgerandet.

Vaterland: St. Domingo.

Von Herrn Deyrolle mitgetheilt.

7. C. nigricornis Say: Subrotundatus, postice subattenuatus, elytris parum, thorace valde convexo, opacus, subtiliter parum dense granulatus, niger, interdum subcupreo-micans, brevissime rufo-setosulus. Caput clypeo medio valde bidentato, dentibus lateralibus genisque antice obtusis. Thorax postice linea longitudinali subimpressa, lateribus medio leviter tantum rotundatis, antice arcuatis medioque denlatis, angulis posticis rotundatis. Impressio scutellaris obsoleta. Elytra parcius quam thorax et subseriatim granulosa, 
vix distincte striata. Palpi cum antennis picei. Corpus subtus cum pedibus nitidulum, nigrum; prosterno non carinato, antice foveolato; femoribus posticis non marginatis, tibiis anticis intus ante medium leviter angulato-dilatatis, posticis apice bispinosis. - Long. $3 \frac{1}{2}-4$ lin.

Ateuchus nigricornis Say Journ. Acad. Phil. III. p. 207. (1823.)

Canthon nigricornis Lec. Col. of Kans. p. 10. (1859.)

Coprob. ateuchoides Sturm Cat. 1843. p. 104.

Coprob. latimanus Dej. Cat. 3 ed. p. 152.

Coprob. Melsheimerii Knoch i. litt.

C. alutaceus Germar i. litt.

Von ziemlich gerundeter, nach hinten leicht zugespitzter Gestalt, ohne Glanz, das Halsschild stark gewölbt, die Flügeldecken flachgedrückt; schwarz, hier und da leicht kupfrig scheinend, fein gekörnelt, die Körnchen auf den Flügeldecken noch feiner und zerstreuter, leicht in Reihen geordnet, aufserdem mit äufserst kurzen, kaum wahrnehmbaren rothbraunen Börstchen besetzt. Das Kopfschild vorn breit abgesetzt, in der Mitte mit zwei starken, aber ziemlich weit auseinander gerückien Zähnen, die Seitenzähne und auch das vordere Wangenende stumpf-winkelig. Das Halsschild hinten mit leicht vertiefter, zuweilen undeutlicher Längslinie, der Seitenrand, von der Seite besehen, in der Mitte leicht gerundet, gegen die abgerundeten Hinterecken fast gerade, nach vorn leicht bogig gewölbt, und unten in der Mitte mit einem Zähnchen verse. hen; die Körnchen sind schmal und länglich, mit nach hinten gerichteter Spitze. Der Scutellareindruck ist sehr flach und macht sich wenig bemerkbar. Die Flügeldecken kürzer als zusammen breit, unter den Schultern am breitesten, von da nach hinten eiförmig zugespitzt, nur sehr undeutlich gestreift, die Körnchen zerstreut, nicht länglich, an der Basis zwei höckerartige Knöpfchen. Das Pygidium gekörnt, an der Basis ziemlich flach und in der Mitte leicht gekielt, die Spitze gewölbt. Taster und Fühler schwarzbraun. Die Unterseite sammt den Beinen mäfsig glänzend, schwarz; das Prosternum ohne Querleisten, der vordere Abschnitt jedoch muldenartig vertieft; die Schenkel wenig kräftig, die hinteren ohne Randlinie vorn; die Vorderschienen mit drei sehr kräftigen Randzähnen, der mittlere fast dem obersten etwas näher als dem untersten stehend, der Innenrand vor der Mitte leicht winkelig erweitert; die hintersten Schienen am Eude mit zwei, fast gleich langen Enddornen; das Klauenglied sehr grofs.

Vaterland: Die vereinigten Staaten Nordamerikas, Texas. 
In Mehrzahl von vielen Seiten zugeschickt. Diese Art ist der einzige bisher mir bekannt gewordene Ateuchide, dessen hinterste Schienen mit zwei Enddornen, anstatt mit dem normalen einen, bewaffnet sind; dieser Umstand, weleher bis jetzt allen Beobachtern entgangen zu sein scheint, wird um so auffallender, wenn man die aufserordentlich nahe Verwandtschaft ins Auge fafst, die zwischen diesem Canthon und den übrigen nordamerikanischen Arten, z. B. C. ebeneus, simplex oder dem C. carbonarius besteht. An eine generische Trennung dieser Art ist eben deshalb nicht zu denken, immer aber scheint mir diese Eigenthümlichkeit wichtig genug, um in der synoptischen Tabelle diesen Canthon dadurch den übrigen voranzusetzen.

8. C. affinis Fabr.: Ovalis, leviter convexus, capite cupreo nitidulo, thorace disco viridi-metallico nitidissimo, lateribus opacis, rufo-brunneis, elytris sordide testaceo-brunneis. Caput laeve, clypeo medio acute bidentato. Thorax medio laevis, lateribus medio acutissime angulatus, postice et antice sinuatis, angulis posticis spino. sis. Impressio scutellaris nulla. Elytra leviter at distincte striata, interstitiis opacis, subtilissime vixque perspicue punctulatis, punctis apice distinclius piligeris. Pygidium setigerum, praecipue apice. Palpi cum antennis ferruginei, his rufoclavalis. Corpus subtus cum pedibus fuscobrunneum, metasterno nitido, viridi-aurato; epipleuris latissimis planis; prosterno carinis transversis validis; tibiis anticis apice sculpriformibus, breviler extus dentatis, dentibus acutis, ultimis duobus approximatis. - Long. 4 $\frac{1}{2}-5$ lin.

Ateuchus affinis Fabr. Syst. El. I. p. 64. (1801.)

Canthon oxygonus Perty Del. anim. p. 37. t. 8. f. 3. (1830.)

Canthon affinis Cast. Hist. nat. II. p. 69. (1840.)

Von etwas breiter, ovaler Gestalt, mälsig gewölbt, der Kopf glänzend und kupfrig, das Halsschild sehr stark glänzend, goldiggrün, an den Seiten aber malt, schmutzig - rothbraun, die Flügeldecken gelbbraun. Der Kopf glatt, die Wangen nach Aufsen vortretend, vorn eine sehr kleine Spitze bildend, das Kopfschild in der Mitte mit zwei sehr scharfen, nahe bei einander stehenden Zähnen; diese Zähne erscheinen deshalb besonders scharf, weil sie nicht so fast allein durch den Ausschnitt des Kopfschildes gebildet sind, sondern der Länge nach leicht gekielt sich zeigen. Das Halsschild in der Mitte blank, der Länge nach deutlich vertieft, die Seiten fein runzlig, trüb rothbraun; der Seitenrand ziemlich flach abgesetzt, in der Mitte eine âufserst scharfe, durch eine hintere Ausbuchtung et- 
was zipfelartige Ecke bildend, der vordere Abschnitt etwas hinter der Mitte scharf gezahnt, der hintere leicht ausgebuchtet, die Hinterecken daher, neben welchen die Basis etwas eingeknifft und ausgebuchtet ist, dornarlig vortretend; zuweilen dehnt sich die netzartig gerunzelte Beschaffenheit der Seiten auch auf die Mitte aus, die dann minder glänzend erscheint, aber immer hell goldgrün bleibt. Ein Scutellareindruck ist nicht vorhanden. Die Flügeldecken in der Mitte am breitesten, flachgewölbt, der Seitenrand sciarf abgesetzt; sehr fein gestreift, die Streifen glänzender als die lederartig matten Zwischenräume, diese mit zerstreuten glänzenden Pünktehen, die ein äufserst kurzes Börstchen tragen, welches erst hinten in der Gegend des Endbuckels deutlicher wird; die Naht, der Basalrand and die Aufsenkante sind metallisch-grün gefärbt. Das Pygidium matt, rothbraun, mit kurzen Borstenhaaren, besonders an der Spitze, ziemlich dicht besetzt. Taster und Fühler rothbraun, letztere mit gelbrother Keule. Die Unterseite sammt den Beinen dunkel röthlichbraun, wenig glänzend, die Hinterbrust jedoch in der Mitte und zum Theil auch die Hüften goldig-grün glänzend; auch die Kniee der Vorderbeine an der Aufsenseite, der untere Theil des Kopfschildes und das mit langen Borstenhaaren versehene Kinn glänzen kupfrig-grün; die Epipleuren sehr breit, allmählig und gleichmäfsig gegen die Spitze verschmälert, nicht aufsteigend, sondern horizontal nach unten gelegen; die Vorderschienen ziemlich schmal, an der Spitze gerade abgeschnitten, der Aufsenrand fein und gleichmäfsig gezähnelt, die Randzähne weit nach unten gerückt, fein und spitz, die beiden untersten einander genähert; die hintern Schenkel zerstreut mit borstentragenden Pünktchen besetzt.

Das Männchen hat einen breiten und an der Spitze leicht zweizahnigen Enddorn der Vorderschienen.

Bei dem Weibchen ist dieser Enddorn sehr schief abgestutzt, daher spitz erscheinend und nach Aufsen gerichtet.

Vaterland: Brasilien.

In den Sammlungen nicht gerade selten; der Perty'sche C. oxygonus in der Münchener Staatssammlung ist diese Art, deren äusserst mangelhafte Beschreibung im Syst. El. freilich das Erkennen kaum ermöglicht.

C. affinis hat vieles eigenthümliche, und entfernt sich durch die nicht nach vorn abgerundeten, sondern eckig nach aufsen vorspringenden Wangen, das an den Seiten flach abgesetzte, in der Mitte sehr spitze Halsschild, die breiten Epipleuren und die etwas schmalen Vorderschienen wesentlich von den typischen Canthon- 
Arten; unverkennbar bildet derselbe mit dem nahestehenden $C$. sordidus den Uebergang zur Gattung Deltochilum, die sich von Canthon aufser den nicht erweiterten Vorderschienen kaum mehr anders als durch die Wulste am Endbuckel der Flügeldecken unterscheiden läfst, indem der Mangel der Vorderfüfse, wie ich bereits im Eingange erwähnt, kein stichhaltiges Gattungsmerkmal abgibt. C. sordidus, obwohl in der Körpergestalt wieder den ächten Canthon-Arten nahestehend, schliefst sich vielleicht noch inniger an Dellochilum an, als C. affinis, denn bei ihm macht sich an der Wurzel der Flügeldecken schon eine kleine Schwiele in der Schultergegend bemerkbar, die ganz an die Schulterleiste der Deltochilen erinnert; die horizontal abgesetzten und breiten Epipleuren, so auffallend sie auch bei diesen beiden Arten sind, kommen ihnen doch nicht ausschliefslich $\mathrm{zu}$, denn der ganz unzweifelhaft typische C. Iristis hat sie ganz ähnlich geformt. Auch die Behaarung, die bei $\boldsymbol{C}$. sordidus ihr Maximum erreicht, findet sich, freilich nur sehr schwach angedeutet bei $C$. perplexus oder auf das Pygidium beschränkt bei sehr vielen ächten Canthons wieder, z. B. C. smaragdulus, formosus, virens u. s. w.

9. (: sordidus: Ovalus, leviter convexus, parum nitidus, obscure rufo-brunneus, clypeo antice medio leviter metallescente. Caput subtilissime punctatum, clypeo medio reflexo et bidentato, genis rotundatis. Thorax punctatus, punctis piligeris, lateribus medio subangulatus. Elytra subtilissime reticulala, obsoletissime striata, striis setulosis, humeris subaeneo-callosis, epipleuris latis, planis. Pygidium sat dense pilosum. Palpi cum antennis rufo-brunnei, his clava cinerascente. Corpus subtus vix nilidum, brunneum; pedibus rufo-brunneis, leviter metallescentibus; prosterno absque carinis transversis; tibiis anticis (১) dente ultimo marginali incrassato. - Long. $3 \frac{1}{2}$ lin.

Coprob. fetidus Lacord. Dej. Cat, 3 ed. p. 152.

C. turbatus Reiche i. litt.

Von verkehrt-eiförmiger, leicht gewölbter Gestalt, wenig glänzend, dunkel röthlichbraun, die Flügeldecken etwas heller braun, zuweilen aber auch ganz dunkelbraun. Der Kopf zerstreut und äufserst fein punktirt, das Kopfschild vorn in der Mitte aufgebogen und schwach metallisch glänzend, zweizahnig, die Wangen abgerundet. Das Halsschild fein punktirt, jeder Punkt ein kurzes goldgelbes Borstenhaar tragend, der Seitenrand in der Mitte eckig gerundet, ohne dafs ein scharfer Winkel entsteht, von da bis zu 
den Vorder- und Hinterecken fast gerade; äufserst fein netzartig gerunzelt, daher nur matt glänzend. Kein Scutellareindruck. Die Flügeldecken etwas vor der Mitte am breitesten, wie das Halsschild äufserst fein nadelrissig, aufserdem mit sebr seichten Streifen, die zum Theil einander paarweise genähert sind und Reihen kurzer, goldgelber Härchen bilden; der Schulterbuckel eine kleine Läugsbeule bildend, glänzend und etwas grünlich metallisch; die Ep:pleuren breit und ziemlich flach, ebenfalls zerstreut borstig. Das Pygidium grofs, rothbraun oder dunkelbraun, matt, mit gelben Borsten zerstreut, an der Spitze etwas dichter besetzt. Die Taster und Fühler rothbraun, letztere mit grau behaarter Keule. Die Unterseite nur mäfsig glänzend, schmutzig rothbraun, hier und da, besonders die Hüften, etwas kupfrig glänzend; das Prosternum ohne Querkanten; die Beine rothbraun, auch noch die Schenkel mit kleinen Börstchen besetzt; die Vordersehienen mit drei, ziemlich auffallend nach vorwärts gerichteten Randzähnen, der unterste breit und einen stumpf zugerundeten Lappen bildend $\delta$, oder mit den gewöhnlichen drei Randzähnen $ᄋ$.

Vaterland: Südamerika; Cayenne.

Aus der Reich'schen Sammlung, von Dr. Haag freundlichst mitgetheilt. Eine sehr eigenthümliche Art, die zwar mit C. affinis theilweise die Behaarung und Färbung, auch noch die Gestalt der Epipleuren gemein hat, aber doch durch das nicht mit Querleisten versehene Proslernum und den merkwürdigen Bau der Vorderschienen wesentlich davon abweicht. Trotzdem dafs der Seitenrand des Halsschildes in der Mitte ein sehr deutliches Eck bildet, ist die Querkante der Halsschildunterseite doch auf ein ganz kurzes Leistchen reducirt, welches auf eine kleine Strecke dem Vorderrande des Prosternums von den Hüften aus folgt, ohne die Richtung gegen die Seitenrandmitte einzunehmen. C. asper, der auch manches mit der gegenwärtigen Art gemein hal, hat zwar kein Eck in der Mitte der Halsschildseiten, dagegen wieder sehr deutliche Querleisten. In der Färbung scheinen die Männchen, welche an dem lappenförmig abgerundeten untersten Randzahne der Vorderschienen sehr leicht kenntlich sind, meist dunkler als die Weibchen zu sein, von denen mir nur rostrothe Stücke vorliegen, der Kopf bleibt jedoch auch bei diesen dunkelbraun, der Vorderrand in der Mitte leicht erzgrün. 
10. C. asper: Subovalis, postice leviter subacuminatus, dorso deplanalus, villosulus, obscure rufo-piceus, subcuprascens, parum nitidus. Caput obsoletissime variolose punctatum, vertice longitudinaliter obsolete subcanaliculato, clypeo bidentato. Thorax lateribus ante medium rotundatis, umbilicato-punctatus, rufo-villosus, postice medio late impressus. Elytra subtiliter striata, interstitiis subseriatim parum profunde punctatis, punctis umbilicatis, setigeris. $\boldsymbol{P}_{y-}$ gidium sat convexum, rufo-setosulum. Pälpi cum antennis piceorufi. Corpus sublus opacum, melasterno medio laevi, prosterno valde transversim carinato et antice foveolato; pedibus piceo-rufis, femoribus punctatis, setigeris; tibiis anticis exlus longe et acule tridentatis. - Long. $3 \frac{1}{2}$ lin.

Von ziemlich ovaler, nach hinten etwas spitz verschmälerter Gestalt, einem flachgedrückten Sisyphus nicht unähnlich. Dunkel kupfrig oder röthlichbraun, Kopf und Halsschild ziemlich glänzend, mit etwas grünlichem Kupferschimmer, auch die Flügeldecken malt kupfrig, die ganze Oberseite, mit Ausnahme des nur spärlich behaarten Kopfes, mit ziemlich langen goldgelben, an der Spitze nach rückwärts gekrümmten Borstenhaaren bedeckt. Der Kopf äufserst fein narbig punktirt, der Scheitel in der Mitte mit der Spur einer Längsschwiele, der Vorderrand in der Mitte zweizahnig, die Zähne meist kupfrig glänzend. Das Halsschild dicht punktirt, die Punkte ringförmig, genabelt, aber nur wenig tief, in der Mitte die Punktirung etwas spärlicher, namentlich vorn einen glatten Längsstreif freilassend; der Seitenrand in den hintern zwei Dritteln seiner Länge gerade, dann bogig nach vorn gerundet, die Vorderecken spitz; der Hinterrand mit etwas erhabener Kante, daher scheinbar gerandet, in der Mitte gerade, dann gegen die Hinterecken leicht ausgebuchtet; auf der hinteren Hälfte des Halsschildrückens eine ziemlich muldenartige Längsvertiefung, in deren vorderen Theil ein unmerklich erhöhtes Längsleistchen hineinragt. Die Flügeldecken etwas uneben, sehr fein gestreift, die Streifen feine Rinnen bildend, die Zwischenräume sehr seicht in unregelmäfsigen Reihen punktirt, die Punkte borslentragend; besonders am Endbuckel machen sich durch die Vereinigung der Streifen einige Borstenbüschel bemerkbar. Das Pygidium ebenfalls goldgelb behaart. Taster und Fühler bräunlich roth. Die Unlerseite mattglänzend, dunkel röthlichbraun; die Hinterbrust jedoch in der Mitte mit einem nach vorn gerichteten, glatten dreieckigen Fleck; das Prosternum mit scharfer, von den Vorderhüften aus schief nach aufsen und vorwärts verlaufender Querkante; dieser vordere Abschnitt muldenartig vertieft, dessen Aufsen- 
rand von den Vorderecken an auf eine ganz kurze Strecke gezähnelt, bis wo ein gröfseres Zähnchen, welches sich nach innen als kurzes Leistchen fortsetzt, den hintern ungezähnten und grösseren Randtheil begränzt; die Beine rothbraun, die hintern Schenkel mit zerstreuten Pünktchen, die ein ganz kurzes Börstchen tragen; die Vorderschienen am Ende nur wenig schief abgeschnitten, mit drei scharf zugespitzten Randzähnen, von welchen die beiden untersten einander wenig genähert sind.

Vaterland: Columbien (Moritz!)

Von Dr. Haag freundlichst mitgetheilt. Diese Art erinnert, den Fufsbau abgerechnet, einigermafsen an einen Sisyphus, wozu namentlich die Gestalt des Halsschildes beiträgt, dessen Seitenrand nicht in der Milte seiner ganzen Ausdehnung, sondern erst in jener der vordern Hälfte winkelig nach innen sich biegt, ein Merkmal, durch welches sich $\boldsymbol{C}$. asper zugleich von dem äufserst nahe verwandten $\boldsymbol{C}$. villosus sofort unterscheidet.

11. C. villosus: Praecedenti simillimus vixque ab illo dignoscendus nisi thoracis forma diversa. Obscure rufo piceus, leviter cuprascens, subnitidus, villosulus. Thorax elytris latior, lateribus medio angulatis, dein versus apicem sicut versus angulos posticos rectis; umbilicato-punclatus, postice longitudinaliter medio foveolatus. Prosterno transversim carinato, antice subfoveolato, margine externo medio dentato. Caetera omnino ut in C. aspero. - Long. $3 \frac{4}{5}$ lin.

Eine ausführliche Beschreibung dieser Art erscheint überflüssig, da sie, die etwas bedeutendere Gröfse und dunklere Färbung abgerechnet, vollkommen gleichgebaut mit $\boldsymbol{C}$. asper ist, von dem sie sich jedoch durch das ganz verschieden gebaute Halsschild wesentlich unterscheidet. Während nämlich bei diesem das Eck des Halsschildes weit vor der Mitte des Seitenrandes sich befindet, ist dieser bei $\boldsymbol{C}$. villosus genau in der Mitle winkelig und zwar ziemlich scharf gebogen, von dieser Ecke an nach vorn und nach hinten fast gerade; das Halsschild wird dadurch in seinem gröfsten Querdurchmesser, nämlich von einem Seitenrandwinkel zum andern, merklich breiter als die Flügeldecken, und laufen dessen Ränder in der hinteren Hälfte convergirend der Basis zu, während sie bei $\boldsymbol{C}$. asper parallel verlaufen. Dieser verschiedene Bau spricht sich auch noch auf der Unterseite sehr deutlich aus; hier lauft die Querkante nicht schräg nach vorwärts, sondern gerade seitwärts dem Aufsenrande zu; der Rand des vorliegenden, nur leicht muldenartig ver- 
tieften Theiles, ist wie bei $C$. asper unten gezähnelt, aber auf eine bedeutend gröfsere Ausdehnung, so dafs das letzte gröfsere Zähnchen nicht vor, sondern hinter der Mitte dieses Randabschnittes zu liegen kommt. Die Punktirung des Halsschildes ist aufserdem etwas gleichmäfsiger, und nanentlich auf dem vordern Theile merklich tiefer, auch scheinen mir die vorderen Beine etwas länger und schmäler wie bei $C$. asper zu sein.

Den erroähnten, sehr augenfälligen Unterschied in der Halsschildform als Geschlechtsdifferenz aufzufassen, was bei der übrigen grofsen Aehnlichkeit dieser beiden Thiere sich als denkbar aufdrängt, dem widerspricht der Umstand, dafs ich wenigstens von beiden Arten die Weibchen mit Bestimmtheit vor mir habe, denn der Enddorn der Vorderschienen ist beim $C$. asper sowohl als bei $\boldsymbol{C}$. villosus sehr lang und schmal. Meine einzigen beiden Stücke des C. villosus (der nebenbei gesagt als C. asper Moritz in der Reichschen Sammlung sich befand) sind leider in wenig gut erhaltenem Zustande, namentlich ist auf dem einen derselben die Behaarung auf Halsschild und Flügeldecken fast ganz abgerieben, wodurch dasselbe glänzend und von dem besser conservirten Stück sehr verschieden aussieht.

12. C. mulicus Har.: Ovalis, dorso deplanalus, capite thoraceque nitidis, elytris subnitidis, auralo-viridis vel nigro-violaceus. Caput laeve, anlice rotundatum, clypeo medio sat late et leviter sinuato, reflexo, utrinque rotundato. Thorax lateribus rotundatis, medio aulem non angulatis, laevissimus. Regio scutellaris dislincle impressa. Elytra distincte striata, striis versus apicem evanescentibus, stria suturali obsolete punctata. Pygidium opacum, laeve, margine impressum. Corpus subtus cum pedibus concolor, tibiis anticis scalpriformibus, posticis versus apicem vix dilatatis, arcuatis. - Long. 3 lin.
C. muticus Harold Col. Heft I. 1867. p. 78.
Coprob. planifrons Dej. Cat. 3 ed. p. 152.

Von eiförmiger, auf dem Rücken flachgedrückter Gestalt, Kopf und Halsschild glänzend, besonders das letztere, die Flügeldecken etwas matter glänzend, goldiggrün oder schwarzblau. Der Kopf glatt, die Augen sehr klein, der Aufsenrand vorn weit und wenig tief ausgebuchtet, leicht aufgebogen, beiderseits abgerundet. Das Halsschild in der Mitte am breitesten, der Seitenrand stark bogig gerundet aber ohne Ecke, vollkommen glatt. Die Schildchengegend deutlich vertieft. Die Flügeldecken sebr seicht aber doch deutlich 
gestreift, der Nahtstreif etwas tiefer und leicht punktirt; der Schulterstreif deutlich bis fast zur Spitze, die übrigen Streifen dagegen hier erlöschend. Das Pygidium matt, obne deutliche Punktirung, am Rande ringsherum vertieft, so dafs der eigentliche Aufsenrand sich kantig abhebt. Taster und Fühler heller oder dunkler rothbraun. Die Unterseite glänzend, wie die obere gefärbt, ebenso die Beine; das Prosternum mit verkürzten Querleisten, die von den Vorderhüften ausgehen, aber bald darauf erlöschen; die Vorderschenkel breit, fast linsenförmig; die Vorderschienen kurz und breit. vorn gerade abgeschnitten, die Randzähne mit Ausnahme des untersten nur schwach entwickelt; die hinteren Schienen sehr schmal, nur unmerklich gegen die Spitze erweitert, dabei leicht im Bogen gekrümmt, ihr Ende neben dem Enddorn spitz ausgezogen, so dafs es scheinbar zweispornig erscheint.

Das Männchen unterscheidet sich nur durch einen etwas slärkeren, am Ende stumpfen Schienensporn, der beim Weibchen schmal und allmählig zugespitzt ist.

Vaterland: Brasilien, Buenos Aires, Insel St. Thomas, die Pampas des La Plalagebietes, Caasapava.

Von mehreren Seiten in Mehrzahl zugeschickt. Bei manchen, vielleicht minder ausgefärbten Exemplaren, sind die Flügeldecken etwas röthlich durchscheinend, also meist grünlich violett gefärbt. Bei frisch erhaltenen Stücken sind die beiden Ecken neben der Ausbuchtung des Kopfschildes etwas stumpfer, durch Abnutzung runden sich dieselben aber so ab, dafs sie nur mehr sehr leichte Lappen darstellen. C. planus Luc. Voy. Cast. p. 101 von Minas Geraës und Cuyaba könnte vielleicht diese Art sein: die Beschreibung, welche die gekrümmten Hinterbeine nicht erwähnt, läfst mich jedoch hierüber in $\mathbf{Z w e i f e l}$.

13. C. edentulus: Stalura fere C. mutici, at gracilior, subelongatc-ovalis, nitidus, laevis, niger. Caput subconvexum, clypeo antice medio emarginato. Thorax lateribus rotundatis. Impressio scutellaris distincta. Elytra subtilissime striata. Pygidium dense at parum distincte punctulatum, minus nitidum, apice subtruncatum. Palpi cum antennis picei, his cinereo-clavatis. Corpus subtus cum pedibus nigrum, nitidum; prosterno transversim carinato, carinis antice directis; femoribus posticis marginatis; tibiis anticis apice recte truncatis, intermediis brevibus et sat dilatatis; tarsis posticis articulis primis duobus subelongatulis. 우. - Long. $2 \frac{3}{4}$ lin. 
In der Gestalt dem C. muticus verwandt, doch etwas schmäler und länglicher, glatt und glänzend, schwarz, mit höchst schwachem bläulichen Scheine. Der Kopf leicht gewölbt, das Kopfschild vorn ohne eigentliche Zäbne, nur in der Mitte ausgebuchtet. Das Halsschild mit gleichrnäfsig gerundetem Seitenrande, so dafs in der Mitte kein Eck oder überhaupt nur eine stärkere Biegungsstelle entsteht. Der Scutellareindruck deutlich, greift auch die Mitte der Halsschildbasis an. Die Flügeldecken sehr fein gestreift, der achte Streif in der hinteren Hälfte etwas deutlicher. Das Pygidium flachgewölbt, mäfsig glänzend, sehr fein und etwas undeutlich punklirt, an der Spitze leicht abgestutzt (). Taster und Fühler schwarzbraun, letztere mit grau behaarter Keule. Die Unterseite sammt den Beinen glänzend, schwarz; das Prosternum mit Querleisten, diese aber schief nach vorn gerichtet, daher der vordere Abschnitt schmal, muldenartig vertieft; die Hinterschenkel vorn gerandet; die Vorderschienen am Ende gerade abgestutzt, die mittleren kurz, kürzer als der Fufs, dabei stark erweitert, die hinteren gerade, nicht gekrümmt, gegen die Spitze erweitert; die Tarsenglieder ziemlich gestreckt, das erste eben so lang, wie das zweite.

Vaterland: Die Pampas des La Platagebietes.

Aus der Reich'schen Sammlung, nur ein einzelnes Weibchen. Mit C. muticus hat diese Art nur das ungezahnte Kopfschild, den Bau der Vorderschienen und die Gestalt des Halsschildes gemein, die hinteren Beine dagegen sind sehr verschieden geformt, indem die mittleren Schienen kurz, fast länglich-dreieckig erscheinen; auch die hinteren sind verhältnifsmäfsig ziemlich stark erweitert und gerade, während sie bei jenem fast gleich schmal bis zur Spitze und dabei merklich gekrümmt sind.

14. C. curvipes: E majoribus, convexus, ovalis, nitidus, elytris capitegue interdum subnitidis, colore variabili, laete viridis, plerumque nigro-cyaneus vel omnino ater. Caput antice obsolete subrugosulum, clypeo medio acutissime 4dentalo, genis acutis. Thorax laevis, lateribus medio rolundatis. Impressio scutellaris distincta. Elytra obsolete striata, stria humerali breviter et subtilissime carinulata. Pygidium leviter convexum, laeve. Palpi cum antennis pi. cei. Corpus subtus cum pedibus subnitidum, ut supra coloratum; proslerno absque carinis transversis; femoribus antice marginalis, postice basi margine bidentato; tibiis anticis intus subangulatim dilatatis, posticis valde arcuatis, anle opicem leviter emarginatis. Long. $7 \frac{1}{2}$ lin.

Berl. Entomol. Zeitschr. XII. 


\section{Var. Omnino purpurascens.}

C. subrutilans Klug i. litt.

Eine der gröfseren Arten, eiförmig, ziemlich gewölbt, glänzend, Kopf und Halsschild zuweilen etwas trüb, von veränderlicher Färbung, bald schön goldiggrün, bald schwärzlichblau oder vohl auch ganz schwarz mit nur schwachem violetten Scheine. Der Kopf vorn sehr fein runzlig, das Kopfschild mit vier scharfen Mittelzähnen, auch das Wangenende spitz und zuweilen zwischen diesem und dem Nebenzahne noch ein Vorsprung, so dafs dann fast 8 Zähne sich zeigen. Das Halsschild glatt, der Seitenrand ziemlich gleichmäfsig im Halbkreise gerundet, nach vorn kaum bogig gewölbt. Der Scutellareindruck deutlich, greift auch die Mitte der Halsschildbasis an. Die Flügeldecken nur sehr schwach gestreifı, der Humeralstreif deutlich, aber nur auf eine kurze Strecke an der Wurzel sehr fein leistenartig; zuweilen in der Mitte neben der Naht schwache Spuren von Querfältchen. Das Pygidium glatt, leicht gewölbt. Taster und Fühler schwarzbraun. Die Unterseite sammt den Beinen ebenso gefärbt wie die obere, doch meist etwas dunkler; das Prosternum ohne Querleisten und ohne Randzähnchen; die Hinterschenkel vorn gerandet, hinten mit zwei Zähnchen. eines gleich bei der Trochanterenspitze, ein zweites etwas kräftigeres gleich daneben; die Vorderschienen kurz und breit, ihr Innenrand stumpfwinkelig erweiterl; die mittleren Schienen deutlich, die hinteren nur sehr schwach vor der Spilze ausgebuchtet, diese stark bogig gekrümmt.

Vaterland: Porto Allegro, Montevideo; die kupfrige Varietät aus Casapava.

Von Herrn Deyrolle milgetheilt, auch im Berliner Museum. Als der nächste Verwandte dieser prachtvollen Art, von der ich nur Weibchen gesehen habe, ist $\boldsymbol{C}$. 5 maculalus zu betrachten; dieser unterscheidet sich aber leicht durch mehr eckigen Seitenrand des Halsschildes, nicht eingedrückte Basis desselben und durch die nicht gleichmäfsig im Bogen, sondern erst von der Mitte ab winkelig gekrümmten, dabei erweiterten hintersten Schienen.

15. C. quinquemaculatus Cast.: Subdilatato-ovalis, sat convexus, nitidus, elytris interdum leviter opacis, capite thoraceque rubrocupreis, hoc transversim nigromaculato, elylris vel omnino nigrocoeruleis vel omnino rufis, colore valde variabili. Caput-laeve, clypeo medio acute 4 dentato, denlibus longiludine fere aequalibus. Thorax lateribus medio rotundato-angulatis, versus angulos posti- 
cos fere rectis, antice non arcuatis. Impressio scutellaris minuta. at sat profunda. Elytra parum distincte striata, stria humerali subtiliter usque ante medium carinulata. Pygidium rufum, leviler convexum, vix nitidum, obsoletissime punctulatum. Palpi cum antennis rufo-picei. Corpus sublus nigro-virescens, abdominis lateribus plerumque rufis; prosterno absque carinis transversis; pedibus nigro-aeneis; femoribus medio rufis, posticis antice marginatis et postice ad basin emarginatis, tibiis posticis a medio dislincte incurvatis. - Long. $5-5 \frac{1}{2}$ lin.

C. 5maculatus $\mathrm{C}$ ast. Hist. Nat. II. p. 69. (1840.)

C. sanguinicollis Guér. Verhandl. Zool. Botan. Ver. Wien V. p. 586. (1855.)

C. cincticollis Luc. Voy. Casteln. p. 99. (1859.)

Var. a. Caput rufum, margine tanlum nigro-aeneo; thorax rufo-testaceus, punctis 3 vel 5 transversim positis; elylra rufa, basi tantum leviter infuscata; abdominis latera et segmentum ultimum rufa.

Var. b. Caput obscure viridi-aeneum; thorax rufo-metallicus, fascia transversa medio versus basin producta, nigro-aenea; elytra obscure rufa, basi, sutura apiceque et lateribus fuscis, interdum omnino rufo-brunnea.

C. cincticollis Luc. I. c.

Var. c. Caput nigro-aeneum; thorax cupreo-rufus, macula longitudinali media nonnullisque lateralibus nigris, elytra atrocyanea.

Von ziemlich gewölbter, etwas kurzer und breiter Gestalt, glänzend, die Flügeldecken hier und da etwas trüber; in der Färbung sehr veränderlich, Kopf und Halsschild meist kupfrigroth, letzteres mit einer Querreihe schwarzer Punkte, die wobl auch in eine Binde zusammenfliefsen; die Flügeldecken heller oder dunkler rothbraun, zuweilen auch ganz dunkel oder schwärzlichblau. Der Kopf glatt, das Kopfschild mit vier scharfen, an Länge unter sich fast gleichen Zähnen, nur die mittleren etwas schmäler. Das Halsschild glatt oder nur höchst fein an den Seiten punktirt, hinten in der Mitte, der Schildchenstelle gegenüber, nicht eingesenkt, wohl aber etwas flachgedrïckt; der Seitenrand in der Mitle nur gerundet gebogen, von da nach hinten und vorn fast gerade, also auch nicht bogig gewölbt. Der Scutellareindruck von geringer Ausdehnung, aber doch ziemlich tief. Die Flügeldecken kaum deutlich gestreift, der Humeralstreif aber bis fast zur Mitte sehr fein erbaben, dann vertieft. Das Psgidium nur schwach glänzend, gelbroth, 
leicht gewölbt, fein und undeutlich punktirt, die Punkte mit einem äufserst kurzen Börstehen. Taster und Fühler dunkel rothbraun, die Keule etwas heller. Die Unterseite schwarz oder schwärzlich erzgrün; das Prosternum obne Spuren von Querkanten; die Schenkel roth mit schwärzlichen Enden, die hinteren vorn gerandet, ihr Hinterrand auf der Unterseite neben der Trochanterenspitze ausgebuchtet und stumpf gezahnt; die hinteren Schienen von der Mitte an gekrïmmt und nach innen sehr merklich erweitert; die Tarsen dunkel rothbraun.

Var. a. Bei sehr hell gefärbten Stücken ist die ganze Oberseite roth oder rothbraun, selbst der Kopf ist nur am Aufsenrande schwärzlich; auf dem Halsschilde stehen vier kleine schwärzliche Punkte in einer Querreihe; die Flügeldecken sind höchstens an der Basis etwas angedunkelt; der Hinterleib ist schwarzgrünlich, die Seiten und der letzte Hinterleibsring roth.

Var. b. Der Kopf grünlich kupferfarben, auf dem rothen Halsschilde eine schwärzlichgrüne Querbinde, die sich in der Mitte gegen den Hinterrand verlängert; die Flügeldecken schwarz, jede auf der Scheibe mit einem grofsen, röthlichbraunen Fleck.

Var. c. Kopf und Halsschild metallisch blutroth, auf letzterem ein schwarzer Längsfleck und daneben einige kleinere; die Flügeldecken schwärzlich stahlblau.

Vaterland: Das obere Gebiet des Amazonenstromes bis zum östlichen Peru; Pebas, Sarayacu (Castelnau!).

Von den Herren Deyrolle, Bonvouloir und Dohrn, von leizterem namentlich ein prachtvolles, fast ganz rothbraunes Stück aus dem östlichen Peru. Obwohl in der Färbung höchst veränderlich, ist diese Art doch an den scharfen, fast gleich langen Mittelzähnen des Kopfschildes, der nur verflachten, nicht eingedrückten Mitte des Halsschildes und dem kleinen, namentlich bei Ansicht von oben sehr in die Augen fallenden Ausschnitte am Hinterrande des letzten Schenkelpaares leicht zu erkennen. Durch letzteres Merkmal unterscheidet sie sich am sichersten von dem sonst sehr nahe stehenden $\boldsymbol{C}$. Sallei, der übrigens immer unten viel dunkler gefärbt ist und am Prosternum ein zwar kurzes, aber doch stets deulliches Wurzelstück vou Querleisten erkennen läfst. Die Var. b. erinnert in hohem Grade an C. 7 maculatus var. histrio; der ganz verschiedene Bau des Kopfes und der Hinterbeine geslaltet jedoch keine Verwechslung. Die Unterschiede von dem ziemlich nahverwandten C. curvipes sind bei diesem angegeben.

Vielleicht ist der hier beschriebene Canthon nur als der am 
kräftigsten entwickelte Typus einer vom südlichen Mexiko anfangend durch ganz Central-Amerika und Columbien bis ins Gebiet des oberen Amazonenstromes verbreiteten, in der Färbung sehr variablen Form zu betrachten; denn die folgenden C. speciosus, spinosus, dentiger und Sallei haben alle mit ihm die ausgezeichnete scharfe Zahnung des Kopfschildes, das in der Mitte des Seitenrandes nur sehr stumpf erweiterte Halsschild und die gekrümmten hinteren Schienen gemein. Der Ausschnitt am hintersten Schenkelpaare neben der Trochanterenspitze, welcher dem C. 5maculatus eigenthümlich ist, könnte möglicherweise nur ein Attribut der vollkommeneren Gestaltung sein, welche derselbe schon darch seine meist ansehnlichere Gröfse beurkundet. Hierüber kann nur zahlreiches, die ganze Verbreitungsregion ersehöpfendes Material Aufschlufs geben, weshalb ich mich darauf beschränken mufs, die Möglichkeit dieses Sachverhalts anzudeuten.

16. C. dentiger: Simillimus C. 5 maculato, at minor, thorace pygidioque laevibus dignoscendus. Aeneo-niger, thorace testaceo, submetallico, puncto laterali utrinque infuscato, elytris laevibus, sat nitidis, rufo-testaceis, basi suturaque nonnihil infuscatis. Caput laeve, clypeo omnino fere ut in C.5maculato dentato. Thorax lateribus medio rotundatis, vix angulatis. Elytra absque striis distinctis, siria humerali obsoleta. Pygidium subnitidum, laeve, fuscotestaceum. Palpi cum antennis rufo-picei, his rufoclavatis. Corpus subtus cum pedibus nigrum, femoribus posticis marginatis, medio rufo-testaceis; prosterno absque carinis transversis, tibiis posticis levissime tantum incurvatis. - Long. 4 lin.

Dem C. 5maculatus sehr ähnlich, aber kleiner und nicht ganz so breit, auch gleichmäfsiger glänzend, schwärzlich erzfarben, das Halsschild schmutzig röthlichgelb, der Vorder- und der Hinterrand wie bei C. 5maculatus schwärzlich gesäumt, sonst aber nur mit zwei kleinen schwärzlichgrünen Flecken beiderseits in der Mitte des Seitenrandes, die Flügeldecken bräunlichroth, ihre Basis und die Naht schwärzlich, eine Zeichnung, die nirgends mit Bestimmtheit abgegränzt ist, in ihrer Anlage aber an die Var. c. des C. septemmaculatus erinnert. Der Kopf wie bei C. 5maculatus gestaltet, nur dafs der mittlere Einschnitt, welcher die beiden Hauptzähne trennt, nicht tiefer als die beiden daneben befindlichen ist. Das Halsschild glatt, ohne Punktirung, der Seitenrand in der Mitte weniger vortretend als bei $C$. 5maculatus, also noch gleichmäfsiger gerundet und weniger winkelig. Der Scutellareindruck tief, aber auf die 
Wurzelgegend der Naht beschränkt, der mittlere Theil der Halsschildbasis nur höchst unmerklich gesenkt. Die Flügeldecken glatt, undeutlich gestreift, vom Schulterstreif ist nur eine höchst undeutliche Spur unterhalb des Schulterbuckels an der Basis zu bemerken. Das Pygidium schmulzig gelbbraun, glatt, ziemlich glänzend. Taster und Fühler braun, letztere mit rother Keule. Die Unterseite sammt den Beinen schwarz, die hinteren Schenkel in der Mitte rothgelb, vorn gerandet; das Prosternum ohne Querleisten, doch findet sich bei den Hüften ein sehr abgekürztes Stückchen davon, welches gerade gegen den Aufsenrand gerichtet erscheint; die hinteren Sehienen nur unmerklich gekrüınmt.

Vaterland: Columbien; Bogotà.

Ein einzelnes Weibchen von Hrn. Deyrolle mitgetheilt. Wegen der scharfen Kopfsehildzähne könnte diese Ari nur mit C. 5 maculalus verwechselt werden, von dem sie aber aufser den Färbungsunterschieden das unpunktirte, an den Seiten minder eckige Halsschild und die kleine Andeutung der Prosternalleisten leicht unterscheiden.

Anm. Ich habe diese Art beim Schlusse meiner Arbeit nicht mehr vor mir, da ich sie Hrn. Deyrolle zurückgeschickł; ich kann sie daher mit dem mir erst später bekannt gewordenen C. Sallei, von dem sie vielleicht nur eine ausgezeichnete Farbenvarietät ist, nicht mehr vergleichen.

17. C. podagricus: Ovalis, sat convexus, subsericans, viridis, elytris obscure rufis. Caput subtiliter punctatum, clypeo acute 4 dentato. Thorax lateribus subtiliter punctulatis, medio subangulatis. Impressio scutellaris distincta. Elytra obsolele striata, stria sulurali, praecipue parte basali, distinctiore. Pygidium subnitidum, obscure cyaneo-viride. Corpus subtus sal nitidum, nigrum, pedibus leviler virescentibus, tibiis posticis pone medium fortius incurvatis et apicem versus sat dilalatis. - Long. 4 lin.

Von ovaler, ziemlich gewölbter Gestalt, nur mäfsig glänzend, besonders das Halsschild etwas seidenglänzend, dunkel goldiggrün, die Flügeldecken bräunlichroth. Der Kopf fein aber deutlich punktirt, der Aufsenrand in der Mitte mit vier scharfen Zähnen. Das Halsschild an den Seiten äufserst fein punktirt, auch in der Mitte, hier aber kaum wahrnehmbar, mit zerstreuten, äufserst feinen Pünktchen besetzt, der Seitenrand in der Mitte zwar leicht eckig, aber doch im ganzen nur leicht gerundet. Der Scutellareindruck deutlich, aber nur von geringer Ausdehnung. Die Flügeldecken vor der 
Mitte am breitesten, fein aber doch erkennbar gestreift, der Nahtstreif namentlich im oberen Theile sehr deutlich, der Schulterstreif bis über die Mitte hinaus deutlich erhaben. Das Pygidium matt bläulichgrün, ohne deutliche Punktirung. Taster und Fühler rothbraun. Die Unterseite sammt den Beinen schwarz und ziemlich glänzend, letztere etwas grünlich schinmernd; die hinteren Schienen von der Mitte an ziemlich stark gekrümmt, nach innen vor der Spitze winkelig erweitert; die obere Seitenkante der mittleren vor dem Ende mit zwei feinen Kerbzähnen.

\section{Vaterland: Brasilien.}

Das einzige mir vorliegende Stück, aus der Münchener Staatssammlung von Dr. Gemminger freundlichst zur Beschreibung mitgetheilt, halle ich für ein Männchen, da der Enddorn ziemlich breit, am Ende abgestulzt und ausgerandet ist. Die Mittelschienen sind bei dieser Art noch nicht als ausgerandet zu betrachten, wohl aber ist die obere Seitenkante nicht mehr gleichnäfsig bis zur Spitze gekerbt, sondern es zeigt dieselbe vor dem Ende zwei deutliche, gröfsere Zähnchen. In der Gestalt hat $C$. podagricus die gröfste Aehnlichkeit mit $\boldsymbol{C}$. Sallei, entfernt sich aber von diesem, wenn man auch von allen Färbungsunterschieden absieht, durch das viel bestimmtere Eck am Seitenrande des Halsschildes, dessen viel minder spitze Vorderecken, und die nach innen und gegen das Ende stärker erweilerten hintersten Schienen.

18. C. Sallei Har.: Sat convexus, ovalis, nitidus, elytris subnitidis, piceus, thorace leviter virescente, maculis quatuor in angulis dispositis testaceis vel omnino piceo vel rufo, elytris nigris, interdum rufo-signatis. Caput subtilissime punclulalum, clypeo acute 4 dentalo, dentibus lateralibus mediis nonnihil brevioribus. Thorax lateribus medio obtuse rotundato-angulatis, antice vix arcuatis, non dentatis. Impressio scutellaris distincta. Elytra obsoletissime striata, stria humerali subtilissime carinulata, brevi. Pygidium subsericeoopacum, leviter convexum, medio interdum sat distincte carinulatum, nigrum, basi interdum utrinque testaceo-notalum. Corpus subtus cum pedibus nitidum, nigro-virescens; prosterno vestigio brevi carinarum; femoribus vel piceis vel medio obscure rufescentibus, posticis marginatis; tibiis posticis a medio distincle incurvatis. Long. 4-5 lin.

C. Sallei Har. Ann. Soc. France 1863. p. 174.

C. gutticollis Klug i. litt.

V ar. Minor, thorace rufo-aeneo, macula triangulari inversa 
punctoque utrinque laterali nigro-aeneis; elytris rufis, basi suturaque fuscis; pygidio rufo vel medio leviter lantum infuscato.

Var. Capite elytrorumque basi nigris exceptis, omnino testaceus, quo habitu C. 5 maculatum maxime simulat.

In der Gestalt dem C. 5maculatus sehr nahestehend, doch nicht ganz so breit, etwas mehr gewölbt, glänzend, die Flügeldecken meist nur mattglänzend; schwarz oder grünlich schwarz, auf dem Halsschilde zuweilen 4 gelbe Flecken, nämlich in jeder Ecke einer, die Flügeldecken ebenfalls schwarz oder schwärzlich grün, an den Seiten und an der Spitze bier und da schmal röthlich gesäumt. Der Kopf äufserst fein punktirt, die Punkte nach hinten noch feiner und spärlicher, das Kopfschild mit vier scharfen Zähnen, die mittleren schmäler und unmerklich läager. Das Halsschild glatt oder an den Seiten höchst fein nur punktirt, der Seitenrand in der Mitte nur sehr stumpf gerundet, von da nach vorn kaum gewölbt, ungezahnt; die Mitte der Basis verflacht und zugleich durch den Scutellareindruck unmerklich vertieft. Dieser von geringer Ausdehnung, ziemlich tief. Die Flügeldecken mikroskopisch fein netzartig chagrinirt, sehr fein gestreift, der Humeralstreif kurz, nur sehr subtil erhaben. Das Pygidium schwach gewölbt, mit feinen Querpunkten ziemlich dicht besetzt, etwas seidig-matt, einfarbig schwarz oder wohl auch an der Wurzel jederseits mit einem röthliehgelben Fleck; der Länge nach sehr schwach, zuweilen aber, besonders an der Wurzel, recht deutlich gekielt. Taster und Fühler dunkel rothbraun. Die Unterseite sammt den Beinen ziemlich glänzend, schwarz oder schwärzlich mit leichtem grünen Glanze; die hinteren Schenkel zuweilen in der Mitte rothbraun durchscheinend; das Prosternum mit einem sehr kurzen Basaltheile von Querleisten; das hinterste Schienenpaar von der Mitte ab sehr deutlich gekrümmt und am Innenrande erweitert; die Tarsen dunkelroth.

Bei einer etwas kleineren Varietät aus Columbien, von Herrn Dr. Schaufufs eingesendet, ist das Halsschild röthlichgelb, ein mit der Spitze nach hinten gerichteter dreieckiger Fleck und am Seitenrand jederseits in der Mitte eine Makel sind schwärzlich-grün; die Flügeldecken sind rothbraun, ihre Basis, die Nabt und die Epipleuren sind schwarz; das Pygidium ist roth, dessen Spitze sowie die Mitte dunkel erzgrün.

Eine noch weitere Ausdehnung gewinnt die gelbe Farbe bei einem Stücke aus Bogotà, indem die ganze Oberseite mit Ausnahme von Kopf und Basis der Flügeldecken schön rothgelb erscheint; diese Form ähnelt ungemein der Var. a. des C. 5maculatus, läfst 
sich aber doch an der gewölbteren Gestalt und der dunkeln Unterseite, sowie an den nicht ausgerandeten Hinterschenkeln leicht unterscheiden. Nach einem ähnlichen Stücke ist meine erstmalige Beschreibung des C. Sallei gefertigt.

Vaterland: Columbien; Nova Valencia, Veragua, St. Martha, Nicaragua, Bogotà.

Berliner Museum, auch von den Herren Deyrolle und Kirsch mitgetheilt. Die Art hat die Bildung des Kopfschildes, des Halsschildes und der Hinterschienen mit $\boldsymbol{C}$. 5maculalus gemein, sie hat aber einen deutlichen Ansatz von Prosternalleisten und es fehlt ihr die Ausbuchtung der Hinterschenkel neben der Trochanterenspitze. Die Stücke mit den gelben Halsschildflecken haben auf den ersten Anblick eine täuschende Aehnlichkeit mit dem typischen C. $7 \mathrm{ma}$ culatus, nur fehlt der Basalfleck in der Mitte, und können dieselben wegen des ganz versehieden gezahnten Kopfschildes nicht damit verwechselt werden.

19. C. speciosus: Abbreviato-ovalis, convexus, nitidus, obscure viridi-cyaneus. Caput laeve, clypeo quadridentato, dentibus mediis acutis, lateralibus basi latioribus, genis antice angulatis. Thorax lateribus vix perspicue punctulatis, medio rotundatis, antice et postice subrotundatis. Impressio scutellaris distincta. Elytra obsoletissime striata, interstitiis lateralibus subtilissime vixque perspicue remote punctulatis. Pygidium leviter convexum, subsericeum, distincte punctalum. Palpi cum antennis rufo-picei. Corpus subtus cum pedibus atro-cyaneum, prosterno transversim non carinato nec antice dentato; femoribus posticis marginatis, tibiis anticis apice oblique truncatis. - Long. 4 lin.

Coprob. speciosus Chevrol. i. litt.

Erinnert im Aussehen etwas an C. politus, aber nicht so gestreckt, namentlich die Flügeldecken kürzer, glänzend, dunkel bläulichgrün. Der Kopf glatt, nur am Aufsenrande leicht runzlig, das Kopfschild mit vier Zähuen, die mittleren ziemlich schmal, die seitlichen an der Wurzel breit, auch die Wangenenden eckig. Das Halsschild an den Seiten äufserst fein und kaum wahrnehmbar punktirt, der Seitenrand in der Mitte gerundet, ohne Ecke, nach vorn und nach hinten fast gerade, der Hinterrand neben den Ecken nur sehr schwach ausgebuchtet. Der Scutellareindruck deutlich, greift auch die Mitte der Halsschildbasis an. Die Flügeldecken höchst fein gestreift, der Humeralstreif bis fast über die Mitte hinaus sehr

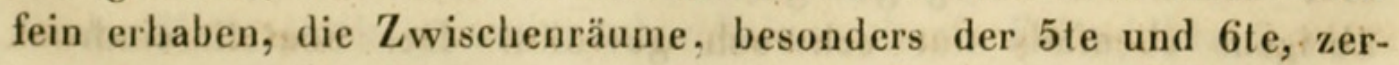


streut aber äufserst fein und kaum wahrnehmbar punktirt. Das Pygidium blauschwarz, leicht gewölbt, etwas seidenartig glänzend, sehr deutlich punktirt. Taster und Fühler rothbraun. Die Unterseite sammt den Beinen etwas minder glänzend, wie die Oberseite gefärbt, nur dunkler, die Tarsen dunkelroth; die hinteren Schenkel vorn gerandet; die Vorderschienen am Ende schief abgestutzl; das Prosternum ohne Querkanten, nur mit Spuren eines Wurzeltheiles derselben bei den IIüften, der äufsere Vorderrand ohne Zähnchen. Vaterland: Mexiko.

Ein einzelnes Weibchen von Hrn. Deyrolle mitgetheilt. Ich mufs es dahingestellt sein lassen, ob nicht diese Art später noch mit C. Sallei vereinigt werden mufs, mit dem sie den ganzen Körperbau gemein hat; sie weicht jedoch durch den starken Glanz der Oberseile, welcher sich also auch über die Flügeldecken ausdehnt, sowie namentlich durch gewölbteres, glänzenderes und mit zerstreuten, ziemlich groben Punkten bedecktes Pygidium so erheblich von C. Sallei ab, dafs ich sie vorläufig wenigstens von diesem trennen möchte. Die Artunterscheidung ist überhaupt bei den Canthons mit gekrümmten hinteren Schienen ziemlich schwierig und dürften bestimmlere Aufschlüsse ersı durch Vergleich zahlreicheren Materials zu erzielen sein.

20. C. spinosus Har: Simillimus C. 5maculati varietatibus obscuris at minus nitidus, elytris distinclius striatis thoracisque laleribus fortius angulatis distinguendus. Olscure viridi-aeneus, interdum nigro-cyaneus. Capitis clypeus acute 4 dentatus. Thorax dense, at subtilissime punctatus, lateribus medio obtuse angulatis. Impressio scutellaris distincta. Elytra sat distincte striata, interslitiis dense at parum profunde punctulatis. Pygidium leviter punctalum, punctis setigeris. Palpi cum antennis rufo-picei. Corpus sublus cum pedibus nitidum, obscure viridi-aeneum; prosterno non carinato, libiis posticis ( () incurvalis. - Long. $5 \frac{1}{4}$ lin.

\section{C. spinosus Harold Ann. Soc. France 1863. p. 174.}

Den einfarbig dunkeln Stücken des C. 5maculatus sehr ähnlich, aber allenthalben minder glänzend und durch deutliche Punktirung der ganzen Oberseite leicht zu unterscheiden. Dunkel grün oder schwärzlich blau. Der Kopf äufserst fein runzlig-punktirt, das Kopfschild vierzahnig, die beiden mittleren Zähne lang und schmal. Das Halssehild sehr fein punktirt, der Seitenrand in der Mitte etwas deutlicher eckig gebogen als bei $\boldsymbol{C}$. 5maculatus, nach vorn übrigens ebenfalls nur schwach gewölbt. Der Scutellareindruck 
deutlich, greift auch die Mitte der Halsschildbasis leicht an. Die Flügeldecken mit deullich vertieften Streifen, der Humeralstreif nicht erhaben, die Zwischenräume dicht und fein punktirt, die Punkte etwas ineinander fliefsend. Das Pygidium leicht gewölbt, der Länge nach schwach gekielt, deutlich punktirt, die Punkte borstentragend, Taster und Fühler rothbraun, letztere mit graubraun behaarter Beule. Die Unterseite sammt den Beinen glänzend, schwärzlich grün; das Prosternum ohne Querkanlen und ungezahnl; die Hinterschenkel fein gerandet, die hintersten Schienen beim Männchen sehr deutlich winkelig gekrümmt.

Vaterland: das südliche Mexiko.

Von Herrn Bonvouloir mitgetheilt. Von den dunkelbeinigen Abänderungen des C. 5maculatus durch den mangelnden Humeralstreif und den etwas eckigeren Seitenrand des Halsschildes sowie durch die feine aber dichte Punktirung der Oberseite gut zu unterscheiden.

21. C. compactus: Convexus, rotundato-ovalus, nitidus, cupreo-viridis, elytris subopacis rufo-brunneis, sutura et interdum fascia vel punctis medio fuscis. Caput laeve, clypeo quadridentato, dentibus mediis basi parum dilatatis, lateralibus sat acutis, genis antice subangulatis. Thorax lateribus basique subtilissime punctulatus, postice linea longitudinali subimpressa, lateribus medio subangulato-rolundalis. Impressio scutellaris sat profunda. Elytra subtiliter striata. Pygidium viride, opacum, subtilissime punctatum. Palpi cum antennis piceo-rufi, his rufo-clavatis. Corpus subtus cum pedibus nitidulum, nigro-viride; prosterno absque carinis transversis, margine laterali antico autem medio denticulato; femoribus posticis marginatis, tibiis anticis apice oblique truncatis; abdominis segmento ultimo medio longitudinaliter subcarinulalo. - Long. 5 lin.

$$
\text { C. crux Illig. i. litt. }
$$

Von gewölbter, gerundet-eiförmiger, dabei etwas plumper Gestalt, glänzend, goldig grün mit röthlichem Kupferglanz, die Flügeldecken nur wenig glänzend, lederbraun, ihre Naht und beiderseits ein Punkt hinter der Mitte, oder auch eine Querbinde schwärzlich. Der Kopf glatt, die Mittelzähne des Kopfschildes schmal, die Nebenzähne spitz, aber an der Basis breit, der Saum von da bis zu den stumpfspitzen Wangenenden sehr leicht nach aufsen bogig. Das Halsschild an den Seiten und hinten äufserst fein punktirt, auf der hinleren Hälfte eine leicht vertiefte Längslinie, der Seitenrand in der Milte stark gerundet, aber keine scharfe Ecke bildend, nach 
hinten und nach vorn fast gerade. Der Scutellareindruck ziemlich tief, greift auch die Mitte der Halsschildbasis merklich an. Die Flügeldecken fein, aber doch deutlich gestreift. Das Pygidium grün, netzartig äufserst fein nadelrissig, seidig glänzend, höchst fein punktirt. Taster und Fühler rothbraun, letztere mit rother Keule. Die Unterseite und die Beine ziemlich glänzend, schwärzlich grün; das Prosternum ohne Querkanten, der äufsere Vorderrand in der Mitte mit einem sehr stumpfen Zähnchen; die Hinterschenkel gerandet, die hinteren Schienen leicht gekrümmt, die vorderen am Ende schief abgeschnitten, ihr Innenrand in der Mitte selsr unmerklich erweitert; das letzte Hinterleibssegment zerstreut punktirt und in der Mitte sehr fein leistenartig erhaben.

\section{Vaterland: Brasilien, S. Paulo.}

Berliner Museum, auch von Herrn Deyrolle mitgetheilt.

Die Querbinde in der Mitte der Flügeldecken ist öfters zusammenhängend, meist aber in einzelne Punkte aufgelöfst und fehlt zuweilen wohl auch ganz; häufig ist namentlich die Form, wo auf jeder Flügeldecke 2 Punkte erscheinen, nänlich je einer im 3ten und 5ten Zwischenraum. Es ist noch zu bemerken, dafs eine äufserst schwache Spur der Humeralstreifen manchmal wahrzunehmen ist.

Bei dem Männchen sind die hinteren Schienen sehr merklich gekrümmt und viel länger als bei dem Weibchen, der Innenrand der Vorderschienen ist leicht stumpfwinkelig erweitert. Die Art nähert sich durch ihre krummen Hinterbeine dem $\boldsymbol{C}$. curvipes, dieser hat aber einen sehr deutlichen Humeralstreifen, und sind die Mittelschienen entschieden vor der Spitze ausgerandet.

22. C. cupricollis: Breviter ovalis, sat convexus, capite thoraceque subnitidis, aurato-cupreis, elytris opacis, atris vel subcoeruleo-atris. Caput clypeo quadridentato, genis antice sat acutis. Thorax subsericeo-punctulatus, lateribus medio subacute angulatis, antice arcuatis et dentatis. Impressio scutellaris distincta. Elytra obsoletissime striata. Pygidium parum convexum, nigrum, opacum. Palpi cum antennis obscure rufo-picei, his fusco-clavatis. Corpus subtus nigrum, pedibus atro-coeruleis; prosterno non curinato, femoribus posticis marginatis; tibiis anticis apice oblique truncatis, posticis (ठ) a medio distincte incurvatis. - Long. 5 lin.

C. cupricollis Klug i. litt.

Von breit-eiförmiger, ziemlich plumper und gewölbter Gestalt, Kopf und Halsschild nur mäfsig glänzend, goldig kupferroth, die mattseheinenden Flïgeldecken schwarz oder sehr dunkel blauschwarz. Der Kopf glatt, das Kopfschild vierzahnig, die mittleren Zähne schmal, 
aber einander wenig genähert, das vordere Wangenende winkelig. Das Halsschild auf seidig matterem Grunde mit feinen glänzenderen Pünktchen, der Seitenrand in der Mitte eckig, nach vorn gewölbt und gezahnt, die Mitte der Basis leicht verflacht, hie und da die Spur eines grünlichen Längsstreifens. Der Scutellareindruck deutlich, auf den Wurzeltheil der Naht beschränkt. Die Flügeldecken höchst unmerklich gestreift, die Zwischenräume netzartig chagrinirt, auf glanzlosem Grunde Spuren glänzender Pünktchen. Das Pygidium nur leicht gewölbt, matt, schwarz. Taster und Fühler röthlichbraun, letztere mit schwärzlicher Keule. Die Unterseite nur mäfsig glänzend, schwarz, die Beine etwas glänzender, mit bläulichem Scheine; das Prosternum ohne Querleisten, die Hinterschenkel vorn gerandet; die Schienen verhältnifsmäfsig breit, die vorderen am Ende schief abgestutzt, die hintersten beim Männchen sehr deutlich von der Mitte an erweitert und gekrümmt, ihre Borsten schwarz.

Vaterland: Brasilien.

Aus der Reich'schen Sammlung, Berliner Museum. Fast ebenso plump gebaut wie $C$. compactus, von diesem durch die Färbung und das schwarze Fühlhorn leicht zu unterseheiden. Im Farbenkleide erinnert eine Abänderung des $\boldsymbol{C}$. seminitens sehr an die gegenwärtige Art, weicht aber doch durch blankes Halsschild, etwas unebene Flügeldecken und die nicht gekrümmten hinteren Schienen sehr davon ab. Der sehr bezeichnende Name kann für diese Art beibehalten werden, da der von Lucas (Voy. Casteln. Zool. p. 99.) beschriebene Canthon cupricollis gar nicht in diese Gattung, sondern zu Deltochilum gehört.

23. C. monilifer Blanch.: Ovalis, convexus, statura C. triangularis, at major, parum nitidus, obscure cupreus. Caput laeve, clypeo antice medio bidentalo. Thorax lateribus medio rotundatis. Impressio scutellaris fere nulla. Elytra absque striis distinctis, stria humerali autem basi distincla longe ante medium evanescente. Pygidium laeve, opacum, cupreum. Palpi cum antennis picei. Corpus subtus nigrum, nitidum, metasterno pedibusque obscure viridiaeneis, femoribus posticis medio rufis. - Long. 6 lin.

Canthon monilifer B lanch. Voy. d'Orbigny. Col. p. 164. (1843).

Coprobius annulipes $\mathrm{D}$ ej. i. litt.

Von der Gestalt des C. triangularis, aber viel gröfser, nur wenig glänzend, dunkel kupferfarben, die Ränder, besonders die des Halsschildes grünlich glänzend, auf diesem auch ein paar unbeslimmle 
röthliche Flecke, beiderseits neben der Mitte und etwas dem Hinterrande genähert. Der Kopf glatt, der Aufsenrand in der Mitte mit nur zwei, ziemlich breiten und wenig spitzen Zähnen. Das Halsschild glatt, ohne deutliche Punktirung, in der Mitte mit einer unmerklich vertieften Längslinie, der Seitenrand in der Mitte einfach gerundet, ohne Winkelbildung. Kein Scutellareindruck. Die Flügeldecken ohne deutliche Streifen, höchstens der Nahtstreif kenntlich, der Schulterstreif dagegen sehr deutlich bis fast zur Mitte erhaben. Das Pygidium dunkel kupferroth, sehr flachgewölbt, matt. Taster und Fühler pechbraun. Die Unterseite sammt den Beinen schwärzlich grün, auch die Epipleuren grünlich glänzend; alle Schenkel in der Mitte roth, die hintersten vorn deutlich gerandet.

Vaterland: Brasilien, Santa Cruz de la Sierra, Chiquitos.

Aus der Münchener Slaatssammlung, auch von den Herren Deyrolle und Bonvouloir mitgetheilt. Diese ansehnliche Art, deren kupfrige Färbung auf den Flügeldecken zuweilen etwas heller röthlichbraun sich zeigt, erinnert in der Grölse und im plumpen Körperbau an C. septemmaculatus, der auch ganz ähnlich gefärbte Beine hat, sich aber sehr leicht durch den eckigen Seitenrand des Halsschildes und den mangelnden Schulterstreifen unterscheidet. Letzteren hat auch Blanchard in der angezogenen Beschreibung erwähnt und die Art überhaupt kenntlich beschrieben, nur finde ich das Halsschild entschieden glatt, nicht sehr fein punktirt (très finement pointillé).

24. C. triangularis Drury: Convexus, ovalus, subnitidus, elytris opacis, obscure aeneo-viridis, thorace rufo-testaceo, melallescente, maculis fusco-aeneis plus minusve confluentibus adsperso, elytris fuscis vel fusco-ferrugineis. Caput parum distincte remote punctulatum, antice medio ad marginem impressum, clypeo bidentato. Thorax laevis, lateribus valde rotundato-angulatis, margine ad angulos anticos leviler deplanato. Elytra obsoletissime vixque perspicue striata, stria humerali parte basali tantum distincta. Impressio scutellaris nulla. Pygidium testaceum, plus minusve infuscatum, opacum. Palpi cum antennis rufo-picei, his subcinereo-clavatis. Corpus subtus vel lestaceum vel brunneum, femoribus rufo-testaceis, basi apiceque fuscis, tiöiis anticis totis, posticis majore ex parte fusco-aeneis. - Long. $4 \frac{1}{2}-5 \frac{1}{2}$ lin.

Mas: A femina nullo fere modo differt; calcar apicalis tibiarum anticarum in utroque sexu acuminalus.

Scarab. triangularis Drury Illustr. nat. hist. I. (1770.) p. 82. 
t. 36. f. 7. et II. 1773. Index. - F a br. Syst. Ent. p. 30. (1775.) - Oliv. Ent. I. 3. p. 166. t. 15. f. 139.

Ateuchus triangularis Fabr. Syst. El. I. p. 63.

Var. Thorace pygidioque rufo-testaceis, absque maculis, corpore sublus livido-testaceo.

Coprobius flavicollis D ej. Cat. 3 ed. p. 152.

Var. Thorace punctis sex fusco-aeneis, 2 lateralibus, 4 discoidalibus in quadratum positis; pygidio corporeque subtus fusco-teslaceis.

Scarab. sexpunctatus Oliv. Ent. I. 3. p. 166. t. 2. f. 16. a. b. c. Ateuchus sexpunctatus Fabr. Syst. El. I. p. 65 .

Canthon sexpunctatus Cast. Hist. Nat. II. p. 69.

Coprobius vicinus et perplexus $\mathrm{Dej}$. Cat. loc. cit.

Var. Maculis thoracis plus minusve confluentibus, vel maculam inversam triangularem exhibentibus vel thoracem omnino fere obfuscantibus; pygidio corporeque subtus fuscis, metasterno femoribusque solis rufo-testaceis.

Var. Omnino fuscus.

Von länglich-eiformiger, ziemlich starkgewölbter Gestalt, namentlich auch die Bauchseite convex, nur mäfsig glänzend, die Flügeldecken lederartig matt; Kopf dunkelgrün oder kupfrig, Halsschild schmutzig gelbroth, mit Metallglanz und mehr oder weniger ausgebreiteten dunkel erzfarbigen Flecken, die Flügeldecken röthlichbraun oder schwärzlich. Der Kopf ohne deutliche Punktirung, das Kopfschild in der Mitte nur zweizahnig, die Zähne mit breiter Basis. Das Halschild olıne deutliche Punktirung, der Seitenrand in der Mitte stark vortretend, aber abgerundet, keine Ecke bildend; gegen die Vorderecken etwas flach abgesetzt und leicht geschweift, so dafs diese sehr scharf zugespilzt sind. Der Scutellareindruck höchst unmerklich. Die Flügeldecken in der Mitte am breitesten, kaum wahrnehmbar gestreift, der Schulterstreif aber kenntlich, wenngleich nur äufserst fein leistenartig erhaben, nur bis ungefähr vor die Mitte reichend. Das Pygidium matt, flachgewölbt. Taster und Fühler rothbraun, letztere mit dunkelgrau behaarter Keule. Die Unterseite etwas glänzender als die obere, röthlichgelb oder schmutziggelb, manchmal sogar schwärzlich, immer aber die Mitte der Hinterbrust und der hinteren Schenkel rothgelb; die beiden untersten Randzähne der Vorderschienen einander etwas genähert; an den Mittelschienen die obere Seitenkante vor der Spitze einen sehr stumpfen Winkel bildend; die hinteren Schenkel vorn ohne vertiefte Randlinie. 
Das Männchen ist vom Weibchen fast gar nicht zu unterscheiden, da der Enddorn in beiden Geschlechtern zugespitzt ist; höchstens das an der Basis minder breite und am Ende minder stumpf abgerundete Pygidium läfst dasselbe erkennen.

Var. Ganz hell gefärbt, das Halsschild nämlich ungefleckt rothgelb, ebenso das Pygidium und die Unterseite, an welcher nur die Mittelbrust, am Prosternum die Gegend um die Hüften, die Ränder, Vorderschienen und die Gelenkstellen der Hinterbeine schwärzlich erscheinen.

Var. Das Halsschild mit 6 dunkel erzfarbigen Flecken, von denen vier in der Mitte im Quadrate und je einer neben der Mitte des Seitenrandes gestellt sind; das Pygidium ist dunkler röthlichbraun, ebenso die ganze Unterseite; zuweilen fehlen die beiden Seitenflecke und sind nur die vier in der Mitte deutlich (C. vicinus Dej.).

Var. Diese Halssehildflecken fliefsen in eine Makel zusammen, welche entweder ein umgestürztes Dreieck bildet, dessen Spitze gegen die Schildchengegend gerichtet ist, oder es bleibt überhaupt nur der Seitenrand und ein Theil des Hinterrandes rothgelb; in diesen Fällen ist wohl auch noch der Seitenrand unterbrochen, indem der vorspringende Winkel gleichfalls dunkelgrün erscheint; das Pygidium ist mehr oder weniger, manchmal vollständig schwarz, auch die Unterseite wird grofsentheils verdunkelt, immer aber bleiben, selbst bei den stärksten Nigrinos die Mitte der Hinterbrust, die der hinteren Schenkel und ein Fleckchen an den vorderen rothgelb gefärbt.

Vaterland: Brasilien, Cayenne, auch vom Amazonenflufs.

Eine sehr häufige und sehr veränderliche Art, die unter ihren Genossen mit erbabenem Schulterstreifen wegen des nur zweizahnigen Kopfschildes und der constant gelb gefärbten Schenkel leicht zu erkennen ist; in letzterer Beziehung könnte höchstens $C$. monilifer damit verwechselt werden, der aber gröfser ist und sich durch die Gestalt der mittleren Schienen, den mehr abgerundeten Seitenrand des Halsschildes und die schwarze Hinterbrust leicht unterscheidet.

Sehr nahe ist sie aber mit dem C. Tmaculatus der folgenden Abtheilung verwandt, mit dem sie das uur zweizahnige Kopfschild, die rothgelben Schenkel und die Färbung überhaupt, wenigstens in der Anlage der Halsschildzeichnungen gemein hat. Sie unterscheidet sich aber doch sehr bestimmt, ganz abgesehen von dem Vorhandensein des erhabenen Schulterstreifens, welcher jenem fehlt, 
durch mehr längliche, höher gewölbte Gestalt, die minder abgerundete Mitte des Halsschildseitenrandes, die schmäleren Epipleuren und die stets gelbe Hinterbrust, die bei $C$. 7 maculatus constant schwarz gefärbt ist. Geschlechtsunterschiede finden sich, wie schon bemerkt, so gut wie gar keine, wenigstens keine absoluten: unter: der grofsen Anzahl von Exemplaren, die ich untersucht, glaube ich die Männchen nur an dem relativ etwas längeren, minder stumpfen Pygidium erkennen zu können.

Drury hat a. a. O. die Art zuerst beschrieben und abgebildet, jedoch erst im zweiten Bande (1773) im Index benannt, daher sein Name erst von diesem Zeitpunkte an in Berechtigung tritt; immerhin bleibt aber seine Autorschaft älter als die des Fabricius, die erst von 1775 datirt.

25. C. nigriceps: Simillimus C. triangulari at thorace breviore, elytris distinctius striatis, tibiisque intermediis sensim arcuatis praecipue dignoscendus. Niger vel nigro-aeneus, thorace flavotestaceo, interdum longitudinaliter nigro-lineato, elytris sordide testaceo-brunneis. Caput laeve, clypeo bidentato. Thorax laevis, la. teribus medio angulatis, antice et postice rectis, angulis posticis valde obtusis. Elytra subtiliter, at distincte striata, stria humerali brevi et subtilissima. Pygidium sat convexum, flavo-testaceum, basi longitudinaliter subtilissime carinulatum, apice obsoletissime flavosetosulum. Palpi cum antennis rufi. Corpus subtus flavo-testaceum vel rufo-testaceum, tibiis tarsisque piceo-rufis vel piceis; prosterno absque carinis, femoribus posticis antice non marginatis. - Long. $4 \frac{1}{4}-4 \frac{1}{2} \operatorname{lin}$.

C. corvatus Klug i. litt.

Var. Subtus unacum pedibus omnino flavo-testaceus.

Var. Elytris basi apiceque infuscatis, epipleuris nigro-fuscis.

C. immaculatus Sturm i. litt.

Dem C. triangularis, insbesondere dessen Var. flavicollis höchst ähnlich, aber durch die viel stumpferen Hinterecken des Halsschildes zu unterscheiden. Von ziemlich länglich-eiförmiger Gesłalt, nur wenig glänzend, schwarz oder grünlichschwarz, das Halsschild rothgelb, zuweilen mit schwarzer Längslinie in der Mitte, auch der äufserste Hinterrand schwärzlich, die Flügeldecken schmutzig röthlichbraun, zuweilen ihre Basis und die Spitze, dann aber auch die Epipleuren, schwärzlich gefärbt. Der Kopf glatt, der Aufsenrand in der Mitte zweizahnig. Das Halsschild glatt, breit und kurz, der Seitenrand in der Mitte eckig gerundet, nach vorn und nach hin- 
ten fast geradlinig, die Hinterecken sehr stumpf. Ein Scutellareindruck macht sich nicht bemerkbar. Die Flügeldecken etwas länger als bei $\boldsymbol{C}$. triangularis, sehr fein, aber deutlich gestreift, die Streifen äufserst fein punktirt, der Schulterstreif nur sehr schwach erhaben und kurz, kaum über den Schulterbuckel hinabreichend; der äufserste Randstreifen vor der Spitze nach innen laufend und mit dem zweiten hier vereinigt; der Scitenrand viel weniger als bei C. triangularis in der Schultergegend nach unten gekrümmt, die Epipleuren daher im oberen Theile bedeutend breiter. Das Pygidium gelb, gleichmälsig ziemlich stark gewölbt, gegen die Spitze mit äufserst kurzen gelblichen Börstehen beselzt, an der Basis die Spur eines glatten, etwas mehr glänzenden Längskieles. Taster und Fühler roth, letztere mit rothgrau behaarter Keule. Die Unterseite heller oder dunkler bräunlich-gelb, meistens die Mittelbrust, ihre Nebenstücke und die Hüften am Ende schwärzlich; das Prosternum ganz glatt, ohne alle Spur von Querleisten, auch der vordere Seitenrand ohne alle Zähnchen; die Beine mit gelben, an der Wurzel und an der äufsersten Spitze schwärzlichen Schenkeln; die hinteren ohne Randlinie vorn; die Schieuen rothbraun, die mittleren länger und schmäler als bei C. triangularis, allmäblich leicht gekrümmt, also ohne stumpfwinkelige Biegung der Kanten; die Fülse mit etwas gröfserem zweiten Gliede, länger als die halben Schienen.

Var. Es kommen auch Stücke mit ganz gelber Unterseite und Beinen vor.

Vaterland: Brasilien und Cayenne; Pará.

In einigen Stücken von Hrn. Deyrolle mitgetheilt, bald als $\boldsymbol{C}$. flavicollis Dej., bald als C. melanocephalus Oliv. bestimmt, welcher aber eine Art der Gattung Canthidium ist. Es kommen wahrscheinlich noch andere Farbenabänderungen als die angegebenen vor, die bemerkten Unterschiede werden aber genügen, um die Art von C. triangularis zu unterscheiden. Da der Schulterstreif bei ihr nur sehr schwach erhaben ist, könnte sie indefs viel leichter mit C.rufulus verwechselt werden, der die Färbung, die stumpfen Hinterecken des Halssehildes und den Fufsbau mit ihr ganz gemein hat; er ist jedoch etwas kürzer, die Flügeldecken, denen der Humeralstreif absolut fehlt, sind feiner gestreift, ihre Epipleuren sind mehr horizontal nach unten gelagert, das Pygidium ist flach und die Hinterbrust hat in der Mlitle stets einen kupferröthlichen Schein. Stücke, bei denen die Basis und die Spilze schwarz ist, erinnern sebr an $C$ septemmaculatus var. histrio, unterseheiden sich aber von diesem leicht durch die viel längere Gestalt, das grofse Pygidium und die unge- 
randeten Hinterschenkel, ferner durch den eigenthümlichen Verlauf des Randstreifens der Flügeldecken, welcher hinten sich nach innen gegen die Naht wendet und hier mit dem zweiten Längsstreifen in Verbindung tritt.

26. C. septemmaculatus Latr.: Convexus ovalis, latiusculus, nitidus vel subnitidus, elytris plerumque subopacis, nigro-aeneus, thorace elytrisque rufo-testaceis, summa diversitate nigrosignatis. Caput laeve, clypeo antice medio marginato et bidentato. Thorax laevis, lateribus medio rotundatus, antice absque dente marginali, basi juxta angulos posticos leviter emarginala. Impressio scutellaris obsoleta. Elytra vix distincte striata, stria suturali magis apparente, punctulata. Pygidium laeve. Palpi cum antennis rufopicei, his nigro-clavatis. Corpus subtus nitidulum, nigrum, abdomine interdum rufo; pedibus nigris, femoribus medio rufis; prosterno absque carinis transversis; femoribus posticis antice distincte marginatis. - Long. 4-6 lin.

Ateuchus septemmaculatus Latr. Voy. Humb. et Bonpl. Obs. I. p. 180. t. 17. f. 5. (1811.)

Var. a. Thorax aeneo-nitidus, rufo-testaceus, fascia media obscure viridi-aenea punctoque utrinque minuto ad latera. Elytra rufa, basi, sutura apiceque cum epipleuris nigris. Pygidium rufum. Corpus subtus nigro-aeneum, abdominis lateribus rufis. Forma haec potius normalis videtur.

Coprobius histrio Lep. et Serv. Encycl. meth. X. p. 352. (1825.)

Canthon histrio Cast. Hist. Nat. II. p. 69. (1840.)

Coprobius histrio Dej. Cat. ed. p. 152.

Ateuchus fasciatus Mannerh. Nouv. Mlém. I. p. 37. t. 2. f. 1. (1829).

Var. b. Ut praecedens coloralus, at minus nitidus praecipue thorace non aeneomicante, maculis thoracis elytrorumque atris non virescentibus.

Var. c. Minus nitidus, niger; thorax rufus, macula transversa punctoque laterali nigris, basi anguste infuscatus; elytra nigra, fascia plus minusve lata, transversa, ad suturam interrupla, rufa. Corpus subtus nigrum, abdomine rufo, excepto segmento ultimo.

Canthon coronatus Perty. Del. anim. p. 37. t. 8. f. 1. (1830.)

Var. d. Ut praecedentes signatus, at magis infuscatus, obscure rufescens, thoracis macula transversa interdum utringue cum puncto laterali conjuncta et postice cum basi connexa; pygidium 
nigro-fuscum, basi lantum leviter rufescens; sublus niger abdominis lateribus solis obscure rufescentibus.

Var.e. Ut praecedens coloratus, thorax autem fere omnino nigro-aeneus, lateribus antice et postice ante basin macula utrinque obliqua rufis exceptis; elytra striis longitudinalibus nigris, maculam basalem cum apicali plus minusve conjungentibus. Pygidium basi sola rufescens. Abdomen lateribus tenuiter rufum. Femora medio tantum rufa.

C. variegatus $\mathrm{Klug}$ i. litt.

C. sugillatus $111 \mathrm{ig}$. i. litt.

Var. f. Plerumque major, niger vel nigro-virescens. Thorax nilidulus, maculis quinque rufo-lestaceis, quatuor ad angulos positis, quinta in media basi ante scutellum. Elytra omnino infuscata, interdum ad latera medio rufescentia. Pygidium totum nigrum vel maculis duabus basalibus rufo-lestaceis. Corpus subtus lolum nigrum, femoribus medio tantum rufis.

C. septemmaculatus Latr. loc. cit.

Von gewölbter, ziemlich breit eiförmiger Gestalt, mehr oder weniger glänzend, glall, schwarz oder grünlich schrvarz, das Halsschild gelblichroth, meist mit einem dunklen Querfleck, zuweilen auch fast ganz dunkel, die Flügeldecken meist schwarz mit breiter rother, an der Nath unterbrochener Querbinde, zuweilen auch ganz schwarz. Der Kopf glänzend, der Aufsenrand vorn gerandet und in der Mitte zweizahnig. Das Halsschild mit in der Mitte gerundetem Seitenrande, von da bis zu den Vorderecken nur Jleicht geschwungen, ohne Randzälınchen, die Basis neben den Hinterecken leicht ausgebuchtet. Die Flügeldecken äulserst fein, fast undeutlich gestreift, der Nahtstreif etwas tiefer, sehr fein punktirt. Der Scutellareindruck nur an der Nahtwurzel bemerklich. Das Pygidium matt, leicht gewölbt. Taster und Fühler rothbraun, letztere mit schwarzer graubehaarter Keule. Die Unterseite ziemlich glänzend, schwarz, zuweilen der ganze Hinterleib mit Ausnahme des letzten Segments, oder nur die Seitenränder roth; das Prosternum ohne Querkanten; die Schenkel roth, an der Spitze und am Ende schwarz, die Schienen schwärzlich, die Tarsen dunkel rothbraun; die hinteren Schenkel vorn deutlich gerandet.

Vaterland: Brasilien, Cayenne, Columbien, Panama.

Eine grofse Reihenfolge dieser Art, deren Mittheilung ich der Gefälligkeit der Herren Deyrolle, Kirsch und Dr. Haag verdanke, bestimmt mich in allen den erwähnten Formen nur eine, wenngleich sehr variable Art zu erkennen. Neben einem kleinen $C$. coronatus 
gestellt, macht allerdings der meist viel gröfsere, dann auch stärker gewöbłe C. septemmaculatus einen höchst fremdartigen Eindruck, aber ich wiederhole, dafs ich in Grölse, Glanz und Färbung alle nur wünschenswerthen Uebergänge vor mir habe, von welchen namentlich Var. e., die meist aus Columbien (Bogolà), Venezuela vor. kommt, ganz schöne Zwischenformen, theils zu den dunkleren, theils zu den belleren Formen bietet. In sehr schönen Exemplaren wurde C. septemmaculatus Var. $f$. aus Panama von Dr. Moritz Waguer mitgebracht; Latreille gibt Xalapa als Fundort an. Diese Stücke erinnern viel an $\boldsymbol{C}$. monilifer, der jedoch durch sehr deutlichen Schulterstreif sofort sich unterscheiden läfst.

Als der nächste Verwandte dieser Art erscheint immerhin der ebenso veränderliche $\boldsymbol{C}$. triangularis, der im ganzen Körperbau ungemein viel Aehnlichkeit bietet, obwohl er durchwegs schmäler geformt ist. Die Färbung beider Arten hat zwar einige Analogie, doch entwickelt sie sich nach einem ganz andern Plane: so sind z. B. bei $C$. Iriangularis die Flügeldecken unter allen Umständen einfarbig. Am leichtesten unterscheidet sich letztere Art durch den Mangel der Randlinien an der Vorderkante der Hinterschenkel und den sehr deutlichen Humeralstreifen. Auch die Geschlechtsunterschiede sind bei beiden Arten die nämlichen, die Männchen sind auch hier nur an dem etwas längeren Pygidium und minder kugelig gewölbten Bauch zu erkennen.

Als Stammform dürfte, wenigstens nach der Anzahl der Sammlungs-Exemplare zu schliefsen, die Var. a. oder c. zu belrachten sein; die Namen dieser beiden Formen wären passender gewesen als der Latreille'sche, der sich nur auf eine ausgezeichnete Abänderung bezieht, die mehr auf Centralamerika beschränkt scheint. Die entschiedene Priorität der Beschreibung Latreille's mufs aber unter allen Umständen aufrecht erhalten bleiben.

27. C. cyanocephalus: Subdilatato-ovalis, convexus, nitidus, rufescens, subviridi-aeneus, capite, thoracis linea media longitudinali et elytrorum basi obscure viridi-aeneis. Caput laeve, clypeo medio bidentato. Thorax lateribus medio sat acute angulatis. Impressio scutellaris nulla. Elytra subtiliter striata. Pygidium planum, laeve, nitidum, basi medio obsolete longitudinaliter tuberculatum. Corpus subtus rufo-brunneum, metasterno medio leviter viridi-aeneo, femoribus rufo testaceis, tibiis tarsisque obscure rufis; prosterno non carinato, femoribus posticis absque linea marginali, tibiis posticis angustis et gracilibus, intermediis subarcuatis. - Long. 3 lin. 
Coprobius cyanocephalus Dej. Cat. 3 ed. p. 152.

C. nigrocinctus Ioritz i. litt.

Von etwas breit-eiförmiger Gestalt, ziemlich gewölbt, glatt und glänzend, röthlichbraun mit grünlichem Metallglanz, der Kopf und eine Längslinie des Halsschildes, sowie die Basis der Flügeldecken schwärzlich erzgrün. Das Kopfschild in der Mitte mit zwei ziemlich spitzen Zähnen, daneben abgerundet, auch die Wangen nach vorn kaum kenntlich abgesetzt. Der Seitenrand des Halsschildes in der Mitte eine ziemlich scharfe Ecke bildend, dann nach vorn wie nach rückwärts ziemlich gerade. Ein Scutellareindruck ist nicht vorhanden. Die Flügeldecken ebenso gewölbt wie das Halsschild, fein aber sehr deutlich gestreift, die Epipleuren flach abgeseizt und dunkel erzfarbig mit röthlichem Längsfleck in der Mitte. Das Pygidium grofs und flach, glatl, glänzend, rothgelb, an der Basis in der Mitle sehr leicht gekielt. Taster und Fühler rothbraun. Die Unterseite röthlichbraun, die Hinterbrust in der Mitte metallisch grün; die Schenkel rothgelb, Schienen und Füfse röthlichbraun; das Prosternum ohne Querkanten und auch vorn ohne Randzahn; die mittleren Schienen leicht gekrümmt, die hinteren gerade, beide schmal und wenig verdickt, die Vorderschienen mit etwas nach vorwärts gerichteten Randzähnen.

Vaterland: Cayenne, Orinoco, Guyana.

Von Herrn Deyrolle mitgetheilt. Unter den Arten mit rothen, vorn nicht gerandeten Schenkeln, wovon zur Zeit nur C. rufulus und imitans bekannt sind, sehr leicht an der geringen Gröfse und dem metallischen Glanze zu erkennen. Die schwärzliche Mittellinie des Halsschildes ist zuweilen durch einen grünlichen Streifen ersetzt, auch sind an den Flügeldecken oft alle Ränder und die Naht schmal schwarz gesäumt. Bei einer andern Varietät, die Schomburg aus Guyana mitgebracht, verschwinden diese schwarzeu Zeichnungen und wird die Oberfläche mehr grünlich erzglänzend.

28. C. rufulus: Affinis C. triangulari, at minor, parum nitidus, obscure aeneus, thorace ferrugineo, elytris fusco-rufis. Caput laeve, clypeo bidentalo. Thorax nonnihil pone medium rotundatoangulatus, angulis posticis obtusis. Impressio scutellaris nulla. Elytra parum distincte striata, epipleuris latis. Pygidium flavum, planiusculum. Palpi cum antennis rufi, his cinereo-clavatis. Corpus subtus cum pedibus sordide testaceum, metasterno medio leviter cupreo-metallico; prosterno absque carinis transversis, femoribus posticis antice non marginatis. - Long. 6 lin. 
In der Färbung einem kleinen $C$. triangularis var. flavicollis ähnlich, in der Gestalt aber dem C. septemmaculatus näher stehend, matlglänzend, der Kopf kupfrig erzfarben, das Halsschild rostroth, die lederartig matten Flügeldecken schmutzig erzfarben. Der Kopf glatt, der Aufsenrand vorn mit zwei an der Basis breiten, ziemlich scharfen Zähnen, das vordere Wangenende abgerundet. Das Halsschild etwas hinter der Mitte an den Seiten eckig gebogen, die Ecke selbst abgerundet, sowohl der vordere als der hintere $\mathrm{Ab}$ schnitt geradlinig, die Hinterecken sehr stumpf; der Saum der Basis erscheint schwärzlich. Ein Scutellareindruck ist nicht zu bemerken. Die Flügeldecken sehr fein, fast undeutlich gestreift, durchaus kein Schulterstreif zu erkennen, der Seitenrand bei den Schultern fast gar nicht nach abwärts geschwungen, die Epipleuren daher schon an der Wurzel sehr breit und horizontal gelagert. Das Pygidium gelb, glatt, nur sehr leicht gewölbt, besonders gegen die Spitze etwas verflacht. Taster und Fühler roth, letztere mit grau behaarter Keule. Die Unterseite sammt den Beinen schmutzig braunroth, die Schenkel etwas heller gelb, mit leicht gedunkelten Kniestellen; das Metasternum in der Mitte metallisch glänzend, leicht kupferröthlich. Das Prosternum ohne Querleisten, auch vorn kein Randzähnchen; die hinteren Schenkel ohne Randlinie; an den hinteren Tarsen das zweite Glied länger wie das erste und wie das dritte.

Vaterland: Von den Ufern des Amazonenstromes.

Nur ein einzelnes Stäck, von Hrn. Deyrolle mitgetheilt. Ich hatte anfänglich diese Art, trotz der bedeutenden Färbungsunterschiede (die sich aber bei einer gröfseren Anzahl von Exemplaren wohl nicht als stichhaltig erweisen würden) für einerlei mit $\boldsymbol{C}$. imitans gehalten; es zeigen sich aher doch bei näherer Betrachtung Formen- und Sculpturunterschiede, die nicht mehr auf Rechnung individueller Eigenthümlichkeiten geselzt werden können: C. rufulus ist nämlich entschieden breiter, dic Ecke des Halsschildrandes liegt nicht genau in der Mitte, sondern etwas hinter derselben, so dafs die Linie von den Vorderecken bis zum Mitteleck entschieden länger ist als jene bis zu den Hinterecken; endlich ist das Pygidium merklich flacher, namentlich an der Spitze sehr eben. Von C, triangularis unterscheidet sich die gegenwärtige Art leicht durch den mangelnden Humeralstreifen, von C. septemmaculatus durch die ungerandeten Hinterschenkel, von $\boldsymbol{C}$. nigriceps durch das kaum gewölbte Pygidium. 
29. C. imitans: Simillimus C. triangulari at multo minor striaque humerali defficiente dignoscendus. Ovalis, vix nitidus, nigro-aeneus, thorace testaceo nigro-aeneo maculato, elytris fuscis. Caput laeve, clypeo sat acute bidentato. Thorax lateribus medio rotundatis, non angulatis. Impressio sculellaris nulla. Elytra absque striis distinctis. Pygidium leviter convexum, flavum, medio nigro-maculalum. Palpi rufi, antennae rufo-piceae. Corpus subtus nitidulum, rufo-testaceum, coxis metasternique lateribus infuscatis; prosterno absque carinis; pedibus rufo testaceis, femoribus basi et apice nigris, tibiis cum tarsis obscure rufis. - Long. 4 lin.

Einem kleinen $\boldsymbol{C}$ : triangularis höchst ähnlich, aber durch den mangelnden Schulterstreif und den minder eckigen Seitenrand des Halsschildes leicht zu unterscheiden. Von rein ovaler Gestalt, sehr wenig glänzend, der Kopf dunkel erzfarben, das Halsschild gelb, mit einem grünlich schwarzen Mittelfleck, der durch Zusammenfliefsen einzelner Makeln entstanden scheint und sowohl mit dem Vorder-als dem Hinterrande zusammenstöfst, die Flügeldecken bräunlich schwarz. Der Kopf glatt, die beiden Zähne des Kopfschildes scharf und durch einen ziemlich tiefen und breiten, dreieckigen Einschnitt getrennt. Der Seitenrand des Halsschildes in der Mitte nur mäfsig gebogen, die Hinterecken sehr stumpf. Kein Scutellareindruck. Die Flügeldecken ohne deutliche Streifen, der Seitenrand gleich hinter der Basis bogig aufwärts geschwungen, die Epipleuren daher auch vorn breit und flach gelagert. Das Pygidium gleichmäfsig leicht gewölbt, gelb mit einem schwarzen Mittelfleck. I)ie Taster bräunlich roth, die Fühler braun. Die Unterseite ziemlich glänzend, röthlich gelbbraun, die Seiten der Hinterbrust und die Hüften schwärzlich; die Schenkel gelb, ihre Wurzel und die Füfse röthlichbraun; das Prosternum ohne Querleisten, auch der vordere Aufsenrand ohne Zähnchen; die hinteren Schenkel vorn nicht gerandet.

Vaterland: Venezuela.

Von Hrn. Deyrolle mitgetheilt, nur ein Stück. Höchst wahrscheinlich ändert diese Art in der Färbung analog wie die verwandten Arten ab, daher ich bei Vergleichung derselben keinen Bezug darauf nehme. Der sehr ähnliche $\boldsymbol{C}$. triangularis ist bedeutend gröfser, sein Humeralstreif und die winkelig gebogenen mittleren Schienen entfernen ihn wesentlich. Näher ist $\boldsymbol{C}$. nigriceps verwandt, der den nämlichen Fufsbau und die stumpfen Hinterecken des Halsschildes hat: er ist aber sehr deutlich gestreift und unterscheidet sich durch sein hochgewölbtes, oben leicht gekieltes Pygi- 
dium. C. septemmaculatus hat gleichfalls ein viel kürzeres, breiteres und flacheres Pygidium, ist übrigens leicht an den gerandeten Hinterschenkeln zu erkennen. C. rufulus endlich ist breiter und flacher, der Seitenrand des Halsschildes in der Mitte viel entschiedener eckig, das Pygidium namentlich gegen die Spitze deutlich verflacht.

30. C. semiopacus: Elongato-ovalis, postice angustatus, nitidus, elytris sericeo-opacis, niger, elytris apice interdum vel omnino rufescentibus. Caput laeve, clypeo-medio bidentato. Thorax laevissimus, lateribus leviter rotundatis, medio autem angulatis, basi juxta angulos posticos emarginata. Impressio scutellaris distincta, thoracem autem non aggrediens. Elytra vix perspicue striata, disco subdeplanata. Pygidium opacum, leviter convexum. Palpi cum antennis picei, his cinereo-clavatis. Corpus subtus subnitidum, nigrum, femoribus posticis rufis. - Long. $4 \frac{3}{4}-5$ lin.

C. nitidicollis Illig. i. litt.

C. femoratus Perty i. litt.

Von ziemlich länglich-ovaler Gestalt, nach hinten etwas spitz verschmälert, glänzend, die Flügeldecken seidenartig matı, schwarz, die Flügeldecken zuweilen an der Spitze röthlichbraun oder auch ganz roth. Der Kopf glatt, das Kopfsehild in der Mitte zweizahnig, daneben sehr abgerundete Spuren von Nebenzähnen, die Wangenecke aber ganz abgerundet. Das Halsschild stark gewölbt und sehr blank, der Seitenrand verhältnifsmäfsig nur leicht gerundet, in der Mitte aber doch ein deutliches Eck bildend, indem die untere Querkante stark leistenartig in den Aufsenrand übergeht; von der Mitte bis zu den Vorderecken ist der Seitenrand nur leicht geschwungen, das untere Randzähnchen etwas hinter der Mitte; der Hinterrand neben den Hinterecken ausgebuchtet, daher sowohl diese als das stumpfe Zähnchen am inneren Ende der Ausbuchtung, deutlich vortretend. Der Scutellareindruck ist flach und erstreckt sich nur auf den Basaltheil der Naht, ohne den Hinterrand des Halsschildes anzugreifen. Die Flügeldecken auf dem Rücken etwas flach gedrückt, hinter den Schultern am breitesten, äufserst fein und kaum wahrnehmbar gestreift, nur der Nahtstreif deutlicher. Das Pygidium mälsig gewölbt, mattglänzend, schwarz. Taster uud Fühler dunkel rothbraun, letztere mit grau behaarter Keule. Die Unterseite schwarz, ziemlich glänzend; das Prosternum mit scharfen Querkanten, auch der vor ihnen liegende Abschnitt muldenartig vertieft; die Beine pechschwarz, die hinteren Schenkel roth. 
Vaterland: Brasilien, Cayenne.

Aus der Münchner Staalsșammlung und aus der Reich'schen. In der länglichen, nach hinten spitz verschnälerten Gestalt bildet diese Art mit C. angustalus, femoralis und quadrigultatus u. s. w. eine sehr natürliche Gruppe, die von der breiten und runden Form des C. deplanalus, angularis u. s. w. erheblich abweicht, aber doch durch alle $\mathbf{Z}$ wischenstufen in dieselbe ganz unmerklich übergeht. Eine merkwürdige Varietät aus Pará befindet sich als $C$. coloratus Klug im Berliner Museum; dieselbe ist etwas kleiner als die Stammform, die Beine sind ganz gelb, das Halsschild dunkel kupfrig mit röthlichem Vorder- und Seitenrande; auf den rothbraunen Flügeldecken sind die Nath und die Basis leicht erzfarben gedunkelt.

31. C. nitidicollis Luc.: Ovalis, sat convexus, nitidus, elytris opacis, cupreo-aeneus, thorace rufo-aeneo. macula media obscure cuprea, elylris fuscis. Caput laeve, dentibus clypei lateralibus parum prominulis. Thorax laevissimus, lateribus medio angulatis, antice vix arcuatis, pone medium denlatis, postice leviter rotundatis. Impressio scutellaris nulla. Elytra distincte leviter striala, epipleuris angustis. Pygidium rufum laeve. Palpi cum antennis mufi. Corpus subtus nigrum, metasterno cupreo-aeneo, prosterno transversim carinato; pedibus nigris, femoribus rufis, posticis antice non marginatis; tibiis anticis apice oblique truncatis. - Long. 5 lin.

C. nitidicollis Luc. Voy. Casteln. p. 98. (1859.)

Von eiförmiger, etwas plumper Gestalt, glänzend, die Flügeldecken matt. Der Kopf kupfrig, das sehr blanke Halsschild schön röthlich kupferfarben, der Seitenrand und der Hinterrand metallisch roth, die Flügeldecken schwärzlich. Der Kopf glatt, die Nebenzähne des Kopfschildes nur stumpfwinkelig, die vorderen Wangenenden deutlich spitz. Das Halsschild stark gewölbt, der Seitenrand in der Mitte eckig gebogen, nach hinten leicht gerundet, wach vorn kaum gewölbt und hinter der Mitte gezahnt. Ein Scutellareindruck macht sich nicht bemerkbar. Die Flügeldecken kurz vor der Mitte am breitesten, fein aber deutlich gestreift, die Epipleuren schmal, seitlich gestellt. Das Pygidium glatt, gleichmäfsig leicht gewölbt, roth. Taster und Fühler röthlich. Die Unterseite schwarz, die Mitte der Hinterbrust dunkel kupfrig-glänzend, die Seiten des Hinterleibes röthlich; das Prosternum mit Querleisten; die Beine schwarz mit gelbrothen Schenkeln, die hinteren Schenkel vorn ohne Randlinie; die Vorderschienen am Ende schief abgeschnitten, die drei Randzähne in gleichweiter Entfernung von einander.

Vaterland: Gebiet des Amazonenstromes. 
Aus der Münchner Staalssammlung und von Hrn. Deyrolle zur Beschreibung mitgetheilt. In der Gestalt erinnert diese Art einigermafsen an C. monilifer, ist aber kleiner und durch den mangelnden, bei jenem sehr deutlichen, Humeralstreifen leicht zu unterscheiden. Der Halsschildfleck scheint ganz analog wie bei C. triangularis in der Gestalt zu ändern, er fällt übrigens wegen des stark metallischen Glanzes der ganzen Oberseite des Thorax wenig in die Augen.

32. C. luteicollis Er.: Ovalis, leviter convexus, nitidus, elytris opacis, obscure viridi-aeneus, thorace laete teslaceo-rufo, elytris fusco-rufis. Caput laeve, clypeo medio bidentato, dentibus lateralibus obtusis, genis antice aculiusculis. Thorax laevis, lateribus nonnihil pone medium obtusissime vel vix angulatis, antice leviler tantum subarcuatis. Impressio scutellaris nulla. Elytra absque striis, suturali sola leviter distincta, punctulata: Pygidium rufo-testaceum, laeve, vix convexum. Palpi cum antennis brunneo-testacei, his subgriseo-clavatis. Corpus subtus nitidum, obscure rufum, metasterno medio leviter metallescente; prosterno transversim carinato, foveolato, margine obsolete subdentato; femoribus posticis laete testaceorufis; pedibus anticis, tibiis tarsisque obscure rufis; tibiis anticis apice leviler oblique truncatis. $\sigma^{\top}$. - Long. $5 \frac{3}{4}$ lin.

\section{C. luteicollis Er. Wiegm. Arch. 1847. I. p. 105.}

Eine ansehnliche, auf den ersten Aublick einigermafsen an $\boldsymbol{C}$. nigriceps erinnernde Art, aber breiter, rein oval, nur mälsig gewölbt, der Kopf leicht glänzend, dunkelgrün, das sehr blanke und glänzende Halsschild lebhaft gelbroth, gegen den Hinterrand etwas grünlich, die Flügeldecken matt, schmutzig rothbraun. Der Kopf glatt, das Kopfschild in der Mitte zweizahnig, die Nebenzähne sebr stumpf, die Wangen mit ihrem vorderen Ende eine kleine rechtwinkelige Spitze bildend. Der Seitenrand des Halsschildes unmerklich hinter der Mitte zwar eckig, die Spitze des Winkels selbst aber sehr stumpf, nach hinten sehr leicht gerundet, nach vorn gerade, äufserst schwach bogig aufgehoben, daher auch ohne Randzähnchen. Kein Scutellareindruck. Die Flügeldecken ohne deutliche Streifen, kein Humeralstreif, auch der Nathstreif nur höchst fein, aber doch erkennbar punktirt. Das Pygidium matt, rothbraun, sehr flach gewölbt, nur bei starker Vergröfserung feine Pünktchen, die ein äufserst kurzes Börstchen tragen. Taster und Fühler bräunlich-gelb, letztere mit graubraun behaarter Keule. Die Unterseite ziemlich glänzend, dunkel bräunlich roth, die Hinterbrust in der Mitte und zum Theil die Hüften etwas metallisch grün; das Prosternum mit scharfen Quer- 
kanten, davor grubig vertieft; die hinteren Schenkel lebhaft gelbroth, ungerandet; die vorderen sowie die Schienen und Füfse dunkelroth.

Vaterland: Peru.

Nur ein einzelnes Männchen im Berliner Museum.

33. C. politus: Ovalis, postice subacuminatus, convexus, nitidus, obscure viridi-chalybeus. Caput laeve, clypeo medio reflexo, bidentalo. Thorax laevis, lateribus medio angulatis, versus angu. los posticos rectis, antice breviter et valde arcuatis. Impressio scutellaris nulla. Elytra subtiliter at distincte striata, striis, praecipue sulurali, punctulalis. Pygidium nigrum, sericeo-opacum. Palpi cum antennis rufo-picei, his rufo-cinereo clavatis. Corpus subtus subopacum, nigrum, metasterno nitidulo chalybeo, pedibus anticis piceis, posticis rufo-femoratis. - Long. $4 \frac{1}{2}-4 \frac{3}{4}$ lin.

Mas. Calcari apicali dilatato, apice extus dentato, intus rotundato-lobato.

Canthon geniculatus Schauf. i. litt.

C. rubripes Reiche i. litt.

Von eiförmiger, nach hinten aber etwas spitz verschmälerter Gestalt, gewölbt, glatt und glänzend, dunkel stahlblau mit etwas grünlichem Scheine. Der Kopf glatt, der Aufsenrand vorn in der Mitte aufgebogen und zweizahnig, das Wangenende vorn eine kleine, sehr stumpfe Spitze bildend. Der Seitenrand des Halsschildes in der Mitte gebogen, nach hinten gerade, nach vorn in einem kleinen, aber starken Bogen aufgekrümmt, dann wieder gerade, das Randzähnchen in der hintern Hälfte dieses Abschnittes. Kein Scutellareindruck. Die Flügeldecken gleich unter den Schultern am breitesten, sehr fein aber deulich gestreift, die Streifen weitläufig äufserst fein pnnktirt, der Nahtstreif etwas tiefer und zugleich deutlicher punktirt. Das Pygidium schwarz, seidenartig mattglänzend, der Länge nach leicht gewölbt. Taster und Fühler rothbraun, letztere mit rothgrau behaarter Keule. Die Unterseite schwärzlich und mattglänzend, die stahlblaue Hinterbrust jedoch mit stärkerem Glanze, die sehr schmale Mitte des Vorderrandes ein kleines Knöpfchen bildend; die Vorderbeine schwärzlich mit schwachem Metallglanz, die Vorderschenkel am Ende nicht ausgebuchtet; die hintern Schenkel rothbraun; ihre Wurzel und das Ende schwärzlich, die Schienen schwärzlich, die Tarsen dunkel rothbraun.

Bei dem Männchen ist der Enddorn der Vorderschienen breit, am Ende nach aufsen mit einem Zähnchen versehen, nach innen einen gerundeten Lappen bildend. 
Vaterland: Columbien und das südliche Mexiko; Bogotà.

Von den Herren Kirsch, Schaufuss und Deyrolle mitgetheill. Der in der Körpergestalt sehr ähnliche $\boldsymbol{C}$. acutus ist beträchtlich kleiner und unterscheidet sich leicht durch die nur mattglänzenden Flügeldecken und die dunkeln Beine. Letztere sind übrigens auch bei $\boldsymbol{C}$. politus zuweilen sehr dunkel rothbraun, fast schwarz gefärbt.

34. C. Lafargei Drap.: Simillimus C. 4 guttato, at major, postice minus angustatus, aliter coloratus. Nitidissimus, laevissimus, niger, thoracis lateribus rufis, elytris nigris, medio transversim late rufo-brunneo fasciatis. Caput clypeo medio acute bidentato. Thorax basi ante humeros emarginata, lateribus medio angulatis, antice arcuatis et dentatis. Impressio scutellaris fere nulla. Elytra absque striis impressis. Pygidium sat convexum, nigrum, nitidum, vix vel vix perspicue punctulatum. Palpi cum antennis ferruginei. Corpus subtus nigrum, thorace metasternoque medio rufis; femoribus pallido-testaceis, tibiis tarsisque rufescentibus; prosterno carinato, femoribus antice non marginatis. - Long. $3 \frac{1}{2}$ lin.

Ateuchus Lafargei Drapiez An. Sc. phys. Brux. III. p. 188. t. 39. f. 3. (1819.)

C. limbatus B a d et i. litt.

Dem C. 4 guttatus höchst nahe verwandı, ebenso glänzend und blank wie dieser, doch etwas gröfser, nach hinten minder spilz verschmälert, überdies sehr verschieden gefärbt. Der Kopf ist schwarz, ebenso das Halsschild, letzteres jedoch mit breit blutroth gesäumten Seiten, so dafs eigentlich nur ein schwarzer Längsstreif in der Mitte übrig bleibt; die Flügeldecken ebenfalls schwarz, über ibre Mitte eine ziemlich breite, meist ununterbrochene und auch den Aufsenrand erreichende röthlich braune Querbinde. Das Halsschild am Hinterrande den Schultern gegenüber ausgeschnitten, der Seitenrand in der Mitte eckig, dann nach vorn gewölbt und unten gezähnelt, die Vorderecken scharf. Ein eigentlicher Scutellareindruck ist nicht vorhanden. Die Flügeldecken ohne Spuren vertiefter Streifen, schon bald unter den Schultern nach hinten verengt. Das Pygidium gleichmäfsig leicht gewölbt, glänzend, schwarz, fast glatt. Taster und Fühler röthlichbraun, letztere mit gelbbraun behaarter Keule. Die Unterseite schwarz, mit leichtem grünlichen Erzglanz; Halsschild und Mitte der Hinterbrust roth; die hinteren Schenkel gelb, die vorderen sowie die Schienen und Füfse braunroth.

Vaterland: Bahia.

Berliner Museum. Durch ihre gelben Beine kommt diese Art 
in der synoptischen Tabelle neben $\boldsymbol{C}$. politus zu stehen, von dem sie die flachere, nach hinten spitzigere Gestalt leicht unterscheidet; ihre nächsten Verwandten, mit denen sie namentlich die blank polirte Oberfläche und die leicht wadenartig verdickten hinteren Schienen gemein hat, sind $\boldsymbol{C}$. 4 guttatus und $\boldsymbol{C}$. subhyalinus, von denen sie sich durch die sehr eigenthümliche Färbung wieder entfernt.

35. C. femoralis Chevr.: Convexus, postice subangustalus, laevis, nitidus, nigro-aeneus, interdum subvirescens. Caput obsoletissime punctulatum, antice rugulosum, clypeo 4dentato, dentibus lateralibus minoribus, genis antice non a clypeo distinctis. Thorax lateribus medio acute angulatis, antice fortiter arcuatis, angulis posticis subprominulis. Impressio scutellaris sat profunda. Elytra vix distincte striata. Pygidium subopacum, convexum. Palpi cum antennis ferruginei. Corpus subtus nigrum, leviter nitidum, pedibus posticis rufo-testaceis vel rufis, geniculis tarsisque plus minusve infuscatis; prosterno transversim carinato, antice foveolato margineque denticulato; femoribus posticis non marginatis. - Long. $3 \frac{1}{2}-4$ lin.

C. femoralis Chevrol. Col. Mlex. Cent. I. 4. nro. 74. (1834.)

C. ochropus Harold Col. Heft I. p. 79. (1867.)

C. xanthopus Germar i. litt.

Von gewölbter, auf den Flügeldecken leicht niedergedrückter Gestalt, nach hinten unmerklich verschmälert, glatt und glänzend, schwarz mit dunkel grünlichem oder schwarz bläulichem Metallschein. Der Kopf schwach punktirt, vorn etwas runzlig, das Kopfschild mit vier Zähnen, die seitlichen wenig vorragend und an der Basis sehr breit, das vordere Wangenende vom Kopfschide nicht abgesetzt. Das Halssehild mit in der Mitte scharfeckig gerundetem Seitenrande, dessen vorderer Theil dann stark, wenn auch nur auf eine kurze Strecke, bogig gewölbt und am Ende dieses Bogens leicht unten gezahnt. Der Scutellareindruck ziemlich tief, greift aber die Mitte der Halsschildbasis nicht an. Die Flügeldecken äufserst fein, fast undeutlich gestreift. Das Pygidium schwarz, minder glänzend, ziemlich gewölbt, fein punktirt. Taster und Fühler rostroth. Die Unterseite minder glänzend wie die obere, schwärzlich; die hinteren Beine rothgelb oder roth, die Kniestellen und die Tarsen etwas dunkler rothbraun, die vorderen meist ganz schwarz; das Prosternum mit Querkanten, vor denselben, besonders in der äufseren Ecke, wo sich die Kniee der Vorderbeine anlegen, muldenartig vertieft; die hinteren Schenkel ungerandet, die Vorderschienen am Ende schief abgestutzt, die hinteren etwas wadenartig verdickt. 


\section{Vaterland: Mexiko, Costa Rica.}

Diese Art wird hie und da mit $C$. politus verwechselt, von dem sie sich aber sehr leicht durch das vierzahnige Kopfschild und den tiefen Scutellareindruck unterscheidet, viel näher ist sie dagegen mit $\boldsymbol{C}$. angustatus verwandt, der aber etwas schmäler ist und in beiden Geschlechtern durch die ausgezeichneten Sexualdifferenzen leicht zu erkennen ist; die Stücke aus Centralamerika sind in der Regel etwas reiner grün gefärbt.

36. C. angustatus Har.: Statura C. quadriguttati, at major, subangustato-ovalis, laevis nitidus, brunneus, capile thoraceque leviter aenescentibus. Caput clypeo medio bidentato, dente laterali utrinque obtuso, genis antice a clypeo non distinctis. Thorax lateribus médio angulatis, antice arcuatis et dentalis, basi juxta angulos posticos emarginata. Impressio scutellaris obsoleta. Elytra vix distincte striala. Palpi cum antennis rufo-caslanei. Corpus subtus fusco-brunneum, metasterno medio leviter cuprascente, pedibus rufo-testaceis, tarsis fusco-rufis; prosterno transversim carinato, femoribus posticis non marginatis. - Long. $4 \frac{1}{2}-5$ lin.

Mas. Pygidium convexum, laeve, parum nitidum; tibiae anticae bidentatae.

Fem. Pygidium abbreviatum, latissimum, segmento abdominis ultimo maximo; tibiae anticae tridentatae, calcari apicali acuminato.

$$
\text { C. angustatus Harold Col. Heft I. p. 79. ðૅ. (1867.) }
$$

Von der länglichen Gestalt des C. semiopacus, quadriguttatus und femoralis, glatt und glänzend, schmutzig gelblichbraun, der Kopf und das Halsschild, letzteres besonders am Hinterrande in der Mitte, und die Nath zuweilen etwas grünlich erzfarben. Der Kopf vorn mit zwei Zähnen, die Nebenzähne etwas stumpf, das Kopfschild dann abgeruudet, ohne vorderes Wangeneek. Das Halschild stark gewölbt, der Seitenrand in der Mitte eckig, nach vorn dann einen kleinen Bogen bildend, und am Ende desselben gezahnt; die Basis sehr merklich neben den Hinterecken ausgebuchtet, das innere Ende dieser Ausbuchtung eine kleine höckerartige Anschwellung bildend, ähnlich wie bei C. janthinus. Der Scutellareindruck ist kaum bemerkbar. Die Flügeldecken ohne deutliche Streifen. Taster und Fühler röthlich gelbbraun. Die Unterseite dunkler braun, die Beine bräunlich-gelb, die Kniestellen dunkler, die Tarsen rolhbraun; die Hinterbrust in der Mitte meist etwas heller rothbraun und leicht kupfrig, die Vorderbrust mit Querkanten; die Hinterschenkel ohne Randlinie. 
Bei dem Männchen ist das Pygidium wenig glänzend, gewölbt und so lang als an der Basis breit; die Vorderschienen haben nur zwei Randzähne, ihr Enddorn ist ziemlich breit und am Ende etwas tief abgestutzt.

Bei dem Weibchen ist das Pygidium sehr kurz, an der Basis viel breiter als lang, dagegen ist der letzte Bauchring sehr grofs und bei der starken Wölbung des Bauches zum Theil noch von oben sichtbar, so zwar dafs er mit zum Pygidium zu gehören scheint und dieses wie mit einer Querleiste versehen aussieht; die Vorderschienen sind dreizähnig, ihr Enddorn schmal und spitz.

Vaterland: Columbien: Costa Rica, Bogotá.

Von Dr. Moritz Wagner und Herrn Kirsch mitgetheilt, das Weibchen aus der Münchner Staatssammlung. Der auffallende Geschlechtsunterschied im Bau der Vorderschienen und des Pygidiums zeichnen diese Art sehr aus, im Uebrigen ist sie jedoch mit C. femoralis sehr nahe verwandt, der namentlich die nämlichen, leicht wadenartig verdickten hinteren Schienen hat; er ist aber doch etwas breiter, anders gefärbt und zeigt einen deutlichen Scutellareindruck. Bei den Stücken aus Bogotà, die zugleich etwas kleiner sind, zeigt sich hinten an der Halsschildbasis in der Mitte ein kleiner, dunkel kupfriger Längsfleck.

37. C. probus Germ.: Statura C. liturati, sericeo-opacus, ater. Caput laeve, margine antico reflexo et sexdentato, dentibus aequalibus et aequaliter interse distantibus. Thorax laevis, valde convexus, lateribus medio valde rotundatis, tunc apicem versus valde sinuatis. Impressio scutellaris obsoleta. Elytra obsolete, at distincte siriala, vix perspicue subtilissime reticulata, stria humerali obsoleta. Pygidium opacum, apice leviter convexum. Palpi cum antennis picei. Corpus subtus cum pedibus nigrum subnitidum, femoribus posticis margine antico non lineato. - Long. 3 lin.

Ateuchus probus Germ. Ins. spec. nov. p. 98. (1824.)

Ganz von der Körpergestalt des C. lituratus, das Halsschid also stark gewölbt, die Flügeldecken viel flächer, nach hinten leicht verschmälert, seidenartig mattglänzend, einfärbig schwarz. Der Kopf glatt, der Aulsenrand aber sehr fein runzlig punktirt, das Kopfschild mit sechs gleich grofsen und auch gleichweit von einander abstehenden Zähnen. Das Halsschild vollkommen glatt, der Seitenrand etwas hinter der Mitte sehr stark, aber durchaus nicht im Winkel gerundet, nach vorn sehr stark aufgebogen aber doch noch etwas gerundet, so dafs die Vorderecken verhältnifsmäfsig stumpf erscheinen. Der Scutellareindruck deutlich, aber auf die Flügeldecken 
beschränkt. Die Flägeldecken äufserst fein, aber doch sehr deutlich gestreift, die Streifen äufserst flache Rinnen bildend, der Schulterstreif erst etwas unter der Basis beginnend und meist undeullich;

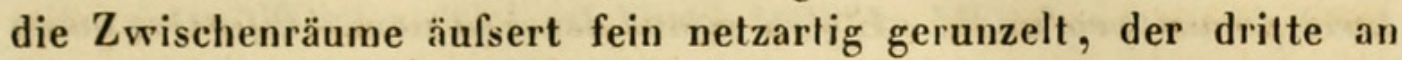
der Basis etwas gewölbt, seine Mitte nach vorn fast ein kleines Dörnchen bildend. Das Pygidium schwarz, matt, flach, die Spitze jedoch etwas beulig gewölbt und zugleich glänzender. Taster und Fübler sclıwarzbraun. Die Unterseite sammt den Beinen schwarz, ziemlich glänzend, die hinteren Schenkel vorn ohne Randlinie, wohl aber findet sich eine solche von den Knieen bis fast zur Mitte hin; keine Prosternalleisten, der Seitenrand mil einem sehr undeutlichen Zähnchen.

Vaterland: Nordamerika; Kentucky, Süd-Carolina.

Germar's Type, aufserdem von mehreren Seilen mitgetheili. Eine ausgezeichnete Art, die zwar bei flüchtiger Betrachtung leicht für einen dunkel gefärbten $C$. lituratus zu halten wäre, sich aber von diesem sowie von den übrigen Artgenossen durch mehrere besondere Eigenthümlichkeiten unterseheidet. Die sechs Zähne des Kopfschildes sind bei dieser und der folgenden Art in ganz gleichen Zwischenräumen gestellt, während bei allen andern immer die $\mathrm{Ne}$ benzähne näher an die Mittelzähne als an die spilzen Wangenecken gerückt sind; sie entstehen bei $\boldsymbol{C}$. probus durch tiefe Einschnitte des Kopfschildes, von welchen auch der Wangeneinschnitt scharf geformt ist. Auch die Gestalt des Halsschildes ist auffallend: dasselbe ist sebr stark kissenartig gewölbt, der Seitenrand sebr slark gerundet, nach vorn aber in die Höhe gewölbt und dann wieder gegen die Vorderecken hin leicht gerundet, so dafs auch diese Ecken nur wenig spitz sind. C. ebeneus, der ein ganz gleichgeformtes Kopfschild hat, kann wegen der raubgekörnten Oberfläche und der bedeutenderen Gröfse nicht damit verwechselt werden.

Diese Art ist eine der wenigen, bei welchen der erhabene Schulterstreif, dessen Anwesenheit oder Mangel die beiden folgenden Hauplabtheilungen der Canthon-Arten bestimmt, bald mehr bald weniger deutlich erkennbar ist, so dafs ich in der synoptischen Tabelle dieselbe von vorn herein ausscheiden mufste, wozu übrigens die sehr eigenthümliche $Z$ ahnung des Clypeus, welche nur ihr und dem C. ebeneus eigen ist, willkommene Anhaltspunkte bot.

38. C. ebeneus Say: Subelongato-ovalis, dorso, praecipue elytrorum, depressus, dense granulalus, niger, interdum leviter subvirescens. Caput laeve subtiliter subgranulalum, clypeo sexdentato, Berl. Entomol. Zeitschr. XII. 
dentibus magnitudine inter se aequalibus. Thorax basi medio submarginatus, lateribus nonnihil pone medium valde rotundatis, antice leviter arcuatis, margine laterali serrulato. Impressio scutellaris parum profunda. Elytra minus dense al nonnihil fortius quam thorax granulata, substriala, utrinque ad basin juxla regionem scutellarem sublumidula. Pygidium granulalum, basi longitudinaliter carinatum. Corpus sublus cum pedibus nitidulum, nigrum; prosterno absque carinis; , femoribus posticis non marginatis. - Long. 4-5 lin.

Ateuchus ebeneus Say Journ. Acad. Phil. III. p. 208. (1823).

Coprob. depressipennis Dej. Cat. 3 ed. p. 152.

Von etwas länglich-eiförmiger Gestalt, nur flachgewölbt, besonders die Flügeldecken eben, rauh gekörnelt, schwarz, ohne Glanz, hie und da leicht grünlich scheinend. Der Kopf nur fein und wenig erhaben gekörnelt, das Kopfschild mit sechs gleich grofsen Zähnen, indem auch der Wangeneinschnitt ebenso tief, oder fast noch tiefer ist als jener. welcher die Nebenzähne von den Mittelzähnen trennt, letzlere am weitesten auseinanderstehend. Das Halsschild in der Mitte der Basis und auch um die sehr stumpfen Hinterecken herum leicht gerandet, auf der hinteren Hälfte die Spur einer glatten Längslinie, der Seitenrand gekerbt, etwas hinter der Mitte ziemlich stark, aber nicht eckig gerundet, nach vorn leicht bogig gewölbt. Der Scutellareindruck flach, wenig in die Augen fallend. Die Flügeldecken gröber, aber nicht so dicht gekörnelt wie das Halsschild, deutlich aber nur seicht gestreift, an der Basis beiderseits neben der Schildchengegend leicht aufgetrieben. Das Pygidium ziemlich grob gekörnelt, an der Basis mit leicht erhabenem Längskiel. Taster und Fühler schwarzbraun, letztere mit graubehaarter Keule. Die Unterseite sammt den Beinen ziemlich glänzend schwarz; das Prosternum ohne Querkanten, ganz vorn etwas stumpf gezähnelt; die Hinterschenkel ohne Randlinie, die vorderen an beiden Rändern lang behaart; die Vorderschienen am Innenrande vor der Mitte sehr stumpfwinkelig erweitert, ihr Enddorn nach aus. wärts gerichtet und in beiden Geschlechtern spitz, beim Männchen nur etwas derber.

Vaterland: Nordamerika.

Von mehreren Seiten in Mehrzahl zugeschickt erhalten. Durch die eigenthümliche Zähnelung des Kopfschildes, das in so fern wirklich sechs Zähne hat, als auch die Wangen durch einen sehr tiefen Einschnilt einen ächten Zahn bilden, sehr ausgezeichnet und in dieser Beziebung nur mit $\boldsymbol{C}$. probus vergleichbar. Auch abgesehen von diesem Merkmal ist C. ebeneus dureh die Randung des 
Halsschildes in der Mitte und um die Hinterecken herum sehr gekennzeichnet. Der $C$. depressipennis der Dejean'schen Sammlung gehört sicher hieher: unter demselben Namen beschreibt Leconte mit kurzen Worten (Col. of Kans. 1859. p. 11.) eine neue Art aus Georgia, die sich von $C$. ebeneus durch mehr gerundete Gesialt, feinere Körnelung und minder plötzlich gerundeten Seitenrand des Halsschildes unterscheiden soll. Unter der grofsen Anzahl Stücke, die ich vor mir habe, zeigen allerdings einige eine feinere, namentlich auf dem Halsschilde zuweilen nur schwache Körnelung, in der Gestalt weichen dieselben aber durchaus nicht von den gröber gekörnten ab nnd verhalten sich höchstens zu diesen wie Chalcites zu C. laevis.

39. C. perplexus Lec.: Ovalis, leviter convexus, nitidus, metallicus, cupreo-aeneus vel nigro-aeneus. Caput punctatum, oculis sat magnis, clypeo quadridentato, dentibus aegualiter distantibus, genis antice ob̈tusissimis. Thorax dense et fortiter punclatus, latteribus postice rolundatis, antice leviler arcuatis. Impressio scutellaris nulla. Elytra sat profunde striata, interstitiis punclulatis, punctis setam brevissimam sicuti squamulam ferentibus. Pygidium subdeflexum punctulatum. Palpi cum antennis ferruginei. Corpus subtus cum pedibus rufo-piceum vel piceo-rufum, leviter metallescens; prosterno carinato et antice foveolato, margine non dentalo, metasterno punctalo; femoribus posticis non marginatis, tibiis anticis intus emarginatis, inlermediis leviter incurvatis. - Long. 2$2 \frac{1}{2}$ lin.

C. perplexus Lec. Journ. Acad. Phil. 2 Ser. I. p. 85. (1848).

C. flavipes Chevr. i. litt.

C. punctulatus Pilate i. litt.

Coprob. humilis Dej. Cat. 3 ed. p. $15 \%$.

Coprob. cuprascens Dej. Cat. 3 ed. p. 152.

Var. Elytris macula humerali apiceque rufis.

Von rein eiförmiger Gestalt, gleichmäfsig nur leicht gewölbı. glänzend, erzfarben, meist kupfrig oder schwärzlich. Der Kopf punktirt, der obere Theil der Augen verhälınifsmäfsig grofs, das Kopfschild vorn mit vier in gleicher Entfernung von einander befindlichen, im Ganzen aber nahe beisammen stehenden Zähnen, der Seitenrand dann nacb hinten ziemlich gleichmäfsig gerundet, so dafs das vordere Wangenende nur einen sehr kleinen Vorsprung bildet. Das Halsschild dicht und ziemlich grob punktirt, die Punkle gegen die Mitle des Hinterrandes an Gröfse zunehmend, der Seiten- 
rand im Halbkreis gerundet, nur vorn sehr leicht aufwärts geschwungen. Ein Sculellareindruck macht sich nicht bemerkbar. Die Flügeldecken selir deutlich gestreift, die Streifen zuweilen an der Spitze etwas vertieft, der Humeralstreif erlischt in der Mitte und ist nur höchst fein leistenartig; die Zwischenräume fein punklirł, jeder Punkt ein, in gewisser Richtung besehenes, glänzendes haarförmiges Schüppchen tragend; dieselben Punkte zeigen sich auf dem Pygidium, der Unterseite und den hinteren Schenkeln. Das Pygidium ziemlich breit, etwas angezogen. Taster und Fühler röthlich. Die Unterseite sammt den Beinen heller oder dunkler rothbraun. meist mit etwas Kupferglanz; das Metasternum punktirt, das Prosternum mit Querleislen und selır deutlichen Grübchen, ohne Randzähnchen; die hinteren Schenkel ungerandet; die Vorderschienen am Innenrande ausgebuchitet und an der Spitze fast gerade abgeschnitten ( $\left.\sigma^{\star}\right)$, oder nicht ausgebuchtet und abgestulzt ( $($ ); der Enddorn der Männchcn breit und am Ende ausgebuchtet, der Weibchen allmählig zugespitzt.

Var. Bei einigen meist dunkel gefärbten Stücken ist ein Schulterfleck und die Spitze der Flügeldecken rötblich gefärbt.

Vaterland: Von den vereinigten Slaaten bis nach Mexiko und Yucatan verbreitet, vielleicht auch noch in Bolivia zu Hause.

In Mehrzahl von verschiedenen Seiten. Obwohl diese kleine Art in Gröfse und Färbung ziemlich veränderlich ist, macht sie sich doch auf den ersten Blick durch die dichte Punktirung des Halsschildes und die viel feinere, aber schuppige der Flügeldecken leicht kennllich. Sie hat aufserdem noch einige Eigenthümlichkeiten, wie z. B. die gröfseren Augen und den Geschlechtsunterschied im Bau der Vorderschienen, welch lefzteres Merkmal an Canthidium erinnert. Die aus dem Norden stammenden Stücke (Louisiana, Illinois) sind meist dunkel kupfrig, dabei elwas feiner geslreift; auf ein solches einzelnes Stück ist $C$. perplexus L ec. gegründet; die Exemplare aus Texas und Mexico sind stärker gestreift und meist schwärzlich erzfarben; ob die Art auch noch in Bolivia vorkommt, wie ein von Deyrolle eingesendetes Stück angibt, scheint doch zweifelhaft.

40. C. Lecontei: Ovalis, leviter depressus, opacus, ater. Caput dense af subtilissime granulalum, clypeo quadridentato, genis subangulato-rolundatis. Thorax subtilissime et densissime granulatus, lateribus medio rotundato-angulatis, antice leviter arcuatis. Impressio scutellaris distincta. Elylra obsoletissime reticulato-ru- 
gosa, punctis minutis glabris el subnitidis adspersa, distincte striata, stria humerali usque ultra medium elevata. Pygidium leviter convexum, obsolete punclulatum, punctis setis brevissimis. Palpi cum antennis nigro-picei, his cinereo-clavatis. Corpus subtus cum pedibus nilidulum, nigrum; prosterno absque carinis transversis nec denticulato; femoribus posticis non marginatis, tibiis anticis intus non angulatim-dilatatis. - Long. 3 lin.

In der Gestalt dem C. lituratus nicht unähnlich, auf dem Rücken, namentlich auf den Flügeldecken, etwas flachgedrückt, ohne Glanz, tief schwarz. Der Kopf und ebenso das Halsschild, sehr dicht aber äufserst fein gekörnelt. Das Kopfschild vorn gröber gerunzelt und vierzahnig, die Zähne wenig spitz, mehr zipfelartig, die Wangen vorn eine stumpfabgerundete Spilze bildend, aufserdem im Halbkreise gerundet. Das Halsschild mit in der Mitte winkelig gebogenem Seitenrande, der hintere Theil desselben leicht gerundet, der vordere leicht gewölbt. Der Scutellareindruck wenig tief, greift aber doch die Mitte der Halsschildbasis merklich an. Die Flügeldecken mit nur leicht gerundeten Seiten, fein aber sehr deutlich gestreift, der Humeralstreif sehr deutlich, bis zur Mitte leistenartig; die Zwischenräume mikıoscopisch fein netzartig gerunzelt und mit kleinen nicht gerunzelten, daher etwas mehr glänzenden Pünktchen oder Fleckchen besetzt. Das Pygidium leicht gewölbt, undeutlich punktirt, die Punkte mit einem äufserst kurzen Börstchen besetzt, welches nur an rein erhaltenen Słücken wahrzunehmen ist. Taster und Fühler schwarz, letztere mit graubehaarter Keule. Die Unterseite sammt den Beinen leicht glänzend schwarz, das Prosternum ohne Querkanten, auch der äufsere Vorderrand ohne deutliches Zähnchen; die Hintersehenkel ungerandet, die Vorderschienen innen ohne winkelige Erweiterung.

Valerland: Texas.

Von Herrn Lehrer Schmidt in Hamburg mitgetheilt. Am nächsten steht diese Art vielleicht dem C. probus, der die nämliche Sculptur der Flügeldecken, aber auf denselben viel feinere Streifen hat, namentlich ist der bei $\boldsymbol{C}$. Lecontei sehr deutliche Humeralstreif bei $C$. probus meist unkenntlich. Dieser hat aufserdem ein sehr gleichnıafsig sechsfach gezahntes Halsschild und sind Kopf und Halsschild glatt. ohne Skulptur und daher auch efwas glänzend, nicht wie bei jenem dicht gekörnelt. Möglicherweise ist diese Art der C. praticola Lec. Col. Kans. p. 10. Nach Leconte's Beschreibung ist aber seine Art gerundet (rolundalus), die Streifen der Flügeldecken sind parum distincta und soll der Seitenrand des Halsschil- 
des vorn ein Randzähnchen haben, lauter Angaben, die auf meinen C. Lecontei durchaus nicht passen.

41. C. speculifer Cast.: Pernilidus, laevissimus, plerumque obscure viridi-cyaneus, interdum chalybeus, cupreus vel viridis. Caput clypeo medio valde bidentalo. Thorax transversus, convexus, linea iongiludinali postice leviler impressa, lateribus arcuatim rotundat is, margine reflexo, anle medium subtus dentalo, angulis anticis valde acutis. Regio scutellaris profunde impressa. Elytra obsolelissime striala, stria humerali usque ad medium carinulata, tunc evanescente. Pygidium nitidum, laeve, valde tuberosum. Palpi cum antennis rufo-picei, his rufo-teslaceo clavalis. Corpus sublus nigrum, subnitidum; melasterno nitido, viridi-cyaneo, apice leviter tuberculato, lateribus sericeis; pedibus nigris, tibiarum anticarum calcari apicali in utroque sexu dilatato. - Long. 7-9 $\frac{1}{2}$ lin.

Mas: Differl a femina tibiis anticis apice ubrupte incrassat is et incurvatis, calcaris apicalis parte interiore rolundato-lobata, exteriore multo majore.

Fem.: Tibiis anticis ad apicem dilalatis at vix inflexis, calcari apicali bidentato, dente interno majore et latiore.

C. speculifer Cast. Hist. Nat. II. p. 68. (1840)

Coprob. parellinus Sturm Cat, 1843. p. 104.

C. conopygus Klug i. litt.

Von verlängert eiförmiger Gesłalt, hinten wegen des hochgewölbten Pygidiums scheinbar zugespitzt, sehr blank und glänzend, dunkel stahlblau mit etwas grün, zuweilen auch ganz grün. Der Kopf am Aufsenrande äufserst fein gerunzelt, die vordere Wangennaht hinten neben den Augen eine kleine Vertiefung bildend, der Vorderrand in der Mitte mit zwei slarken Zähnen, von da bis zu den abgerundeten Wangen nach aufsen stark bogig gerundet. Das Halsschild in der Mitte breiter als die Flügeldecken, stark gewölbt und nach vorn abfallend, der Seitenrand etwas abgesetzt, stark und gleichmälsig bogig gerundet, also ohne Ecke in der Mitte, vor den Vorderecken etwas geschweift, diese daher sehr seharf zugespitzt; auf der hinteren Hälfte die Spur einer Längsvertiefung. Die Schildchengegend mit Einschlufs der Halsschildbasis merklich vertieft. Die Flügeldecken etwas vor der Mitte am breitesten, nur mit Spuren von Streifen, der Schulterstreif bis fast zur Mitte leistenartig, dann allmählig erlöschend. Das Pygidium gewölbt, fast einen Kegel darstellend, glänzend und glatt. Taster und Fühler braun, letztere mit rother Keule. Die Unterseite viel matter glänzend als die 
Oberseite; schwarz, die Hinterbrust jedoch blaugrün und metallglänzend, nach vorn einen stumpfen Höcker bildend, ihre Seiten schwarz und seidenartig mattscheinend; das Prosternum ohne Querleisten, die Beine schwarz, die hinteren Schienen nur scheinbar gekrümmt, ibr innerer Rand gerade; der Enddorn der Vorderschienen in beiden Geschlechtern breit und ausgerandet.

Bei dem Männchen sind die Vorderschienen am Ende nach innen eckig erweitert und einwärts gekrümmt, der Enddorn hat ëinen äufseren spitzen Zahn und einen sehr breiten, abgerundeten inneren Lappen.

Bei dem Weibchen sind die Vordersehienen auch am Ende gerade, nach innen nur wenig erweitert, ihr Enddorn ist in zwei Zähne getheilt, einen inneren, breiteren und einen äufseren, schmalen.

Vaterland: Brasilien, Cayenne, auch noch in Bogotà.

Nicht selten, nach den Sammlungsexemplaren zu schliefsen. Wegen ihrer Gröfse und dem sehr stark gewölbten Pygidium kann diese prachtvolle Art mit keiner der folgenden verwechselt werden; nur $\boldsymbol{C}$. bicolor steht ihr ziemlich nahe, hat aber viel stumpfere Vorderecken des Halsschildes und ein minder stark gewölbtes Pygidium. Die Vorderschenkel haben bei beiden Geschlechtern, die übrigens einander täuschend ähnlich sind, am Innenrande etwas vor der Spilze ein kleines Zähnchen. Eine sehr schöne kupfrig rothe Varietät dieser Art sah ich im Berliner Museum.

42. C. bicolor Cast.: Valde affinis C. speculifero, at capite toto laevi, thoracis angulis anticis vix acuminatis pygidioque minus convexo dislinguendus. Pernitidus, laevissimus, viridi-aeneus, elytris nigris. Caput oculis et supra magnis, omnino laeve, margine antico reflexo medio bidentato. Thorax lateribus medio obluse rotundat is, non angulat is, deinde versus angulos anticos et posticos leviter rotundatis. Regio scutellaris non impressa. Elytra laevia stria suturali distincta, humerali longe ante medium abbreviata. Pygidium convexum, viride, nitidum. Corpus subtus nigrum, metaslerno abdominisque apice leviter viridi-cupreis, pedibus nigris; femoribus anticis ante apicem margine antico non dentatis. ․ - Long. $8 \frac{1}{2}$ lin.

C. bicolor C a st. Hist. nat. II. p. 69.

Dem C. speculifer sehr ähnlich, aber verschieden gefärbt, metallisch grün, die Flügeldecken schwarz mit Mefallglanz. Der Kopf vollkommen glalt, die Eindrücke zwischen den auch oben grofsen Augen, wo die $W$ angennähte einmünden, sehr deutlich, der Aufsenrand vorn aufgebogen, in der Mitte zweizahnig, von da bis zur 
kenntlichen Wangenecke leicht im Bogen gerundet. Das Halsschild etwas hinter der Milte am breitesten, hier der Seitenrand stark alier slumpf gerundet, von da nach vorn leicht gerundet, nicht a us gebuchtet, daher die Vorderecken stumpf; dabei ist der Seitenrand ziemlich breit und flach abgesetzt, hinten keine Spur einer Längslinie. Die Schildchengegend ohne Eindruck. Die Flügeldecken kaum mit Spuren von Streifen, doch der Nahtstreif kenntlich, der Schulterstreif kurz, weit vor der Milte schon erlöschend. Taster und Fühler rothbraun, letztere mit rother Keule. Das Pygidium grün, glänzend mit undeutlichen Spuren von Punktirung, gewölbt. Die Unterseite kupfrig-schwarz, die Hinterbrust und die Hinterleibsspitze grünlich, erstere nach vorn flach, ohne höckerige Anschwellung; die Beine schwarz, die Vorderschenkel an der vorderen Kaule ohne Zähnchen, der Enddorn der Vorderschienen in zwei ungleiche Zähne getheilt. (Weibchen.)

Vaterland: Cayenne.

Obwohl ich von dieser Art nur ein Weibchen vor mir habe, welches mir Dr. Haag freundlichst mittheilte, stehe ich doch nicht an, in demselben eine ausgezeichnete Art zu erblicken, da die Unterschiede von $C$. speculifer, mit dem sie allein verglichen werden kann, höchst bedeutend sind. C. bicolor unterscheidet sich, abgesehen von'der Färbung, die vielleicht ebenso veränderlich bei ihm ist wie bei den verwandten Arten, von $C$. speculifer durch den vorn ganz glatten, nicht runzligen Kopf, die stumpfen Vorderecken des Halsschildes, die bei jenem sehr scharf zugespitzt sind, den Mangel des Scutellareindruckes, den deutlichen Nahtstreif, den kurzen Schulterstreif, das minder gewölbte Pygidium, die vorn nicht beulige Hinterbrust und die ungezähnten Vorderschenkel. Von den folgenden Arten kann wegen des flachen Pygidiums hier gar keine in Frage kommen.

43. C. circulatus: Sat convexus, valde nitidus, laevis, rotundatus, cyaneus. Caput laeve, margine antico vix punctato, clypeo medio bidentato, tunc utrinque rolundato, genis antice acutiusculis. Thorax vix perspicue obsoletissime punctulalus, lateribus nonnihil ante medium angulatis, poslice fere rectis, antice sat fortiler arcuatis non denticulatis, basi ante humeros vix emarginata. Impressio sculellaris nulla. Elytra distincte striata, stria humerali subtili, ante medium evanescente. Palpi cum antennis picei, his cinereo-clavatis. Corpus subtus nigro-piceum, nitidum, pedibus inter- 
dum rufo-piceis; prosterno transversim carinalo et antice foveolato, femoribus posticis antice non marginatis. - Long. 3 lin.

Von kurzgerundeter, doch nach hinten etwas zugespitzter Ge. stalt, ziemlich hochgewölbt, namentlich vorn, sehr glänzend und blank, dunkel stablblau, hie uud da mit elwas grünlichem Scheine. Der Kopf glatt, auch der Aufsenrand kaum punktirt, das Kopfschild in der Mitte zweizahnig, die Zähne dreieckig, daneben gerundet, das vordere Wangenende spitz. Das Halsschild kaum wahrnehmbar höchst seicht punktirt, der Seitenrand ein klein wenig vor der Mitte eckig gebogen, nach hinten ziemlich gerade, nach vorn ziemlich stark bogig gewölbt; die Basis neben den Hinterecken den Schultern gegenüber, nur höchst unmerklich ausgebuchtet. Kein Scutellareindruck. Die Flügeldecken höchst undeutlich gestreift, der Humeralstreif lang vor der Mitte erlöschend, zwar sehr fein erhaben, aber doch auf dem blanken Grunde gut zu erkennen. Das Pygidium leicht gewölbt, schwärzlich stahlblau, mäfsig glänzend, fein und deutlich punktirt, jeder Punkt ein äufserst kurzes Börstchen tragend. Taster und Fühler rothbraun, letztere mit grau behaarter Keule. Die Unterseite sammt den Beinen glänzend, schwarz mit elwas bläulichen Scbeine, die Beine zuweilen dunkel rölblichbraun; das Prosternum mit Querkanten, der vorliegende Theil sehr deutlich muldenartig vertieft; die Hinterschenkel vorn oline Randlinie; die Vorderschienen am Ende gerade abgestutzt, ihr Innenrand vor der Mitte etwas ausgebuchtet.

Vaterland: Mexico.

Berliner Museum. Diese kleine, rundliche und glänzende Art ist besonders dadurch ausgezeichnet, dafs der vor der mittleren Ecke liegende Theil des Seitenrandes des Halsschildes bei ihr entschieden der kürzere ist; unten ist derselbe muldig vertieft und die Stelle, wo sich die Kniee der Vorderbeine einlegen, nach vorn durch eine Ecke begränzt, die aber kaum als Zähnchen bezeichnet werden kann.

44. C. melancholicus: Statura C. violacei, leviter nitidus, ater, subviolaceus, laevis. Caput clypeo obtuse bidentalo. Thorax lateribus rotundalis. Impressio sculellaris fere nulla. Ely/ra parum dislincle striala, stria humerali autem valde usque medium carinala. Pygidium laeve, subconvexum, opacum. Palpi cum antennis picei, his cinereo-clavalis. Corpus sublus sat nilidum, nigrum, pedibus atro-virescentibus; prosterno non carinato nec dentalo; fe- 
moribus posticis antice non marginatis, intermediis punctis nonnullis majoribus, seligeris; tibiis intermediis ante apicem emarginatis, bituberculatis; posticis intus leviter dilatatis. - Long. 6-8 lin.

In der Gestalt dem C. violaceus oder C. tristis ganz ähnlich, nur mäfsig glänzend, glatt, schwarz, hie und da etwas violeft scheinend. Der Kopf vorn mit zwei stumpfen, an der Basis breiten Zähnen, der Aufsenrand dann noch zwei Bogen bildend, wovon die Wangen den hintern, gröfsern ausmachen. Das Halsschild mit ziemlich gleichmäfsig, in der Mitte kaum rrinkelig gerundetem Seitenrande, die Vorderecken etwas zipfelartig nach auswärts gebuchtet. Ein Scutellareindruck ist fast gar nicht vorhanden. Die Flügeldecken nur sehr seicht gestreift, der Humeralstreif dagegen scharf leistenartig bis etwas vor die Mitte erhaben. Das Pygidium wenig glän. zend, glatt, leicht gewölbt. Taster und Fühler schwarzbraun, letztere mit grau behaarter Keule. Die Unterseite mäfsig glänzend, die Beine schwärzlich erzgrün; das Prosternum obne Querkanten und ohne Randzahn, dagegen stellenweise rauh gekörnelt, borstentragend, die hinteren Schenkel mit einzelnen, groben, borstentragenden Punkten; die Vorderschienen oberhalb der drei unteren Randzähne, von denen die beiden untersten einander genähert sind, słark gezähnelt, eines von diesen Zähnchen, welches nur mehr durch einzelne vom obersten Randzahn getrennt ist, auffallend vergröfsert, so dafs ein deutlicher vierter Randzahn entsteht; die hinteren Schienen in der Mitte leicht wadenartig verdickt, die mittleren vor der Spitze leicht ausgebuchtet und bildet die äufsere obere Kante hier zwei höckerartige Stufen.

\section{Vaterland: Brasilien.}

Aus der Münchner Staatssammlung von Dr. Gemminger mitgelheilt. Eine in der Gestalt wenig auffallende, durch die erwähnten Eigenthümlichkeiten des Fufsbaues aber höchst ausgezeichnete Art.

45. C. fuscipes Er.: Subelongatus, subopacus, vix nitidus, leviter convexus, fusco-niger. Caput margine antico subtiliter rugosulo, clypeo bidentato. Thorax laevis, lateribus nonnihil pone medium angulatis, postice leviter rotundatis, antice leviter tantum subarcuatis, sublus non dentatis. Impressio scutellaris nulla. Elytra obsoletissime striata, stria suturali autem distincte punctulata, humerali brevi at distincte subliliter elevala. Pygidium planiusculum, fusco-nigrum, subtilissime subreticulatum. Palpi cum antennis testaceorrufi. Corpus subtus, fusco-nigrum, pedibus rufo-piceis; pro- 
sterno non carinato, femoribus posticis absque linea marginali, larsis rufescentibus. - Long. $3 \frac{1}{4}$ lin.

C. fuscipes Er. Wiegm. Arch. 1847. I. p. 105.

Von etwas länglicher, doch ziemlich geradseitiger Gestalt, nur mäfsig gewölbt, sehr matt glänzend, schwarz. Der Kopf glatt, der Aufsenrand etwas röthlichbraun und leicht gerunzelt, in der Mitte mit zwei wenig spitzen, an der Basis sehr breiten Zähnen, das vordere Wangenende sehr stumpf abgerundet. Das Halsschild glatt und nur microskopisch sehr fein punktirt, den Schultern gegenüber auf eine kurze Strecke leicht ausgebuchtet, der Seitenrand etwas hinter der Milte eckig gebogen, von da nach hinten leicht gekrümmt, nach vorn sehr flach gewölbt, ohne unteres Randzähnchen. Kein Scutellareindruck. Die Flügeldecken mit verhältnifsmäfsig nur schwach gerundeten Seiten, äufserst seicht gestreift, mikroskopisch äufserst fein netzartig gerunzelt, der Schulterbuckel glatt und daber etwas glänzend, der feine Humeralstreif nur wenig über denselben hinausreichend. Das Pygidium matt, nur sehr schwach gewölbt, schwärzlich. Taster und Fühler rostroth, letztere mit gelbroth behaarter Keule. Die Unterseite schwärzlich, ebenso mattglänzend wie die obere; die Schenkel schwärzlich, die Kniee aber sowie die Schienen und Füfse dunkel braunroth; das Prosternum ohne Querkanten, keine Randlinie an den Schenkeln; die Epipleuren gegen die Spitze und das letzte Abdominalsegment etwas rötlilich durchscheinend.

Vaterland: Peru.

Berliner Museum, 2 Stücke.

46. C. smaragdulus Fabr.: Nitidissimus, laevissimus, laete viridi-auratus, interdum cyaneo-viridis. Caput clypeo antice nigricante, medio acute bidentato. Thorax lateribus medio angulatis, a medio usque ad basin rotundatis, antice sinualis et dentatis. Impressio scutellaris obsoleta, thoracis basin non aggrediens. Elytra ovata, obsoletissime striata, stria humerali usque ad medium elevata, tunc punctulata, margine basali leviter foveolato. Pygidium planum, subnitidum subtilissime reticulatum, medio longitudinaliter subelevatum, utrinque obsoletissime impressum. Corpus subtus minus nitidum el obscurius, prosterno carinis transversis abbreviatis, pedibus obscure viridibus. Tibiae anticae in ulrogue sexu calcari apicali dilatato et bifido. - Long. 5-7 lin.

Scarab. smaragdulus F abr. Spec. Ins. I. p. 34. - Oliv. Ent. I. 3. p. 159. t. 14. f. 131. 
Ateuch. smaragdulus Fabr. Syst. El I. p. 58.

Canthon smaragdulus Cast. Hist. Nat. II. p. 68.

C. chloriles Klug i. litt.

Sehr blank und glänzend, lebhaft grün gefärbt nit etwas Goldglanz, zuweilen etwas bläulichgrün, seltener slahlblau. Der Kopf vorn am Aufsenrande schwärzlich. in der Nitte mit zwei scharfen Zähuen, der Rand von da bis zur Wangenspitze leicht im Bogen gerundet. Das Halsschild blank, der Seilenrand in der Mitte eckig gebogen, von da bis zum Hinterrande gerundet, bis zu den Vorderecken nach aufwärls im Bogen geschwungen und vor der Mitte dieses Theiles gezahnt, bei Seitenansicht demnach Sförmig. Die Schildchengegend nur leicht vertieft, diese Vertiefung ohne Einflufs auf die Halsschildbasis. Die Flügeldecken eiförmig, ihre grölste Breite etwas vor der Mille, höchst undeutlich gestreift, die Streifen meist nur als schwärzliche Striche erkennbar, die indefs nicht vertieft sind; auch der Nahtstreif durchaus nicht tiefer als die übrigen, der Schulterstreif deutlich bis zur Mitle gekielı, dann verlieft und schwach punktirt; am Basalrande die $Z$ wischenräume leicht gehöckert und die Streifenwurzel vertieft. Das Pygidium ebenso gefärbt wie die Oberseite, jedoch minder glänzend, mikroskopisch fein netzarlig gerunzelt, der Länge nach schwach erlıaben, daneben beiderseils flach verlieft, mit kurzen Börstchen weilläufig beselzt. Taster und Fühler rolibbraun, letztere mit röthlichgelber Keule. Die Unterseite schwärzlichgrün, höchstens der Hinlerleib, mit Ausnahme des lelzten Ringes, schwarz. Die Beine ebenso gefärbt wie die Oberseite, nur dunkler und etwas minder gläuzend; die beiden untersten Randzähne der Vorderschienen einander etwas genähert, ihr Enddorn in beiden Gesehlechtern breit und am Ende ausgerandet, daher zweizalınig; die hinteren Schienen leicht gekrümmt, von der Mitte an merklich verdickt.

Bei dem Männchen ist der Enddorn der Vorderschienen etwas kürzer, dessen innerer Zahn breit und etwas stumpf.

Bei dem Weibchen sind beide Zähne sebr spitz, der äufsere dabei merklich länger als der innere.

Valerland: Brasilien, Cayenne.

Eine sehr häufige Art, welche vielfach mit dem nahverwandten $C$. prasinus, zuweilen auch mit dem ganz verschiedenen $C$. speculifer verwechselt wird. Lelzterer unlerscheidet sich indefs sehr leicht durch gerundete, in der Mille nicht eckig gebogene Seitenränder des Halsschildes und durch sein kegelförmig gewölbtes, glänzendes Pygidium; sehr nahe ist aber die Verwandtschaft mit dem 
C. prasinus, der auch schon in Färbung und Gröfse näher herantrilt, während $C$. speculifer meist stahlblau und um ein merkliches gröfser ist. C. smaragdulus entfernt sich von C. prasinus durch reineres, minder goldiges Grün, durch das sehr bestimmte Eck, welches der Seitenrand des Halsschildes in der Milte bildet, durch den Mangel deutlicher Streifen, namentlich den nicht tieferen Nahtsłreif, durch grünes Pygidium und durch ebenfalls grüne, nicht schwarze Färbung der Unterseile; endlich sind bei ihm die Beine ebenfalls grün und die hinteren Schienen von der Mitte an viel auffallender verdickt und gekrümmter.

Wie ich schon im Eingange erwähnt habe, sind die Geschlechtsunterschiede bei dieser Art, wie bei den damit verwandten, fast gar nicht erkennbar; auch die stumpfere und breitere Gestalt des inneren Zahnes am Enddorne der männlichen Vorderschienen ist nur sehr relativ und nur bei solchen Exemplaren wahrnehmbar, bei denen keine Abnützung des Fufses staltgefunden hat.

Nach d'Orbigny, der in der Umgebung von Rio-Janeiro die Art in grofser Anzahl getroffen, fliegt dieselbe Abends und verbreitet dabei ein starkes Schnurren; unler Tags hält sie sich in Exkrementen auf und beschäftigt sich mit Pillenwälzen.

Ein sehr schönes, dunkel-erzfarbiges Stück sandte Hr. Deyrolle zur Ansicht ein. Ein sehr kleines, blaues Exemplar befindet sich im Berliner Museum als C. Roslenayi Buquet, angeblich aus NeuGranada.

In der eben genanuten Sammlung trägt die Art den Namen C. chloriles, da der Sc. smaragdulus $\mathbf{F}$ a b r. von Klug, jedoch ganz mit Unrecht, auf C. viridis B e a uv. bezogen wurde. Dieser Annahme widerspricht die Bezeichnung laevissimus in der Diagnose des Sc. smaragdulus sowie die Vaterlandsangabe: America meridionalis; die Frabricius'sche Beschreibung und die Olivier'sche beziehen sich entschieden auf ein und dieselbe Art.

47. C. prasinus. Har.: Simillinus C. smaragdulo, at elytris distincle striatis, thoracis lateribus non acute angulatis pedibusque nigris distinguendus. Valde nitidus, laevis, laele aurato-viridis. Caput clypeo medio bidentalo Thorax medio lateribus obtuse rotundatis, antice parum sinuatis el obsolete dentalis. Elytra subtiliter at distincte striata, stria suturali profunde impressa, punctulata, humerali ante medium punctala. Pygidium sericans, subnitidum, nigrum vel cuprascens, planum, longitudinaliter obsolelissime sulcalum. Corpus subtus cum pedibus nigrum vel nigro-violaceum, 
his cyanescentibus; prosterno absque carinis. Differentiae sexuales $u t$ in C. smaragdulo. - Long. 5-6 lin.

C. prasinus Harold Col. Heft I. 1867. p. 78.

Coprobius prasinus Dej. Cat. 3 ed. p. 151.

Canthon beryllinus Klug i litt.

Canthon chalciles Heyden Mus. Senkenb.

Canthon sulcatus Cast. Hist. Nat. II. p. 69. (nec Perty.)

Dem $C$. smaragdulus sehr ähnlich, aber meist kleiner und reiner grün, ohue Beimischung von Blau. Der Kopf wie bei jenem gestaltet. Das Halsschild blank, nur bei starker Vergröfserung fein und zerstreut punktirt, der Seitenrand in der Mitte stumpf gerundet, ohne dafs eine Ecke entsteht, hinten gerundet, vorn viel minder geschwungen als bei $C$. smaragdulus, auch mit schwächerem unteren Zähnchen. Die Flügeldecken fein aber doch deutlich gestreift, der Nahtstreif jedoch sehr markirt und mehr oder minder deutlich punklirt, der Schulterstreif schon vor der Mitte kein Leistchen mehr bildend, sondern vertieft und in eine undeutliche Punktreihe übergehend. Das Pygidium flach, seidig matlglänzend, nicht grün gefärbt, sondern schwarz mit etwas Kupferschein, der Länge nach äufserst schwach gefurcht, die Furche meist nur am Wurzeltheile erkennbar. Taster und Fühler braun, letztere mit röthlichbrauner Keule. Die Unterseite dunkelblau oder schwarz, mit Ausnahme der Brustseiten und des Hinterleibes glänzend, ebenso die Beine, letztere dunkelstahlblau oder bläulich; die hinteren Schienen vou der Wurzel gegen die Spitze allmählig erweitert. das Prosternum ohne Querkanten.

Bei dem Männchen ist der Enddorn der Vorderschienen kurz und breit, vorn in einen äufseren spitzen Zahn und in einen inneren stumpf-abgerundeten, breiten Lappen getheilt.

Bei dem Weibchen ist der Enddorn schmäler, in zwei scharfe Zähne getheilt, von denen der äufsere etwas länger wie der innere ist.

Vaterland: Brasilien, Bahia.

Häufig in den Sammlungen. Durch die verschieden gefärbte Unterseite, die blauen oder schwarzblauen Beine, den tiefen Nahtstreif, den abgerundeten Seilenrand des Halsschildes, den viel kürzeren Schulterstreif, die schmäleren Hinterschienen und den Mangel der Querleisten am Prosternum von C. smaragdulus leicht zu unterscheiden, auch sind die Geschlechtsunterschiede in der Gestalt des Enddornes der Vorderschienen schon viel bestimmter ausgeprägt. Der C. sulcatus Càst. hat mit der Copris sulcala Perty, 
welche Castelnau hiebei citirt, nichts zu schaffen; letztere ist ein Canthidium, wie ich schon (Col. Heft I. p. 16.) erwähnt habe, und hat Castelnau darunter unzweifelhaft die obige Art gemeint.

48. C. aequinoctialis: Convexus, nitidus, laevis, ater. Caput clypeo medio bidentalo, oculorum parte superiore sat magna. Thorax lateribus medio angulatis, antice arcuat is et pone medium subdentatis. Impressio scutellaris nulla. Elytra vix distincte striata. stria humerali subtili, longe ante medium evanescente. Pygidium laeve sat convexum. Palpi cum antennis ferruginei. Corpus subtus cum pedibus minus nitidum, nigrum; prosterno transversim carinato, antice foveolato; tibiis anticis apice recte truncalis. Long. 6 lin.

Coprob. aequinoctialis Dej. Cat. 3 ed. p. 151.

Von ziemlich breiter, der Länge nach gleichmäfsig gewölbter Gestalt, sehr blank und glänzend, schwarz. Der Kopf mil zweizahnigem Kopfschilde, die Zähne klein und eng beisammen stehend, der obere Abschnitt der Augen ziemlich grofs. Das Halsschild beiderseits in der Mitte eckig gebogen, der hintere Theil fast geradlinig, der vordere bogig gewölbt und hinter seiner Mitle mit einem sehr stumpfen Randzähnchen; die Basis neben den Ilinterecken etwas ausgebuchtet, diese daher die Schultern umfassend. Ein Scutellareindruck ist gar nicht vorhanden. Die Flügeldecken mit nur leicht angedeuteten Streifen, auch der erhabene Schuterstreif höchst feiu, schon weit vor der Mitte erlöschend. Das Pygidium gleichmäfsig gewölbt, glatt. Taster und Fühler rostroth. Die Unterseite sammt den Beinen minder glänzend wie die obere, schwarz, nur die Schenkel mit äufserst schwachem glasig-grünen Scheine; das Prosternum mit Querleisten, der vor denselben liegende Abschnitt leicht muldenartig vertieft; die Vorderschienen breit, am Ende gerade abgestułzt, die obere Kante der Mittelschienen gleichmäfsig im Bogen gekrümmt.

Vaterland: Columbien, Neu-Granada.

Von Hrn. Deyrolle mitgetheilt, nur einige Männchen, welche an den Vorderschienen einen kurzen und breiten, am Ende leicht ausgebuchteten Enddorn haben.

49. C. deplanatus: Rotundato-ovatus, sat nitidus, viridis, elytris deplanalis obscure glauco-viridibus. Caput laeve, clypeo dentibus mediis triangularibus, lateralibus cum genis obtuse rotundatis. Thorax laevis, convexus, lateribus medio rotundalo-angulatis, an- 
tice sinuatis el dentatis, angulis anticis valde acuminatis. Impressio sculellaris fere nulla. Elytra lata, subtiliter striala, stria suturali dislincle punctala, usque ante medium carinulata, tunc impressa. Pygidium subnilidum, planum, laeve, viride. Palpi cum antennis rufo-picei, his rufo-clavalis. Corpus subtus cyaneo-viride, pedibus obscure viridibus; prosterno transversim carinalo; tibiis intermediis ante apicem leviler emarginalis. - Long. 5 lin.

Von breiter, gerundet-eiförmiger Gestalt, hinten flachgedrückt, mäfsig glänzend, goldiggrün, die etwas fellglänzenden Flügcldecken schmulzig lauchgrün. Der Kopf glatt, der Aufsenrand schwarz, das Kopfschild in der Mitte mit zwei dreieckigen Zähnen, die Nebenzälıne und die Wangenspitzen slumpf abgerundet. Das Halsschild glatt, der Seitenrand in der Milte sehr stark gebogen, ohne dafs jedoch eine eigentliche Ecke entsleht, von da nach vorn stark aufwärts geschweift und unten sehr deullich gezahnt; die Vorderecken spitz vortretend, neben den hinteren eine kleine Ausbucbtung, daher auch nach innen, ähnlich wie bei $\boldsymbol{C}$. janthinus, doch nicht so stark, eine kleine Beule. Ein Sculellareindruck macht sich nicht bemerklich. Die Flügeldecken breit, vor der Milte am breilesten, sehr fein gestreift, der Nahtstreif punktirt und deutlich, der Schulterstreif bis zur Mitte leistenartig, dann verlieft; an der Basis einige Unebenheilen, durch leichte Wölbung des zweiten und dritten Zwischenraumes. Das Pygidium grün, wenig glänzend, glatt. kaum gewölbt. Die Taster und Fühler röllılichbraun, letztere mit rother Keule. Die Unterseite schwärzlich blaugrün, besonders der Hinterleib, dessen letzler ling und die Beine grün; das Prosternum mit sehr deutlichen Querleisten; die Miltelschienen bis zur Mille allı́nählig und ziemlich stark erweitert, dann bis an's Ende gleichbreit, die Aufsenkante daher einen sehr merklichen Winkel bildend.

Vaterland: Brasilen.

Aus der Reich'schen Sammlung, auch im Mus. Berol.

50. C. forcipatus: Statura C. nigricornis et C. carbonarii, rolundato-ovalus, dorso deplanatus, parum nitidus, elytris leviter opacis, niger, capite thoraceque subvirescentibus. Caput clypeo anlice oblique angustalo, medio acute bidentato, dentibus lateralibus obtuse angulatis, genis acutissime spinosulis, spina nonnihil extus directa. Thorax lateribus parum distincte punclulatus, convexus, medio lateribus fortiter at vix acute angulatis, antice arcuatis. Impressio scutellaris distincta. Elylra sublilissme reticulala, tenuiter 
at distincte striata, stria humerali subtilissime carinulata interstitiis vix perspicue punctulatis, striis summa basi bipartitis. Pygidium leviter convexum, sericeo-opacum, punctulatum. Palpi cum antennis rufo-picei, clava fusca. Corpus subtus cum pedibus nilidum nigrum; prosterno transversim carinato, margine sat acute dentato; femoribus posticis marginatis, tibiis anticis apice oblique truncatis. - Long. 4 lin.

Von der kurzgerundeten Gestalt des C. nigricornis und C.car. bonarius, doch die Flügeldecken etwas länger, wenig glänzend, die Flügeldecken fast matt, schwarz, Kopf und Halsschild mit schwachem erzgrünem Scheine. Der Kopf nach vorn verschmälert, das Kopfschild in der Mitle mit zwei schmalen Zähnen, die Nebenzähne stumpfeckig, das Wangenende eine kleine, aber scharfe Spitze bildend, die zugleich etwas seitlich gerichtet ist. Das Halsschild gewölbt, an den Seiten sehr fein punktirt, der Seitenrand in der Mitte eine starke, aber doch nicht scharfe Ecke bildend, der vordere Abschnitt gewölbı und gezahnt. Der Scutellareindruck deutlich, greift auch die Mitte der Halsschildbasis an. Die Flügeldecken äufserst fein netzartig chagrinirt, die Zwischenräume äufserst fein punktirt, der Humeralstreif nur sehr fein leistenartig erhaben; die übrigen Streifen fein aber deutlich, an der äufsersten Basis sehr eigenthümlich erweitert, so dafs ihre beiden Ränder sich fein leistenartig erheben. Das Pygidium seidig matt, fein punktirt. Taster und Fühler rolhbraun, letztere mit dunkler Keule. Die Unterseite sammt den Beinen glänzend, schwarz; am Prosternum Querleisten und an den Hinterschenkeln Randlinien.

Vaterland: Pará.

Berliner Museum, zwei Stücke. Die Art hat manches recht Ausgezeichnete, namentlich erinnert sie in der Bildung des Kopfschildes an $\boldsymbol{C}$. sanguineomaculatus und $\boldsymbol{C}$. lituratus; die beiden Mittelzähne sind lang und schmal, die Nebenzähne höchstens rechtwinkelig, das Wangenende bildet ein scharfes, etwas seitwärls gerichtetes Spitzchen.

51. C. virens Mannerh.: Ovatus, convexus, dorso elytrorum deplanatus, nitidus, fusco-viridis vel cyaneo-viridis. Caput obsolete punctulatum, clypeo distincte sexdentalo. Thorax lateribus distincte punclatis, medio angulatis, versus apicem sinuat is et dentatis. Impressio scutellaris profunda. Elytra striala, stria suturali profunde impressa, humerali apicem fere attingente, interstitiis planis, obsoletissime reticulatis, subserialim subtiliter punctulatis. Palpi cum an- 
tennis rufo-picei. Pygidium leviler convexum, opacum, obsolete transversim rugosulum. Corpus subtus cum pedibus obscure virescens, femoribus punctulatis. - Long. $3 \frac{3}{4}-5$ lin.

Mas. Calcari apicali tibiarum anticarum latiore, apice truncato.

Fen. Calcari apicali acuminalo.

Ateuch. virens Il annerh. Nouv. Mém. Mosc. 1829. I. p. 36.

Coprob. bidens Mannerh. Dej. Cat. 3 ed. p. 152.

Von gerundet-eiförmiger, ziemlich hochgewölbter Gestalı, auf dem Rücken elwas flachgedrückt, glänzend, doch die Flügeldecken nicht ganz so vollglänzend wie Kopf und Halsschild, ziemlich dunkel grün oder lauchgrün, zuweilen auch bläulichgrün. Der Kopf fein und zerstrent punktirt, die Punktirung auf deu Wangen und neben den Augen am Hinterrande deutlicher, das Kopfschild in der Mitte mit zwei scharfen Zähnen, von da bis zur ebenfalls zahnartigen vordern Wangenecke nochmals eckig vortretend, so dafs sechs deutliche Spitzen entstehen, von welchen die vier mittleren in ziemlich gleicher Entfernung von einander slehen. Das Halsschild an den Seiten und hinten bis gegen die Mitle hin sehr deullich punktirt, der Seitenrand in der Milte ein deutliches Eck bildend, von da nach hinten nur schwach gerundel, nach vorn aufwärts im Bogen gekrümmt und gezahnt. Der Scutellareindruck sehr merklich, auch die Mitte der Halsschildbasis angreifend. Die Flügeldecken in der Mitte am breitesten, sehr deutlich gestreift, der Nahtstreif ticf, diese daber leistenartig, der Schulterstreif deutlich bis fast zur Spitze, der kantige Theil bis zur Mitte reichend; der zweite Sireif sehr im Bogen gekrümmt, der 5te und der 9te an der Basis einander sehr genä-

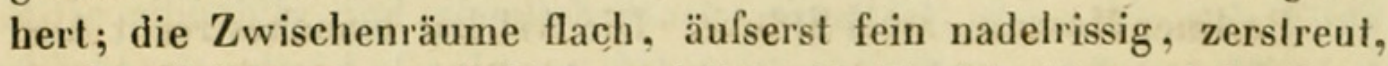
an den Seilen etwas dichter punktirt; die Punkte hie und da etwas gereiht, das Pygidium leicht gewölbt, nur mäfsig glänzend, mit eingeritzten Querrunzeln und sehr seichten, aber borstentragenden Punkten. Die Taster und Fühler rothbraun. Die Unterseite schwärzlich-grün, die Hinterbrust jedoch und die Beine wie die Oberseite gefärbt; das Prosternum mit abgekürzten, von den Vorderhüften ausgehenden Querleistchen; die hinteren Schenkel fein punktirt, die Vorderschienen, die Wurzel der hinteren und die Tarsen etwas kupfrig.

Bei dem Männchen ist der Enddorn der Vorderschienen gleichbreit, an der Spitze abgestutzt.

Bei dem Weibchen ist derselbe schmäler und allmählig zugespitzt, dabei etwas nach aufsen gekrümmt.

Vaterland: Brasilien. 
In den Sammlungen eine der häufigeren Arten, durch den slarken Scutellareindruck, den tiefen Nahtstreif und das rauh punktirte, sehr deutlich behaarte Pygidium leicht kenntlich.

52. C. substriatus: Simillimus C. conformi, at antennis rufo-testaceis distinguendus. Nigro-cyaneus vel obscure viridis, nitidus, elytris opacis. Caput postice sublaeve, antice rugosulum, cly. peo medio acute bidentato, genis antice sat acutis, angulo intermedio rotundato. Thorax lateribus sat distincte punctatis, medio distincte angulatis, postice fere rectis, antice sinuatis, dentatis. Impressio scutellaris profunda. Elytra sublilissime striata. Antennae piceo-rufae, clava rufo-testacea. Corpus subtus nitidum, nigro-coeruleum vel atro-viride, pedibus concoloribus, femoribus laevibus. - Long. $3 \frac{3}{4}$ lin.

Dem C. conformis höchst ähnlich, ebenso gebaut und auch in der Färbung gleich, glänzend, die Flügeldecken matt. Der Kopf hinten nur sehr fein und weitläufig punktirt, vorn aber runzlig; das Kopfschild vorn mit zwei scharfen Mittelzähnen, auch die Wangenspitze noch zahnartig, der mittlere Vorsprung hingegen sehr abgerundet. Das Halsschild an den Seiten fein, aber deutlich punktirt, der Seitenrand hinten fast gerade, vorn geschweift und aufgebogen, die Mitte ein deutliches Eck bildend. Der Scutellareindruck und die Flügeldecken wie bei $\boldsymbol{C}$. conformis. Das Pygidium matt, an der Spitze gerundet abgestutzt. Die Taster und Fübler rostroth, letztere mit rothgelber Keule. Die Unterseite sammt den Beinen glänzend, bläulich oder grünlich-schwarz; die hinteren Schenkel glatt, ohne Punkte.

\section{Vaterland: Brasilien, Corrientes.}

Aus der Münchener Slaatssammlung und von Dr. Haag mitgetheilt. Ich habe von dieser Art nur zwei Weibchen vor mir, die dem $C$. conformis aufserordentlich nahe stehen und leicht damit verwechselt werden können. Die gegenwärtige Art fällt aber sagleich durch ihr rothgelbes Fühlhorn auf, der Kopf ist nicht gleichmäfsig mit grofsen und kleinen Punkten bedeckt, wie bei jenem, sondern hinten nur sebr einzeln, vorn dagegen runzlig punktirt, der Vorsprung zwischen der Wangenspitze und dem Mittelzahne ist sehr abgerundet, das Halsschild an den Seiten deutlicher und weiter gegen die Mitte hin punktirt, der Seitenrand springt in einen viel deutlicheren Winkel in der Mitte vor, endlich ist das Pygidium am Ende minder spitz, sehr breit abgerundet. 
53. C. seminulum Har.: Rolundato-ovalis, dorso leviler depressus, nitidulus, elytris opacis, atro-coeruleus. Caput laeve, clypeo medio parum acute bidentato, genis antice a clypeo vix distinctis. Thorax lateribus rotundatis, versus angulos anticos subarcuatis, lateribus subtiliter punctulatus. Impressio scutellaris distincta. Elytra subtiliter striala, stria humerali distincta, at subtilissime tantum elevata. Pygidium basi obsoletissime transversim elevatum, subtilissime rugosulum. Palpi cum antennis rufo-picei, his cinereoclavatis. Corpus subtus cum pedibus subnilidum, obscure atro coeruleum; prosterno carinis ante marginem abbrevialis, femoribus posticis marginatis, tibiis anticis apice rerte truncatis. - Long. 2 lin.

C. seminulum Harold Col. Heft I. p. 79.

Eine der kleinsten Arten, von gerundet-eiförmiger Gesłalt, auf dem Rücken etwas flachgedrückt, wur mäfsig glänzend, die Flügeldecken matt, bläulich-schwarz. Der Kopf glatı, das Kopfschild vorn mit zwei wenig spilzen, an der Basis breilen Zähnen, die Wangen nach vorn vom Kopfschilde kaum abgesetzt. Das Halsschild an den Seiten zerstrent und fein punktirt, der Seitenrand gerundet, nach vorn sehr leicht bogig geschwungen. Der Scutellareindruck deutlich, aber wenig tief, greift auch die Halsschildbasis an. Die Flügeldecken sehr seicht gestreift, der Humeralstreif deutlicher vertieft als die übrigen, im oberen Theile nur äufserst schwach erhöht. Das Pygidium an der Wurzel glatt, dann der Breite nach unmerklich erhöht, äufserst fein nadelrissig gerunzelt. Taster und Fühler rothbraun, letztere mil graubehaarter Keule. Die Unterseite sammt den Beinen leicht glänzend, schwärzlich, mit leichtem bläulichen Scheine; das Prosternum mit deullichen Querkanten, die aber vor dem Aufsenrande erlöschen, dieser ohne Zähnchen; die Hinterschenkel vorn gerandet, die Vorderschienen am Ende gerade abgestutzt, die Randzähne wenig kräftig.

Vaterland: Brasilien (Bahia), vielleicht auch Buenos Aires.

Aus der Reich'schen Sammlung. Diese kleine Art erinnert etwas an $C$. probus, sie ist aber kürzer und durch das nur zweizahnige Kopfschild sofort zu unterscheiden. Der in manchen Abänderungen ähnlich gefärbte $C$. viridis ist breiter, er hat weder den Humeralstreifen noch den Scutellareindruck des $\boldsymbol{C}$. seminulum und sind bei ihm die Querkanten des Prosternums vor dem Aufsenrande nicht abgekürzt.

5. C. seminitens: Subdilatato-ovalis, depressus, nitidus, elytris sericeo-opacis, obscure viridi-cyaneus. Capul laeve, clypeo qua- 
dridentato, dentibus mediis basi vix, lateralibus valde dilatatis, genis antice subacutis. Thorax laevis, lateribus medio angulatis, antice arcuatis medioque dentatis. Impressio scutellaris distincta. Elytra sat plana, parum distincte striata, inaequalia et subcallosa, callo humerali nitido. Pygidium sericans. Palpi cum antennis picei, his cinereo-clavalis. Corpus sublus cum pedibus nitidulum, nigroviride vel nigro-cyaneum; prosterno non carinato, femoribus posticis antice marginatis, tibiis anticis apice oblique truncatis. - Long. 4-4 $\frac{1}{3}$ lin.

Mas. Tibiarum anticarum calcari apicali sat elongato, versus apicem sensim dilatato, apice exciso; pygidio longitudine et latitudine basali aequalibus.

F e m. Calcari apicali elongato, acuminato; pygidio longitudine multo latiore, apice transversim marginato, parte apicali laevi, nitida.

Var. Thorace obscure cupreo, elytris nigris, vix cyanescentibus.

C. seminitens Germar i. litt.

Von der leicht breit-eiförmigen Gestalt des C. conformis, aber flacher als dieser, glänzend, dunkel grünlich-blau oder schwarzblau, die Flügeldecken matt, nur die Naht und der stark beulige Schulterbuckel glänzend. Der Kopf glatt, das Kopfschild vierzahnig, die mittleren Zähne ziemlich schmal, die Nebenzähne aber mit breiter Basis, die Wangenenden stumpfwinkelig. Das Halsschild glatt, die Seiten etwas minder glänzend, der Seitenrand in der Mitte eckig gebogen, die Ecke aber wenig scharf, von da nach vorn leicht bogig gewölbt und in der Mitte gezahnt. Der Scutellareindruck deutlich, greift auch die Mitte der Halsschildbasis an, die dadurch zugleich unmerklich die Geslalt einer Schneppe annimmt. Die Flügeldecken nur schwach gewölbt, undeutlich gestreift, mit einzelnen, sehr flachen, grübchenartigen Eindrücken und dazwischen etwas beuligen Stellen, die im Ganzen wenig auffallend, aber doch immer erkennbar sind; der Humeralstreif äufserst fein, bald unter dem Schulterbuckel erlöschend, zuweilen sogar undeutlich. Das Pygidium matt, etwas seidig glänzend. Taster und Fühler schwarz, letztere mit graubehaarter Keule. Die Unterseite sammt den Beinen ziemlich glänzend, ebenso gefärbt wie die obere, nur noch etwas duñkler; das Prosternum ohne Querkanten, die hintern Schenkel gerandet, die Randlinie aber sehr weit nach vorn gerückt; die Vorderschienen an der Spitze schief abgeschnitten.

Das Männchen hat an den Vorderschienen einen ziemlich langen, an der Wurzel schmalen, gegen das Ende erweiterten und 
hier ausgeschnittenen Enddorn; das Pygidium ist ebenso lang als an der Basis breit, ziemlich flach.

Bei dem Weibchen ist der Enddorn schmal und allmählig zugespitzt, das Pygidium ist viel kürzer als an der Basis breit, die eigentliche Randlinie begränzt dasselbe vor der Spitze in der Art, dafs der obere Theil hier gerade abgestutzt erscheint, während der untere, welcher die eigentliche Spitze bildet, gewölbt und glänzend sich zeigt.

Var. Bei einigen Stücken sind die Flügeldecken tiefschwarz, Kopf und Halsscbild dagegen dunkel kupferröthlich.

Vaterland: Brasilien, Montevideo, St. Catharina.

Eine der häufigeren Arten, die mit C. conformis in nächster Verwandtschaft steht, aber doch durch die flacheren und namentlich etwas unebenen Flügeldecken, sowie durch das an den Seiten unpunktirte Halsschild leicht zu unterscheiden ist. Die angeführte Varietät (Mus. Deyrolle) mit kupfrigem Halssehilde erinnert ungemein an C. cupricollis, sie unterscheidet sich aber leicht durch die eigenthümlichen Buckel der flachen Flügeldecken und das blanke Halsschild, welehes bei jenem immer mattglänzend ist. Der Geschlechtsunterschied in der Abtheilung des Pygidiums beim Weibchen erinnert an $\boldsymbol{C}$. angustalus, bei diesem ist aber der untere Theil nicht mehr das Pygidium, sondern der erste Bauchring.

55. C. conformis: Stalura et summa similitudo C. virentis, at elytris opacis, subtilissime tantum striatis facile dignoscendus, nigro-violaceus vel obscure viridi-coeruleus. Caput ut in illo clypeo 4dentato. Thorax lateribus subtilius punctulatis, medio subacute angulatis, a medio versus basin fere rectis. Impressio scutellaris profunda. Elytra obsoletissime striata, subtilissime reticulata, stria suturali reliquis vix distinctiore. Pygidium parum convexum, opacum, setigerum. Palpi cum antennis picei, his clava cinereo-pubescente. Corpus sublus nigro-virescens vel nigro-violaceum, pedibus concoloribus. - Long. 3-4 lin.

Mas. Differt a femina calcari apicali tibiarum anticarum crassiore, apice non acuminato, sed truncato; pygidio longiore, minus convexo.

Coprobius nitidicollis Sturm Cat. 1843. p. 104.

Gestalt und Aussehen des C. virens, durch nur matt glänzende Flügeldecken und deren kaum wahrnehmbare Streifen leicht zu unterscheiden. Kopf und Halssehild, namentlich letzteres, glänzend, die Flügeldecken äufserst fein nadelrissig, daher nur matt glänzend, 
die leicht erhabene Naht jedoch ziemlich vollglänzend. Sehr dun kel violett-blau, manchmal auch sehwärzlich blau-grün, namentlich die Flügeldecken hier und da dunkelgrün. Der Kopf sehr fein aber ungleich punktirt, das Kopfschild deutlich vierzahnig, die Wangenspitzen jedoch ziemlich schwach. Das Halsschild an den Seiten fein und zerstreut punktirt, der Seitenrand in der Mitte eckig, der Winkel jedoch nicht scharf, sondern leicht abgerundet, von da bis zum Hinterrande fast gerade, nach vorn sehr merklich aufwärts gebogen und gezahnt. Der Scutellareindruck sehr deutlich, anch die Mitte der Halsschildbasis angreifend. Die Flügeldecken in der Mitte am breitesten, äufserst schwach gestreift, auch der Nahtstreif nur unmerklich tiefer als die übrigen; die ganze Nahtgegend etwas gewölbt und glänzender; der Schulterstreif deutlich bis zur Spitze, der 5te und 6te an der Wurzel wie bei $\boldsymbol{C}$. virens einander genähert. Das Pygidium matt, flach, undeutlich punktirt, mit zerstreuten, äufserst feinen Börstchen besetzt. Taster und Fühler dunkelbraun, letztere mit graubehaarler Keule. Die Unterseite sammt den Beinen wie die obere, nur etwas dunkler gefärbt; die Hinterschenkel zerstreut und nur sehr fein punktirl.

Das Männchen unterscheidet sich durch kürzeren, breiten, an Ende in zwei Zähne ausgebuchteten Enddorn der Vorderschienen und durch flacheres, mehr länglich dreieckiges Pygidium.

Das Weibchen hat einen einfachen, längeren und allmählig zugespitzten Enddorn; das Pygidium ist leicht gewölbt, breiter.

Vaterland: Brasilien, Montevideo.

Aus der Münchener Staatssammlung und von Tarnier erstanden. Von $\boldsymbol{C}$. virens unterscheidet sich die gegenwärtige Art durch etwas kürzere, relativ breitere Gestalt, die minder scharfe Ecke des Seitenrandes des Halsschildes, die nur sehr fein markirten Längsslreifen der Flügeldecken und deren viel matteren Glanz. Näher noch scheint sie mit $\boldsymbol{C}$. substriatus verwandt, der sich nur durch das verschieden gefärbte Fühlborn und die entschieden scharfen Ecken der Seitenränder des Halsschildes von ihr trennen läfst. Auch C. seminitens steht in naher Beziehung damit, unterscheidet sich aber doch leicht dureh die viel flacheren, namentlich in der Nahtgegend nicht gewölbten, dabei etwas unebenen Flügeldecken, das an den Seileu unpunklirte Halsschild, den minder deutlichen Humeralstreifen und die sehr eigenthümlichen Geschlechtsunterschiede am Pygidium. 
56. C. fastuosus: Subelongalo-ovalis, leviler convexus, nitidus, elytris subopacis, viridi-aeneus. Caput laeve, antice nigrum, clypeo valde quadridentato, genis antice acutis. Thorax laevis. lateribus medio sat acute angulatis, antice arcuatis et ante medium dentatis. Impressio sculellaris parum profunda. Elytra subtiliter punctato-striata, slria sulurali pro/undiore. Pygidium subconvexum, opacum. Palpi cum antennis rufo-picei, his rufo-testaceo clavatis. Corpus subtus nigro-aeneum, pedibus obscure viridi-aeneis; prosterno transversim carinato, carinis ante marginem abbreviatis; femoribus posticis marginatis, tibiis intermediis margine superiore obtuse angulato. - Long. $4 \frac{1}{2}$ lin.

Von elwas länglich - eiförmiger, mäfsig gewölbter Gestalt, auf den ersten Anblick dem $C$. dives sebr ähnlich, aber kleiner, durch den deutlich erhabenen Humeralstreif und die unbewaffneten Schenkel leicht von demselben zu unlerscheiden. Glänzend, metallischgrün, die nur mattglänzenden Flügeldecken etwas dunkler. Der Kopf äufserst fein und kaum wahrnehmbar punktirt, vorn schwarz, das Kopfschild mit vier scharfen Zähnen, auch das Wangenende merklich spitz. Das Halsschild glatt, der Seitenrand in der Mitte eine scharfe Ecke bildend, ziemlich breit abgesetzt, nach hinlen leicht gerundet. vorn bogig geschwungen und vor der Mitte gezahnt; das gewöhnliche Seitenrandgrübchen durch ein merkliches Höckerchen vertreten. Ein Scutellareindruck macht sich nur in der unmitlelbaren Nahtgegend bemerkbar, wo die Naht selbst in ihrem Wurzeltheile furchenartig vertieft ist. Die Flügeldecken sehr fein, aber deutlich punktirt-gestreift, der Nahtstreif etwas tiefer, der Humeralstreif im ersten Drittel seiner Länge erhaben, die übrigen Streifen bis zum Schulterbuckel sämmtlich an der Basis vertieft und ihre Zwischenräume hier gewölbt. Das Pygidium leicht gewölbt, mattglänzend, äufserst fein punktirt. Taster und Fühler rothbraun. letztere mit gelbrother Keule. Die Unterseite grünlichschwarz, die Beine erzgrïn; das Prosternum mit Querleisten, die erst kurz vor dem Aufsenrande erlöschen, aufserdem am Rande und hinten mit langen rothbraunen Borsten besetzt, von denen einige auch nochi auf den Epimeren der Hinterbrust erscheinen; die hinteren Schenkel gerandet; die Vorderschienen innen vor der Mitte höchst unmerklich erweitert, daher etwas gekrümmt erscheinend; an den mittleren ist die äufsere, obere Kante gleich hinter der Mitte winkelig nach unten gebrochen, was auch theilweise aber nur ganz unmerklich bei den hinteren der Fall ist.

Vaterland: Brasilien. 
Nur ein einzelnes Stück, von Hrn. Deyrolle zur Ansicht mitgetheilt. Die Art ist besonders durch das sechszahnige Kopfschild, das slark eckige Halsschild und die rothbraune Behaarung auf der Unterseite ausgezeichnet.

57. C. thoracicus: Simillimus C. janthino, at colore diversus, subrotundato-ovatus, convexus, nilidus, elytris opacis, obscure viridis vel cupreus, thorace rufo-lestaceo, metallico, postice fuscoaeneo signato, elylris vel nigris vel obscure nigro-viridibus. Caput laeve, antice subrugosulum, clypeo medio bidentato, dentibus lateralibus et genis obtuse rolundatis. Thorax laevis, lateribus medio valde angulatis. Impressio scutellaris nulla. Elytra subtilissime striata, stria sulurali parte basali distincta, humerali usque ad medium carinulata. Palpi cum antennis rufi. Corpus subtus cum pedibus obscure viride vel nigrum, tibiis intermediis extus ante apicem emarginatis. - Long. $3 \frac{1}{2}-4 \frac{1}{5}$ lin.

Var. Thorace omnino rufo, absque maculis aeneis.

Coprobius thoracicus Dej. Cat. 3 ed. p. 152.

Von ziemlich kurzer, gerundet - eiförmiger Gestalt, das Halsschild stark gewölbt und nach vorn etwas steil abfallend, die matten Flügeldecken flachgedrückt, sonst glänzend, dunkelgrün oder kupfrig, das Halsschild rötblich goldgelb, hinten mit einer dunklen, meist erzgrünen Makel, die nach vorn bis über die Mitte reicht und sich nach hinten allmählig über die Basis verbreitet, ohne die Hinterecken zu erreichen; zuweilen ist dieselbe durch eine mittlere Längslinie getheilt, oder auf ein paar Punkte in der Mitte reducirt, die zuletzt auch verschwinden. Die Flügcldecken schwärzlicb, mehr oder weniger grünlich. Der Kopf glatt, vorn äufserst fein runzlig, das Kopfschild mit zwei starken Mittelzähnen, die Nebenzähne aber und auch die Wangenecken stark abgerundet. Das Halsschild glatt, in der Mitle sehr stark an den Seitenrändern gekrümmt, der Winkel kaum abgerundet, an den Hinterecken wie bei C.janthinus etwas ausgebuchtet, daher nach innen an der Basis eine kleine zahnartige Erhöhung. Ein Scutellareindruck macht sich nicht bemerk. lich. Die Flügeldecken kaum so lang als zusammen breit, äufserst schwach und kaum wahrnehmbar gestreift, der Nahtstreif an der Basis etwas deutlicher und punktirt, der Schulterstreif sehr deutlich bis zur Mitte erhaben, dann ganz erlöschend. Das Pygidium matt oder nur wenig glänzend, schwärzlichgrün oder schwarz, ohne deutliche Punktirung. Taster und Fühler braunroth, letztere mit rother Keule. Die Unterseite sammt den Beinen ziemlich glänzend, 
schwarz oder dunkelgrüu; die mittleren Schienen und zum Theil auch die hinteren, diese aber nur schwach, vor der Spitze an der Aufsenkante ausgebuchtet; das Prosternum unten mit abgekürzten, deutlichen Querleisten; die Tarsen dunkel erzfarben, die Klauen dunkelroth.

Vaterland: Guyana, Brasilien, Casapava

Aus der Reich'schen Sammlung, auch von Dr. Haag und Hrn. Deyrolle mitgetheilt. Eine in Grölse und Zeichnung elwas veränderliche Art, die aber immer leicht an den Querkanten des Prosternums zu erkennen ist, die im letzten Drittel ihrer Länge, bevor sie den Aufsenrand erreichen, plötzlich erlöschen; das Randzähnchen dieses Aufsenrandes ist sehr weit nach vorn gerückt. In dieser Beziehung nähert sie sich aber dem C. janthinus aufserordentlich, und ich vermag in der That aufser der erwähnten Färbung des Halsschildes nur noch die rothen Fühler und die rothe Behaarung an der Unterseite der Tarsen, welche bei jenem schwarz ist, als Unterschied aufzufinden; bei meinen wenigen Stüeken des C. thoracicus scheinen indefs die Nebenzähne des Kopfschildes mehr abgerundet als bei $C$. janthinus zu sein, und würde dieses Merkmal, wenn nicht mechanische Abnützung dasselbe erzeugt, vielleicht das beste Unterscheidungsmerkmal abgeben.

58. C. janthinus Blanch.: Affinis C. conformi, at thoracis lateribus acutius angulatis, tibiisque intermediis ante apicem emarginatis facile dignoscendus. Nitidus, sat convexus, elytris sutura calloque humerali exceptis subopacis, nigro-violaceus. Caput laeve, antice obsolele rugosulum, clypeo 4dentato, dentibus mediis latis, lateralibus oblusis, genis antice angulatis. Thorax laevis, lateribus medio fortiter angulatis, postice fere rectis, antice arcualis et longe ante medium dentatis, basi ad humeros emarginata et intus subluberculata. Impressio scutellaris fere nulla. Elytra parum distincte striata, stria humerali distincte usque ad medium carinulata, interstitiis 2 et 3 summa basi tumidulis. Pygidium laeve, opacum. Palpi cum antennis picei, his cinereo-clavatis. Corpus subtus cum pedibus nigrum, nitidum; prosterno carinis ante marginem abbreviatis; femoribus posticis marginatis. - Long. 4-5 lin.

Mas. Differt a femina calcari apicali tibiarum anticarum dilatato, apice bifido, pygidio magis deflexo ad apicem.

C. janthinus Blancb. Voy. d'Orbigny. Col. p. 161. (1843.)

Coprob. patagonicus Guér. i. litt.

C. obscuratus Reiche i. litt.

Var. Thorace obscure cupreo, medio infuscato. 
Dem C. conformis ähnlich, aber durch schwachen Scutellareindruck, breitere Gestalt und den Fufsbau verschieden, ziemlich gewölbt und glänzend, die Flügeldecken, mit Ausnahme der Naht in der Schildchengegend und des Schulterbuckels mattscheinend, bläulich schwarz, zuweilen fast rein schwarz. Der Kopf glatt, vorn jedoch leicht gerunzelt, der Scheitel in der Mitte unmerklich ge wölbt, das Kopfschild mit zwei länglich-dreieckigen Mittelzähnen, die Nebenzähne ziemlich stumpf, das vordere Wangenende recht eckig. Das Halsschild glatt, der Seitenrand in der Mitte in einer starken Ecke gebogen, nach hinten fast gerade, nach vorn stark bogig gewölbt, das Randzähnchen sehr weit nach vorn gerückl, fast im ersten Drittel dieses Abschnitts; die Hinlerecken ziemlich vortretend, indem die Basis hier den Schultern gegenüber ausgeschnitten ist. Die innere Grenze dieses Ausschnittes bezeichnet eine kleine höckerartige Anschwellung des Hinterrandes. Ein eigentlicher Scutellareindruck ist kaum zu bemerken. Die Flügeldecken etwas hinter den Schultern am breitesten, sehr fein, zuweilen fast undeutlich gestreift, der Nahtstreif in seiner vordern Hälfte leicht punktirt, der Humeralstreif bis zur Mitte deutlich fein erhaben, dann vertieft; der 2te und 3te Zwischenraum dicht an der Basis etwas höckerig. Das Pygidium matt, ohne Punktirung. Die Taster und Fühler dunkelbraun, letztere mit graubehaarter Keule. Die Unterseite sammt den Beinen ziemlich glänzend, schwarz, die Schenkel hier und da mit sehr schwachem bläulichen Scheine; das Prosternum mit sehr deutlichen Querkanten, die aber den Aufsenrand nicht erreichen, sondern kurz vor demselben plötzlich erlöschen; die mittleren Schienen mit vor der Spitze stumpfwinkelig gebrochener oberer Aufsenkante, die auch von da bis ans Ende nicht mebr gekerbt, sondern gezähnelt ist; die hinteren Schenkel vorn gerandet.

Das Männchen unterscheidet sich von dem Weibchen durch breiteren, an der Spitze in zwei Zähnchen getheilten Enddorn der Vorderschienen; auch ist das Pygidium etwas gewölbter und zugleich mit der Spitze etwas mehr gegen die Bauchfläche gekrümmt.

Vaterland: Das nördliche Patagonien und die südlichen Bezirke der argentinischen Republik; Montevideo. d'Orbigny traf die Art während des Monats Januar in der Bucht von San Blas auf der Insel Jabalis in grofser Menge.

Aus der Münchner Staatssammlung und aus der Reich'schen, auch von den Herren Deyrolle und Bouvouloir mitgetheilt, die Stücke aus Montevideo im Berliner Museum Unter den verwand- 
ten Arten könnte $C$. janthinus höchstens mit $C$. conformis oder substriatus verwechselt werden, von denen aber ersterer durch minder eckig gebogenen Seitenrand des Halssehildes und tiefen Scutellareindruck, letzterer durch gelbes Fühlhorn sich unterscheidet; auch ist bei beiden das Halsschild an der Wurzel den Schultern gegenüber nicht so merklich ausgebuchtel. Unter den Arten ohne Schulterstreif steht ibr C. tetraodon am nächsten, dieser entfernt sich aber leicht durch glänzende Flügeldecken, die gezahnten Vorderschenkel und die fehlenden Prosternalleisten. Der in der Färbung höchst ähnliche $C$. latipes, der auch die abgekürzten Leisten des Prosternums mit $\boldsymbol{C}$. janthinus gemein hat, läfst sich leicht durch den mangelnden Humeralstreifen, die ausgebuchteten Vorderschenkel und die am Innenrande eckig erweiterten Vorderschienen unterscheiden.

Eine schöne Varietät dieser Art sammelte Prof. Strobel auf seiner letzten Reise durch die argenlinische Republik, und zwar in der Nähe von San Luis. Dieselbe ist von mittlerer Gröfse, das Halsschild dunkel kupfrig, ein wenig scharf begränzter Fleck am Vorderrande und in der Mitte dunkel erzfarben. Diese Form erinnert ungemein an $C$. thoracicus, der aber doch durch stumpfer gezabntes Kopfschild und die rothen Fühler sich gut unterscheiden läfst.

59. C. bispinus Germ.: Ovalis, modice convexus, vix nitidus, elytris opacis, niger. Caput subtiliter dense punclulatum, clypeo medio acute bidentato, dentibus lateralibus etiam acutis, genis autem subspinosulis. Thorax densissime, disco autem remotius punctulatus, lateribus medio angulatis, versus apicem et versus basin subrectis. Impressio scutellaris distincta. Elytra postice subangustata, vix perspicue striata, stria humerali usque ad medium fere distincta, sutura leviter convexa, subnitida. Pygidium nigrum, opacum, sat convexum. Palpi cum anlennis picei, his rufo-clavatis. Corpus subtus cum pedibus sat nilidum, nigrum; tibiis intermediis margine externo et inferiore ante apicem leviter emarginato. Long. $4 \frac{1}{2}-5$ lin.

Ateuchus bispinus Germar Ins. spec. nov. p. 97. (1824.)

Coprobius angulatus Dej. Cat. 3 ed. p. 152.

Von ziemlich breit-ovaler, mäfsig gewölbter Gestalt, nur wenig glänzend, die Flügeldecken matt, tiefschwarz. Der Kopf dicht und fein runzlig-punktirt, das Kopfschild in der Mitte mit zwei 
stärkeren, ziemlich auseinander gerückten Zähnen, die Nebenzähne auch noch spitz, die Wangenecke rechtwinkelig. Das Halsschild sehr dicht und leicht runzlig, aber wenig tief punktirt, die Punktirung in der Mitle feiner und zerstreuter, der Seitenrand eckig gebogen, dann aber nach vorn und nach hinten fast gerade. Der Scutellareindruck sehr deuflich, auch die Halsschildbasis angreifend, hier zuweilen die Spur einer schwach vertieften Längslinie. Die Flügeldecken unter den Schultern am breitesten, nach hinten leicht verschmälert, äufserst schwach gestreift, der Schulterslreif sehr fein, bis zur Mitte deutlich; die Nahtgegend etwas gewölbt und auch ziemlich glänzend; auf den matten Flügeldecken bemerkt man bei stärkerer Vergröfserung kleine, mehr glänzende Pünktchen. Das Pygidium malt und schwarz, gleichmäfsig leicht gewölbt. Die Taster und Fühler dunkelbraun, letzlere mit rother Keule. Die Unterseite sammt den Beinen ziemlich glänzend und schwarz; das Prosternum mit sehr abgekürzten Querkanten, das Metasternum äus. serst fein punktirl; die mittleren Schienen an der äufseren oberen Kante vor der Spitze unmerklich ausgerandet; die hinteren Schenkel mit zerstreuten Pünktchen, vorn gerandet; die Vorderschienen oberhalb der Randzähne sehr stark gezähnelt.

Vaterland: Buenos Aires, vielleicht auch Brasilien.

Germar's Type gegenwärtig in meiner Sammlung.

In der Gestalt ist diese Art mit $\boldsymbol{C}$. latipes nahe verwandt, sie ist aber noch etwas kürzer, hat ein sehr deutlich viergezahntes Kopfschild und entfernt sich von ihm wie von allen übrigen Verwandten durch die deutliche, besonders an den Seiten ineinander fliefseude aber wenig tiefe Punktirung des Thorax. Die Querkanten des Prosternums sind auf ein sehr kurzes Leistehen bei den Vorderhüften reducirt. Ein aus Salto grande stammendes Stück im Berliner Museum unterscheidet sich durch etwas geringere Gröfse und leichten grünlichen Schein des Halsschildes.

60. C. cinctellus Germ.: Abbreviato-ovalis, sat convexus, nitidulus, obscure viridis, elytris atro-viridibus, macula basali, margine apiceque rufis. Caput punctatum, clypeo medio acule bidentato, dentibus lateralibus acutis, genis spinosulis. Thorax dense et sat fortiter punctalus, lateribus medio rotundalis, vix angulatis. Impressio sculellaris sat profunda. Elylra distincte striata, stria suturali valde impressa, humerali subtilissime usque ultra medium carinulata. Pygidium opacum, nigro viride, subtilissime transver- 
sim rugosulum. Palpi cum antennis rufo-picei. Corpus subtus cum pedibus nigrum, nilidum; femoribus posticis marginatis, tibiis apice tarsisque piceo-rufis. - Long. $2 \frac{1}{2}-3 \frac{1}{4} \operatorname{lin}$.

Ateuchus cinctellus Germ. Ins. spec. nov. p. 98.

Ateuchus pictus Mannerh. Nov. Mlém. Mosc. 1829. I. p. 39.

Coprobius fasciatus Beaudet-Lafarge i. litt.

C. transversus Klug i. litt.

C. denticulatus Illig. i. litt.

Choerid. fasciatum Cast. Hist. nat. II. p. 83. (1849.)

Von ziemlich gewölbter, kurz eiförmiger Gestalt, leicht glänzend, dunkelgrün, die Flügeldecken schwärzlich grün, ein Fleck an der Basis und die Spitze, beide durch den Seitenrand verbunden, roth. Der Kopf punktirt, die ziemlich weit auseinander stehenden Mittelzähne des Kopfschildes spitz, auch die Nebenzähne scharf, der Rand von ihnen bis zu den eckigen Wangenenden nochmals nach aufsen einen kleinen Bogen bescbreibend. Das Halsschild dicht und stark punktirt, der Seitenrand gerundet aber ohne eine merkliche Ecke zu bilden. Der Scutellareindruck sehr bemerkbar. Die Flügeldekken kurz und breit, deutlich gestreift, der Nahtstreif sogar tief, der

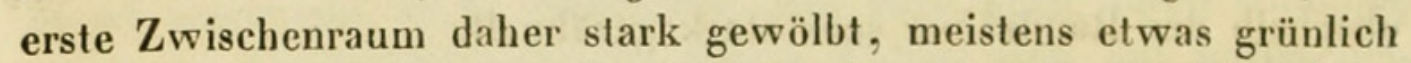
scheinend; der Schulterstreif sehr fein, aber bis über die Mitte hinaus leistenartig; die Zwischenräume besonders an den Seiten undeutlich punktirt. Das Pygidium matt, grün, äufserst fein und kaum wahrnehmbar quer nadelrissig, dabei zerstreut punklirt, die Punkte ein äufserst kurzes Börstchen tragend. Taster und Fühler rothbraun. Die Unterseite glänzend, schwarz; die Beine schwärzlich mit sehr schwachem grünlichen Metallglanz, die Spitze der Schienen und die Tarsen rothbraun; die äufsere obere Kante der Mittelschienen vor der Spitze nicht nach abwärts gebogen; die hinteren Schienen gegen das Ende unmerklich gekrümmt.

Vaterland: Cayenne.

Germar's Type, auch aus der Reich'schen Sammlung und vou Dr. Haag mitgetheilt. Diese kleine Art ist in den Sammlungen zuweilen mit C. lituratus vermengt, von dem sie sich trotz der analogen Zeichnung doch sehr leicht durch die kürzere, mehr gerundete Gestalt, den sehr deutlichen Scutellareindruck und den sehr tiefen Nahtstreifen unterscheidet. Die Färbung der Flügeldecken unterliegt ähnlichen Abänderungen wie bei $\boldsymbol{C}$. lituratus, so dafs bei dunkel gefärbten Stücken die ganzen Flügeldecken schwärzlichgrün erscheinen. Sie dürfte auf Cayenne beschränkt sein, da alle mir vorliegenden Stücke nur diese Lokalität angeben. 
61. C. lituratus Germ.: Subelongato-ovalis, postice nonnihil acuminatus, nitidulus obscure viridis vel cupreus, elylris opacis, fuscis, rufo-notatis. Caput dense punclulatum, clypeo quadridentato, dentibus mediis majoribus, a dentibus lateralibus usque ad angulum anticum genarum sinuato. Thorax dense punclatus, lateribus medio rotundato-angulatis, basi juxta angulos posticos obtusos brevissimo spatio emarginatus. Impressio scutellaris nulla. Elytra subtilissime striata, stria humerali plerumque usque ad medium dislincta, interdum obsoleta. Pygidium sericeo-opacum, medio longitudinaliter subcarinatum, obsolete punctulalum. Palpi cum antennis ferruginei. Corpus subtus cum pedibus nitidum, nigrum vel leviter subvirescens; prosterno non carinato, femoribus posticis marginatis, tibiis intermediis oblique carinatis. - Long. $2 \frac{1}{2}-3$ lin.

Ateuchus lituratus Germ. Mag. Ent. I. 1. p. 117. (1813.)

C. lituratus Perty Del. anim. p. 38. t. 8. f. 4. (1830.)

Coprob. lituratus Illig. Dej. Cat. 3 ed. p. 152.

Var. a. Elytris fuscis, basi, margine et ad apicem macula an. nuliformi rufis; macula in elyiro sinistro simulat formam numero: 6.

C. lituratus Germ., Perty, Illig.

Var. b. Nonnihil nilidior, plerumque obscure viridis, elytris rufis, fascia transversa media el postica breviore, sulura connexis, fuscis.

Var. c. Elytris fuscis, basi tantum pone humeros et callo apicali rufis.

C. quadripustulatus Guér. Verhandl. Zool. Bot. Wien. V. p. 587. (1855.)

C. quadripustulatus Dej. Cat. 3 ed. p. 152.

Var.d. Elytris fuscis, parte apicali rufa.

Var. e. Elytris rufis, callo humerali maculisque nonnullis longitudinalibus medio transversim posilis nigris.

Var. $f$. Elytris omnino fuscis, vel virescentibus, interdum totus obscure atro-coeruleus.

Ateuch. chlorophanus Hannerh. Nouv. Mem. Mosc. 1829. I. p. 38 .

C. prasinus Klug i. litt.

Von ziemlich länglich - eiförmiger Gestalt, nach hinten leicht verschmälert, etwas trüb oder mattglänzend, die Flügeldecken namentlich nur maltscheinend, schwärzlich erzfarben oder grünlich, die Flügeldecken mit sehr veränderlichen rothen Zeichnungen auf schwärzlichem Grunde. Der Kopf dicht und sehr fein punktirt, 
nach vorn etwas verlängert und zugleich verschmälert, das Kopfschild mit zwei starken, an der Basis breiten Mittelzähnen, daneben sehr deutliche Nebenzälne, deren äufsere Seite bis zum vorderen stumpfspitzen Wangenende leicht ausgebuchtet ist. Das Halsschild gewölbt, dicht und gleichmäfsig fein punktirt, in der Mitte die Spur einer glatten Längslinie, der Seitenrand in der Mitte winkelig, aber abgerundet, die Hinterecken sehr stumpf, neben ihnen die Basis auf eine ganz kurze Strecke eingedrückt und ausgebuchtet. Ein Scutellareindruck macht sich kaum bemerkbar. Die Flügeldecken minder gewölbt als das Halsschild, sehr fein aber deutlich gestreift, der Nahtstreif kaum tiefer wie die übrigen, der Humeralstreif meist bis zur Mitte deutlich, zuweilen aber auch sehwerer zu erkennen. Das Pygidium seidig-matt, schwarz, äufserst fein punktirt, der Länge nach, besonders im Basaltheile, schwach gekielt, und neben diesem Kiele im oberen Theile beiderseits etwas flach eingedrückt. Taster und Fühler röthlich. Die Unterseite sammt den Beinen glänzend, schwarz, zuweilen mit grünlichem oder bläulichem Metallscheine; das Prosternum ohne Querleisten, die hinteren Schenkel vorn gerandet, die Mittelschienen mit einer Querleiste, indem die äufsere obere Kante von der Mitte an allmählig gegen die Unterseite verläuft.

Var. a. Auf dunklen, schwarzen Flïgeldecken eine rothe Querbinde in der Wurzelgegend, welche aber die eigentliche Basis nicht berührt, dagegen am Seitenrande sich fortsetzt und an der Spitze ringförmig schliefst; auf der linken Flügeldecke betrachtet ähnelt diese Zeichnung dem Zahlzeichen: 6.

Var. $b$ Etwas gröfser, meist glänzender und feiner punktirt, das Halsschild öfters grün, die Flügeldecken roth, die Basis, eine Querbinde in der Mitte und eine kleinere vor der Spitze, beide in der Nahtgegend mit einander verbunden, schwarz; die obere Gränze des vorderen schwarzen Querflecks ist etwas bogig.

Var, c. Meist kleiner, auf den dunklen Flügeldecken ist nur ein Fleckchen unter dem Schulterbuckel und die Spitze roth.

Var. d. Die Flügeldecken sind ganz dunkel, meist etwas grünlich, mit Ausnahme der rothen Spitze.

Var. e. Die Flügeldecken ganz roth, nur die Schulterbeule und eine in Längsflecke aufgelöste Querbinde in der Mitle schwarz.

Var. $f$. Ganz dunkel gefärbt, zuweilen dunkel violett, oder grünlich.

Vaterland: Von Columbien über Brasilien und Buenos Aires bis nach Patagonien verbreitet; auch auf den Antillen. 
In grofser Anzahl von vielen Seiten mitgetheilt. Eine weitverbreitete und daher auch sehr veränderliche Art, die aber in allen Kleidern und Gröfsenverhältnissen leicht an der Querleiste der mittleren Schienen zu erkennen bleibt, bei denen die äufsere obere Kante von der Mitte an schief gegen den unteren Enddorn sich wendet, ein Verhältnifs, welches bei keinem andern Canthon sich wiederfindet. Ich habe natürlich nicht alle mir vorliegenden Färbungsunterschiede aufführen können, sondern mich darauf beschränkt, die auffallendern oder häufiger vorkommenden hervorzuheben. Hierüber und über die geographische Verbreitung der einzelnen Varietäten habe ich noch folgendes zu bemerken. Die Var. a, der typische $C$. liturutus Germ., scheint auf das eigentliche Brasilien beschränkt zu sein, während die Var. $b$. mehr in Columbien zu Hause ist, von wo sie Dr. Moritz Wagner in Mehrzahl mitbrachte. Auch die Var. c (C. 4 pustulatus Guér. Dej.) gehört den nördlicheren Gegenden an, während mir von Var, $d$ und $f$ nur Stücke aus Buenos-Aires vorliegen. Höchstens bei flüchtiger Betrachtung könnte C. cinctellus mit der gegenwärtigen Art verwechselt werden; derselbe ist aber mehr gerundet-eiförmig, hat einen sehr markirten Scutellareindruck, merklich vertieften Nahtstreif und bildet der Seitenrand des Kopfschildes zwisehen den Wangenenden und der Spitze des Nebenzahnes nochmals einen kleinen Vorsprung, während er bei $\boldsymbol{C}$. lituratus gerade umgekehrt ausgebuchtet ist. Der nächste, wenngleich nicht damit zu verwechselnde Verwandte des $C$. lituratus ist der C. sanguineomaculatus, der namentlich im Bau des Kopfsehildes und zuweilen auch in der Zeichnung der Flügeldecken manches analoge aufweist; er hat aber Wangenecken und keine Querleisten an den Mittelschienen.

62. C. sanguineomaculatus Blanch.: Modice convexus, abbreviato-ovatus, subnitidus, nigro-subaeneus, thoracis macula laterali elytrorumque basali et apicali obscure rufis, interdum deficientibus. Caput obsolete punctatum, fronte intra oculos leviter bituberculata, genis extus angulato-rotundatis, antice non a clypeo distinctis, hoc medio longe bidentato et utrinque iterum acute at brevius dentato. Thorax leviter punctatus, lateribus leviter rotundatis, angulis posticis rolundatis, marginatis. Elytra thorace capiteque simul sumtis breviora, parum profunde at distincte striata, indistincte punctulata. Pygidium piceum vel rufum, parum distincte punctatum. Palpi cum antennis rufo-picei. Corpus subtus cum pedibus nigrum, prosterno non carinato, femoribus posticis antice non mar- 
ginatis, tibiis posticis apicem versus minus dilatatis, anticis fortissime tridentatis. - Long. $3 \frac{3}{4}$ lin.

Tetraechma sanguineomaculata Bl anch. Voy. d'Orb. Col. p. 168 t. 10. f. 6.

Coprobius spiniceps Reiche i. litt.

Von mäfsig gewölbter, verkürzt-eiförmiger Gestalt, nur wenig glänzend, schwärzlich erzfarben, besonders der Kopf etwas grünlich, ein Fleck beiderseits am Halsschilde, einer auf den Schultern und die Spitze der Flügeldecken dunkel röthlich, zuweilen aber auch ungefleckt. Der Kopf undeutlich punktirt, die Stirn zwischen den Augen mit zwei kleinen, von einander entfernt stehenden Höckerchen, die Wangen nach aufsen eine stumpf-abgerundete Ecke bildend, nach vorn vom Kopfschilde nicht abgesetzt, dieses verflacht, mit nach vorn verengten Seitenrändern, in der Mitte zwei längere Zähne, daneben noch ein spitzer aber kürzerer Zahn. Das Halsschild gleichmälsig fein und wenig dicht punktirt, der Seitenrand nur leicht im Bogen gerundet, die Seitenrandlinie setzt sich auch noch um die abgerundeten Hinterecken forl. Kein merklicher Scutellareindruck. Die Flügeldecken kürzer als Kopf und Halsschild zusammengenommen, eben so lang als breit, deutlich aber nur seicht gestreift, der Schulterstreif nur im ersten Drittel seiner Länge fein leistenartig, dann deutlich in einen gewöhnlichen vertieften Längsstreifen übergehend; die $Z$ wischenräume undeutlich punktirt. Das Pygidium sehr seicht punktirt, schivärzlich, hie und da rothbraun. Taster und Fühler röthlichbraun. Die Unterseite sammt den Beinen schwarz, diese wenig kräftig, namentlich die hinteren Schienen gegen das Ende nur schwach erweitert, die äufsere obere Kante der mittleren vor der Spitze etwas ausgerandet, mit einigen gröfseren, aber stumpfen Zähnen; die Tarsen rothbraun, ihre einzelnen Glieder etwas schmal, das Klauenglied so lang wie die vorhergehenden drei zusammengenommen, die Vordersehienen mit drei sehr starken, weit auseinander stehenden Zähnen; das Prosternum obne Spur von Querleisten.

Vaterland: Patagonien, Bolivia.

Aus der Münchner Staatssammlung und von Hrn. Deyrolle mitgetheilt. Herr d'Orbigny hat diese Art im Monat Januar an der Bucht von San-Blas in Palagonien aufgefunden. Der verlängerte und dabei zugleich nach vorn verschmälerte Kopf giebt ihr ein eigenthümliches, fast an einige Megal hopa-Arten, z. B. puncticollis B l a nch. erinnerndes Aussehen, die Aufstellung einer besonderen Gattung rechtfertigt sich aber durchaus nicht, da diese Kopfbildung durch 
jene des C. liluratus vollständig mit der normalen der übrigen Canthon-Arten vermittelt wird.

63. C. laevis Drury: Hujus generis maximus, sat convexus, vix nitidus, granulalus, niger, leviter cuprascens. Caput clypeo obtuse bidentato, oculis angustalis. Thorax lateribus medio obtuse rotundato-angulatis. Impressio scutellaris nulla. Elytra minus profunde, at dislincte striata. Pygidium opacum leviter convexum. Palpi cum antennis picei, his fusco-cinereo clavatis. Corpus sublus cum pedibus nigrum, subnitidum; prosterno absque carinis, margine dentato; femoribus posticis antice marginatis. - Long. 6 $10 \mathrm{lin}$.

Mas. Parum differt a femina, pygidio autem longiore, apice magis convexo, tibiarumque anticarum calcari apice bifido, non simplici ut in illa.

Scarab. laevis Drury. Exot. Ins. I. p. 79. t. 35. f. 7. - Oliv. Ent. 1. 3. p. 160. t. 10. f. 89.

Scarab, pilularius Deg. Mém. Ins IV. p. 311. t. 18. f. 14.

Ateuch. volvens Fabr. Syst. El. I. p. 60.

C. volvens Cast. Hist. Nat. II. p. 68.

Var.: Cupreus vel virescens.

C. chalcites Dej. Cat. 3 ed. p. 151.

C. viridescens Le c. i. litt.

Var.: Obsoletius granulatus.

C. chalcites Haldem. Proc. Ac. Phil. I. p. 304.

Var.: Clypeo minus distincte dentalo.

C. obtusidens Ziegl. Proc. Ac. Phil. II. p. 45.

Die gröfste Art dieser Gattung, ziemlich stark gewölbt, nur matt glänzend, schwarz, jedoch immer mit mebr oder weniger deutlicher Kupferfärbung, auf der ganzen Oberseite dicht und fein gekörnelt, auf Kopf und Halsschild die Körner meist noch feiner. Das Kopfschild in der Mitte mit zwei stumpfen Zähnen, das vordere Wangenende abgerundet. Das Halsschild mit in der Mitte abgerundet eckigem Seitenrande, der vordere Abschnitt gleichmäfsig sehr schwach gewölbt, vor der Mitte aber mit einem deutlichen Randzähnchen. Kein Scutellareindruck. Die Flügeldecken sehr wenig tief, aber doch recht deutlich gestreift. Das Pygidium matt, gleichmäfsig gewölbt. Taster und Fühler schwarzbraun, die Keule dunkelgrau behaart. Die Unterseite sammt den Beinen immer schwarz, mälsig glänzend; das Prosternum ohne Querleisten, die Hinterschenkel vorn gerandet, die hinteren Schienen vor dem Ende leicht eingeschnürt.

Das Männchen unterscheidet sich durch längeres, an der Spitze 
mehr gewölbtes Pygidinm, und durch breiteren, am Ende zweizahnigen Enddorn der Vorderschienen, welcher beim Weibchen einfach und allmählig zugespitzt ist.

Vaterland: Die vereiniglen Staaten Nordamerikas, südlich bis in's nördliche Mexiko verbreitet.

Die häufigste und am längsten bekaunte Art dieser Gattung, immer leicht kenntlich an der feinen Körnelung der ganzen Oberfläche, die jedoch, und zwar unabhängig von der Gröfse des Thieres, sich oft theilweise oder auch ganz, sehr abschwächen kann. Auf gröfsere Stücke, bei denen die Flügeldecken nur mehr fein, Kopf, Halsschild und Pygidium aber fast gar nicht mehr gekörnelt, sondern eher dicht gerunzelt erscheinen, ist $\boldsymbol{C}$. chalciles $\mathrm{Hald}$. gegründet. Kleinere Stücke, wie sie mir aus dem nördlichen Mexiko vorliegen, meist als $\boldsymbol{C}$. lugens $\mathrm{Ch}$ evr. bestimmt, erinnern, wenn die Körnelung bei ihnen sich sehr abschwächt, sehr an $C$. gagatinus, unterscheiden sich aber sofort durch den Mangel der Querleisten am Prosternum. Wie in der Sculptur so kommen auch in der Färbung Abänderungen vor: schön kupfrig röthliche Stücke benannte Dejean in seiner Sammlung $\boldsymbol{C}$. chalcites; aufserdem ist es aber meist ein mehr oder weniger intensiver grünlicher Erzglanz, welcher sich besonders auf dem Halsschilde bemerklich macht. Die Geschlechtsunterschiede fallen wenig in die Augen, bei ganz rein erhaltenen Stücken ist der Enddorn des männlichen Vorderfufses sehr deutlich am Ende in einen gröfseren äufseren und in einen kleineren inneren $Z$ ahn getheilt.

Trotzdem diese Art soweit verbreitet und sicher eine der häufigsten ist, ermangeln wir doch jedweger Mittheilung über ihre Lebensweise; die Larve wurde indefs von Herrn Candèze in den Mém. Liège XVI. 1861 p. 345 . t. 2. f. 2 . beschrieben und abgebildet.

C. vigilans Lec.: Simillimus omnino praecedenti, at oculis non angustatis, sed majoribus, ovalibus antennisque non piceis sed rufis distinguendus. Niger, subopacus, subtiliter dense granulatus. - Long. $7 \frac{1}{2}-9$ lin.

C. vigilans Lec. Journ. Ac. Phil. IV. 1858, p. 16.

Vaterland: Texas.

Eine ausführliche Beschreibung dieser Art ist unnöthig, da sie in Allem mit C. laevis vollkommen übereinstimmt, nur ist das Fühlhorn nicht schwarzbraun, sondern roth und sind die Augen um Vieles, mehr als um die Hälfte, gröfser wie bei der genannten Art. Dieser Unterschied ist kein relativer, sondern es hat das Auge des 
C. vigilans zugleich eine andere Gestalt; bei ihm ist dasselbe nämlich fast rein eiförmig, indem sowohl die innere wie die äufsere Gränzlinie Bogenlinien sind: bei $C$. laevis stellt das Auge immer ein der Länge nach halbirtes Oval dar, indem nur die äufsere Gränzlinie gerundet, die innere dagegen geradlinig ist, so dafs das vordere Ende des Anges zugleich spitz sich gestaltet, während es bei C. vigilans auch vorn abgerundet ist. Weitere Unterschiede vermag ich nicht aufzufinden; der Seitenrand des Halsschildes scheint mir in seinem vorderen Abschnitte etwas minder gleichmäfsig flachgewölbt zu sein, indem der Theil hinter dem Randzahne etwas selbstständiger als Bogen gewölbt erscheint, auch ist die Naht in der oberen Hälfte leicht eingedrückt; diese Unterschiede sind aber sehr unmerklich und dürften, sowic die rein mattschwarze, etwas seidig scheinende Färbung, welche wenigstens alle meine Exemplare zeigen, von keinem Belang sein. C. vigilans ist in den Sammlungen regelmäfsig mit der vorhergehenden Art vermengt, von der er sich in der That nur bei näherer Betrachtung uulerscheiden lälst.

65. C.fractipes: Subdilatato-ovalis, convexus, leviter nilidus, niger, capite thoraceque obsolete subcuprascentibus. Caput leviter convexum, clypeo bidentato. Thorax sparsim punctatus lateribus medio valde roturdalis. Elylra obsolete striata, interstitiis subseriatim. parce punctatis, ad basin leviter convexis. Pygidium subconvexum, punctis nonnullis raris. Palpi cum antennis picei. Corpus subtus leviter nilidum, cum pedibus nigrum; metasterno antice subtumidulo, prosterno absque carinis; femoribus posticis non marginatis, tibiis intermediis et posticis versus apicem profunde emarginatis. - Long. 4 lin.

Coprob. Reichei Guérin i. litt.

Von ziemlich gerundeter und gewölbter Gestalt, mäfsig glänzend, schwarz, Kopf und Halsschild mit schwachem Kupferscheine. Der Kopf leicht gewölbt, undeutlich und nur sehr seicht narbig, das Kopfschild vorn mit zwei einander wenig genäherten Zähnen, die Wangen nach vorn vom Kopfschilde nicht abgesetzt. Kein Scutellareindruck. Das Halsschild gewölbt, zerstreut punktirt, der Seitenrand in der Mitte stark gerundet, die Hinterecken abgerundet. Die Flügeldecken gewölbt und gerundet, seicht gestreift, die Zwischenräume mit eingestochenen, zerstreuten und theilweise in eine Reihe geordneten Pünktchen besetzt, die Basalgegend des Iten, 3ten und 5ten leicht gewölbt. Das Pygidium flachgewölbt, weitläufig 
punktirt. Taster und Fühler dunkel pechbraun. Die Unterseite leicht glänzend, sammt den Beinen schwarz; die Hinterbrust vorn in der Mitte sehr stumpf-beulig; das Prosternum ohne Querkanten; die hinleren Schenkel ohne Randlinie, vorn aber und zum Theil auch hinten, wenigstens an der Wurzel, mit Wimperhaaren besetzt; die Vorderschienen mit drei, in gleicher Entfernung stehenden und einander wenig genäherten Randzähnen; die hioteren Schienen, noch mehr aber die mittleren, vor der Spitze sebr tief ausgebuchtet.

Vaterland: Patagonien, das südliche Gebiet des argentinischen Freistaats.

Aụs der Münchner Staatssammlung und von Hrn. Strobel mitgebracht. Dem Fufsbau nach ein Coeloscelis, in der übrigen Sculptur aber von den typischen Arten der Gattung in nichts verschieden. Die Art würde am besten neben C. Lacordairei, rugosus u. s. w. zu stellen sein, da es aber unmöglich ist in der Ausrandung der Schienen eine Gränze zu bestimmen, so wird sie in der synoptischen Tabelle durch ihre nicht gehöckerten Flügeldecken weit von denselben entfernt.

66. C. gagatinus Har.: Ovalis vel subabbreviato-ovalis, convexus, nilidus vel subnitidus, ater vel atro-violaceus. Caput antice subtilissime rugosulum, clypeo obtuse bidentalo. Thorax laevis vel lateribus tantum subtilissime punctatus, medio utrinque obtuse angulatus, basi ad humeros subemarginata. Impressio scutellaris fere nulla. Elytra subquadrata, lateribus leviter rotundatis, obsoletissime striata. Pygidium laeve, opacum. Palpi cum antennis picei. Corpus subtus cum pedibus nitidulum, atrum, leviter aenescens; prosterno transversim carinato et dentato; femoribus posticis antice marginatis, postice a basi usque ad medium fere ciliatis; tibiis anticis apice vix oblique truncatis. - Long. 6-8 lin.

Mas. Pygidium valde convexum, tibiarum anticarum calcar apicalis dilatatus, apice late emarginatus.

Fem. Pygidium leviter convexum, calcar apicalis acuminalus, extus directus.

C. gagatinus Harold. Ann. Soc. Ent. France 1863. p. 173.

Var: Omnino ater, opacus.

Coprob. lugens Chevrol. Dej. Cat. 3 ed. p. 151.

C. carbonarius $\mathrm{K} l \mathrm{~g}$ i. litt.

Var: Atro-coeruleus, magis nitidus.

C. amethystinus Har. Ann. Soc. Ent. France 1863. p. 173. 
Coprob. amelhystinus Klug i. litt.

Ateuch. humectus Say i. litt.

Coprob. venustus Sturm Cat. 1843. p. 104.

Var: Obscure glauco-viridis.

C. gagatinus Reiche i. litt.

In der Körpergestalt dem C. laevis nicht unähnlich, aber gewölbter und kürzer, glatt, nur wenig glänzend, meist mattscheinend, von dunkler, in der Regel schwärzlich violetter Färbung, zuweilen aber auch ganz schwarz. Der Kopf glatt, vorn deutlich, aber äufserst fein gerunzelt, das Kopfschild mit zwei stumpfen, an der Basis breiten Zähnen. Das Halsschild glatt oder höchstens an den Seiten mit feiner Punktirung, der Seitenrand in der Mitte abgerundet eckig, nach hinten leicht gekrümmt, nach vorn einen schwachen Bogen bildend mit einem unteren Randzähnchen; die Basis neben den Hinterecken den Schultern gegenüber nur leicht ausgebuchtet. Ein eigentlicher Scutellareindruck ist nicht zu bemerken, doch ist die Naht in der Schildchengegend etwas vertieft. Die Flügeldecken fast etwas breiter als lang, mit gerundeten Seiten, ihre grölste Breite in der Mitte, schwach und kaum wahrnehmbar gestreift. Das Pygidium glatt, seidig matt. Die Uuterseiłe sammt den Beinen ebenso glänzend wie die obere und auch ebenso gefärbt, nur etwas schwärzlicher; die Taster und Fühler pechschwarz, letztere mit dunkelgrau behaarter Keule; das Prosternum mit starken Querleisten; die hinteren Schenkel vorn gerandet, hinten von der Trochanterenspilze an bis etwas über die Mitte schwarz gewimpert; die Vorderschienen am Ende fast meifselförmig abgestutzt, die beiden untersten Randzähne einander unmerklich genähert.

Bei dem Mä n nchen ist der Enddorn der Vorderschienen breit. am Ende leicht zweizahnig, dureh Abnutzung aber meist löffelartig gerundet; das Pygidium ist in der Mitte stark gewölbt.

Bei dem Weibchen ist der Enddorn schmal zugespitzt und mit der Spitze nach aufsen gerichtet; das Pygidium ist gleichmäfsig leicht gewölbt.

Var. Einfarbig tief schwarz, sehr matt glänzend, auch die Unterseite düster.

Var. Dunkel stahlblau oder violett, meist glänzender, zuweilen ziemlich stark glänzend, dann auch das Halsschild an den Seiten leicht punktirt.

Var. Grünlichblau, die Unterseite schwärzlichgrün, wie die obere nur wenig glänzend.

Vaterland: Mexiko. 
In den Sammlungen unter den angegebenen Namen häufig verbreitet. Eine grofse Reihe von Exemplaren, die ich vor mir habe. läfst mich in denselben mit Bestimmtheit nur eine in Glanz und Färbung zwar ziemlich veränderliche, immer aber durch die Bewimperung der Hinterschenkel leicht kenntliche Art erkennen, für die ich den Namen gagatinus als den passenderen beibehalte, obwohl die Var. amethystinus, die ich früher als eigene Art beschrieben, die gewöhnlichere Form zu sein scheint. Der Unterschied in der Gestalt der Vorderschienen, der mich a. a. O. zur Trennung von C. amethystinus und gagatinus veranlafste, ist nur scheinbar und durch Abnützung bedingt, indem der untersle Zahn bei rein erhaltenen Stücken mit dem Vorderrande doch einen kleinen Bogen beschreibt, wodurch das Schienenende mehr schief abgeschnitten sich darstellt. Ob diese Varietälen an bestimmte Localitäten gebunden sind, vermag ich bei der sehr allgemeinen Vaterlandsangabe: Mexiko, der meisten meiner Exemplare nicht anzugeben. Herr Sallé jedoch, der eine grofse Anzahl dieser Thiere unter genauer Bezeichnung des Fundortes aus Mexiko mitbrachte, bemerkte mir, dafs die blane Form (C. amethystinus) im Monate Mai von ihm auf dem Orizaba, die grünliche dagegen (C. gagatinus Reiche) von Boucard im November bei Parada in der Gegend von Oaxaca auf Kolh gesammelt worden. Die schwarze Form (C. lugens) scheint mehr dem Süden anzugehören; wo die Wimpernhaare am Hinterrande der Schenkel abgenutzt sind, könnten solche Stücke allenfalls mit den schwarzgefärbten des C. tristis verwechselt werden; dieser hat aber kantig abgesetzte, breite und flache Epipleuren, aufserdem noch ein viel flacheres Pygidium.

67. C. angularis: Subquadrato-ovatus, depressiusculus, laevis, nitidissimus, viridi-chalybeus. Caput omnino laeve, vertice medio obsolete tumidulo. Thorax lateribus medio rolundato-angulatis, versus basin subrectis, antice sinuatis; angulis posticis obtuse prominulis. Impressio scutellaris parum distincta. Elytra latitudine fere aequaliter longa, obsoletissime punctulato-striata. Pygidium opacum, laeve, planiusculum. Palpi cum antennis picei. Corpus subtus minus nitidum, cum pedibus atro-cyaneum; prosterno transversim carinato, metasterno antice arcuatim linealo; femoribus anticis ad apicem antice non emarginalis, tibiis anticis margine interiore leviter sinuato. - Long. $4 \frac{1}{4}-5$ lin.

Mas. Differt a femina calcari apicali tibiarum anticarum dilatato. apice oblique truncato, subbifido; pygidio apice magis inflexo. abdomine minus globoso. 
Fem. Tibiarum anticarum calcari acuminato apice extus directo; pygidio latiore, abdomine globose-convexo.

Coprob. subdepressus Sturm Cat. 1843. p. 104.

C. nigricornis Klug i. litt.

C. azurescens Germ. i. litt.

Von quadratisch-gerundeter Gestalt, nur wenig gewölbt, sehr blank glänzend, dunkel stalilblau mit etwas Beimischung von Grün. Der Kopf ganz glatt, auch vorn nicht runzlig punktirt, die Mitte des Scheitels unmerklich zu einer schwachen Beule erhöht. Das Halsschild hinten ziemlich flach, nach vorn abschüssig gewölbt, der Seitenrand in der Mitte sehr scharf gerundet, aber doch keine Ecke bildend, von da bis zu den zipfelig vortretenden Hinterecken nur sebr wenig mebr gerundet oder nach hinten schief gerichtet, daher bei Ausicht von oben gerade und parallel verlaufend; gegen die Vorderecken ist derselbe leicht in die Höhe gewölbt und etwas geschwungen, so dafs die Vorderecken scharf zugespitzt erscheinen. Ein Scutellareindruck ist zwar vorhanden, derselbe ist aber sehr flach. Die Flügeldecken ebenso lang als zusammen breit, etwas vor der Mitte am breitesten, äufserst fein gestreift, die Streifen aber doch kenntlich punktirt; der Nahtstreif nicht deutlicher wie die übrigen, zuweilen aber auch gar kein Streif erkennbar; an den Seiten erscheinen zuweilen unregelmäfsige, höchst unmerkliche Querfältchen. Das Pygidium sehr leicht gewölbt, matt. Taster und Fühler schwarzbraun, die Keule der letzteren dunkelgrau behaart. Die Unterseite viel schwächer als die obere glänzend, sammt den Beinen dunkel stahlblau; das Prosternum mit starken Querleisten, vor denselben vertieft, das Metasternum hinter der vordern Gränze mit einer Bogenlinie; die Vorderschenkel vorn gegen das Ende nicht ausgerandet; die Vorderschienen am Innenrande nur sehr unmerklich etwas vor der Mitte ausgebuchtet, die hinteren Tarsen zuweilen stahlgrün.

Das Männchen unterscheidet sich im Ganzen nur sehr wenig von dem Weibchen, der Enddorn der Vorderschienen ist aber breit, vorn schief abgestutzt und leicht zweispitzig, das Pygidium ist mit der Spilze etwas mehr gegen die Bauchfläche gebogen, der Bauch selbst minder kugelig gewölbt.

Vaterland: Brasilien.

Aus der Reich'schen Sammlung, auch von Dr. Haag mitgetheilt. Von den sehr nahverwandten folgenden Arten durch die glänzende polirte Oberfläche, die innen nicht gezahnten Vorderscbienen und 
die vor dem Ende neben der Gelenkstelle nicht ausgeraudeten Vorderschenkel leicht zu unterseheiden.

68. C. opacus Bohem.: Ovalis, sat convexus, niger, leviler subcuprascens, omnino sericeo-opacus, thorace maculis oblongis, sericantibus. Caput laeve, clypeo medio bidentato. Thorax lateribus tenuiter marginatis, medio rolundaitis, postice fere rectis, antice leviter tanlum arcuatis. Inpressio scutellaris nulla. Elytra obsoletissime substriala. Pygidium opacum, leviler subconvexum. Palpi cum antennis picei. Corpus sublus sat nitidum, cum pedibus nigrum; prosterno transversim tenuiter, at distincte carinato. - Long. $2 \frac{1}{2}-$ $3 \frac{1}{2}$ lin.

Mas. Tibiae anticae calcari apicali apice bifido; femoribus intermediis margine postico ad basin leviler sinuala; tibiis posticis jam ante medium incrassatis.

Fem. Tibiae anticae calcari apicali simplici; femorilus intermediis non emarginatis, tibiis posticis sensim et parum a basi apicem versus dilatatis.

C. opacus Bohem. Res. Eugen. 1858. p. 40.

C. velutinus Harold i. litt.

Von eiförmiger, elwas breiter Gestalt, ziemlich stark gewölbt, schwarz, Kopf und Halsschild zuweilen etwas kupfrig, ganz mattglänzend und seidenartig, das Halsschild mit seidigen, länglichen Flecken marmorirt. Der Kopf glatt, der Vorderrand in der Mitle zweizahnig, das vordere Wangenende abgerundet. Das Halsschild an den Seiten sehr fein gerandet, der Seitenrand in der Mitte gerundet, nach hinten gerade, nach vorn nur schwach gewölbt, ohne Randzahn, auch die Vorderecken nur wenig spitz. Ein Scutellareindruck macht sich nicht bemerklich. Die Flügeldecken kurz vor der Mitte am breitesten, höchst undeutlich gestreift, etwas uneben, der 3te und 5te $\mathrm{Z}$ wischenraum an der Basis in der Mitte sehr deutlich gehöckert. Das Pygidium malt, nur wenig gewölbt. Die Taster und Fühler schwärzlich. Die Unterseite sammt den Beinen schwarz und ziemlich glänzend. die Behaarung der Vorderschenkel und die Borsten der Trochanteren gelblich; die Brustseiten äufserst fein, aber deutlich netzartig gerunzelt, der letzte Hinterleibsring von dem vorhergehenden durch eine etwas tiefere Querlinie getrennt; das Prosternum mit feinen, aber deutlichen Querkanten.

Bei dem Männchen ist der Enddorn der Vorderschienen zwar wenig breit, am Ende aber sehr deutlich in zwei Spitzen gespalten; die hintern Schenkel sind unten leicht ausgerandet, so dafs am Ende 
der Trochanterenspitze ein stumpfer Winkel entsteht; die Schienen, besonders aber die des hintersten Paares sind schon weit vor der Mitte wadenartig verdickt.

Bei dem Wëibchen ist der Enddorn der Vorderschienen schmal und allmählig zugespitzt; die hintern Schenkel sind nicht ausgebuchtet und auch die Schienen nicht wadenartig verdickt, sondern allmählig und nur schwach gegen das Ende erweitert.

Vaterland: Die Pampas der argentinischen Republik.

Von Herrn Tarnier erstanden und von Herrn Deyrolle mitgetheilt; Herr Pr. Strobel fand ihn zwischen Mendoza und San Luis. Auch habe ich durch die höchst freundliche Vermittelung des Herrn Stål das typische Boheman'sche Exemplar vor mir. welches ein wahrscheinlich in Weingeist verdorbenes Stück dieser Art ist, daher in der Beschreibung die sammetarligen Fleckchen des Thorax nicht erwähnt sind. Dieselbe ist mir erst während des Druckes zugekommen und steht sie daher in der synoptischen Tabelle als velutinus verzeichnet, unter welchem Namen ich sie auch früher mehreren Bekannten mittheilte.

69. C. corpulentus: Rotundalo-ovatus, crassus, convexus, nitidus, elytris subnilidis, alro-cyaneus vel obscure viridis. Caput laeve, genis antice obtusis. Thorax laevis, lateribus postice rectis, medio obtuse angulatis, antice leviter arcualis et pone medium dentatis. Impressio scutellaris obsoleta. Elytra striis vix discernendis. Pygidium opacum. Palpi cum antennis picei. Corpus subtus cum pedibus nitidulum, concolor; prosterno carinato, tibiis anticis ante medium obtusissime angulatis, femoribus anticis margine antico medio obsolete subdenticulato. - Long. $5 \frac{1}{2}-6$ lin.

Von breiter, plumper, verkürzt-eiförmiger Gestalt, stark gewölbt, glatt, glänzend, die Flügeldecken nur mäfsig glänzend, sehr dunkel scliwarzblau oder grün, mit etwas röthlichem Goldglanz. Der Kopf glatt, höchstens der äufserste Vorderrand sehr fein runzlig, die vorderen Wangenenden stumpf abgerundet. Das Halsschild sehr stark gewölbt, hinten der Länge nach leicht*eingedrückt, der Seitenrand hinten gerade, in der Mitte eckig, vorn in einem sehr kurzen Bogen gewölbt, dann wieder gerade, hinter der Mitle gezahnt; die Basis neben den Hinterecken ausgebuchtet, diese daher lappig abgeselzt. Ein Scutellareindruck macht sich nur schwach im Wurzeltheile der Naht bemerklich. Die Flügeldecken etwas vor der Mitte am breitesten, kaum erkennbar gestreift. Das Py. gidium mattglänzend, glatt, leicht gewölbt. Taster und Fühler 
schwärzlich. Die Unterseite sammt den Beinen mäfsig glänzend, ebenso gefärbt wie die obere; das Prosternum mit Querkanten, auch der vordere Abschnitt theilweise noch gewölbt; die vordern Schenkel in der Mitte mit einem sehr stumpfen, zuweilen undeutlichen Zähnchen; die Vorderschienen innen kurz vor der Mitte einen sehr stumpfen Winkel bildend.

Vaterland: Brasilien.

Diese Art ist durch ihre breite und plumpe Gestalt sofort erkenntlich; am nächsten schliefst sie sich in der Gestalt des Halsschildes, dessen Seitenränder in der hintern Hälfte ebenfalls parallel laufen, an C. angularis an; dieser ist aber viel glänzender und auf dem Rücken entschieden flachgedrückt. Die Färbung scheint auch bei dieser Art etwas unbeständig; im Berliner Museum befindet sich ein sehr kleines Exemplar mit lebhaft grünglänzendem Halsschilde und röthlich gelbbraunen Flügeldecken, die nur einen schwachen grünlichen Schein haben.

70. C. coeruleicollis Blanch.: Rotundalo-ovalis, leviler convexus, subnitidus, capite thoraceque nigro-cyaneis, elytris obscure ferrugineis. Caput laeve, margine antico leviter viridi-aeneo, clypeo bidentato. Thorax laevis, lateribus nonnihil pone medium rotundatoangulatis, antice valde arcuatis et dentatis. Impressio scutellaris fere nulla. Elytra absque striis distinctis. Pygidium leviter convexum, subsericeum, obscure atro-cyaneum. Palpi cum antennis obscure rufo-picei, his cinereo-clavalis. Corpus subtus cum pedibus nitidulum, cyaneo-nigrum; prosterno carinato, femoribus posticis tenuiter marginalis, tibiis anticis apice truncatis, tarsis obscure rufis. - Long. 3 lin.

C. coeruleicollis Blanch. Voy. d'Orb. Col. p. 165.

Von ziemlich kurz eiförmiger Gestalt, mäfsig gewölbt, nur leicht glänzend, namentlich die Flügeldecken trüb, diese rothbraun, Kopf und Halsschild schwarzblan, Kopfschild mit zwei Zähnen, das Wangenende eckig. Das Halsschild glatt, der Seitenrand etwas hinter der Mitte stark gebogen, aber kein scharfes Eck bildend, nach vorn stark gewölbt, in der Mitte ein starkes Randzähnchen. Der Scutellareindruck nur sehr unmerklich. Die Flïgeldecken ohne deutliche Streifen. Das Pygidium seidig mattglänzend, ohne Punktirung, leicht gewölbt, schwarz, mit sehr schwachem bläulichen Scheine. Die Unterseite leicht glänzend, sammt den Beinen schwarz; das Prosternum mit Querkanten; die hinteren Schenkel mit sehr feiner Randlinie, die Vordersehienen am Ende gerade abgestulzt, die bei- 
den untersten Randzähne einander genähert; die Tarsen dunkelroth.

\section{Vaterland: Montevideo.}

Von Herrn Tarnier mitgetheilt. In der Gestalt erinnert die Art etwas an die gröfsten Stücke des C. viridis, sie ist aber noch um ein merkliches gröfser, die Flügeldecken sind breiter und die Vorderschienen am Innenrande nicht eckig erweitert.

71. C. rutilans Cast.: Abbreviato-ovalis, latiusculus, subnitidus, elytris leviter opacis, purpureus. Caput laeve, genis antice subangulatis. Thorax valde convexus, lateribus nonnihil pone medium subangulatim rotundatis, antice leviter arcuatis medioque dentatis. Impressio scutellaris distincta, thoracis basin non aggrediens. Elytra leviter subconvexa, obsoletissime striata. Pygidium leviter convexum. Palpi cum antennis picei, his cinereo-clavatis. Corpus subtus cum pedibus nitidulum, obscure atro-cyaneum; femoribus anticis margine antico ad apicem emarginato et denticulato, tibiis anticis intus ad basin obtuse dentatis; prosterno transversim carinato. - Long. 4-4 $\frac{1}{2}$ lin.

F e m. Differt tibiarum anticarum calcari apicali simplici acuminato, apice non bifido.

C. rutilans C a st. Hist. nat. II. p. 69. (1840).

Coprobius rutilans Klug Dej. Cat. 3 ed. p. 152.

$\mathrm{V}$ ar. Thorace nitido, atro-cyaneus et nonnihil virescens.

Coprob. cyanescens Dej. Cat. 3 ed, p. 152.

C. azureus Klug i. litt.

Von ziemlich breiter, gerundet eiförmiger Gestalt, glatt, etwas trüb glänzend, die Flügeldecken noch etwas matter, dunkel purpurfarben. Der Kopf glatt, der Aufsenrand in der Mitte zweizahnig, das vordere Wangenende eckig. Das Halsschild stark gewölbt, der Seitenrand etwas hinter der Mitte stumpfwinkelig gerundet, nach vorn leicht gewölbt nnd in der Mitte gezahnt; der Hinterrand neben den Hinterecken etwas ausgebuchtet, diese daher etwas dornartig, aber nicht abstehend wie bei $\boldsymbol{C}$. angularis, sondern dem Leibe angeschlossen. Ein Scutellareindruck ist nur am Wurzeltheile der Naht bemerklich. Die Flügeldecken kaum so lang als zusammen breit, nur leicht gewölbt, äufserst schwach gestreift, in den Streifen feine Pünktchen erkennbar. Das Pygidium leicht gewölbt. Taster und Fühler schwarz, letztere mit graubehaarter Keule. Die Unterseite sammt den Beinen leicht glänzend, bläulich-schwarz; das Prosternum mit Querkanten; die Vorderschenkel vorn am Ende 
ausgebuchtet, der ausgeschnittene Theil mit 5 bis 6 Zähnchen besetzt; die Vorderschienen am inneren Rande bald unter den Knieen hackig gezahnt, dann noch einmal vor der Mitte sehr stumpfwinkelig erweitert.

Das Weibchen unterscheidet sich nur durch einfachen, an der Spitze nicht zweizahnigen Enddorn der Vorderschienen und etwas breiteres Pygidium.

Var. Das Halsschild glänzend, die ganze Oberseite dunkel stahlblau, mit etwas grünlichem Scheine, besonders auf dem Thorax.

Vaterland: Brasilien, südlich bis nach Buenos Aires verbreitet.

Diese schöne Art scheint nicht selten zu sein und habe ich eine grofse Reihe derselben vor mir. Die blauen Stücke (C. cyanescens Dej.) vermag ich durehaus nicht von den rothen zu unterscheiden, höchstens dafs die Ausschnittstelle der Vorderschenkel bei denselben elwas undeutlicher gezahnt erscheint als bei der Mehrzahl der typischen Exemplare. Uebergänge in der Farbe sind mir allerdings nicht vorgekommen, doch ist das Halsschild bei einigen Stücken des C. rutilans schon minder mattglänzend, auch sind die Flügeldecken bald röthlicher bald dunkler gefärbt. Nähere Fundorte vermag ich bei der immer noch üblichen und doch so vagen Angabe: Brasilien, welche die Mehrzahl meiner Stücke aufweist, nicht anzugeben. Die blaue Varietät (ich habe Exemplare aus St. Catharina, Parà und Porto Allegro vor mir) scheint mehr auf das eigentliche Brasilien beschränkt, während die rothe Form sicher auch noch in Buenos Aires auftritt.

72. C. latipes Blanch.: Quoad staturam C. rutilanti simillimus, nitidus, elytris opacis, nigro-violaceus, elyiris nigris. Caput antice rugosulum, genis antice distinctis, at rotundatis. Thorax convexus laevis, lateribus medio rotundato-angulatis, postice arcuatis, antice arcualis et ante medium dentatis. Elytra obsoletissime striala. Pygidium opacum, nigrum. Palpi cum antennis picei. Corpus subtus cum pedibus nilidulum, nigrum; femoribus anticis versus apicem emarginatis, at vix denticulatis; tibiis anticis intus ad basin dentalis et iterum ante medium obluse dilatatis. - Long. $4 \frac{1}{2}-5 \frac{1}{2}$ lin.

C. latipes Blanch. Voy. d'Orbigny. Col. p. 161. (1843).

Ganz wie C: rutilans gebaut, doch die Flügeldecken etwas breiter, diese mattglänzend und schwarz, Kopf und Halsschild lebhafter glänzend, schwärzlich violett. Der Kopf glatt, nur gegen den Aufsenrand hin fein runzlig, das vordere Wangenende etwas 
vortrelend aber abgerundet. Das Halsschild ebenso gewölbt wie bei $\boldsymbol{C}$. rutilans, der Seitenrand aber viel S förmiger, in der Mitte stark und fast eckig gerundet; vorn bis zu den Vorderecken bogig geschwungen und etwas vor der Mitte gezahnt. Der Scutellareindruck schwächer als bei $\boldsymbol{C}$. rutilans. Die Flügeldecken äufserst schwach gestreift, der Schulterbuckel etwas glänzend, die gröfste Breite in der Mitte. Das Pygidium schwarz, matt, gleichmälsig leicht gewölbt. Taster und Fühler schwarz. Die Unterseite sammt den Beinen mälsig glänzend und schwarz, der Hinterleib und die Brustseiten äufserst fein netzartig gerunzelt; das Prosternum mit Querkanten; die Vorderschenkel vor den Knieen tief ausgebuchtet, so dafs das Ende der Vorderkante zahnartig sich abhebt; die Ausbuchtung selbst ohne deutliche Zähnchen; die Vorderschienen wie bei $C$. rutilans am Innenrande unten gezahnt und vor der Mitte schwach stumpfwinkelig erweitert.

Vaterland: Montevideo, La Platagebiet.

Von den Herren Tarnier und Deyrolle mitgetheilt. Auf den ersten Anblick sieht die Art einem sehr dunkel gefärbten C. rutilans täuschend ähnlich; sie entfernt sich aber durch die viel merklicher ausgebuchteten, dabei aber ungezähnelten Vorderschenkel und den viel mehr geschwungenen Seitenrand des Halsschildes, bei dessen vorderem Theile das Randzähnchen vor der Mitte angebracht ist. Blanchard vergleicht a. a. O. die Art mit C. speculifer, der durchaus nichts damit gemein hat; von Herrn d'Orbigny wurde sie im Monat Dezember bei Montevideo an der Meeresküste aufgefunden. Von dem in der Färbung sehr nahe stehenden $\boldsymbol{C}$. janthinus entfernt sie sich sogleich durch den Mangel des Schulterstreifen.

73. C. juvencus: Parvulus, hirsutulus, rotundatus, sat convexus, nitidus, ater, leviter cyanescens. Caput remote, at fortiter punctatum, antice leviler angustatum, acute bidentalum, genis antice acutiusculis. Thorax parce at fortiter punctatus, lateribus medio acute angulatis, antice arcuatis, dentalis. Impressio scutellaris distincla. Elytra subseriatim profunde punctata. Pygidium opacum, laeve. Palpi cum antennis rufo-picei. Corpus subtus nigrum, pedibus rufo-piceis; prosterno transversim carinato; femoribus posticis antice non marginatis; tibiis anticis dentibus duobus ultimis leviter approximatis. - Long. $1 \frac{1}{2}$ lin.

Coprobius juvencus Dej. Cat. 3 ed. p. 152.

Eine der kleinsten Arten, von gerundeter, ziemlich hoch gewölbter Gestalt, glänzend, schwarz mit bläulichem Scheine, bor- 
stentragend, allenthalben grob, aber wenig dicht punktirt. Der Kopf nach vorn leicht verschmälert, das Kopfschild in der Mitte mit zwei scharfen Zühnchen, das vordere Wangenende ziemlich spitz. Das Halsschild mit scharf eckigem Seitenrande, nach vorn bogig gewölbt und in der Mitte dieses Bogens gezahnt. Der Scutellareindruck ist flach, aber deutlich und erstreckt sich auch auf die Mitte der Halsschildbasis. Die Flügeldecken mit höchst undeutlichen Spuren von Streifen, wohl aber sind die groben Punkte in ziemlich regelmäfsige Reiben geordnet und diese zum Theil leicht paarweise einander genähert. Das Pygidium schwarz, matt. Taster und Fühler dunkel röthlichbraun. Die Unterseite ziemlich glänzend, schwärzlichbraun; das Prosternum mit Querleisten; die hinteren Schenkel vorn ohne Randlinie; die Vorderschienen am Innenrande ohne winkelige Erweiterung, gegen das Ende unmerklich einwärts gekrümmt, die beiden untersten Randzähne leicht einander genähert.

Vaterland: Columbien; Carthagena.

Von Herrn Deyrolle freundlichst mitgetheilt. An der wenig dichten, aber groben Punktirung der ganzen Oberseite ist dieser kleine Canthon leicht zu erkennen, jeder dieser Punkte trägt ein gelblichgraues Börstchen, wodurch auf den Flügeldecken regelmäfsige Haarreihen entstehen. Bei unausgefärbten Stücken ist oft die ganze Unterseite sammt den Beinen rothbraun.

74. C. viridis Beauv.: E minoribus hujus generis, convexus, rolundatus, nitidulus, elytris minus nitidis, obscure aurato-viridis vel atro-cyaneus. Caput aequaliter sat dense, at subtilissime punctulatum, genis antice acutiusculis. Thorax subtilissime punctulatus, lateribus ante medium rolundatus. Impressio scutellaris fere nulla. Elytra obsolete, at distincte striala, striis lateralibus plerumque vix distinctis. Pygidium leviter convexum, subtiliter punctulatum, punctis setis brevissimis. Palpi cum antennis picei. Corpus subtus cum pedibus nitidulum; prosterno carinato, antice foveolato, postice convexo; tibiis anticis ante medium intus angulatim dilatatis. - Long. $2-3$ lin.

Copris viridis Beauv. Ins. Afr. et Am. p. 23. t. 3. f. 2. (1805.) Onthophagus viridicatus Say Bost. Journ. I. p. 173. (1837.)

Copobrius viridulus Dej. Cat. 3 ed. p. 152.

Coprob. metallicus Sturm Cat. 1843. p. 104.

Var. Minor, cupreus.

Ateuchus obsoletus Say Journ. Ac. Phil. III. p. 208. 
Var. Major, saepius atro-cyaneus, interdum obscure cupreus. Canthon globiformis Reiche i. litt.

Von ziemlich hochgewölbter, gerundeter Gestalt, einem Can. thidium nicht unähnlich, mäfsig glänzend, die Flügeldecken etwas matter scheinend, goldig grün oder rein grün, zuweilen auch schwarzblau. Der Kopf gleichmälsig und ziemlich dicht, aber äufserst fein punktirt, das Kopfschild zweizahnig, das vordere Wangenende ziemlich spitz. Das Halsschild gleichmälsig äufserst fein punktirt, die Seiten sehr fein gerandet, vor der Mitte eckig, der hintere Theil gleichmäfsig leicht gerundet, der vordere leicht geschwungen, das untere Randzähncben nur schwach angedeutet. Der Scutellareindruck klein und wenig tief, greift aber doch die Halsschildbasis etwas an. Die Flügeldecken kürzer als zusammen breit, sehr fein und flach gestreift, die äufseren Streifen etwas undeutlich, die mittleren $\mathrm{Z}$ wischenräume an den Rändern etwas erhaben, auch der erste an der Spitze leicht gewölbt. Das Pygidium an der Basis flacher, an der Spitze stärker gewölbt, sehr fein punktirt, jedes Pünktchen ein feines und äufserst kurzes Börstchen tragend. Taster und Fühler dunkel röthlichbraun, letztere mit grau behaarter Keule. Die Unterseite sammt den Beinen ziemlich glänzend, ebeuso gefärbt wie die obere, nur etwas dunkler und bei den grünen Stücken mit etwas Kupferglanz; das Prosternum mit Querleisten, der vordere Abschnitt leicht muldenartig vertieft, der hintere gewölbt; die Vorderschenkel an der oberen Vorderkante fein sägeartig gezähnelt; die Vorderschienen am Innenrande vor der Mitte plötzlich im stumpfen Winkel erweitert; den dadurch gebildeten Zähnchen entspricht eine kleine napfförmige Vertiefung auf der Oberseite der Vorderschenkel, worin sich dasselbe bei angezogenen Füfsen lagert.

Vaterland: Nordamerika, südlich bis nach Niexiko, Texas und Yucatan verbreitet.

Die südlichen, meist aus Mexiko stammenden Stücke dieser Art sind zuweilen um ein Merkliches gröfser und in der Regel noch feiner punktirt und gestreift als die nördlichen; die kleinsten, öfters kupferfarbigen Exemplare, sind mehr im Westen zu Hause und finden sich noch in den Rocky Mountains. Nach Leconte (Col. of Kansas p. 11) kommt diese Art vorzugsweise gern auf Laub vor. Sie ist an den winkelig erweiterten Vorderschienen in allen Gröfsen- und Farbenabänderungen leicht zu erkennen; nur C. fallax steht ihr auch in dieser Beziehung äulserst nahe und unterscheidet sich eigentlich nur durch die vollglänzende Oberfläche, die deutli- 
chere Punktirung des Halsschildes und die schärferen Seitenrandecken desselben.

75. C. fallax: Simillimus C. viridi, omnino autem nitidissimus, minus abbreviatus, obscure viridis. Caput obsolete punctulatum, genis antice subangulatis. Thorax subtiliter, lateribus autem postice distinctius punctulatus, ante medium distincte angulatus. Elytra obsoletissime striata, laevia. Pygidium nitidum, apice sat convexum, absque punctis distinctis. Palpi cum antennis rufo-picei. Corpus subtus cum pedibus nitidulum, nigro-viride; prosterno transversim carinato, antice foveolato, postice convexo; libiis anticis intus angulatim dilatatis. - Long. 3 lin.

Dem C. viridis sehr ähnlich, aber ganz blank und glänzend, auch nicht so kurz geformt, schwärzlich-grün. Der Kopf äufserst fein, fast undeutlich punktirt, das vordere Wangenende stumpf-winkelig, auch die Nebenzähne sehr schwach angedentet. Das Hálsschild kurz vor der Mitte scharf eckig-gerundet, nach hinten der Seitenrand minder gerundet als bei $\boldsymbol{C}$. viridis, daher auch die Hinterecken deutlicher vortretend; nach vorn etwas minder hoch und gleichmäfsiger geschwungen; äufserst fein punktirl, die Punktirung aber an den Seiten sehr deutlich. Der Scutellareindruck klein. Die Flügeldecken höchst fein und kaum wahrnehmbar gestreift. Das Pygidium glänzend, an der Spitze ziemlich gewölbt, undeutlich punklirt. Taster und Fühler rothbraun, letztere mit schwärzlicher, grau behaarter Keule. Die Unterseite sammt den Beinen ziemlich glänzend, schwärzlich blaugrün; das Prosternum mit Querleisten, diese Leisten, bevor sie den Aufsenrand erreichen, winkelig nach vorwärts gebogen; die Vorderschenkel wie bei $C$. viridis, nur noch etwas stärker gezähnelt; die Vorderschienen wie bei $\boldsymbol{C}$. viridis am Innenrande vor der Mitte eckig. erweitert.

Vaterland: Brasilien.

Von Herrn Deyrolle freundlichst zur Ansicht mitgetheilt, nur ein Stück. Die angegebenen Merkmale werden genügen, um die Art von $\boldsymbol{C}$. viridis mit Bestimmtheit zu unterscheiden; unter den Arten mit vierzahnigem Kopfschilde tritt $\boldsymbol{C}$. modestus, namentlich in Sculptur und Färbung nahe heran, er kann aber wegen seiner mehr länglichen Gestalt und den einfachen, vorn sehr schief abgeschnittenen Vorderschienen nicht damit verwechselt werden.

76. C. acutus: Convexus, ovalis, postice subacuminatus, nitidus, elytris subnitidis, nigro-cyaneus vel nigro-virescens. Caput 
laeve clypeo bidentato. Thorax obsoletissime vixque perspicue punclulatus, lateribus medio angulatis, antice arcuatis, pone medium dentatis, sinuatis, angulis anticis valde acutis. Impressio scutellaris minuta, at profunda. Elytra obsoletissime striata. Pygidium opacum, obsoletissime punctatum, punctis setigeris. Palpi cum antennis picei. Corpus subtus cum pedibus nigrum, sat nitidum; prosterno transversim carinato, femoribus anticis ante apicem non emar ginatis. - Long. 3-4 lin.

Canthon violaceus Horitz i. litt.

C. coerulescens Klug i. litt.

Von ziemlich hochgewölbter, eiförmiger Gestalt, hinten etwas spitz, glänzend, die Flügeldecken mit Ausnahme der Schildchengegend mattglänzend, bläulich- oder grünlichschwarz, die Flügeldecken meist reiner schwarz. Der Kopf gerundet, glatt, der Aufsenrand in der Mitte zweizahnig. Das Halsschild äufserst fein und kaunı wahrnehmbar punktirt, nur vorn und in der Mitte die Punkte etwas deutlicher; der Seitenrand in der Mitte eckig gebogen, die vordere Hälfte stark, aber nur auf eine kurze Strecke bogig gewölbt, so dafs das untere Randzähnchen hinter der Mitte steht; die Vorderecken scharf dornartig ausgezogen, die Basis neben den hinteren leicht ausgebuchtet. Der Scutellareindruck ist tief, beschränkt sichı aber auf die eigentliche Schildchengegend und greift den Hinterrand des Halsschildes nicht an. Die Flügeldecken vor der Mitte am breitesten, äufserst fein gestreift, nur der Nahtstreif deutlicher. Das Pygidium matt, leicht gewölbt, undeutlich punktirt, die Punkte ein äufserst kurzes, feines Börstchen tragend. Taster und Fühler braun, letzlere mit graubehaarter Keule. Die Unterseite samm! den Beinen schwarz, glänzend; das Prosternum mit Querleisten, der Hinterleib an den Seiten zerstreut punktirt, auch hier die Punkte borstentragend; die Vorderschenkel am Ende ohne Ausbuclitung; die Vorderschienen mit deutlich genäherten untersten zwei Randzähnen.

Vaterland: Columbien und das nördliche Brasilien, Insel Sł. Thomas.

Ein kleineres unausgefärbtes Stück aus der Reich'schen Sammlung, wo es sich unter dem Namen C. violaceus Moritz befand, ist mehr violett und anf der Unterseite schwarzbraun mit röthlichbraunen Beinen. Die sehr scharfen Vorderecken des Halsschildes unterscheiden diese Art leicht von den übrigen; das Mäunchen hat etwas längere Vorderschienen und einen breilen, am Ende zweizah. nigen Enddorn, der beim Weibchen schmal und allmählig zugespitzt 
ist. In naher Beziehung steht C. aculus auch zu C. politus, und ist den schwarzbeinigen Stücken desselben höchst ähnlich; doch unterscheidet ihn die geringe Gröfse, die nur mattglänzenden Flügeldecken und der vordere leicht ausgehöhlte Abschnitt des Prosternums, der viel dichter punktirt ist als bei jenem.

77. C. viduus: Simillimus C. acuto, convexus, ovatus, minus nitidus, aeneo-niger, elylris opacis, nigris. Caput punclulatum, clypeo bidentato. Thorax subtilissime vel vix punctulatus, lateribus medio angulatis, postice rectis, antice arcuatis, pone medium dentatis et versus angulos anticos rectis. Impressio scutellaris distincta. Elytra obsolete striata. Pygidium opacum, obsoletissime punctulatum. Palpi cum antennis obscure rufi. Corpus subtus cum pedibus sat nitidum, nigro-aeneum; prosterno transversim carinato, femoribus posticis non marginatis, tibiis anticis leviter incurvalis. - Jong. $3 \frac{4}{5}$ lin.

Coprob. viduus Lacord. Dej. Cat. 3 ed. p. 152.

Ganz vom Aussehen des C. acutus, aber etwas plumper und breiter, minder glänzend, namentlich auch das Halsschild fast ebenso trüb wie die Flügeldecken, grünlich-schwarz, die mattglänzenden Flügeldecken meist reiner schwarz. Der Kopf fein punktirt, das Kopfschild in der Mitte zweizahnig, das vordere Wangenende winkelig. Das Halsschild äufserst fein, an den Seiten hie und da deutlicher punktirt, der Seitenrand in der Mitte scharf eckig, nach hinten, nicht wie bei $\boldsymbol{C}$. acutus leicht gerundet, sondern ganz gerade, nach vorn in einem kleinen schwachen Bogen gewölbt, dann bis zu den Vorderecken wieder gerade, vor diesen Ecken also nicht wie bei $\boldsymbol{C}$. acutus ausgebuchtet. Der Scutellareindruck wenig tief aber deutlich, greift auch die Mitte der Halsschildbasis an. Die Flügeldecken sehr schwach gestreift, der Schulterbuckel an seinem inneren und unteren Ende ein höchst unmerkliches Höckerchen oder Fältchen bildend. Das Pygidium matt, schwarz, äufserst fein punktirt. Taster und Fühler rothbraun, letztere mit rothgrauer Keule. Die Unterseite sammt den Beinen ziemlich glänzend, schwarz; das Metasternum in der Mitte fein punktirt, das Prosternum mit Querleisten; die hinteren Schenkel ohne Randlinie; die Vorderschienen deutlich nach einwärłs gekrümmt, in der Mitte des Innenrandes ein sehr stumpfer Vorsprung; die hinteren Schienen gerade.

Vaterland: Cayenne.

Von Hrn. Deyrolle mitgetheilt. Von C. acutus durch die Unterschiede in der Gestalt des Halsschildes leicht zu unterscheiden; 
der ebenfalls nahe verwandte $C$. politus ist viel glänzender; es fehlt ihm die Punklirung auf Kopf und Halsschild, sowie der Scutellareindruck; endlich sind seine Flügeldecken um ein merkliches länger. Die Unterschiede von dem höchst nahestehenden C. subcyaneus sind bei diesem angegeben.

78. C. subcyaneus Er.: Simillimus C. acuto et C. viduo; subnitidus, niger, leviler subcyanescens. Caput subtilissime punctulatum, clypeo antico medio impresso, bidentato. Thorax laevis, lateribus medio acute angulatis, antice leviter subdeplanatis. Impressio scutellaris distincta. Elytra obsoletissime striata. Pygidium subsericans, apice obsolete punctatum. Palpi cum antennis obscure rufi. Corpus sub/us cum pedibus subnitidum, nigrum; prosterno carinato, femoribus posticis non marginalis, tibiis anticis leviter incurvatis et apice recte truncatis. - Long. $3 \frac{1}{2}$ lin.

C. subeyaneus Er. Schomb. Guyan. III. p. 563. (1848).

Ganz vom Aussehen des C. acutus und C. viduus, von ersterem durch den vorn minder bogig gewölbten Seitenrand des Halsschildes und den geringeren Glanz verschieden. Gleichmälsig ziemlich mattglänzend, schwarz, mit ganz schwachem bläulichen Scheine. Der Kopf nur äufserst fein und kaum wahrnehınbar punktirt, der Aufsenrand vorn in der Mitte vertieft, zweizalınig, die Nebenzälıne sehr slumpf abgerundet, das vordere Wangenende kaum abgesetzt. Das Halsschild glatt, der Seitenrand in der Mitte eine scharfe Ecke bildend, von da nach hinten gerade, nach vorn nur sehr schwach bogig gewölbt und in der Mitte gezahnt, der ganze Seitenrand etwas breit abgesetzt; auf der hinteren Hälfte eine frine, vertiefte Längslinie. Der Scutellareindruck sehr deutlich, greift auch die Mitte der Halsschildbasis an. Die Flügeldecken höchst fein gestreift, der Nahtstreif etwas deutlicher, der Schulterbuckel ziemlich beulig, daneben der 5te und 6te Streif einander sehr genähert und im Basaltheile leicht verlieft. Das Pygidium seidig matt, die Spitze etwas gewölbt, glänzender und zugleich fein punktirt. Taster und Fühler rothbraun. Die Unterseite sammt den Beinen ziemlich. glänzend, schwarz; das Prosternum mit Querkanten, die hinteren Schenkel ohne Randlinie; die Vorderschienen unmerklich gekrümmt, ihr Innenrand in der Mitte mit einem sehr stumpfen Vorsprung versehen, das Ende gerade abgeschnitten.

Vaterland: Britisch Guyana.

Berliner Musêum, auch von Hrn. Deyrolle mitgetheilt. Von dem nahverwandten $\boldsymbol{C}$, acutus durch den geringen Glanz des Hals- 
schildes, dessen schwächer gewölbten und breiter abgeselzten Seitenrand, die minder scharfen Vorderecken und die deutlicheren Nebenzähne des Kopfschildes verschieden. C. viduus stebt dieser Art ungemein nahe und ist möglicherweise damit zu vereinigen: die mir vorliegenden Stäcke unterscheiden sich jedoch durch sehr deutliche Punktirung des Kopfes und der Halsschildseiten, auch scheint der Seitenrand dieses letzteren in der Mitte eine noch schärfere Ecke als bei $\boldsymbol{C}$. subcyaneus zu bilden, zugleich ist er schmäler abgesetzt.

79. C. gemellatus Er.: Statura C. tristis. at nonnihil latior, subnitidus. niger. Caput clypeo bidentato, genis antice obtuse angulatis. Thorax lateribus pone medium rotundatis, angulis posticis rotundatis. Impressio scutellaris nulla. Elytra striis parum distinctis, potius late subsulcatula, medio utrinque leviter transversim plicalula, basi ante callum humeralem tuberculo longitudinali. Pygidium opacum, leviler subconvexum, subsericans. Corpus subtus cum pedibus vix nilidum, nigrum: prosterno non carinato nec dentato; femoribus posticis absque linea marginali; tibiis anticis versus apicem parum dilatatis, intermediis fortiter emarginatis. - Long. 6 lin.

C. gemellatus Er. Wiegm. Arch. 1847. I. p. 105.

Von der Gestalt des $\boldsymbol{C}$. Iristis, doch etwas breiler, nur wenig glänzend, tief schwarz. Der Kopf undeutlich punktirt, das Kopfschild vorn mit zwei wenig spitzen, an der Basis breiten Zähnen. das vordere Wangenende ein sehr deutliches Eck bildend. Das Halsschild glatt, der Seitenrand hinten stark, vorn nur schwach gerundet, die gröfste Breite also hinter der Mitte, dieHinterecken fast vollständig abgerundet. Ein eigentlicher Scut ellareindruck ist nicht wahrzunehmen. Die Flügeldecken ohne deutliche Streifen, zuweilen sehr seicht gefurcht mit schwach erhabenen $Z$ wischenräumen, etwas uneben, namentlich beiderseits neben der Naht in der Mitte mit einigen sehr flachen Quergrübchen, neben und vor der Schulterbeule ein kleiner mit der Basis unmittelbar zusammenhängender Längshöcker. Das Pygidium nur leicht gewölbt, seidig-matt. Taster und Fühler schwarz, nur sehr wenig glänzend; das Prosternum ohne Querkanten und ohne Randzahn; die hinteren vorn nicht gerandel; die Vorderschienen ( $\sigma^{-1}$ ) etwas verlängert, gegen das Ende nur wenig erweitert, die drei Randzähne ziemlich entfernt von ein. ander, der Innenrand dem obersten gegenüber efwas erweitert; die mittleren Schienen vor dem Ende sehr stark ausgebuchtet, so dafs 
ein merklicher slumpfer Winkel der oberen Kante entsteht; die hinteren Schienen unmittelbar vor der Spitze leicht eingeschnürt.

Vaterland: Peru.

Berliner Museum, auch aus der Reich'schen Sammlung erhalten. Die Streifen der Flügeldecken sind bei dieser Art bald ganz undeutlich bald leicht angedeutet, meistens erscheinen statt ihrer flache Furchen, wobei zugleich die Zwischenräume etwas gewölbt werden; von diesen zeigt in der Regel der zweite einige Querfältchen.

80. C. Chevrolati: Subelongalo-ovalis, sal convexus, laevis, nitidus, obsure viridi-aeneus vel nigro-cyanescens. Caput rotundatum laeve, clypeo bidentato, utrinque rotundato. Thorax valde convexus, lateribus medio subangulatis, antice et postice leviler rotundatis. Elytra pone humeros latiora, versus apicem nonnihil angustala, parum distincte striala, parte basali autem striarum, praecipue quartae, profundiore. Pygidium valde convexum, subporrectum. Palpi cum antennis rufo-picei. Corpus sublus cum pedibus obscure nigro-viride, tarsis piceo-rufis; prosterno absque carinis, margine non denticulato; femoribus posticis, praecipue intermediis, punctis nonnullis majoribus setigeris. - Long. $4 \frac{1}{2}-5 \frac{1}{2}$ lin.

Mas. Differt a femina calcari apicali tibiarum anticarum latiore, apice truncalo, pygidio majore, magis adhuc convexo.

Coprobius Chevrolatii Dej. Cat. 3 ed. p. 151.

Coprob. serrimanus Chevrol. i. litt.

V a r. Subnilidus, cupreus.

V a r. Minor, elytris distinctius striatis.

Coprob. chloris Dej. Cat. 3 ed. p. 152.

C. thalassinus Klug i. litt.

Von etwas länglich-eiförmiger, gewölbter Gestalt, glalt und glänzend dunkel bläulichgrün, zuweilen reiner grün oder auch stahlblau. Der Kopf gerundet, glatt, der Vorderrand schwarz und sehr fein gerunzelt, in der Mitte mit zwei breiten, wenig spitzen Zähnen, daneben abgerundet. Das Halsschild hochgewölbt, auch nach hinten etwas abfallend, der Seitenrand etwas hinter der Mitte nur stumpf gerundet, nach hinten und nach vorn leicht gerundet, hier nur in sehr schwachem Bogen gewölbt, ohne Randzälınchen. Der Scutellareindruck wenig tief und auf den Wurzeltheil der Naht beschränkt. Die Flügeldecken an der Basis schmäler wie das Halsschild, unter den Schultern am breitesten, dann allmählig gegen das Ende verengt, böchst fein und undeutlich gestreifı, an der Basis 
die Streifen jedoch deutlich und etwas vertieft, besonders der 3te und 4te, wodurch eine merkliche, von der Basis etwas schief nach aufsen gerichtete Vertiefung entsteht; auch am Spitzenrande erscheinen die Streifen, besonders der erste, deutlicher. Das Pygidium glatt, stark gewölbt, daher von oben gröfstentheils sichtbar. Taster und Fühler dunkel rolhbraun. Die Unterseite und die Beine etwas minder glänzend, ebenso gefärbt wie die obere, nur dunkler; das Prosternum ohne Querleisten; die hinteren Schenkel gerandet, besonders die mittleren mit mehreren groben, borstentragenden Punkten, die auf den hinteren meistens in eine Reihe geordnet sind; die Tarsen rothbraun.

Das Männchen unterscheidet sich vom Weibchen durch breiteren, an der Spitze abgestutzten und leicht ausgerandeten Enddorn der Vorderschienen; das Pygidium ist sehr hoch, fast kegelförmig gewölbt.

V a r. Mattglänzend, kupferfärbig.

Var. Fast um die Hälfte kleiner als die grölsten Stiucke der Stammform, die Flügeldecken deutlicher gesireift, meist grünlichblan.

Vaterland; Mexiko.

Nach der Verbreitung in den Sammlungen zu schliefsen eiue der häufigsten Arten, immer leicht kenntlich an dem etwas vorgestreckten, hochgewölbten Pygidium, dem breiten und auch nach hinten gewölbt abfallenden Halsschilde und den groben Punkten der Hinterschenkel.

81. C. tristis Har.: Subabbreviato-ovalis, latiusculus, leviter convexus, parum nilidus, elytris opacis, niger vel nigro-virescens, capite thoraceque interdum viridibus, nitidulis. Caput parum distincte punctulatum, clypeo medio bidentato, utringue obtuse rotundato, genis antice obtusis. Thorax punctulis nitidis punctisque impressis plus minusve distinctis adspersus, lateribus medio rotundatoangulatus, antice et postice fere rectis. Impressio scutellaris nulla. Elytra parum distincte striata, margine laterali acuto, epipleuris latis. Pygidium planum, margine apicali leviter impresso. Palpi cum antennis picei. Corpus subtus nitidulum, nigrum vel obscure viride, pedibus atroviridibus; prosterno absque carinis transversis, antice non dentato. - Long. 5-6 $\frac{3}{4}$ lin.

Mas. Differt a femina calcari apicali dilatato, apice bifido.

C. tristis Har. Berl. Ent. Zeit 1862. p. 409.

C. opacus Luc. Voy. Casteln. 1859. p. 97. 
C. opacus Klug i. litt.

C. dispar Perty i. litt.

C. campestris Burm. i. litt.

C. viridiobscurus Reiche i. litt.

Von etwas breit-eiförmiger Gestalt, mäfsig gewölbt, maltglänzend, schwarz oder grünlich-schwarz, Kopf und Halsschild zuweilen heller und reiner grün, dann auch etwas glänzender. Der Kopf auf seidig mattem Grunde mit einzelnen glänzenden Pünkıchen, der Aufsenrand vorn etwas aufgebogen, in der Mitte zweizahnig, daneben etwas stumpf gerundet, das vordere Wangenende ebenfalls stumpf gerundet; je reiner grün die Färbung ist, desto deutlicher zeigt sich die Punktirung und erscheint dann auch der Aufsenrand schwarz. Das Halsschild ähnlich wie der Kopf sculptirt, nämlich auf seidenartigem Grunde hellere Pünktchen, aufserdem eine feine, meist sehr deutliche Punktirung; der Seitenrand in der Mitte einen abgerundeten Winkel bildend, der vordere wie der hintere Theil ziemlich geradlinig; das gewöhnliche Seitengrübchen durch ein kleines Höckerchen markirt; die hinteren Ecken durch eine kleine, aber ziemlich tiefe Ausbuchtung der Basis merklich abgesetzt; die Spur einer vertieften Längslinie. Ein eigentlicher Scutellareindruck ist nicht wahrzunehmen, doch ist die Mitte der Halsschildwurzel etwas verflacht. Die Flügeldecken sehr fein, aber doch deutlich gestreift, in den Streifen sehr seicht punktirt, die Zwischenräume äufserst fein netzartig gerunzelt, zerstreut besetzt sowohl mit glänzenden, punktähnlichen Fleckchen als mit feinen, wenig tiefen Pünktchen, eine Sculptur, die bei den schwarzgefärbten, dunkleren Stücken minder deutlich zu erkennen ist als bei den schwärılichgrünen; der Seitenrand nur wenig unter den Schultern gebogen, eine scharfe, leistenartig abgesetzte Kante bildend, die breiten Epipleuren daher flach und ziemlich horizontal nach unten gelagert. Taster und Fühler schwarzbraun, letztere mit grau bebaarter Keule. Das Pygidium wenig senkrecht gestellt, also auch von oben ganz sichtbar, nur sehr wenig gewölbt, neben dem erhabenen Aufsenrande leicht vertieft. Die Unterseite wie die obere gefärbt, auch nur wenig glänzend; die Beine beller oder dunkler schwärzlich grün, auch bei den ganz schwarzen Stücken meist noch mit einem grünlichen Schein; das Prosternum ohne Querleisten, von welchen bei den Hüften nur ein ganz kurzes und feines Rudiment zu erkennen ist; der vordere Aufsenrand nicht gezähnelt; die Behaarung der Beine schvarz, die hinteren Schenkel vorn gerandet und auch hinten von den Knieen bis zur Mitle. 
Bei den Männchen ist der Enddorn der Vorderschienen ziemlich breit, an der Spitze in zwei Zacken getheilt; bei dem Weibchen ist er einfach.

Vaterland: Brasilien, südlich bis nach Buenos Aires verbreitet.

Eine, nach den Sammlungsexemplaren zu schliefsen, nicht seltene Art, die an der feinen Punktirung, dem flachen Pygidium und den breiten Epipleuren leicht $\mathrm{zu}$ erkennen ist. Die schwarzen Stücke dieser Art erinnern etwas an jene des C. gagatinus, der sich jedoch sofort durch seine gerade abgeschnittenen Vorderschienen unterscheidet. Aufser den obigen Namen führt sie auch in manchen Sammlungen den Namen $\boldsymbol{C}$. angulalus Dej., der aber, wie schon oben erwähnt, zu C. bispinus Germ. gehört. Ich habe a. a. O. den Lucas'schen Speciesnamen geändert, da derselbe mit dem älteren Boheman'schen (Res. Eugen. 1858.) collidirt.

82. C. luctuosus: Statura C. tristis, at minor, sericeo-opacus, fuscus, cuprascens, elylris rufescentibus, disco plerumque infuscatis. Caput laeve, clypeo medio bidentato, genis antice acutiusculis. Thorax subsericeo-maculatus, lateribus tenuiter marginatis, medio subacute angulatis, antice breviler arcuatis medioque dentatis. Impressio scutellaris plana at distincla. Elylra subdeplanata, parum distincte striata, epipleuris sat latis. Pygidium planum, atrocyaneum vel fuscum. Palpi cum antennis rufo-picei. Corpus sublus cum pedibus nitidulum, atrum subviolascens; prosterno absque carinis, femoribus posticis antice marginatis. - Long. $3 \frac{3}{4}$ lin.

C. sericatus Klug i. litt.

C. aerarius Germ. i. litt.

In der Gestalt dem $\boldsymbol{C}$. tristis verwandt, aber kleiner und fast noch weniger gewölbt, ohne Glanz, seidigschillernd, schwärzlich mit röthlichem Kupferschein, die Flügeldecken röthlichbraun oder auch schwärzlich, meist jedoch Schultern und Seitenrand röthlich. Der Kopf glatt, der Aufsenrand vorn mit zwei starken, wenngleich minder tief eingeschnittenen Zähnen, daneben gerundet, die vorderen Wangenenden etwas spitz. Das Halsschild ähnlich wie bei $\boldsymbol{C}$. opacus mit seidig schillernden Flecken, die Seiten fein gerandet, in der Mitte winkelig gebogen, dieser Winkel, namentlich auf der Unterseite betrachtet, kaum abgerundet sondern ziemlich scharf, der vordere Theil auf eine kurze Strecke sehr schwach bogig gewölbt, dann deutlich gezahnt. Der Scutellareindruck deutlich, namentlich die Mitte der Halsschildbasis merklich eingedrückt. Die Flügeldecken nur mäfsig gewölbt, sehr fein und fast undeutlich gestreift, der Seitenrand wie bei $\boldsymbol{C}$. tristis scharfkantig, die Epipleu- 
ren breit und flach. Das Pygidium matıglänzend, flach, dunkel stahlblau oder schwärzlich. Die Unterseite sammt den Beinen ziemlich glänzend, schwarz, mit etwas violettem Scheine; das Prosternum ohne Querleisten; die mittleren Schienen sehr allmählig und nur unmerklich gebogen, die hinteren Schenkel mit elwas undeutlichen Randlinien.

Vaterland: Brasilien.

Aus der Germar'schen Sammlung, auch von den Herren Deyrolle und Bonvouloir mitgetheilt. Mit C. Tristis hat diese Art das flache Pygidium und die kantig abgesetzten Epipleuren gemein, sie unterscheidet sich aber leicht durch das Zähnchen am Vordertheile der Halsschildseiten. Die seidig gefleckte Zeichnung des Halsschildes erinnert an $\boldsymbol{C}$. sericinus und $\boldsymbol{C}$. opacus, doch ist sie nicht so deutlich ausgeprägt, nicht grau sondern röthlich, und nur an rein erhaltenen Stücken gut wahrzunehmen. An den hinteren Schenkeln sind die vorderen Randlinien undeutlich, indem sie fast mit der Aufsenkante zusammenfallen, ebenso ist auch der Hinterrand gerandet.

83. C. quadriguttatus Oliv.: Convexus, elongalulus, postice acuminatus, valde nitidus, obscure viridi-aeneus, leviler subcyanescens, elytris obscure ferrugineis, sutura medioque transversim indeterminate infuscatis. Caput laeve, clypeo bidentato. Thorax laevis, lateribus medio angulatus. Impressio scutellaris fere nulla. Elytra laevia; stria suturali distincta, reliquis vix dignoscendis. Pygidium nigrum, sat longum, sericeo-opacum. Palpi cum antennis rufo-picei, his rufo-cinereo clavalis. Corpus subtus nigrum nitidum, metasterno femoribusque viridi-aeneis, tibiis tarsisque rufo-piceis; posterno transversim carinato antice foveolato. - Long. $3-3 \frac{1}{3} \mathrm{lin}$.

M as. Tibiarum anticarum calcari apicali brevi, latissimo, apice emarginato; pygidio magis elongato apiceque subinflexo.

Fem. Calcari apicali elongato, tenui, acuminato.

Scarab. quadriguttatus Oliv. Ent. I. 3. p. 173. t. 27. ᄃ. 230. a. b. (1789).

Scarab. obliquatus Voet. Coleopt. p. 47. t. 28. no. 49.

Ateuchus bidens F abr. Syst. El. I. p. 62. (1801.)

Choeridium elegans Cast. Hist. nat. II. p. 83. (1840.)

Coprob. elegans Dej. Cat- 3 ed. p. 152.

C. limbatus lllig. i. litt.

C. purpurascens Perty i. litt.

Von gewölbter, dabei ziemlich schmaler und verlängerter Gestalt, hinten wegen des minder senkrecht gestellten Pygidiums ziem- 
lich spitz, sehr blank und glänzend, dunkel metallischgrün, namentlich das Halschild mit etwas schwärzlich blauem Glanze, die Flügeldecken bräunlich-roth, die Naht und eine Querbinde in der Mitte, die gegen den Aufsenrand breiter wird, schwärzlich, so dafs vier rothe Makeln entstehen; die Abgränzung dieser Zeichnung ist aber nirgend scharf und es kommen auch Stücke vor, deren Flügeldecken fast ganz rothbraun sind. Der Kopf glatt, der Aufsenrand in der Mitte zweizahnig. Das Halsschild blank, der Seitenrand in der Mitte eckig gebogen, nach vorn im Bogen geschweift und vor der Mitte gezahnt. Ein Scutellareindruck ist kaum angedeutet. Die Flügeldecken gleich hinter den Schultern am breitesten, der Nahtstreif tief, die übrigen Streifen jedoch kaum wahrnehmbar. Das Pygidium ziemlich lang, schwarz oder blauschwarz, seidenartig mattglänzend. Taster und Fühler rothbraun, letztere mit röthlicbgrau behaarter Keule. Die Unterseite schwarz, die Schenkel und die Hinterbrust grünlich; das Prosternum mit Querleisten, vor denselben leicht muldenartig vertieft; die Vorderbeine, die hintern Schienen zum Theil und die Tarsen rothbraun.

Das Männchen hat an den Vorderschienen einen kurzen, sehr breiten, am Ende ausgebuchteten Enddorn; das Pygidium ist länger, an der Spitze gewölbter und zugleich deutlicher nach unten gebogen.

Bei dem Weibchen ist der Enddorn der Vorderschienen lang, dünn und spitz.

Vaterland: Surinam, Cayenne; Pará.

In den Sammlungen nicht selten. Trotz der bedeutenden Unterschiede, welche diese blanke gewölbte Art von dem mattglänzenden, auf dem Rücken flachgedrückten $\boldsymbol{C}$. lituratus entfernen, ist sie doch häufig mit demselben verwechselt. Die angeführten $\mathrm{Be}$ schreibungen sind sämmtlich äufserst mangelhaft; so giebt Olivier das Kopfschild als: arrondi an, die Abbildung dagegen, die übrigens das Thier leicht erkennen läfst, zeigt die zwei Clypeuszähne recht deutlich. Besser ist die des Fabricius, der Vergleich aber mit $\boldsymbol{O}$ thophagus Schreberi, den auch Olivier macht, wohl nur den vier rothen Flecken zu Liebe gestellt. Castelnau hat die Art zu Choeridium gebracht; bei ihm sind überhaupt die Arten von Canthon, Choeridium und Canthidium bunt durcheinander gemengt.

84. C. subhyalinus Har.: Simillimus C. 4-guttato, at aliter coloratus, pygidioque non sericante distinguendus. Valde nitidus. laevissimus, niger, elytris rufo-vel luteo-testaceis. Caput clypeo me- 
dio bidentalo, genis antice a clypeo vix distinctis. Thorax valde convexus, lateribus medio sat acute angulatis, antice arcuatis et dentatis. Impressio scutellaris obsoleta. Elytra absque striis impres sis distinclis, stria suturali sola punctala. Pygidium leviter convexum, nitidulum, laeve. Palpi cum antennis piceo-rufi. Corpus subtus cum pedibus nitidum, nigrum, metasterno femoribusque leviter virescentibus; proslerno transversim carinato; tibiis intermediis et posticis latiusculis. - Long. 3 lin.

C. subhyalinus Harold Col. Heft I. p. 79. (1867).

C. brunnipennis Deyrolle i. litt.

Dem C. quadriguttatus höchst ähnlich, doch nach hinten minder spitz verschmälert, sehr blank, schwarz, die Flügeldecken braungelb oder röthlichgelb. Der Kopf mit nur zweizahnigem Kopfschilde, auch das vordere Wangenende fast ganz abgerundet. Das Halsschild stark gewölbt, der Seitenrand in der Mitte eine scharfe Ecke bildend, dann nach vorn einen kleinen, ziemlich hohen Bogen bildend und am Ende desselben gezahnt. Der Scutellareindruck nur leicht angedeutet. Die Flügeldecken obne deutlich vertiefte Streifen, nur der Nahtstreif angedeutet und durch gröfsere dunkle Punkte, die aber nicht vertieft, sondern mehr durchscheinend sind, markirt; auch die übrigen Streifen sind nur durch eine etwas dunklere Färbung angedeutet. Das Pygidium ziemlich glänzend, glatt, mäfsig gewölbt. Taster und Fühler rostbraun. Die Unterseite sammt den Beinen glänzend, schwarz, die Hinterbrust in der Mitte und die Schenkel meist dnnkel metalliseh grün; das Prosternum mit Querleisten; die Hinterschenkel ohne Randlinien, die hinteren Schienen ziemlich breit und kurz.

Vaterland: Columbien; Bogotà, Neu-Granada.

Von den Herren Kirsch, Schaufufs und Deyrolle mitgetheilt. Die Art hat sehr viel mit C. quadriguttatus gemein, namentlich die ziemlich breiten Schienen der hinteren Beine; bei diesem sind jedoch die Streifen der Flügeldecken angedeutet, namentlich der Nahtstreif sehr kenntlich, auch ist sein Pygidium gröfser, länglicher, dabei seidig mattglänzend, der ganze Körper überhaupt nach hinten viel spitzer auslaufend.

85. C. balteatus Bohem.: Convexus, sat nitidus, laevis, niger, elylris testaceis, sutura maculaque utrinque transversa et obliqua nigris. Caput clypeo quadridentato, dentibus parum acutis. Thorax lateribus leviter rotundatis, antice angustatus, postice dilatatus, angulis posticis rectis, porrectis, anticis acutis. Elytra ro- 
tundato-ovata, subtilissime striata. Pygidium basi longitudinuliter obsolete carinatum. Palpi cum antennis picei. Corpus subtus cum pedibus nigrum; prosterno absque carinis; femoribus posticis non marginatis, punctis nonnullis majoribus adspersis. - Long. 3-3 $\frac{4}{5}$ lin.

C. balteatus Bohem. Res. Freg. Eugen. 1858. p. 41.

Von ziemlich gewölbter Gestalt, mäfsig glänzend, glatı, schwarz, die Flügeldecken gelb, ihre Naht und eine Querbinde schwarz. letztere an Breite von den Schultern gegen die Mitte meist abnehmend. Das Kopfschild mit vier deutlichen, ziemlich gleichgrofsen, aber wenig spitzen Zähnen in der Mitte, auch das Wangenende winkelig. Das Halsschild von hinten nach vorn stark verschmälert, der Seitenrand leicht gerundet, kurz vor den Vorderecken leicht geschwungen, diese daher scharf; die Hinterecken rechtwinkelig, die äufserste Spitze aber abgerundet; die Seitcnrandlinie setzt sich um diese Hinterecken, welche die Schultern weit überflügeln, noch fort und erlischt erst diesen gegenüber. Ein Scutellareindruck macht sich kaum bemerklich und ist auf den Wurzeltheil der Naht beschränkt. Die Flügeldecken an der Wurzel viel schmäler wie das Halsschild, in der Mitte am breitesten, äufserst fein gestreift, die Streifen sehr fein, im Basaltheile etwas deutlicher punktirt. Das Pygidium etwas matłglänzend, schwarz, an der Basis der Länge nach, aber nur ganz unmerklich, erhaben. Taster und Fühler dunkelbraun. Die Unterseite sammt den Beinen schwarz und mäfsig glänzend; das Prosternum ohne Spur von Querkanten; die hintern Schenkel ohne vordere Randlinie, dagegen mit einzelnen gröfseren Punkten.

Vaterland: Guayaquil.

Von Hrn. Deyrolle mitgetheilt. Bei einem sehr kleinen, wahrscheinlich unaúsgefärbten Stücke, sind die Flügeldecken etwas deutlicher gestreift, die Unterseite sammt den Beinen ist dunkelbraun. Durch die erwähnte Beschaffenheit des Halsschildes ist dieser Canthon höchst ausgezeichnet, da bei allen übrigen Arten die winkelige Biegung des Halsschildes in die Mitte oder in die Nähe derselben fällt; nur bei $C$. balteatus ist sie soweit nach hinten gerückt, dafs die dadurch gebildeten Ecken geradezu als die Hinterecken des Halsschildes erscheinen.

86. C. mutabilis Luc.: Subelongato-ovalis, nitidulus, nigroaeneus, elylris rufo-lestaceis, transversim nigro-fasciatis interdum omnino fere nigris. Caput sat dense punctulatum, clypeo dentibus duobus mediis longulis, lateralibus latis, genis antice acutis. Thorax sat dense, disco posticeque nonnihil subtilius et remotius punc- 
tatus, lateribus medio subacute angulatis. Impressio scutellaris distincta. Elytra subtiliter at distincte striata, leviter subopaca. Pygidium leviler sericans, subtilissime punclulatum. Palpi cum an. tennis rufo-picei, his rufo-clavatis. Corpus subtus cum pedibus sat nitidum, nigrum tibiis obscure viridi-aeneis; prosterno absque carinis, femoribus posticis marginatis. - Long. $2 \frac{1}{2}-3 \frac{3}{4}$ lin.

C. mutabilis Luc. Voy. Casteln. p. 100. (1859.)

Var. a. Elytris rufo-testaceis, sutura, fascia irregulari media transversa apiceque nigris.

Var. b. Fascia transversa utrinque abbreviata nonnihil pone medium posita, nigra vel fusca.

Coprobius transversalis Dej. Cat. 3 ed. p. 152.

Var. c. Elytris nigris, basi sola rufis.

Var. d. Elytris nigris, margine laterali rufo.

Var. e. Elylris omnino nigris, vel macula tantum parva humerali et apicali rufis.

Var. $f$. Laetius viridis, elytris rufis, medio longitudinaliter viridisignatis.

Von leicht verlängert-eiförmiger, mäfsig gewölbter Gestalt, nur leicht glänzend, grünlich-schwarz, die Flügeldecken rothgelb mit sehr veränderlicher schwarzer Zeichnung. Der Kopf ziemlich dicht punktirt, die mittleren Zähne des Kopfschildes schmal und lang, die Nebenzähne mit breiter Basis, auch die vorderen $W$ angenenden spitz. Das Halsschild ziemlich dicht punktirt, die Punkte auf derScheibe und nach hinten feiner und weitläufiger, der Seitenrand in der Mitte eckig gerundet, nach vorn leicht im Bogen gewölbt, mit einem kleinen Randzähnchen. Der Scutellareindruck ziemlich tief, greift auch die Mitte der Halsschildbasis an. Die Flügeldecken meist etwas trüber scheinend, sehr fein aber doch ziemlich deutlich gestreift, der Nahtstreif kaum tiefer als die übrigen. Das Pygidium grünlich oder metallisch schwarz, seidig glänzend, sehr fein punktirt, die Punkte etwas der Quere nach nadelrissig. Taster und Fühler roth braun, letztere mit röthlicher Keule. Die Unterseite sammt den Beinen ziemlich glänzend, schwarz, die Schienen mit grünlichem Erzglanze, die Tarsen rothbraun; das Prosternum nur mit Spuren von Querkanten, die hinteren Schenkel vorn gerandet.

Var. a. Auf den rotbgelben Flügeldecken sind die Naht, eine zackige mittlere Querbinde und ein mit der Naht zusammenhängender Theil des Spitzenrandes schwarz oder grünlich schwarz.

Var. b. Bei meist kleineren Stücken ist nur die $\mathrm{Naht}$ und eine 
etwas hinter der Mitle liegende Querbinde, die den Aufsenrand nicht erreicht, schwarz oder schwärzlich.

Var. c. Die Flügeldecken sind nur mehr an der Basis rotb.

Var. $d$. Bei weiterer Ausdehnung des Schwarzen erscheint nur der Seitenrand der Flügeldecken rothgelb gesäumt.

Var. $e$. Dieselben erscheinen endlich ganz schwarz oder es zeigen sich nur mehr Spuren der rothen Färbung am Seitenrande unter den Schultern und an der Spitze.

Var. $f$. Kopf und Halsschild heller grün, auf den rothgelben Flügeldecken ein länglicher Scheibenfleck und zuweilen noch die Naht grün.

Vaterland: Im südlichen Amerika ziemlich verbreitet, Columbien, Cayenne, Amazonas bis nach Corrientes.

In Mehrzahl aus der Reich'schen Sammlung, auch von Dr. Haag und Hrn. Deyrolle mitgetheilt. Die kleineren Stücke erinnern etwas an C. cinctellus, sind auch meist so benannt und damit in den Sammlungen verwechselt; dieser hat aber einen viel tieferen Nahtstreifen, auch die übrigen Streifen sind deutlicher, der Humeralstreif sehr kenntlich, endlich ist am Kopfschilde zwischen dem vorderen Wangenende und dem Nebenzahne noch ein stumpfes Zähnchen zu bemerken, wodurch der Aufsenrand gewisssermafsen achtzähnig erscheint. Die Stücke aus dem Süden sind in der Regel etwas gröfser, mit minder glänzendem und schwächer punktirtem Halsschilde.

87. C. simplex Lec.: Subrotundato-ovalis, dorso elytrorum leviter depressus, opacus, punctis maculisve minutis subnitidis adspersus. Caput clypeo quadridentato, dentibus latis et obtusis, genis antice obtuse angulatis. Thorax postice medio linea longitudinali impressa, lateribus postice rotundalis, antice leviter arcuatis. Impressio scutellaris parum distincta. Elytra subtiliter striata (lateribus, pone humeros, transversim subplicatula, forsan character individualis). Pygidium leviter tantum convexum, opacum. Palpi cum antennis picei. Corpus subtus cum pedibus opacum nigrum; prosterno non carinato, antice non dentato; femoribus posticis non marginatis, tibiis intermediis ante apicem obsolete emarginatis. - Long. $3 \frac{1}{2}$ lin.

$$
\text { C. simplex Leconte Ent. Report. p. 41. (1857). }
$$

Dem C. ebeneus sehr ähnlich, doch etwas kürzer, durch glatte, nicht gekörnte Oberfläche und die nur schwach winkeligen Wangenenden leicht zu unterscheiden. Ohne Glanz, schwarz, dicht 
mit kleinen, leicht glänzenden Pünktchen bedeckt, doch nirgends gekörnelt. Der Kopf mit vorn gerunzeltem Kopfschilde, dieses in der Mitte mit vier breiten, lappigen Zähnen, die Wangen nach aufsen nur schwach gerundet, vorn einen sehr stumpfen kleinen Winkel bildend. Das Halsschild hinten mit deutlich vertiefter Mittellinie, der Seitenrand bogig in der Art geschwungen, dafs die hintere Hälfte halbkreisförmig nach unten, die vordere etwas minder bogig, nach oben gewölbt ist. Der Scutellareindruck sehr unmerklich, legt aber doch die Mitte der Halsschildbasis etwas flach. Die Flügeldecken kaum so lang als Kopf und Halsschild zusammengenommen, sehr fein, aber doch deutlich gestreift, am Aufsenrande unter der Schulter ein Paar Querfältchen. Das Pygidium nur leicht gewölbt, glatt. Taster und Fühler schwarz, letztere mit grau behaarter Keule. Die Unterseite sammt den Beinen matt, schwarz; das Prosternum ohne Querkanten; die Hinterschenkel ohne Randlinie; die Vorderschienen am Innenrande vor der Mitte leicht ausgebuchtet, nicht eckig erweitert, die mittleren vor der Spitze leicht ausgerandet, oben vor der Ausrandung zwei Höckerchen.

Vaterland: Oregon.

Von Herrn Deyrolle mitgetheilt, nur ein Stück, daher möglicher Weise die Fältchen am Seitenrande der Flügeldecken nur individuelle Eigenthümlichkeit. Der nah verwandte $C$. corvinus unterscheidet sich leicht durch breitere Gestalt, den in der Mitte mehr winkelig gebogenen Seitenrand des Halsschildes und dessen deutliche Punktirung.

88. C. corvinus: Rotundato-ovalis, dorso elytrorum leviter subdepressus, opacus, ater. Caput obsolete rugosulum, clypeo sexdentato, dentibus minus acutis. Thorax punctis impressis parum profundis sat dense adspersus, lateribus medio rotundatis, antice leviter arcuatis, non denticulatis. Impressio scutellaris obsoleta. Elytra obsolete striata, humeris sat tumidulis. Pygidium laeve, opacum, subconvexum. Palpi cum antennis picei. Corpus subtus cum pedibus nigrum, subopacum; prosterno absque carinis, femoribus posticis non marginatis, tibiis anticis margine interno teviter sinuato, intermediis ante apicem leviter sinualis. - Long. $3 \frac{1}{3}-4$ lin.

Von der Gestalt des C. simplex, doch etwas gedrungener und breiter, zwar mattglänzend aber doch nicht so ganz glanzlos wie C. simplex und nigricornis, tief schwarz. Der Kopf fein, vorn etwas deutlicher runzlig, das Kopfschild sechszahnig, die Zähne aber mehr zipfelartig, die seitlichen weniger vorragend. Das Halsschild 
mit dentlich vertieften Punkłen und leicht glänzenden punktartigen Flecken versehen; der Seitenrand in der Mitte ziemlich stark, aber doch kaum eckig gerundet, nach vorn sehr leicht bogig, ohne Randzähnchen. Der Seutellareindruck ist unscheinbar. Die Flügeldecken mit gerundeten Seiten, sehr fein gestreift, der Schulterbuckel etwas glatter und glänzender, auch ziemlich beulig aufgetrieben. Das Pygidium leicht gewölbt, matt, obne deutliche Sculptur. Taster und Fühler schwarz. Die Unterseite sammt den Beinen schwarz und mattglänzend; das Prosternum ohne Querkanten; die hinteren Schenkel ohne Randlinie; die Vorderschienen am Innenrande leicht ausgebuchtet, die mittleren vor der Spitze leicht verschmälert.

Var. Die Schultern roth.

Vaterland: Nordamerika; (Sorona; Californien.)

Von den Herren Dr. Haag, Dr. Kraatz und Herrn Deyrolle; letzterer sandte die Art mit C. simplex als zusammengehörend ein; sie unterscheidet sich aber leicht von demselben durch die Sculptur des Halsschildes. Leconte scheint diese Art nicht gekannt zu haben; nach der synoptischen Tabelle, die er über die nordamerikanischen Canthon-Arten in Col. of Kans. 1850 p. 10 giebt, würde sie ebenfalls, wie in der meinigen, neben $C$. simplex zu stehen kommen; die Stücke mit dunkelroth gefärbten Schultern sind fast häufiger als die einfarbig schwarzen.

89. C. tetraodon Blanch.: Subelongato-ovalis, convexus, laevis, nitidus, ater, subviolaceus. Caput subtilissime punctulatum, antice leviter rugosulum, clypeo medio quadridentato, genis angulatis. Thorax lateribus nonnihil pone medium rotundatis, antice et postice subrotundatis, basi juxta angulos posticos sinuata. Impressio scutellaris fere nulla. Elytra obsolete striata, interstitiis summa basi convexis. Pygidium sericans, parum convexum. Palpi cum antennis picei. Corpus subtus cum pedibus minus nitidum, obscure nigro-violaceum; femoribus anticis apice profunde emarginatis et acute dentatis, posticis marginatis; tibiis anticis intus ante medium angulatim dilatatis. - Long. 5 lin.

C. tetraodon Blanch. Voy. d'Orb. Col. p. 162.

C. acanthocnemus Dej. Cat. 3 ed. p. 152.

Aehnlich wie C. Chevrolati gebaut, glatt, glänzend, sehr dunkel bläulichschwarz. Der Kopf äufserst fein punktirt, hinten fast glatt, vorn sehr fein gerunzelt, das Kopfschild vorn vierzahnig, auch die mittleren Zähne mit breiter Basis, das vordere Wangenende deut- 
lich, aber doch nur sehr wenig vortretend. Das Halsschild stark gewölbt, der Seitenrand ohne merkliche Biegung in der Milte, der vordere flach gewölbte Theil aber schon etwas hinter der Mitte beginnend, die Basis neben den Hinterecken ziemlich tief und weit ausgebuchtet, hier auch der Seitenrand etwas breiter abgesetzt, die Ecken daher deutlich vortrelend. Ein Scutellareindruck ist kaum wahrzunehmen. Die Flügeldecken sehr fein gestreift, die Zwischenräune unmittelbar an der Wurzel etwas gewölbt, der Schullerbuckel leicht beulig. Das Pygidium etwas länglich, flach, seidenartig glänzend, schwarzblau. Taster und Fühler schwarzbraun. Die Unterseite sammt den Beinen minder glänzend, schwarz, nur mil schwachem bläulichen Scheine; das Prosternum ohne Querkanten, auch das Randzähnchen nur sehr leicht angedeutet; die Vorderschenkel am Ende sehr tief ausgebuchtet und scharf gezahnt, die hinteren gerandet; die Vorderschienen innen vor der Mitte im leichten Winkel erweitert. ihr Ende gerade abgestutzt, die äufsere obere Kante an den mittleren sowohl als an den hintern gegen das Ende etwas ausgebuchtet.

Vaterland: Brasilien, Montevideo.

Von Hrn. Deyrolle und Dr. Haag mitgetheilt. Diese Art, in der Färbung mit $C$. violaceus vergleichbar, ist sebr leicht am starken Schenkelzahne zu erkennen, welcher bei beiden Geschlechtern gleichmäfsig ausgebildet ist. Der in der Gestalt am nächsten verwandte $\boldsymbol{C}$. Deyrollei unterscheidet sich aufser durch die ungezahnten Schenkel, durch seine Querleisten am Prosternum und die bedeutend schmäleren hinteren Schienen.

90. C. dives: Elongato ovalis, modice convexus, nitidus, laete aurato-viridis, elytris sericantibus, subtilissime reticulatis. Caput punctulatum, vertice subaequali, clypeo dentibus quatuor magnitudine fere aequalibus, genis antice subacutis. Thorax vix perspicue punctulatus, lateribus nonnihil pone medium angulatis. Impressio scutellaris fere nulla. Elytra distincte striala. Pygidium parum convexum, transversim subtilissime reticulatum, subsericans. Palpi cum antennis rufo-picei. Corpus sublus cum pedibus nitidum, obscure viride; prosterno absque curinis, femoribus anticis valde dentatis et emarginalis, posticis marginatis; tibiis anticis intus ante medium angulatim leviter dilatatis. - Long. $5 \frac{3}{4}-6$ lin.

Von ziemlich länglich eiförmiger, nur mäfsig gewölbter Gestalt, schön goldgrün, Kopf und Halsschild glänzend, die Flügeldecken nur matt glänzend, äufserst fein nelzartig gerunzelt. Der Kopf punk- 
tirt, der Scheitel etwas uneben, der Aufsenrand breit schwarz, das Kopfschild vorn mit vier fast gleich geformten Zähnen, das Wangenende mit stumpfer Spitze. Das Halsschild höchst fein und kaum wahrnehmbar zerstreut punktirt, der Seilenrand etwas hinter der Mitte ein sehr stumpfes Eck bildend, von da nach hinten leicht gerundet, nach vorn nur sehr leicht bogig, in der Mitte mit einem schwachen Zälnnchen. Ein Scutellareindruck macht sich nicht bemerklich. Die Flügeldecken nach hinten etwas verschmälert, fein aber sehr deutlich gestreift, die Streifen mit feinen Pünktchen. Das Pygidium fast flach, der Quere nach äufserst fein nadelrissig, seidigglänzend, grün. Taster und Fübler dunkelbraun. Die Unterseite sammt den Beinen mäfsig glänzend, schwärzlich grün, zuweilen auch letztere bläulichschwarz; das Prosternum ohne Querkanten; die Vorderschenkel vor den Knieen ausgerandet und gezahnt, die hinteren gerandet; die Vorderschienen leicht nach einwärts gekrümmt, kurz vor der Mitte am Innenrande winkelig, aber nur leicht erweitert.

Vaterland: Brasilien.

Von mehreren Seiten zugesendet erhalten, zuweilen als $C$. prasinus $\mathrm{Dej}$. bestimmt, der aber eine sehr verschiedene, dem $C$. sma. ragdulus nahestehende Art ist. Obwohl sehr verschieden gefärbt und namentlich durch die netzarlig gerunzelten, daher nur matt glänzenden Flügeldecken von C. telraodon leicht zu unterscheiden, hat diese Art doch sehr vieles damit gemein, so namentlich die Bewaffnung der Vorderschenkel, die Zahnung des Kopfschildes und das flache, längliche Pygidium. C. tetraodon ist aber beträchtlich kürzer, in den Flügeldecken gewölbter und plumper im Fufsbau: Vollständig analog gefärbt und zum Theil auch geformt ist $\boldsymbol{C}$. fastuosus, der sich aber durch seinen deutlichen Humeralstreifen, die unbewehrten Vorderschenkel und die abgekürzten Prosternalleisten wieder weit davon entfernt.

91. C. Deyrollei: Statura fere C. Chevrolati, laevis, nitidus, ater. Caput antice subrugosulum, clypeo sexdentato. Thorax lateribus medio rotundatis, basi utrinque submarginatus. Impressio scutellaris distincta, thoracis basin autem non aggrediens. Elytra subtiliter striata. Pygidium leviter convexum. Palpi cum antennis obscure rufo-picei. Corpus subtus cum pedibus nigrum, nitidum; prosterno transversim carinato, lateribus antice subdentato; femoribus posticis marginatis, intermediis margine antico obtuse angulato; tibiis anticis intus ante medium angulato-dilatatis. - Long. $5 \frac{1}{4}$ lin. 
Einem schwarzen $C$. Chevrolati auf den ersten Anblick nicht unähnlich, nach hinten aber minder verschmälert, glänzend, schwarz. Der Kopf vorn sebr fein runzlig, das Kopfschild sechszahnig, sowohl die Nebenzähne als auch das Wangenende deutlich spitz. Das Halssehild mit kaum wahrnehmbaren Spuren von Punkten an den Seiten besonders gegen hinten, der Seitenrand in der Mitte einfach gerundet, keine Ecke bildend, auch nach vorn und nach hinten gerundet, am vordern Theile ein sehr stumpfes Randzähnchen, die Vorderecken aber scharf; die Basis neben den Hinterecken wie gewöhnlich ausgebuchtet, die innere Gränze des Ausschnittes aber nicht durch Höckerchen bezeichnet, sondern der Rand is! hier etwas wulstig auf eine kleine Strecke gegen die Mitte hin erhaben, so dafs dieser Theil der Basis wie gerandet aussieht. Der Scutellareindruck ziemlich tief, ist aber auf den Wurzeltheil der Naht beschränkt und greifı die Mitte der Halsschildbasis nicht an. Die Flügeldecken sehr fein, aber doch deutlich gestreift, namentlich der 6te Streif in seinem Basaltheile markirt, auch der Humeralstreif kennbar, an der Wurzel hie nnd da sogar die Andeutung eines Leistchens. Das Pygidium ziemlich gewölbt, höchst fein nadelrissig, daher etwas minder glänzend. Taster und Fühler dunkel röthlichbraun. Die Unterseite sammt den Beinen schwarz, glänzend; die hinteren Schenkel gerandet, das Prosternum mit Querleisten; die Vorderschienen innen vor der Mitte plötzlich erweitert, am Ende gerade abgestutzt; die mittleren gegen das Ende nicht ausgerandet. aber doch etwas verengt.

Vaterland: Unbekannt.

Ich benenne diese Art Herrn Henri Deyrolle zu Ehren, welcher mir in höchst zuvorkommeuder Weise die sämmtlichen CanthonArten seiner reichhaltigen Sammlung zur Ansicht einsendete und dadurch die gegenwärtige Bearbeitung dieser Gattung wesentlich förderte. C. Deyrollei steht auch dem C. tetraodon sehr nahe, dieser ist aber mebr bläulich schwarz, das Prosternum hat keine Querleisten und die Vorderschenkel zeichnen sich durch einen starken Zahn und eine daneben befindliche sehr tiefe Ausrandung aus. $\boldsymbol{C}$. janthinus, der in der Färbung nicht unähnlich ist, hat viel breitere, mehr gerundete Flügeldecken und einen sehr deutlichen Humeralstreif.

92. C.formosus: Simillimus C. specioso, at pygidio sericeoopaco distinguendus, abbreviato-ovalis, convexus, nitidus, obscure viridi-cyaneus. Caput laeve, clypeo quadridenlato, dentibus mediis acu- 
tis, lateralibus minus prominulis, basi latis, genis antice angulatis. Thorax lateribus remote et subtiliter punctulatus, medio angulato-rotundatis, postice fere rectis, antice arcuatis. Impressio scutellaris distincta. Elytra obsoletissime striala, stria octuva postice distinctius punctata, interstitiis laevibus. Pygidium parum convexum, subviolaceum, sericeo-opacum subtilissime punclalum, punclis brevissime seligeris. Corpus sublus cum pedibus nilidum, obscure violaceum. - Long. $4 \frac{1}{4}$ lin.

In Gestalt und Färbung den dunklen Stücken des C. Sallei oder dem C. speciosus höchst ähnlich, glänzend, dunkel bläulichgrün. Der Kopf glatt, das Kopfschild vorn vierzahnig, die mittleren zwei Zähne spitz und schmal, die Nebenzähne stumpfwiokelig mit sehr breiter Basis, das vordere Wangenende deutlich eckig. Das Halsscbild an den Seiten zerstreut und sehr fein punktirt, der Seitenrand in der Mitte eckig gerundet, nach hinten fast gerade, nach vorn gewölbt und vor der Mitte gezahnt. Der Scutellareindruck deutlich, greift auch die Mitte der Halsschildbasis merklich an. Die Flügeldecken sehr fein gestreifı, nur der Nahtstreif und auch der achte nach hinten elwas deutlicher, dieser zugleich deutlich punktirt. Das Pygidium nur sehr leicht gewölbt, matt, etwas seidenartig, fein punktirt, die Punkte ein äufserst kurzes Börstchen tragend. Die Taster rothbraun, die Fühler schwarzbraun mit grau behaarter Keule. Die Unterseite sammt den Beinen schwärzlichblau, mit etwas rö̈hlichem oder violettem Scheine; die Hinterschenkel vorn gerandet, das Prosternum ohne Querkanten, nur mit einer Andeutung eines Wurzeltheiles bei den Hüften; die Vorderschienen am Ende schief abgeschnitten, der Enddorn des Männchens gegen das Ende erweitert und hier ausgebuchtet, der äufsere Theil spitziger als der innere.

Vaterland: Rio Janeiro.

Von Herrn Deyrolle mitgetheilt, nur Männchen. Diese Art sieht auf den ersten Anblick einem ganz dunklen C. Sallei täuschend ähnlich, abgesehen von der Verschiedenheit im Pygidium ist jedoch der Bau des Halsschildes ein anderer, indem bei Ansicht von oben $\boldsymbol{C}$. Sallei einen nur gerundeten, $\boldsymbol{C}$. formosús dagegen einen in der Mitte deutlich eckigen Seitenrand hat, dessen vordere Hälfte bei jenem zugleich viel bogiger gerundet als bei $C$. formosus ist. Eine entfernte Aehnlichkeit bietet auch noch $C$. virens, der aber immer viel deutlicher gestreifte Flügeldecken hat, durch 
den Humeralstreifen und das mitunter sogar an den Seiten grob punktirte Halsschild sich leicht unterscheiden lärst.

93. C. modestus Har: Ovalis, convexus, dorso leviler subdeplanatus, valde nitidus, laevis, viridis, elytris obscure viridibus. Caput clypeo medio acute bidentato, dentibus lateralibus latis et parum prominulis, genis antice leviter acutis. Thorax lateribus medio subangulatis, dein rectis, basi juxta angulos posticos emarginata. Impressio scutellaris distincta. Elytra parum distincte striata. Pygidium nitidum, leviter convexum. Palpi cum antennis rufo-picei. Corpus subtus obscure viridi-aeneum, pedibus aeneis, leviter rufescentibus, femoribus posticis marginatis, prosterno non carinato. - Long. 3 lin.

$$
\text { C. modestus Harold Col. Heft I. p. 78. (1867). }
$$

Von eiförmiger, mäfsig gewölbter Gestalt, glatt und glänzend, metalliseh grün, die Flügeldecken etwas dunkler. Der Kopf vorn mit zwei ziemlich spitzen und schmalen Zähnen, die Nebenzähne aber stumpfwinkelig, das Wangenende deutlich spitz. Das Halsschild an der Basis neben den Hinterecken ausgebuchtet, der Seitenrand in der Mitle stumpfwinkelig gebogen, dann nach vorn und nach hinten ziemlich gerade, der vordere Theil fast gar nicht bogig gewölbt. Der Scutellareindruck ist deutlich und greift auch die Mitte der Halsschildbasis an. Die Flügeldecken sehr fein gestreift, die Zwischenräume mit höchst undeutlicher Punktirung. Das Pygidium leicht gewölbt. Taster und Fühler dunkel röthlichbraun. Die Unterseite metallischgrün, die Beine, namentlich die Schienen und Tarsen etwas röthlichbraun; die hinteren Schenkel gerandet, das Prosternum obne Querkanten.

Vaterland: Columbien.

Von Herrn Lehrer Schmidt in Hamburg freundlichst mitgetheilt. Die Art unterseheidet sich von C. speciosus und $\boldsymbol{C}$. formosus durch geringere Gröfse, mehr längliche und flächere Gestalt, sowie durch den vorn fast gar nicht aufgebogenen Seitenrand des Halsschildes.

94. C. carbonarius: Statura fere C. nigricornis, al major, ovalo-rolundatus, niger, opacus, laevis. Caput antice leviter rugosulum, clypeo 4 dentato, dentibus lateralibus parum acutis, genis antice angulatis. Thorax lateribus pone medium angulatus, antice arcuatus medioque dentatus. Impressio scutellaris minuta. Elytra obsoletissime striata, interstilio terlio basi tuberculato. Pygidium 
laeve, subconvexum. Palpi cum antennis picei. Corpus subtus cum pedibus nigrum, subnitidum; prosterno transversim carinalo: femoribus posticis marginatis, tibiis anlicis intus ante medium angulatim dilatatis. - Long. 4-4 $\frac{1}{3}$ lin.

C. anthracinus Perty i. litt.

In der Gestalt dem C. nigricornis ähnlich, doch gröfser und hinten etwas stumpfer gerundet, maltglänzend, fast seidig schimmernd, schwarz, hie und da, besonders am Halsschilde, ein schwacher kupfriger Schein. Der Kopf glatt, vorn runzlig, das Kopfschild vierzahnig, die Nebenzähne aber sehr stumpfwinkelig, die Wangen vorn eckig. Das Halsschild glatt, der Seitenrand hinter der Mitte winkelig gebogen, nach hinten etwas flach abgesetzt und leicht gerundet, nach vorn bogig gewölbt mit einem Randzähnchen in der Mitte; auf der hinteren Hälfte eine leicht vertiefte Längslinie. Der Scutellareindruck deutlich, klein, greift aber doch den äufsersten Saum der Halsschildmitte an. Die Flügeldecken microscopisch fein netzartig gerunzelt, sehr fein gestreift, die Streifen punk-

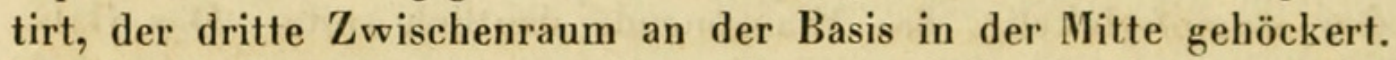
Das Pygidium schwach gewölbt, ohne deutliche Punktirung. Taster und Fühler schwarz. Die Unterseite sammt den Beinen wenig glänzend, schwarz; das Prosternum mit Querkanten; die hinteren Schenkel vorn gerandet, die Vorderschienen am Inneurande vor der Mitte winkelig erweitert und am Ende gerade abgestutzt, ihr Enddorn nach auswärts gekrümmt.

Vaterland: Brasilien.

Aus der Münchener Staatssammlung. Perty fand diese Art, welche er im Eingange zu seinen Delect. anim. Brasil. erwälınt, im Monate November auf Aas.

95. C. confluens: Ovalis, dorso subdepressus, nitidulus, viridi-cupreus, elytris parum nitidis, nigro-ueneis, medio obscure rufis. Caput laeve, clypeo quadridentato, dentibus parum acutis, genis antice rotundatis. Thorax postice longitudinaliter subimpressus, lateribus medio angulatis, postice rectis, antice arcuatis medioque dentatis. Impressio scutellaris distincta. Elytra parum distincte striata. Pygidium opacum, leviter convexum. Palpi cum antennis rufo-picei, his fuscoclavatis. Corpus sublus cum pedibus sat nitidum, nigro-aeneum; prosterno transversim carinato, femoribus posticis non marginatis, tibiis anticis apice oblique truncatis. - Long. $3 \frac{1}{2}$ lin.

Coprob. nitidicollis Reiche i. litt.

Von eiförmiger, ziemlich flachgedrückter Gestalt, Kopf und 
Halsschild glänzend, dunkel kupfrig grün, die Flügeldecken nur matt glänzend, schwärzlich erzfarben mit grünlicher Naht und einer sehr unbestimmt begränzten, dunkelrothbraunen Querbinde. Der Kopf glatt, das Kopfschild vorn mit vier ziemlich stumpfen Zähnen, das vordere Wangenende abgerundet, kein Einschnitt vor demselben. Das Halsschild hinten mit einer leicht vertieften Längslinie, der Seitenrand in der Mitte scharf eckig, von da nach hinten fast gerade, nach vorn leicht bogig geschwungen und in der Mitte gezahnt. Der Scutellareindruck ziemlich tief, greift auch die Mitte der Halsschildbasis leicht an. Die Flügeldecken nur leicht gewölbt, mit Ausnahme des Nahtstreifen nur undeutlich gestreift. Das Pygidium erzfarben, mattscheinend, leicht gewölbt. Taster und Fühler rothbraun, letztere mit dunkler Keule. Die Unterseite sammt den Beinen ziemlich glänzend, schwärzlich, metallisch-grün; das Prosternum mit Querleisten, die hinteren Schenkel ohne Randlinie; die Vorderschienen an der Spitze schief abgeschnitten.

Vaterland: Chiquitos.

Nur ein Exemplar aus der Münchner Staatssammlung, von Dr. Gemminger mitgetheilt. Ich würde auf diese Art den $C$. rubrescens Blanch. (Voy. d'Orb. Col. p. 167.) bezogen habeu, wenn nicht ausdrïcklich in der Beschreibung von Leisten auf den hinteren Schienen die Rede wäre (les jambes intermédiaires et postérieures ont une carène médiane), ein Charakter, der weder auf diesen noch überhaupt auf irgend einen Canthon pafst.

96. C. laesus Er.: Statura C. semiopaci, elongato-ovalis, postice leviter attennuatus, dorso elytrorum leviter subdepressus, capite thoraceque nitidis, viridi-aeneis, elytris opacis, lurido-testaceis, sutura viridi-aenea. Caput obsoletissime subpunctulatum, clypeo antice impressiusculo, 4 dentato, genis antice obtuse angulatis. Thorax lateribus basique subtilissime vixque perspicue remote punctulatus, lateribus medio angulatis, antice arcuatis et dentatis, basi juxta angulos posticos emarginata. Impressio scutellaris obsoleta. Elytra parum distincte striata, stria sulurali punctulata; obsoletissime reticulata, epipleuris fuscis. Pygidium leviter convexum, sericeo-opacum, nigro-cyanescens, subtilissime punctulatum et piligerum. Palpi cum antennis ferruginei, his subcinereo-clavatis. Corpus subtus cum pedibus nitidum, nigro-viridi-aeneum; prosterno carinato, femoribus posticis non marginatis, tibiis subincrassatis, anticis apice oblique truncutis. - Long. $4 \frac{1}{3}$ lin.

C. laesus Er. Wiegm. Arch. 1847. 1. p. 105. 
Von der Gestalt des C. semiopacus, angustatus u. s. w., länglich-eiförmig, nach hinten leicht allmählig verschmälert, auf dem Rücken etwas flachgedrückı, Kopf und Halsschild glänzend, metallisch grün, die Flügeldecken nur matt glänzend, schmutzig gelbbraun mit grünlicher Naht. Der Kopf äufserst fein chagrinirt, etwas minder glänzend als das Halsschild, äufserst fein zerstreut punktirt, der Aufsevrand vorn in der Mitte etwas vertieft, vierzahnig, das Wangenende vorn nur ein stumpfes Spitzchen bildend. Das Halsschild äufserst fein und kaum wahrnehmbar an den Seiten und an der Basis neben den Hinterecken punktirt, der Seitenrand in der Mitte eckig gebogen, nach hinten kaum gerundet, vorn in einem kleinen, von einem deutlichen Zähnchen begränzten Bogen gewölbt; die Hinterecken von oben besehen, wegen der daneben befindlichen Ausbuchtung des Hinterrandes, deutlich zahnartig abgeselzt. Ein Scutellareindruck ist kaum bemerkbar. Die Flügeldecken mit sehr schwachen Spuren von Streifen, diese aber fein punktirt; mikroskopisch fein chagrinirt, ihr umgeschlagener Rand schwarıgrün. Das Pygidium seidig matt. chagrinirt, nur leicht gewölbt, äufserst fein mit borstentragenden Pünktchen besełzt, dnnkelgrün mit etwas bläulichem Scheine. Taster und Fühler rothbraun, letztere mit graubraun behaarter, etwas länglich geformter Keule. Die Unterseite sammt den Beinen glänzend, dunkel metallisch-grün; das Prosternum mit Querleisten und vor denselben leicht vertieft; die hinteren Schenkel glatt, ohne Randlinie; die hinteren Schienen leicht wadenariig verdickt, grün, nur die Tarsen rothbraun; die vorderen Schienen am Ende schief abgestutzt.

Vaterland: Peru.

Zwei Stücke im Berliner Museum. Ohne die dunklen Beine würde sich die Art am nächsten an C. semiopacus schliefsen.

Die nachstehend beschriebene Art weicht in einigen Punkten nicht unerheblich vom Gattungstypus ab, weshalb ich sie nur vorläufig bei derselben belasse:

97. C. gibbicollis: Ovatus, nilidus, piceus. Caput punctatum, clypeo antice rufescente, medio acute bidentato, dentibus sat disjunctis, genis antice unacum clypeo rotundatis. Thorax gibbos. convexus, postice subangustatus; lateribus nonnihil deplanatis, ant medium obtuse angulatis, ciliatis, ciliis tenuibus, recurvis; sat dense punctatus, punctis annuliformibus, basi subsulcato-marginata. Elytra crenulato-striata, striis latis at nullo modo profundis, interstitiis planis, laevibus, versus apicem leviter convexis. Pygidium ab 
elytris obtectum, contractum. Corpus sublus nitidum, cum pedibus obscure rufo-piceum; prosterno carinato et profundissime foveolato; metasterno et femoribus punctatis; tibiis anticis apice scalpriformibus. Palpi cum antennis rufo-testacei. - Long. 2 lin.

Vaterland: Brasilien.

Eine sehr eigenthümliche, durch das stark beulig gewölbte Halsschild auffallende Form. Das Kopfschild hat in der Mitte einen kleinen, aber tiefen halbkreisförmigen Ausschnitt, daneben zwei spitze, gerade nach vorwärts gerichtete Zähne. Die Augen sind ziemlich grofs, die Punkte auf dem Kopfe und zum Theil auch auf dem Halsschilde sind grofs, aber nur seicht und baben daher ein ringförmiges Aussehen. Auch die Längsstreifen der Flügeldecken, die nur vor der Spitze vertieft sind, bilden ganz flache Rinnen, deren Ränder wellenartig gewunden sind. Die Schultern sind etwas spitz. Die Vorderschienen sind am Ende gerade abgestutzt, die Randzähne klein, ebenso der Enddorn und die Vordertarsen, welche kürzer sind als die Schiene am Ende breit.

Wenn das Mesosternum nicht ganz ebenso gebaut wäre wie bei den typischen Canthon-Arten, nämlich sehr schmal und ganz gerade vom Metasternum ahgegränzt, würde ich die Art eher zu Epilissus gebracht haben, wozu die etwas gröfseren Augen und die schwachen Klauen berechtigen würden. Am nächsten steht $C$. gibbicollis etwa dem C. perplexus, der Fufsbau erinnert aber am meisten an C. affinis, asper und villosus, die alle im Körperbau von etwas eigenthümlicher Beschaffenheit sich zeigen.

Das Thier befindet sich zur Zeit nur in wenigen Exemplaren im Berliner Museum und wurde von Dr. Hensel auf seiner Reise in Brasilien gesammelt. Dieser hat zugleich die interessante Beobachtung gemacht, dafs $C$. gibbicollis sich vom abgesonderten Schleime der gröfseren Bulimus-Art nährt und häufig beim Zurückziehen einer Schnecke mit in das Gehäuse hinein unter den Mantel gezogen wird. Eine Notiz hierüber hat Hr. Fr. Stein im vorigen Jahrgange dieser Zeitschrift p. 212 mitgetheilt.

Die mir unbekannt gebliebenen Canthon-Arten, welche bisher beschrieben wurden, folgen hier in chronologischer Reihenfolge:

1. Ateuchus punctalo-striatus Mannerh. Nov. Mém. Mose. 1829. I. p. 37. Gehört sicher zu Canthidium.

2. Canthon minulus Cast. Hist. nat. II. p. 69 aus Cayenne. Nur 1 $\frac{1}{4}$ Lin. lang, vielleicht ein $C$. perplexus oder überhaupt nicht zur Gattung gehörend. 
3. Canthon unicolor Blancb. Voy. d'Orb. Col. p. 160 von Santa Cruz de la Sierra; scheint dem C. bispinus oder tristis nahe verwandt.

4. C. atricornis id. ebenda p. 162 ; scheint meinem C. conformis nahe zu steben.

5. C. quadratus id. p. 163; diese Art soll keine Zäbne am Kopfschilde haben und würde daher neben $C$. muticus und edentulus zu stehen kommen, von denen sie aber durch bedeutendere Gröfse (12 mill.) sehr abzuweichen scheint.

6. C. chalybaeus id. p. 163; scheint in die Nähe von den ohnedies schwierig za unterscheidenden Arten aus der Verwandtschaft des C. substriatus, seminitens u. s. w. zu gehören.

7. C. plicatipennis id. p. 164; soll auf den Flügeldecken kleine Querfältchen zeigen, kann übrigens aus der Beschreibung nicht weiter gedeutet werden. Aus Patagonien, worunter indefs bei Blanchard eher der Süden der argentinischen Republik zu verstehen ist.

8. C. lividus id. p. 164; mir unbekannt.

9. C. rubromaculatus id. p. 165; soll sehr flachgedrückt sein, mir unbekannt.

10. C. xanthurus id. p. 166; eine sehr kleine, kurze und gewölbte Art, vielleicht eher ein Canthidium.

11. C. pilluliformis id. p. 166; aus Buenos Aires, vielleicht mein $C$. seminulum, jedenfalls damil verwandt.

12. C. xanthopus id. p. 166; mir unbekannt.

13. C. rubrescens id. p. 167; die hinteren Beine sollen an den Schienen une carène mediane, also wohl eiue Querleiste haben; da Blanchard selbst angiebt, dafs die Art sich Choeridium nähert, gehört sie wohl kaum mehr zu Canthon.

14. C. costulatus Luc. Voy. Castelnau p. 98. von Cuyaba; soll erhabene Zwischenräume der Flügeldecken haben, was sonst bei keinem ächten Canthon der Fall ist; da Lucas im nämlichen Werke ein ächtes Deltochilum als Canthon cupricolle beschrieben hat, so zweifle ich auch an der Hiehergehörigkeit dieser Art.

15. C. apicalis id. p. 100; wird mit C. lituratus verglichen, von dem er vielleicht nur eine Varietät ist, bei welcher die Flügeldecken auf der hinteren Hälfte roth gefärbt sind.

16. C. planus id. p. 101 von Cuyaba; ich habe schon erwähnt, dafs diese Art vielleicht mein C. muticus ist.

17. C. sexspilolus Guér. Verhandl. Zool. Bot. Ver.. Wien. V. p. 587; dürfte in die Nähe von $C$. imilans gehören.

18. C. abrasus Lec. Col. of Kans. p. 11. von Georgien; ich 
würde die Art unbedingt für $\boldsymbol{C}$. probus halten, wenn nicht die Augen: broader than usual bezeichnet wären, was sich von diesem durchaus nicht sagen läfst.

19. C. cyanellus Lec. ebenda aus Texas; diesen möchte ich für meinen $C$. circulatus ansprechen, wenn nicht ausdrücklich angegeben wäre, dafs das Prosternum keine Querleisten hat.

20. C. praticola id. p. 10 aus Kansas und

21. C. depressipennis id. ebenda, habe ich bereits, ersteren bei $\boldsymbol{C}$. Lecontei, letzteren bei $\boldsymbol{C}$. ebeneus erwähnt.

22. C. indigaceus Lec. Proc. Ac. Phil. 1866 p. 380 und

23. C. puncticollis id. p. 381, beide aus Californien; mir unbekannt.

I $\mathbf{n}$ d e $\mathbf{x}$.

(NB. Um die häufigen WViederholungen zu vermeiden, ist Coprobius von Canthon nicht ausgeschieden.)

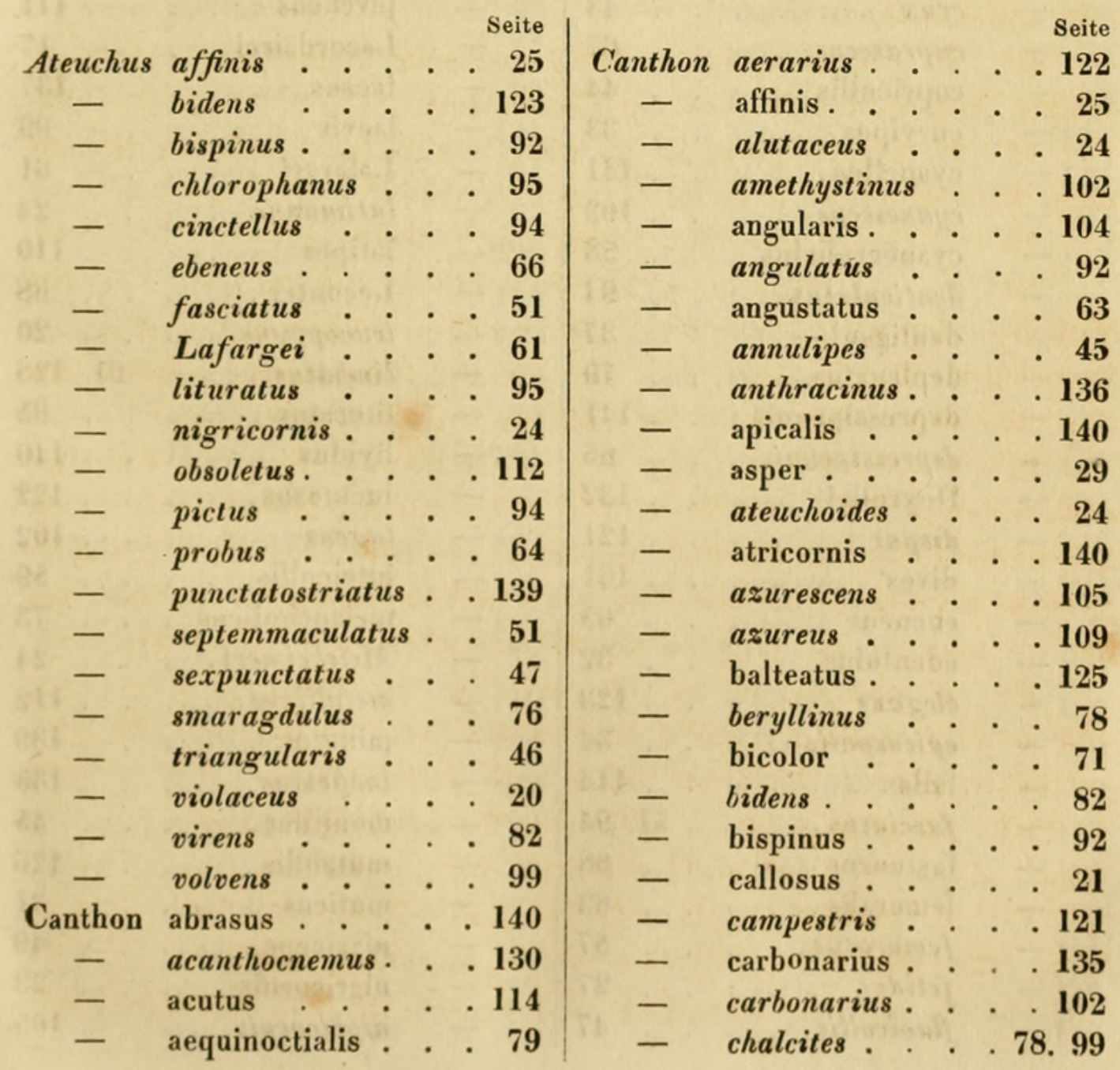




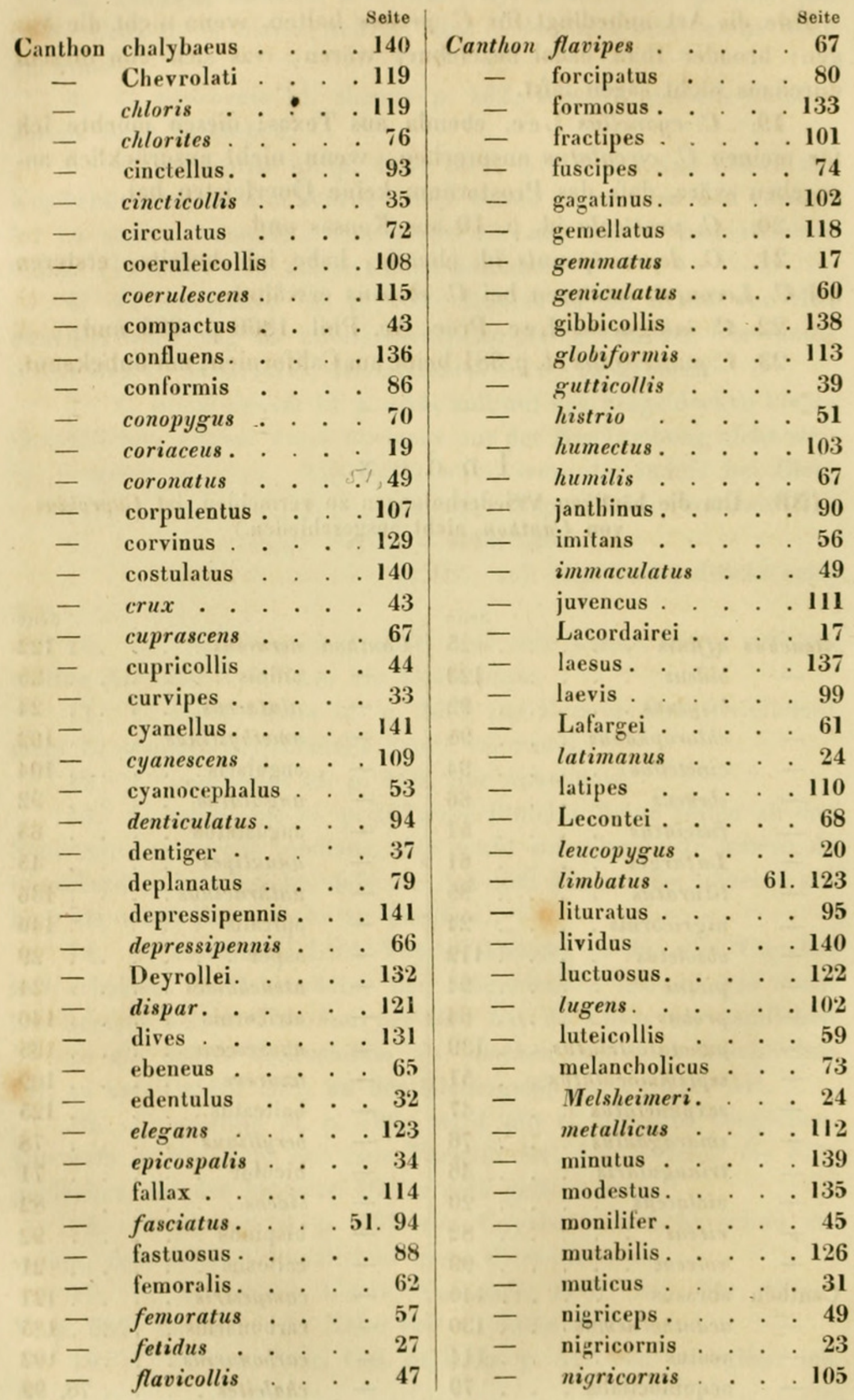




\begin{tabular}{|c|c|c|c|c|c|c|c|}
\hline & nigrocınctus & & $\begin{array}{r}\text { Seite } \\
. \quad 54\end{array}$ & Canthon & sericatus. & & $\begin{array}{r}\text { Seite } \\
122\end{array}$ \\
\hline $\begin{array}{c}\text { anthon } \\
-\end{array}$ & nitidicollis & & 58. 86 & - & sericinus. & - & 18 \\
\hline- & nitidicollis & . & 57 & - & serrimanus. & & $\begin{array}{r}. \\
. \quad 119\end{array}$ \\
\hline- & obscuratus. & . & . 90 & 一 & sexpunctatus & . & . . 47 \\
\hline- & obtusidens & . & . 99 & - & sexspilotus . & . &.$\quad 140$ \\
\hline- & ochropus. . & . . & . 62 & - & signifer. . & . & . 22 \\
\hline - & opacus . . . & .. & .106 & - & simplex & . & . 128 \\
\hline - & орасия & . $\cdot$ & .120 & 一 & smaragdulus. & - & . . 75 \\
\hline- & oxygonus & . . & . 25 & 一 & sordidus. . & . & . .27 \\
\hline - & parellinus . & .. & . 70 & - & speciosus. . & . & . 41 \\
\hline - & patagonicus. . & .. & . 90 & - & speculifer . & . & . .70 \\
\hline - & perplexus & .. & . 67 & - & spiniceps. . & . & . 98 \\
\hline - & perplexus & .. & . 47? & - & spinosus. . & . & . . 42 \\
\hline - & pilluliformis. & .. & .140 & - & subcyaneus . & . &.$\quad .117$ \\
\hline - & planifrons. & . . & . 31 & - & subdepressus. & . & . .105 \\
\hline - & planus. . & .. & .140 & - & subhyalinus. & . & . .124 \\
\hline- & plicatipennis & $\cdot \cdot$ & .140 & - & subrutilans . & . & . 34 \\
\hline - & podagricus . & 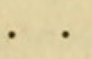 & . 38 & - & substriatus . & . & . 83 \\
\hline 一 & politus . . & $\cdot$. & . 60 & - & sugillatus & · & . $\quad 52$ \\
\hline - & prasinus . & .. & . 77 & - & sulce & . & . . 78 \\
\hline- & prasinus. & .. & . 95 & - & tessellatus. & - & . $\quad 19$ \\
\hline - & praticola. . & . . & .141 & - & tetr & . & . .130 \\
\hline - & probus . . &. & . 64 & - & thalassinus & . &.$\quad 119$ \\
\hline - & punctulatus. & . . & . 67 & - & thol & . & . . 89 \\
\hline - & purpurascens. & $\cdot$. & .123 & - & transversalis & . & . .127 \\
\hline - & quadratatus. & .. & .140 & 一 & ersus. & . & . 94 \\
\hline - & quadriguttatus & $\cdot \cdot$ & .123 & - & triangularis . & . & . $\quad 46$ \\
\hline- & quadripustulatu & us. & . 95 & - & tristis. . & . & . .120 \\
\hline - & quinquemaculat & tus. & · 34 & - & turbatus & - & . $\quad 27$ \\
\hline - & Reichei . . & $\cdot \cdot$ & .101 & - & unicolor. & . & .140 \\
\hline - & Rostenayi . & - & . 77 & - & variegatus & . & . 52 \\
\hline - & rubrescens & $\cdot$. & .140 & - & velutinus. . & - & .106 \\
\hline 一 & rubripes. & $\cdot$. & - 60 & 一 & venustus. & . &.$\quad .103$ \\
\hline 一 & rubromaculatus & 8 & .140 & - & vicinus. & · & . . 47 \\
\hline - & rufulus . . & 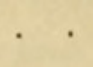 & . 54 & - & viduus & . &.$\quad 116$ \\
\hline 一 & rugosus . & - & . 19 & - & vigilans . & · & . .100 \\
\hline - & rutilans . & . & . 109 & - & villosus . . & - & . 30 \\
\hline - & Sallei . . & . $\cdot$ & . 39 & - & violaceus. & . & . 20 \\
\hline - & sanguineomacul & latus & s. 97 & - & violaceus. . & . &.$\quad .115$ \\
\hline 一 & sanguinicollis & . & . 35 & 一 & virens . & - & . 81 \\
\hline 一 & seminitens . & . & . 84 & - & viridescens. & . & • $\quad$. 99 \\
\hline - & seminulum . & - & . 84 & - & viridiobscurus & . & . . 121 \\
\hline 一 & semiopacus . & · & . 57 & - & viridis . & . & . .112 \\
\hline - & septemmaculatu & us . & . 51 & - & viridulus. . & . & .112 \\
\hline
\end{tabular}



E. v. Harold: Monographie der Gattung Canthon.

\begin{tabular}{|c|c|c|c|c|}
\hline \multirow[b]{2}{*}{ volvens . } & Seite & \multicolumn{3}{|r|}{ Seite } \\
\hline & 99 & Hyboma $L$ & Lacordairei. . & \\
\hline pus & .140 & Onthophag & us. & .112 \\
\hline & 2 & Scarabaeus & & . 99 \\
\hline & 0 & - & 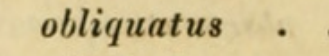 & 123 \\
\hline oeridium & 123 & - & 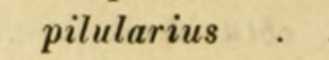 & 99 \\
\hline Jascoute & 94 & - & 8 & 123 \\
\hline elc & 1 & - & 18 & 47 \\
\hline is & 112 & - & tris . & \\
\hline prob & & - & violaceus. . & 20 \\
\hline irin & & Tetraechme & sanguineomacul & \\
\hline
\end{tabular}



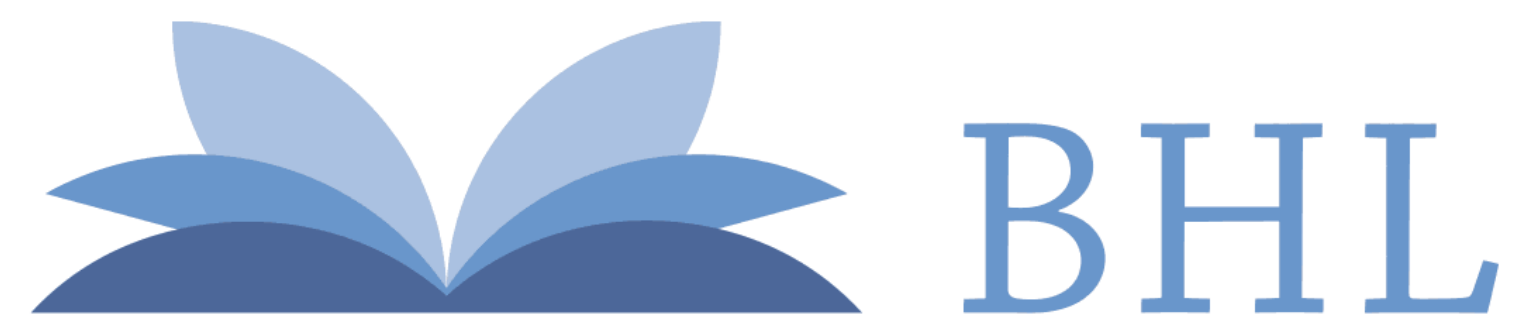

\section{Biodiversity Heritage Library}

Harold, Edgar von. 1868. "Monographie der gattung Canthon." Berliner entomologische Zeitschrift / herausgegeben von dem Entomologischen Vereine in Berlin 12, 1-144. https://doi.org/10.1002/mmnd.18680120104.

View This Item Online: $\underline{\text { https://www.biodiversitylibrary.org/item/34406 }}$

DOI: https://doi.org/10.1002/mmnd.18680120104

Permalink: https://www.biodiversitylibrary.org/partpdf/22401

\section{Holding Institution}

Smithsonian Libraries

\section{Sponsored by}

Smithsonian

\section{Copyright \& Reuse}

Copyright Status: Public domain. The BHL considers that this work is no longer under copyright protection.

This document was created from content at the Biodiversity Heritage Library, the world's largest open access digital library for biodiversity literature and archives. Visit BHL at https://www.biodiversitylibrary.org. 